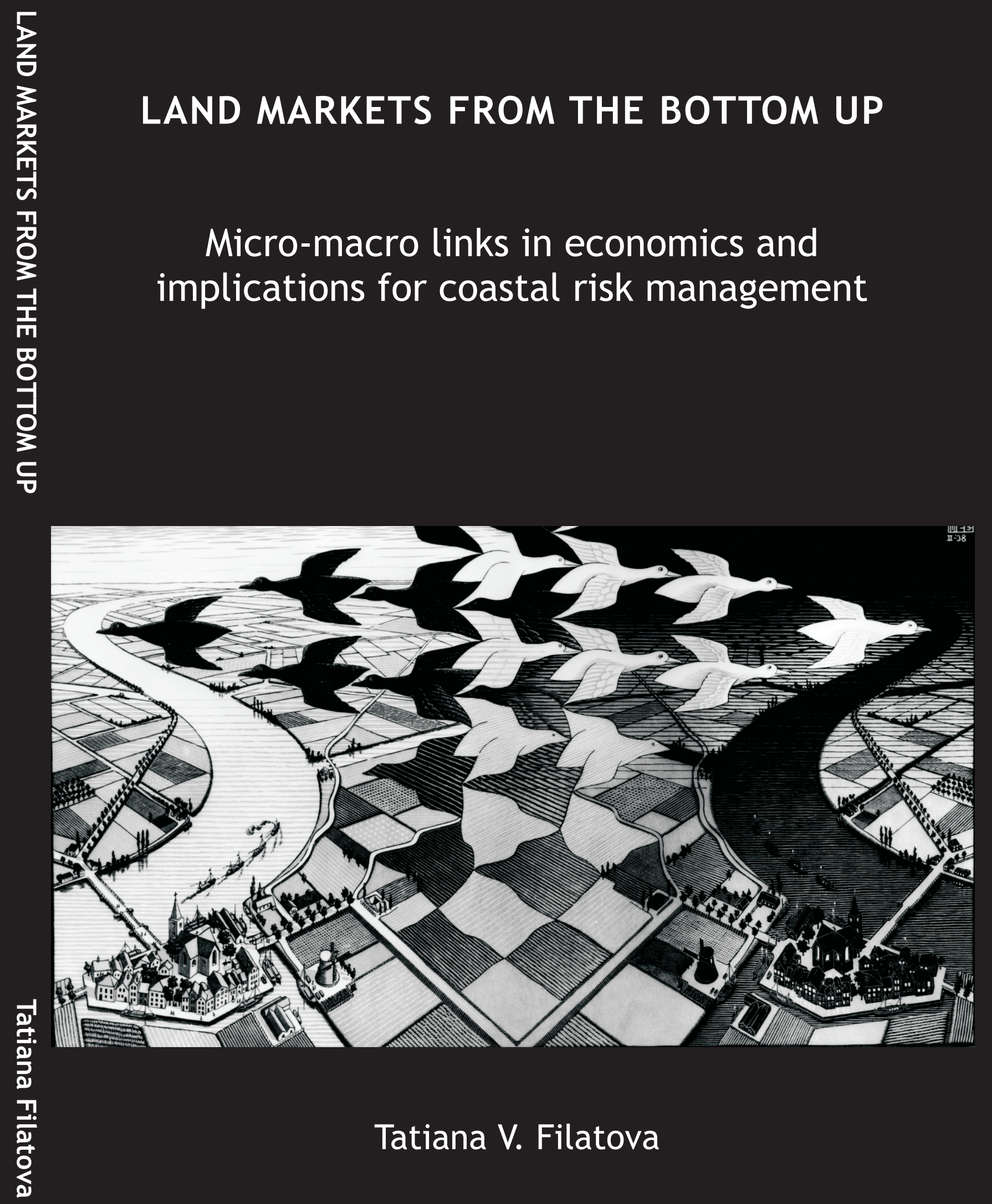




\section{LAND MARKETS FROM THE BOTTOM UP}

Micro-macro links in economics and implications for coastal risk management 

Promotion committee:

prof. dr. F. Eising

prof. dr. A. van der Veen

dr. D.C. Parker

prof. dr. S.J.M.H. Hulscher

prof. dr. ir. A.Y. Hoekstra

prof. dr. R.J.J.M. Jorna

prof. ir. E. van Beek

dr.J.P.M. Mulder
Universiteit Twente, chairman/secretary

Universiteit Twente, promotor

George Mason University, assistant-promotor

Universiteit Twente

Universiteit Twente

University of Groningen

Deltares

Deltares

This research is supported by:

The Earth and Life Sciences (ALW) Division of NWO (LOICZ-NL), Project No. 014.27.012.

Cover: M.C. Escher's 'Day and Night', (c) 2009 The M.C. Escher Company-Holland. All rights reserved. www.mcescher.com

Copyright (C) 2009 by Tatiana V. Filatova, Enschede, The Netherlands

All rights reserved. No part of this publication may be reproduced, stored in a retrieval system, or transmitted, in any other form or by any means, electronic, mechanical, photocopying, recording or otherwise, without written permission of the author.

Printed by Wöhrmann Print Service, Zutphen, The Netherlands

ISBN 978-90-365-2802-3 



\title{
LAND MARKETS FROM THE BOTTOM UP
}

\section{Micro-macro links in economics and implications for coastal risk management}

\author{
DISSERTATION
}

to obtain

the doctors degree at the University of Twente,

on the authority of the rector magnificus,

prof.dr. H. Brinksma,

on account of the decision of the graduation committee,

to be publicly defended

on Thursday April 23, 2009 at 16:45

by

Tatiana Victorovna Filatova

born on 15 June 1981

in Chita, Russia 

This dissertation has been approved by:

prof.dr. A. van der Veen

Promoter

dr. Dawn Cassandra Parker

Assistant promoter 

To my beloved family:

my wonderful, kind and wise parents and my talented and bright brother and sister

Моей любимой семье:

замечательным, добрым и мудрым родителям и талантливым и умным брату и сестре 



\section{Contents}

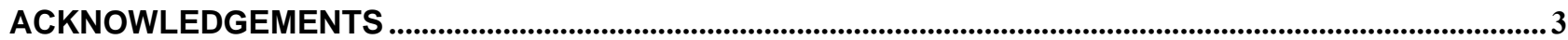

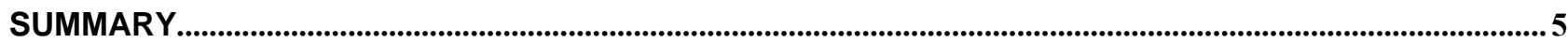

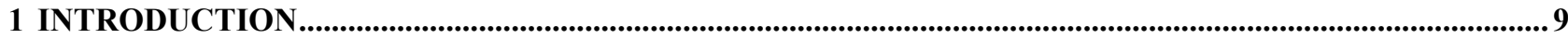

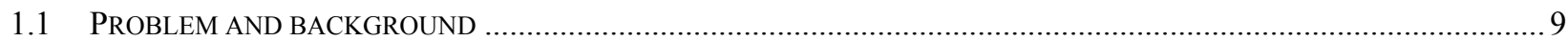

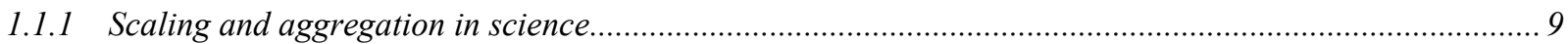

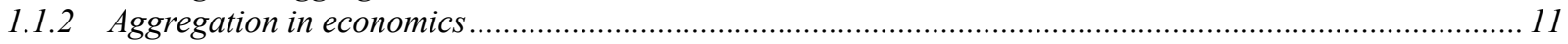

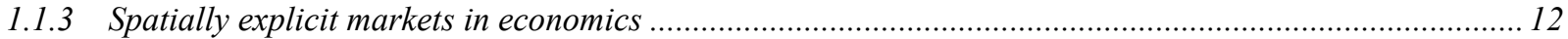

1.1.4 Coastal risk management and relevance of microeconomic decisions .................................................... 16

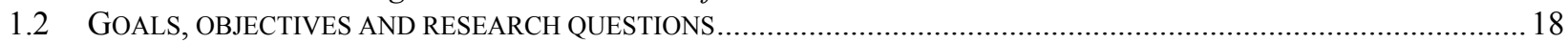

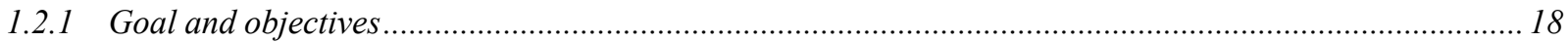

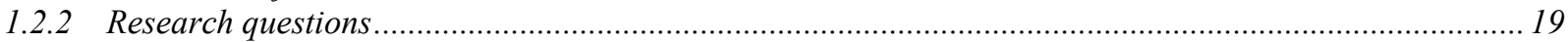

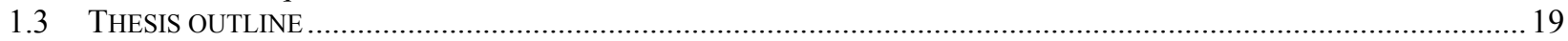

2 COASTAL RISK MANAGEMENT: HOW TO MOTIVATE INDIVIDUAL ECONOMIC DECISIONS TO

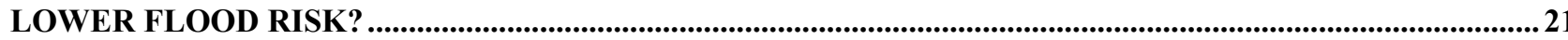

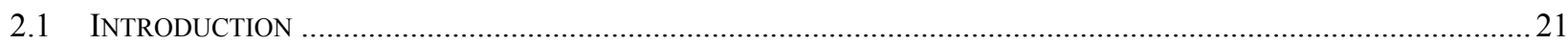

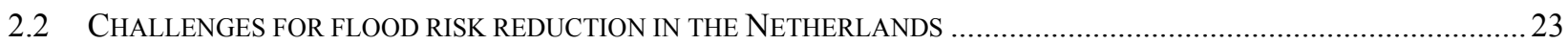

2.3 LAND USE AND HOUSING VALUES IN FLOOD PRONE AREAS: HOW DOES PROBABILITY OF FLOOD ENTER INTO

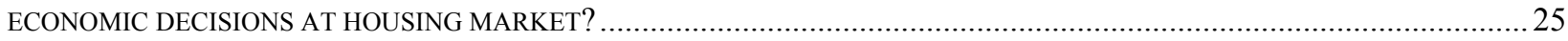

2.3.1 Theory: Urban economics and economic decisions under risk ...........................................................25

2.3.2 Empirical evidence: Hedonic analysis of housing prices in flood-prone areas ........................................26

2.4 PERCEPTION OF RISK OF COASTAL FLOODING IN THE NETHERLANDS ............................................................228

2.5 INCREASING INDIVIDUAL FLOOD RISK AWARENESS AS A COMPLEMENTARY MEASURE TO REDUCE FLOOD RISK.. 30

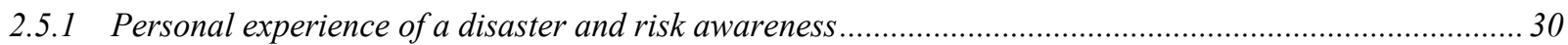

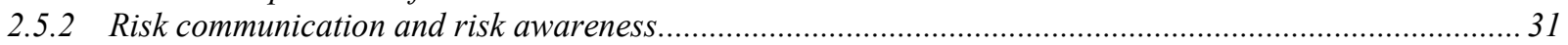

2.5.3 Insurance against flooding as a measure to increase coastal flood risk awareness ....................................33

2.5.4 Building on higher elevation levels as a measure to increase risk awareness .......................................35

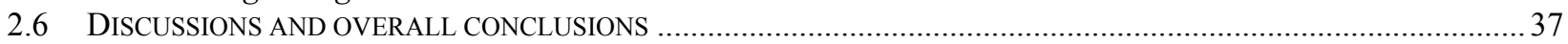

\section{A CONCEPTUAL DESIGN FOR A BILATERAL AGENT-BASED LAND MARKET WITH}

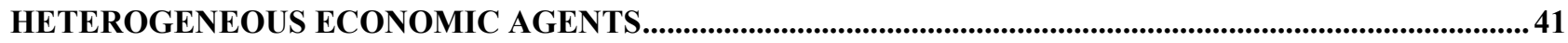

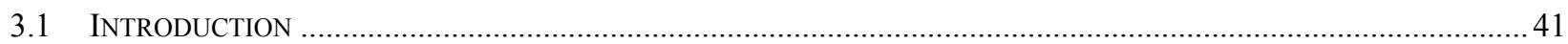

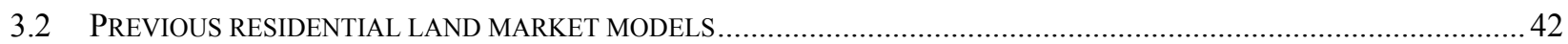

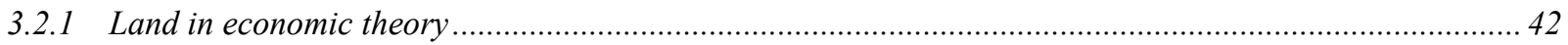

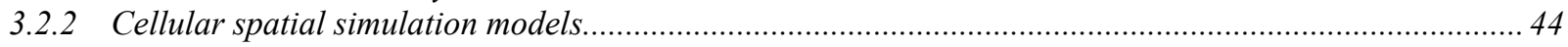

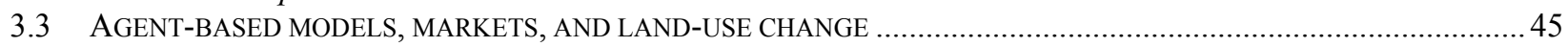

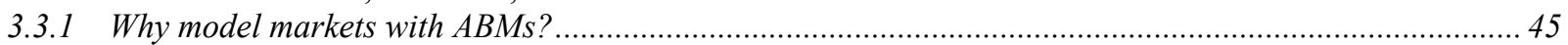

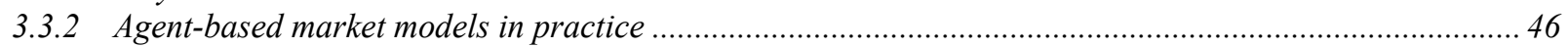

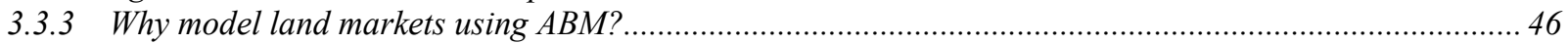

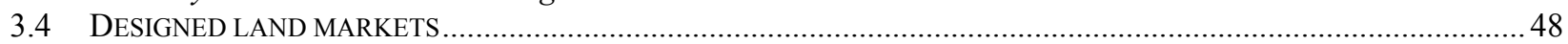

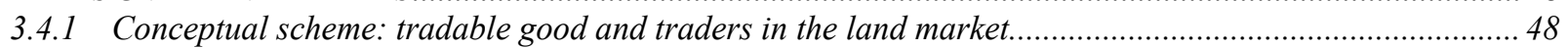

3.4.2 Reservation prices, bid and ask prices, and gains from trade ..............................................................49

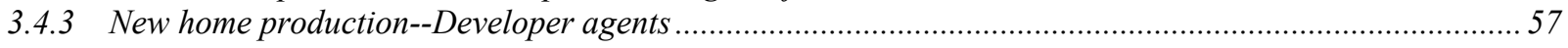

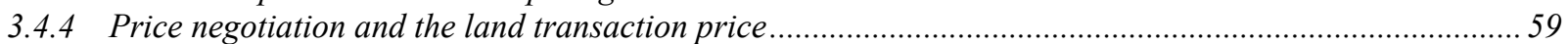

3.5 CONFRONTING THE CONCEPTUAL MODEL WITH THE REAL WORLD: NEXT STEPS ...............................................60

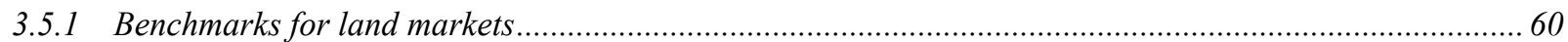

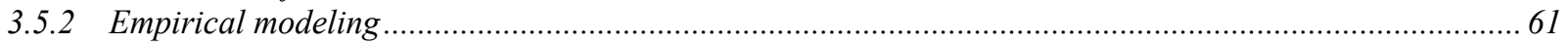

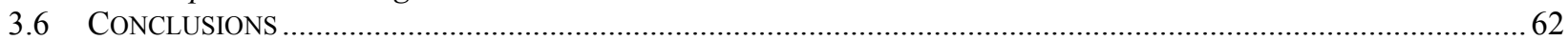

\section{AGENT-BASED URBAN LAND MARKETS: AGENT'S PRICING BEHAVIOR, LAND PRICES AND}

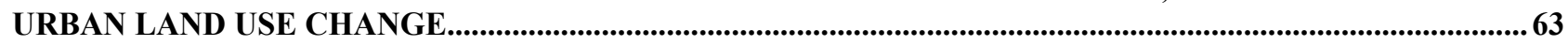

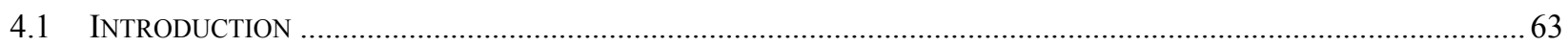

4.2 THE TRADITIONAL ECONOMIC APPROACH TO MODELING URBAN LAND USE AND VALUE ADDED OF ABM ...........65

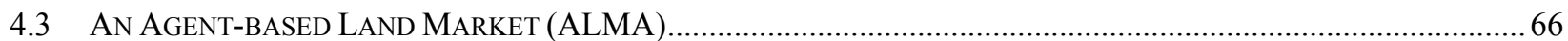

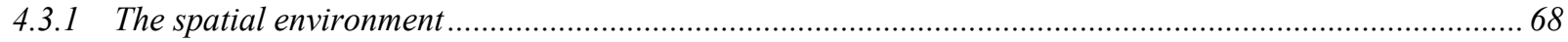

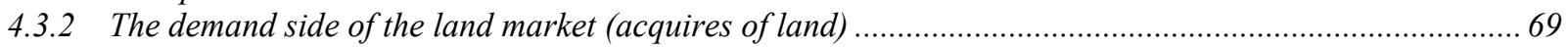

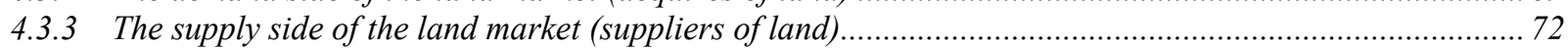

4.3.4 Price negotiation and market transactions (land exchange mechanism) ................................................... 73

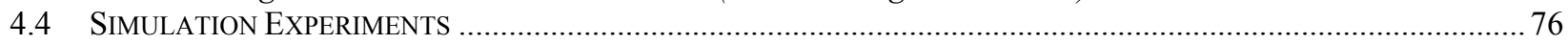




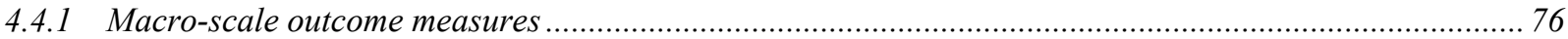

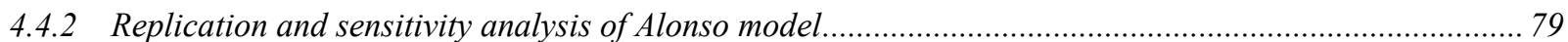

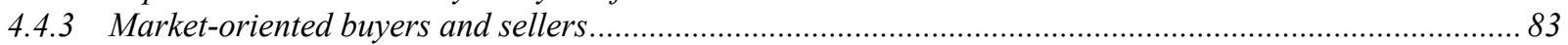

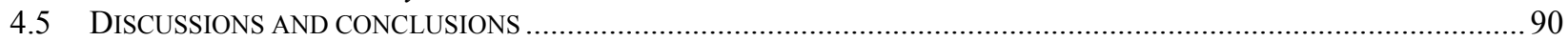

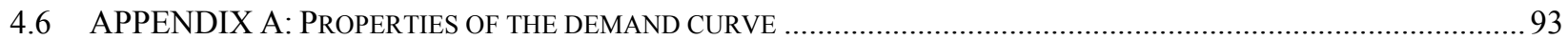

4.7 APPENDIX B: RESULTS OF THE T-TEST BETWEEN DIFFERENT EXPERIMENTS' RUNS .....................................95

5 LAND MARKET INTERACTIONS BETWEEN HETEROGENEOUS AGENTS IN A HETEROGENEOUS LANDSCAPE-TRACING THE MACRO-SCALE EFFECTS OF INDIVIDUAL TRADE-OFFS BETWEEN

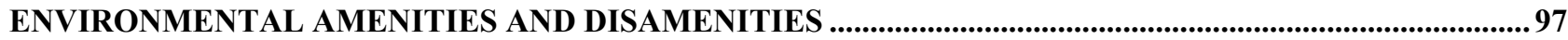

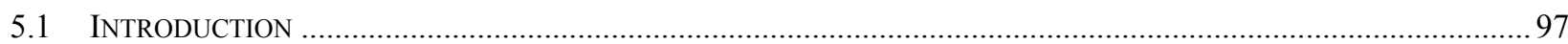

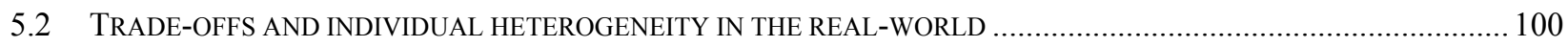

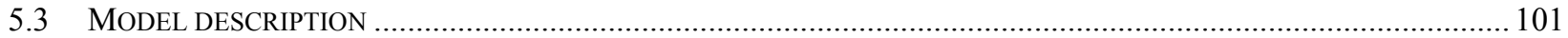

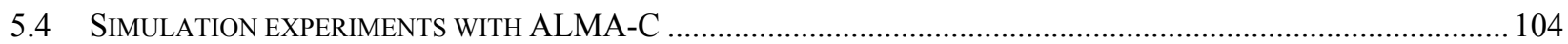

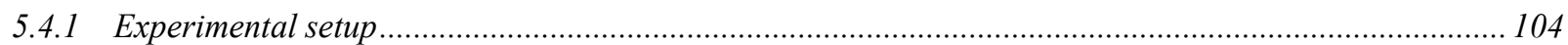

5.4.2 Experiment 5.1: introducing environmental amenities in the bilateral land market............................... 105

5.4.3 Experiment 5.2: trade-offs between amenities and disamenities..................................................... 109

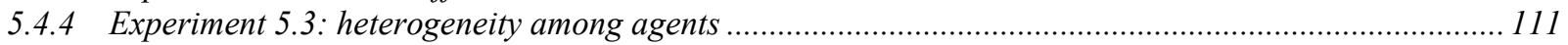

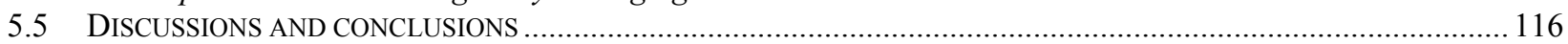

\section{RESPONSE OF ECONOMIC AGENTS IN A LAND MARKET TO CHANGED EROSION RISKS IN}

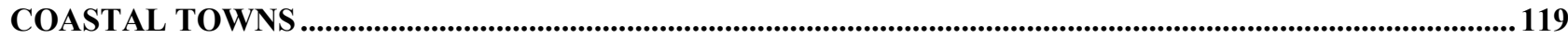

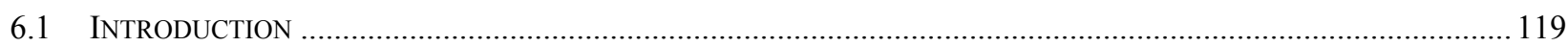

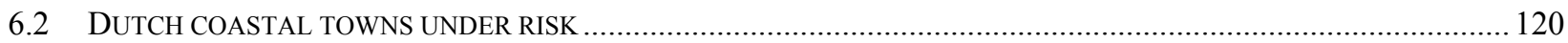

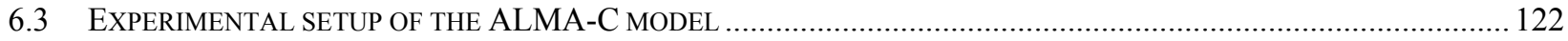

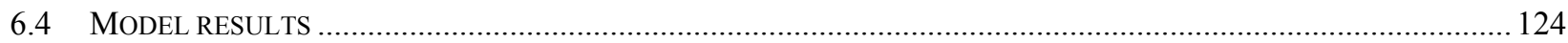

6.4.1 Experiment 6.1: shift of erosion line in a coastal city where individuals perceive erosion probability

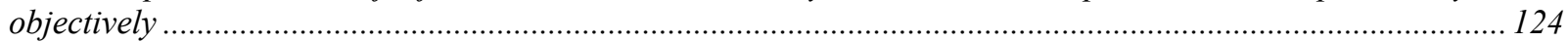
6.4.2 Experiment 6.2: shift of erosion line in a coastal city where agents have heterogeneous perception of

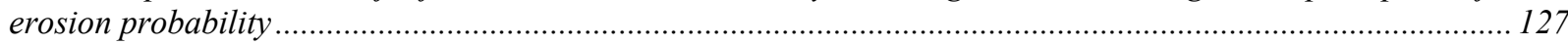

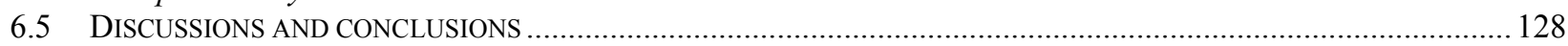

7 USING SURVEY DATA TO PARAMETERIZE AGENTS IN A COASTAL LAND MARKET MODEL .... 131

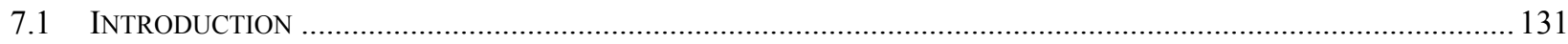

7.2 SURVEY ABOUT FLOOD RISK PERCEPTION AND HOUSING CHOICES IN THE NETHERLANDS ............................... 131

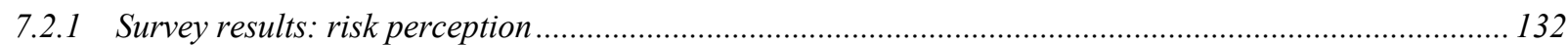

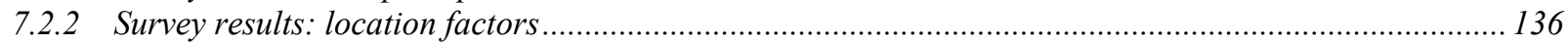

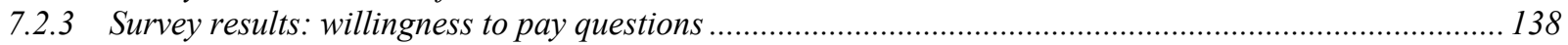

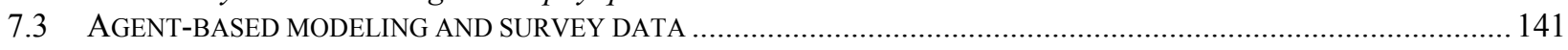

7.3.1 Motivation and a review of the existing spatial ABMs using survey data ........................................... 141

7.3.2 Data from the survey in the Dutch province Zeeland and ALMA-C ................................................. 142

7.4 EXPERIMENTS WITH THE ALMA-C MODEL .............................................................................................. 144 7.4.1 Experiment 7.1: Agents with homogeneous coefficient of perceived damage equal to the mean value of the

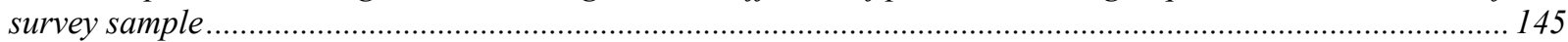
7.4.2 Experiment 7.2: Agents with heterogeneous coefficients of perceived damage parameterized using the

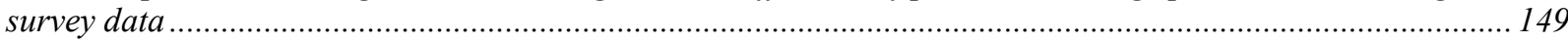
7.4.3 Experiment 7.3: Agents with heterogeneous coefficients of perceived damage parameterized using uniform

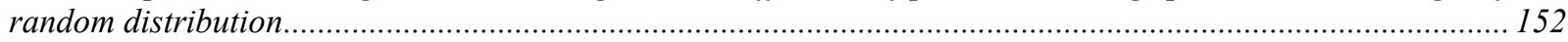

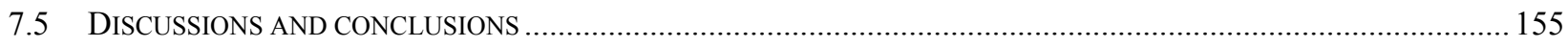

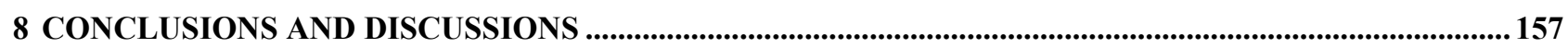

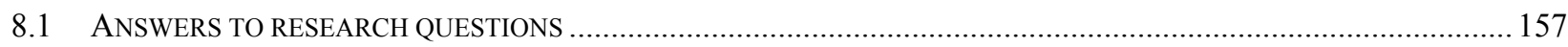

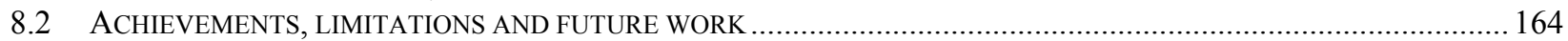

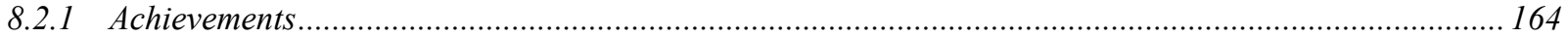

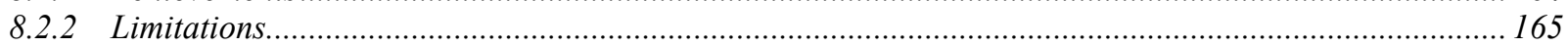

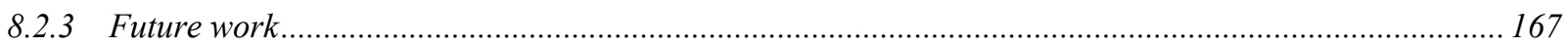

8.3 CONSIDERATIONS FOR PRACTICAL APPLICABILITY OF THE RESULTS FOR COASTAL RISK MANAGEMENT ........... 167

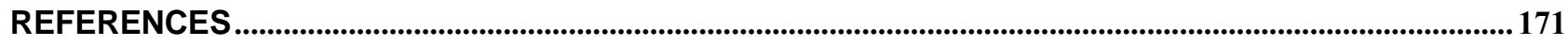

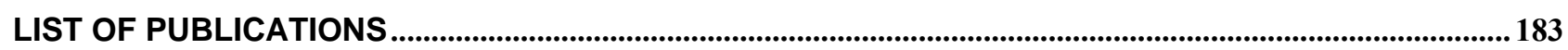

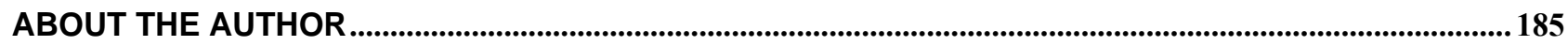




\section{Acknowledgements}

To finish a PhD is not just to get to know a lot about a specific subject. It is a matter of learning to think independently, to be creative and decisive in trying to push existing frontiers in your field, to be able to cope with your mistakes and start over again, and to be ready to take responsibility for what you do. This would not be possible without support of friends and colleagues. To all those people who shared with me the joyful moments on this path, and who were there to give advice in difficult ones, I owe a lot of thanks.

My first thanks go to Prof. Anne van der Veen, Prof. Suzanne Hulscher and Prof. Arjen Hoekstra for giving me the opportunity to pursue this $\mathrm{PhD}$ research at the University of Twente. Anne, thank you for being so open-minded, kind and always supportive of my seemingly impossible but, yet, working initiatives. You helped me to find my own path and taught me to be independent. Sorry if I sometimes overdid the lesson... Many thanks to Suzanne for being equally critical and supportive, and always professional. Thanks to the other members of the project discussion group (Lisette, Kathelijne) and to Jan Mulder who came in later but played a very important role. Jan, I am very grateful to you for giving me the research opportunity at RIKZ, for sharing your optimism and energy and for all the inspiring ideas I enjoyed discussing with you for hours. Also, I would not be here at this moment if it was not for Prof. Irina P. Glazyrina, my mentor in graduate school in Russia, who introduced me to the whole new world of academia, and to whom I am very grateful for this.

The Department of Computational Social Science at George Mason University became my second home university providing a stimulating environment and great experience. I am especially grateful to Dr. Dawn Parker and Prof. Rob Axtell. Your lectures and advice provoked thought and led to many ideas, which made this book possible. Dawn, many thanks for your enthusiasm and enriching discussions, for our walks and your wonderful sense of humor (I am looking forward to your 'book'...). Also thanks to Max, Maciek, Pedro, Maction and Josema - those were great days on campus! (Only in USA people can enjoy staying in office until 22:00 discussing how we should model agents' interactions).

Furthermore, I am grateful to Olivier Barreteau and his colleagues at Cemagref, whom we visited in summer 2005. Also thanks a lot to Hedwig van Delden, Jasper van Vliet and other people at RIKS for interesting and challenging discussions at our meetings. I appreciate the feedback from my colleagues at iEMSs (Sigrun Kabisch, Dagmar and Annegret Haase) and ESSA (Wander Jager, Nigel Gilbert, Scott Moss) conferences, and from the participants of the ZUMA workshop in spring 2006. I am very lucky to meet these wonderful people. 
I am also grateful to my friends on both sides of the Atlantic Ocean. Special thanks to Svetlana (what would I do without you?), Maria K. and Maria B., Liudvika (girls, thanks for your advice on many occasions), Slava B., Sebas and Reini (what is next in our travel plans?), Robin (too much to mention here) and Henning (should I have 'Dutch-lunch' twice per day to learn the language finally or should I just stay more often in the country?), Laura, Nelly L., Gert-Jan H., Novica and Meron. Hasan, Sandeep and Severine: I enjoyed the time we spent together and our laughs. My days in the Netherlands would be incredibly complicated by all the documents I had to handle (which 'surprisingly' are all in Dutch!) if it wasn't for Anne Wesselink who led me through the Dutch bureaucratic jungle. Maite, thanks for your warm candid care and great dinners during these last months. I am very happy to be part of the WEM Department and it is largely because of the joyful atmosphere and nice colleagues. Special thanks to my office mates Henriët and Erik, to Saskia, Joerg, Judith, Rolien, Pieter Roos and Pieter van Oel, Denie, Mesfin, Rene, Arthur, Ella, Rianne, Ertug, Jolanthe, Mehmet and many others. I am grateful to Anke and Briggite for being helpful in many respects but most of all, to Joke who has a gift for arranging everything and solving any problem! And lastly, thanks to Wilbert Grevers and Peter Stauvermann for the motivation in land market research.

Blanca and Freek, I know you from my very first days at the Department. The most trustful, joyful and funny moments of the last four years were in your company. I did not doubt even a minute when deciding who should be right next to me on this important day!

My most sincere thanks are to my family where I always found all the love, advice, cheers and support that I needed. I will proceed in Russian: мамуля, папа, спасибо за вашу мудрость, доброту, оптимизм и поддержку. Женя, Маша, вы оба настолько талантливы и умны, я вами так горжусь. Вы самые замечательные! I am also very happy to get a second loving family with Zoe and Arkady who warmly supported me in pursuing my professional goals.

Alesha, there needs to be another book written to express everything I feel truly in my heart. Thank you for waiting for me all these years... 


\section{Summary}

In 1953 the Netherlands saw the worst devastating coastal flood of the last century. The government stepped in and pledged that this should never happen again, bringing science and technology, engineering and construction to create the most sophisticated and reliable flood defense protection system in the world. However, the government did not realize that it stepped into a vicious circle: the better the land in coastal areas is protected, the more attractive it becomes for people to locate, the higher the demand for and economic value of these flood prone areas are, and, therefore, the more government needs to invest in the protection of these areas. This could have been avoided if there was a better understanding of the feedbacks and relationships between the macro-scale governmental policies and the micro-scale individual homeowners behavior in a land market.

Coastal zone management policy in the Netherlands aims at reducing risk, which is defined as the probability of a disaster multiplied by economic damage. Direct economic damage depends on land patterns and value of properties under risk, which, in turn, are the outcomes of individual microeconomic interactions in a land market. Governmental policy might use instruments (e.g. taxes, insurance, educational programs) to affect individual motivations and rules of local interaction in order to direct land markets in coastal areas towards desired macroscopic outcomes (e.g. more safe allocations). However, the transition from micro-behavior to macro-measures used by policy-makers is discontinuous, non-linear and may be associated with new, emergent effects and properties. Lack of understanding of micro-foundations of macro-phenomena (such as total economic value of the area and spatial pattern of location) can make coastal zone management and spatial planning policies inefficient and unpredictable.

The main goal of this thesis is to get insights into how aggregated economic phenomena in space emerge from interactions of individual economic agents in a land market. Specifically, this study seeks to identify traceable connections between micro and macroeconomic scales exploring a hypothetic city, which replicates the structure and complexity of a typical Dutch coastal town. Although the application is specific, the model is flexible and can be used in many other cases where economic behavior needs to be modeled in a spatially explicit way that involves consideration of environmental amenities, natural hazards and spatial externalities. The conventional economic approach assumes a representative rational agent and a unique equilibrium in the system. To accommodate more spatial and agent heterogeneity and to allow the study to be spatially explicit, this thesis adopts an agent-based approach, which helps to understand the effects 
of relaxing some of the conventional economic assumptions and their implications for coastal risk management policy.

Microeconomic decisions and coastal risk management: Land prices and land patterns and, consequently, direct potential economic damage that contributes to total risk in coastal areas, are the outcomes of microeconomic decisions in a land market. If perceived, the probability of flooding or erosion capitalizes in property prices. Low flood risk awareness biases microeconomic decisions in a land market, and leads to inefficient land use outcomes and increase of risk in hazard-prone areas Recent surveys provide evidence that coastal flood risk perception is low in the Netherlands implying that it might bias efficient land market outcomes. There are factors that influence individual flood risk awareness and have measurable effects on individual land market behavior. Policy makers may consider using some of these factors (such as risk communication, flood insurance or building on high elevation) to increase individual flood risk awareness and to affect microeconomic behavior in a coastal land market for the purpose of decreasing total risk in coastal areas (Chapter 2).

Spatially explicit land market: There is a methodological gap between spatial economics models and cellular spatial simulation models. In attempt to bridge it, we developed an Agent-based Land MArket (ALMA) model. Compared to urban economics a land market in a monocentric city in ALMA is modeled in a spatially explicit way and with a possibility to include heterogeneity in spatial environment and among agents. In comparison with cellular automata land use models, ALMA adds a behavioral component to the cellular grid (agents exhibit microeconomic behavior and have flood risk perceptions). Besides, compared to statistical spatial models the agent-based land market model does not just report the dependencies between aggregated variables (e.g. land price as a function of distance). Rather it allows understanding the processes behind these aggregates. A new spatially explicit land market model structure facilitates the coupling of economic models with the process-based ones, more prevalent in natural sciences. Chapter 3 discusses the conceptual design of the agent-based land market model, while Chapter 4 presents the first implementation of the ALMA model and its structural validation against conventional analytical urban model.

Land market interactions in a coastal town: After checking that the ALMA model behaves the same as a monocentric model in urban economics, we move beyond the restrictions of the conventional model, and add more complexity, which conventional analytical land market models cannot accommodate. We model a coastal city where both, environmental amenities (coastal view) and disamenities (probability of flooding or erosion) are present and are spatially correlated. Our 
model allows performing sensitivity analysis of spatial patterns and land prices to agent attributes and the distribution of spatial amenities and disamenities. It helps developing a deeper understanding of the processes that generate observed spatial data (Chapter 5).

In addition to spatial heterogeneity, we added heterogeneity among economic agents in order to move beyond the representative agent concept. Experiments with agents heterogeneous in their levels of flood risk perception demonstrated that individuals who underestimate coastal risk drive land market into economically inefficient high risk zone. This also implies, that a representative agent model normally used for policy decision support would underestimate developments in the flood-prone zone and, consequently, the flood damage (Chapter 5 and 6).

Land market response to changed risks due to climate change: As a next step, we analyzed the changes in the outcomes of a coastal land market due to the shift of the erosion line, i.e. increase of a probability of erosion because of climate change. A model with homogeneous agents shows that urban developments would move landwards. However, if agents are assumed to have heterogeneous perception of erosion probability, then there will be more developments in the high risk zone (Chapter 6)

\section{Survey about flood risk perception and location choices used in the spatially-explicit land} market model: The results of the 2008 survey showed that most Dutch people do not worry about coastal flooding affecting them personally, while coastal amenity is an important factor for people willing to buy a house. Both these findings imply that, in general, demand for land in coastal areas is high. The land market model parameterized with the actual survey data about individual risk perception of Dutch population showed that all the area seawards from the erosion line will be developed. Although the ALMA model is not a predictive but rather is an explorative model, this finding provides some guidance for what might happen to the towns considered by the Poelmann Commission, when the actual level of coastal risk awareness in Dutch population is taken into account.

Conclusions with respect to methodology: Agent-based modeling is a powerful methodological platform to cover the gap between economic and cellular spatial simulation land use models. The land market model, in which centralized price determination mechanism is replaced by spatially distributed bilateral trading, conforms with the qualitative behavior of a standard monocentric urban model if homogeneity among agents is assumed. There is a big added value of combining agentbased modeling and micro-level survey data: the latter gives the knowledge about real-world preferences and perceptions and the former helps to visualize and quantify the aggregated macrofeatures (resulting from micro-interactions) which are of interest to policy-makers. 
Conclusions with respect to practice: Firstly, our survey showed that the level of coastal flood risk awareness is low in the Netherlands while attractiveness of coastal amenities is high. Secondly, policy makers may consider affecting microeconomic behavior in a land market, specifically individual risk awareness, for the purpose of decreasing total risk in coastal areas. Such instruments as risk communication, insurance and building on high elevations serve as effective instruments to increase risk awareness. Thirdly, the simulations showed that individuals with low flood risk awareness drive urban developments in coastal areas into the zone that a representative agent considers economically inefficient. Thus, potential damage from natural hazards in coastal towns will grow beyond the level anticipated by policy makers. This also implies that conventional economic models used for policy making and decision support (general equilibrium or econometric ones - both assuming a representative agent), might misrepresent the aggregated behavior of the real-world economic agents that are known to be highly heterogeneous. 


\section{Introduction}

\subsection{Problem and background}

This section gives an overview of the scientific problem and background leading to the importance of accounting of different economic scales in the spatial context and its value for coastal risk management. The section starts with underlining the scaling issue in sciences in general and proceeds with the discussion of aggregation in economics in particular. Then, driven by a need for the spatially explicit modeling, a brief overview of the treatment of space in economics and spatially explicit land markets is provided. The section concludes with the discussion of importance of understanding the linkages between microeconomic decisions in space and emerged macroeconomic phenomena for flood risk management on macro level.

\subsubsection{Scaling and aggregation in science}

Dynamics in economic and natural systems are driven by processes on different scales. According to (Gibson et al., 2000) scale is defined as "the spatial, temporal, quantitative, or analytical dimensions used to measure and study any phenomenon" ${ }^{1}$. Processes and interactions occurring on one scale may produce totally different and unexpected properties and phenomena on another scale (Axelrod, 1997). For example, individual bees take action based on some environmental conditions and the behavior of their closest neighbors. These individual behaviors result in a collective action, when a school of fish, or a flock of birds, or a swarm of bees or ants starts to behave as a whole, as an entity, producing effects that cannot be explained in the individual level (Janson et al., 2005; Couzin, 2009). Similarly, the sheer stress of wind has a uniform effect on water molecules in the sea. Yet once they are brought in motion they become parts of wave structures that are impossible to explain at the molecular level, and that have a totally different kind of behavior and impact than just the water itself (Narayanan, 2003).

Heterogeneity of the entities on the micro-level and their interactions are also an important aspect. In ecology the predator-prey model describes a simplified interaction between the whole populations of a predator and a prey. However, in fact, each of the two populations consists of many individual organisms with their own behaviors and physical features (i.e. growth rate, individual activity, mortality, adaptive behavior, etc.) (Grimm and Railsback, 2005; Voinov, 2008). The

\footnotetext{
${ }^{1}$ This thesis also often uses a notion of level, which is defined as "the units of analysis that are located at the same position on a scale" (Gibson et al., 2000).
} 
challenge in these multi-scale phenomena is to find a way to translate individual organismic properties into aggregated parameters that are used to describe populations.

In a variety of examples from different branches of science, the transition from one level of detail to another is discontinuous, non-linear and may be associated with new, emergent effects and properties (O’Neill et al., 1989; Gibson et al., 2000; Levin, 2005; Manson, 2008). This happens in all facets of research: in measurement and data processing, in modeling, in interpreting results and in explaining theories.

Often when transitioning from a micro-scale to a macro-scale, one performs an aggregation, i.e. one applies a certain formalism to describe the large system with fewer variables. While dealing with scaling and aggregation different sciences face some rather general questions: How can models, theories and predictions from one scale be applied at other scales? How can state variables be aggregated, and how to account for aggregation bias? How can data measured on one scale be used on other scales? If scale of observation affects the description of a pattern, how to account for changes in descriptive statistics while changing from one scale to another? How to understand and describe the emergence of processes on one scale from the underlying elements and local interactions on another? How do global processes influence individual behavior and what are the cross-scale feedbacks? What are the impacts of scale of analysis upon the perceptions and limitations of a researcher?

Among these daunting questions this thesis will focus on understanding how macrophenomena emerge from the interactions of individual elements at the micro-level. The scaling problem has both theoretical and applied importance. From the theoretical point of view, the essence of any science is in understanding the nature of processes and in proposing and exploring mechanisms behind observed phenomena. In particular, describing aggregated patterns in terms of processes and elements that produce them is the key to understanding (Levin, 1992). One can explain a phenomenon if one "grows" it from the bottom up, from lower hierarchical levels to the higher ones (Epstein and Axtell, 1996). From the point of view of applied importance, many realworld phenomena, such as coastal erosion, accumulation of greenhouse gases or financial market bubbles are most prominent on the macro-scale, while they originate from and affect micro-scale processes. Thus, to understand potential responses of natural, physical and economic systems to exogenous changes and to develop appropriate policy initiatives, one needs to grasp the feedbacks between processes on different scales. In particular, to find effective economic policies that can change macro-indices, one needs to understand how particular macroeconomic phenomena emerge from interactions among microeconomic agents and how these macroeconomic phenomena impact microeconomic agents' behavior. The present study is about the process of aggregation from micro- 
scale to macro-phenomena in economics of land use with a focus on coastal risk management in the Netherlands.

\subsubsection{Aggregation in economics}

The economy is a complex system (Arthur, Durlauf et al., 1997; Tesfatsion, 2001). Complex systems are characterized by a diversity of components, with local interactions among them, producing nonlinear feedbacks between different hierarchical levels (Levin, 2003). Many emergent macroeconomic features, such as gross national product, inflation rate, prices and unemployment level result from many individual decisions (Dasqupta, 2002). In turn, these aggregated features affect individual micro-decisions. Thus, although micro-behavior and macro-features are studied separately by micro and macroeconomics, there are mutual feedbacks between the two levels. Economists have been attempting for decades to define micro-foundations of macroeconomic phenomena (Gupta, 1969; van Daal and Merkies, 1984; Forni and Lippi, 1997; Simon, 1997; van der Veen and Otter, 2003; Hommes, 2006; Kirman, 2006).

The conventional way of aggregation in neoclassical economics is to assume a "representative" agent (Varian, 1992) - a typical firm or household, the behavioral model of which can be extended to represent the behavior of the whole group of economic agents. In addition, what makes aggregation in mainstream economics possible, is the assumptions that the representative agent is rational, and that unique market equilibrium exists. The budget constrained utility or profit maximization problem for a representative agent is then solved by standard optimization techniques. A macro-phenomenon such as the price for a good is determined at the intersection of demand and supply curves of a representative consumer and producer. Similarly, many other macroeconomic features are derived via modeled labor, commodity, financial and other markets. Thus, a transition from individual microeconomic behavior to a macro-phenomenon is done through the mediation of markets. Interactions between agents are assumed to be averaged out by the law of large numbers. Such analysis has produced some useful results and elegant mathematical outcomes. However, it has been shown that local interactions might cause movements at the aggregated level (Hommes, 2006). In fact, the representative agent model, which assumes that the economy behaves as a typical individual, starts to run into difficulties when confronted with real data. Specifically, microeconomic models faced with aggregated per capita data do not seem to perform well (van Daal and Merkies, 1984).

The departure from the equilibrium concept (Arthur, Holland et al., 1997; Axtell, 2005; Arthur, 2006; LeBaron, 2006), introduction of interactions (Manski 2000; Brock and Durlauf 2001), heterogeneity (Kirman, 1992; Kirman and Vriend, 2001) and bounded rationality (Simon, 1997) 
turn out to be essential to explain some economic phenomena, which conventional models cannot explain. Driven by the need to accommodate more characteristics of the real-world economic systems, another approach to linking micro-foundations and macro-phenomena developed. The computational study of economies modeled as evolving systems of autonomous interacting heterogeneous agents became known as agent-based computational economics (ACE) (Tesfatsion, 2001). A representative agent can be replaced by heterogeneous ones in ACE markets. Moreover, a macroeconomic phenomenon is not determined in the equilibrium but rather through multiple decentralized interactions of economic agents (Tesfatsion and Judd, 2006). In this case the aggregated phenomena emerge as a result of the dynamic interactions of heterogeneous agents (Gilbert and Troitzsch, 2005). Although economic logic is employed to define behavior of microeconomic agents, ACE widely uses simulations, specifically object-oriented programming (Wooldridge, 2002), in addition to conventional analytical tools. Many aggregated economic phenomena were studied with the help of agent-based markets (Epstein and Axtell, 1996; Arthur, Durlauf et al., 1997; Axtell, 2005; Tesfatsion and Judd, 2006).

Thus, representative agent and ACE approaches are two ways to provide aggregation from microeconomic behaviors to macroeconomic features. However, the former does it via centralized equilibrium market clearing while the latter does it through heterogeneous agents operating in outof equilibrium decentralized market. The current thesis adopts an approach of heterogeneous interacting agents in ACE traditions in understanding micro-foundations of macroeconomic phenomena.

\subsubsection{Spatially explicit markets in economics}

The interdisciplinary nature of many real-world problems involves understanding of interconnections of natural and economic systems on a variety of scales (Gibson et al., 2000; Chave and Levin, 2003; Rotmans and Rothman, 2003; Manson, 2008). Different disciplines often use different notions of scales for space, time and organizational complexity (Levin, 2003). The problem of linking ecological-economic systems, i.e. modeling of human-environment interactions, has been widely discussed (O'Callaghan, 1996; Janssen, 2002; Chave and Levin, 2003; Polasky et al., 2005; Matthews et al., 2007; Wu and Irwin, 2008). The two systems exert mutual feedbacks (Irwin et al., 2007; Parker, Hessl et al., 2008). Moreover, interactions between two systems can be non-linear, effects might exhibit time lags, processes take place on different spatial scales, and actions leading to environmental pressure in one region might well take place in another. In addition, the spatial dimension is extremely important in interdisciplinary research because of spatial heterogeneity of the landscape that affects processes in both economic and natural systems. 
The development of interdisciplinary models implies that economic and natural systems should be connected on some basis. The majority of natural sciences research is done in a spatially explicit way. Thus, to have a common dimension with natural science models, economic models should also be developed in a spatially explicit way (Bockstael et al., 1995). In addition, to pursue the interest in understanding micro-foundations of macro-phenomena, the market should be present. These two facts lead us to the problem of modeling a spatially explicit land market rooted in the concepts of spatial economics.

The study of space, or land, in economics is a complicated field in itself since economics is largely aspatial. Randall and Castle (1985) and Hubacek and van den Bergh (2006) provide the detailed reviews of economic studies of land. Here it will suffice to consider two issues: direct modeling of land markets and the extent, at which it is spatially explicit in both theoretical and empirical economic research.

Until the nineteenth century theoretical economics considered land as one of the factors of the production function along with capital and labor (Randall and Castle, 1985). Later, the importance of fertility of land has been recognized (Ricardo, 1821/2001). One of the main foundations of spatial economics was laid out by Von Thunen (1826/1966) who recognized the trade-off between land price and travel costs to the central market place. Urban economics is largely based on the model of Alonso (1964), which extends von Thunen's model for households' location decisions and was further elaborated by Muth and Mills (Brueckner, 1987). Furthermore, real-estate economics focuses on market forces (competition and urban developments) and global processes (credit availability) affecting property prices (DiPasquale and Wheaton, 1995). New economic geography (Krugman, 1991) and economics of agglomeration (Fujita and Thisse, 2002) analyze the endogenous formation of central business district (CBD) and polycentric urban structures. Much of regional economics studies concern the introduction of travel costs in general equilibrium models, location decisions and clustering of firms, and links between trade and location (Weber, 1965; Isard, 1972; Fujita et al., 2001). Environmental economics also touches upon the issue of space while being mainly concerned about environmental amenities (Wu, 2001; Wu and Plantinga, 2003). The main point in all these different branches of economics dealing with space is that land is a scarce resource, which should be allocated efficiently. Economists consider that if no externalities are present, a scarce resource should be allocated efficiently via a market for a certain price. Thus, theoretical studies of economics of space comprise a land market, which is essential to this thesis due to the interest in understanding micro-foundations of macroeconomic phenomena. However, even if these economic theories are concerned with land, they usually do it via travel costs without spatially explicit consideration of the landscape. Moreover, they are based on the representative 
agent model (i.e. agent heterogeneity is left-out) and till now consideration of the spatial heterogeneity of a landscape is quite limited.

On the contrary, empirical research in agricultural, real-estate and environmental economics underlines that the spatial environment is highly heterogeneous, that land markets are affected by governmental policies, and that specific land uses impose externalities on the neighboring land (Irwin and Bockstael 2002; Buurman 2003; Irwin and Bockstael 2004; Wu et al. 2004; Levine 2006). Empirical land market research provides very useful information about the state of the market and static connections between spatial characteristics of spatial goods and transaction prices at a given moment. Nevertheless, it is not easily applicable to conceptual analysis, which can connect microeconomic incentives and macro-phenomena through the market institution. The market-clearing hedonic price function is the result of the interaction of supply and demand (Arnott, 1987) but the process of this interaction is hidden. Thus, any changes in microeconomic preferences or changes in policies would result in different relationships (i.e. regression coefficients) of the estimated hedonic price function for land (i.e. macroeconomic feature). Another branch of research closely related to empirical land use modeling is cellular automata (CA). CA models, which highlight spatial heterogeneity of land and distance-dependent externalities, reflect socioeconomic influences only implicitly through calibrated parameters without direct modeling of land market and economic behavior (White and Engelen, 1993; Batty et al., 1999; Verburg et al., 1999; Jantz et al., 2003; Benenson and Torrens, 2004; van Delden et al., 2007). In summary, empirical land use research provides spatially explicit modeling, but not a direct modeling of the land market which connects individual behaviors with macro-outcomes (e.g., land patterns and land prices).

Therefore, on one hand economic theories concerning space model land markets and by this bridge microeconomic preferences and behaviors with equilibrium land prices and patterns but they lack spatial explicitness. On the other hand, empirical studies, normally involving spatial statistics and GIS ${ }^{2}$, provide spatially explicit setup. However, in that case direct modeling of a land market is absent since hedonic function (i.e. already an outcome of a land market in the previous periods) is likely not to be robust if microeconomic agents' behavior change (or if new participants will be entering a land market). Consequently, there is a need to have a spatially explicit land market model, which uses the advantages of both empirical and theoretical models of spatial economics.

This thesis seeks for an approach to accommodate a spatially explicit representation of a heterogeneous spatial environment while maintaining links between microeconomic agents' behavior and macro-level land market outcomes. Agent-based methodology, used for various types of markets (Tesfatsion and Judd, 2006) and spatially explicit land use modeling (Parker et al. 2002;

\footnotetext{
${ }^{2}$ GIS - Geographic Information Systems
} 
Parker et al. 2003; Matthews et al. 2007), seems to be a useful tool. Apart from for a purely scientific interest for aggregation in economics in the spatial context pursued by the present study, there is a necessity of direct modeling of land markets in land use models (Parker and Filatova, 2008; Polhill et al., 2008) that can be summarized as follows:

- land markets determine the efficient allocation of land (quantity in each location) among competitive uses regulated by prices, which emerge as a result of demand and supply interactions at each location;

- as neighborhood structure changes (i.e. spatial externalities change), demand and the resulting land prices change as well;

- if supply and demand for land are considered jointly, then a land use model allows to account for the competition (demand or supply excess) which speeds up or slows down spatial developments;

- often interdisciplinary research involves policy recommendations in terms of market mechanisms (e.g. subsidies, taxes, insurance), effects of which are hardly testable in land use models if direct modeling of a land market is not present.

To summarize the section and to refer back to the issue of scales in economics discussed above, we note once again that the problem of aggregation in economics is a process of explaining macro-phenomena, such as market prices, through economic institutions, for example markets, assuming certain preferences and incomes at the micro-level. When a research problem involves natural sciences and particularly those dealing with space, the scaling issue in economics is translated into a question of aggregation of individual preferences via the land market. Thus, the conventional problem of aggregating behavior of representative or heterogeneous agents in any neoclassical market is translated into a problem of aggregating these behaviors in a land market as shown in Table 1.1

Table 1.1: Dominant features and processes on different scales in economics

\begin{tabular}{|c|c|c|}
\hline Scale & Neoclassical economics & Spatial economics \\
\hline $\begin{array}{l}\text { MICRO } \\
\text { (individual } \\
\text { decisions } \\
\text { making) }\end{array}$ & $\begin{array}{l}\text { Household consumption behaviour: } \\
\text { - individual preferences for goods } \\
\text { - income } \\
\text { - individual demand (willingness to } \\
\text { pay) } \\
\text { Firms production: } \\
\text { - costs of production } \\
\text { - profits } \\
\text { - individual supply (willingness to } \\
\text { accept) }\end{array}$ & $\begin{array}{l}\text { Households and firms: } \\
\text { - } \quad \text { individual decision where to locate } \\
\text { - } \quad \text { willingness to pay for land } \\
\text { - land tax or property insurance } \\
\text { - } \quad \text { interactions with other agents (market, social, } \\
\quad \text { spatial) } \\
\text { Farmers and developers: } \\
\text { - } \quad \text { opportunity costs of land (agricultural land price) } \\
\text { - } \quad \text { costs of developments } \\
-\quad \text { willingness to accept } \\
\text { - investments in public good }\end{array}$ \\
\hline
\end{tabular}




\begin{tabular}{|l|ll|l|}
\hline & - & aggregated demand and supply & - aggregate demand for and supply of land \\
MACRO & - & equilibrium (supply equals demand) & - spatial equilibrium \\
& - & market prices & - land price \\
(aggregated & - & unemployment rate & land rent gradients (i.e. land prices as a function of \\
phenomena) & - & inflation, etc. & distance from the CBD) \\
& & - total economic value of the area \\
& & spatial patterns \\
\hline
\end{tabular}

\subsubsection{Coastal risk management and relevance of microeconomic decisions}

About two thirds of the world's population live along the coast (Costanza et al., 1999). Coastal zones include some of the most valuable ecosystems on the planet (Costanza et al., 1997), and the expansion of developed urban areas puts these ecosystems under stress. It impacts habitat for species, food production, recreation, erosion control, and sediment retention (Martínez et al., 2007). In the Netherlands coastal zones require a delicate balance between economic development (70\% of Dutch Gross National Product is generated in coastal zone (Veraart et al., 2007)) and ecosystem functions provided by interactions of land and sea (the Dutch costal zone and the whole country is largely protected from flooding and erosion by sand dunes and other safety defense measures (Rijkswaterstaat, 2002)). Space, which is of big value for economic development, is ensured in coastal zones by ecosystem functions such as sediment retention and erosion control. The concept of land-use in economics implies that the spatial configuration of land patterns influence the efficiency of the whole economy by affecting transportation costs or the risk of damage caused by potential natural hazard. Land should be allocated between all alternative uses efficiently, providing adequate protection of humans from natural disasters, as well as protecting natural systems and their functions (e.g. erosion control and sediment transport) from human pressure. All these factors make the comprehensive coastal zone management necessary.

The level of complexity in coastal zone management is high since the processes involved take place on different analytical, temporal and spatial scales and are heterogeneous in nature. The lack of understanding of micro-foundations of macro-phenomena (such as total economic value of the area and spatial pattern of location) might make coastal zone management and spatial planning policies uncertain and unpredictable. Governmental policy might use instruments (e.g. taxes, insurance, educational programs) to affect individual motivations and rules of local interaction in order to direct land markets in coastal cities towards desired macro-scopic outcomes. Conventional economic models based on the assumption of a representative agent produce some guidance but models based on heterogeneous agents (and human behavior is highly heterogeneous) will produce qualitatively different results (Forni and Lippi, 1997; Filatova, van der Veen and Voinov, 2008).

Coastal zone management policy in the Netherlands is shifting to a concept of flood 'risk' instead of flood probability as a criterion for efficient management (Rijkswaterstaat, 2002). The risk 
of flooding or erosion is the probability of a disaster multiplied by the expected damage in terms of economic values and lives. On one hand, this implies that to decrease flood risk, governmental investments in flood protection are likely to be made in areas with high economic value. The economic potential of the area under risk is determined by individual land use decisions (van der Veen and Logtmeijer, 2005) and by the value of properties under risk (Rijkswaterstaat, 2005d) both emerging from many individual interactions on a land market. On the other hand, individual demand for certain locations depends of the flood/erosion safety standards and on the individual attitudes towards risk. The following conceptual scheme reflects the feedbacks between policy decision-making and individual land market decisions (Figure 1.1).

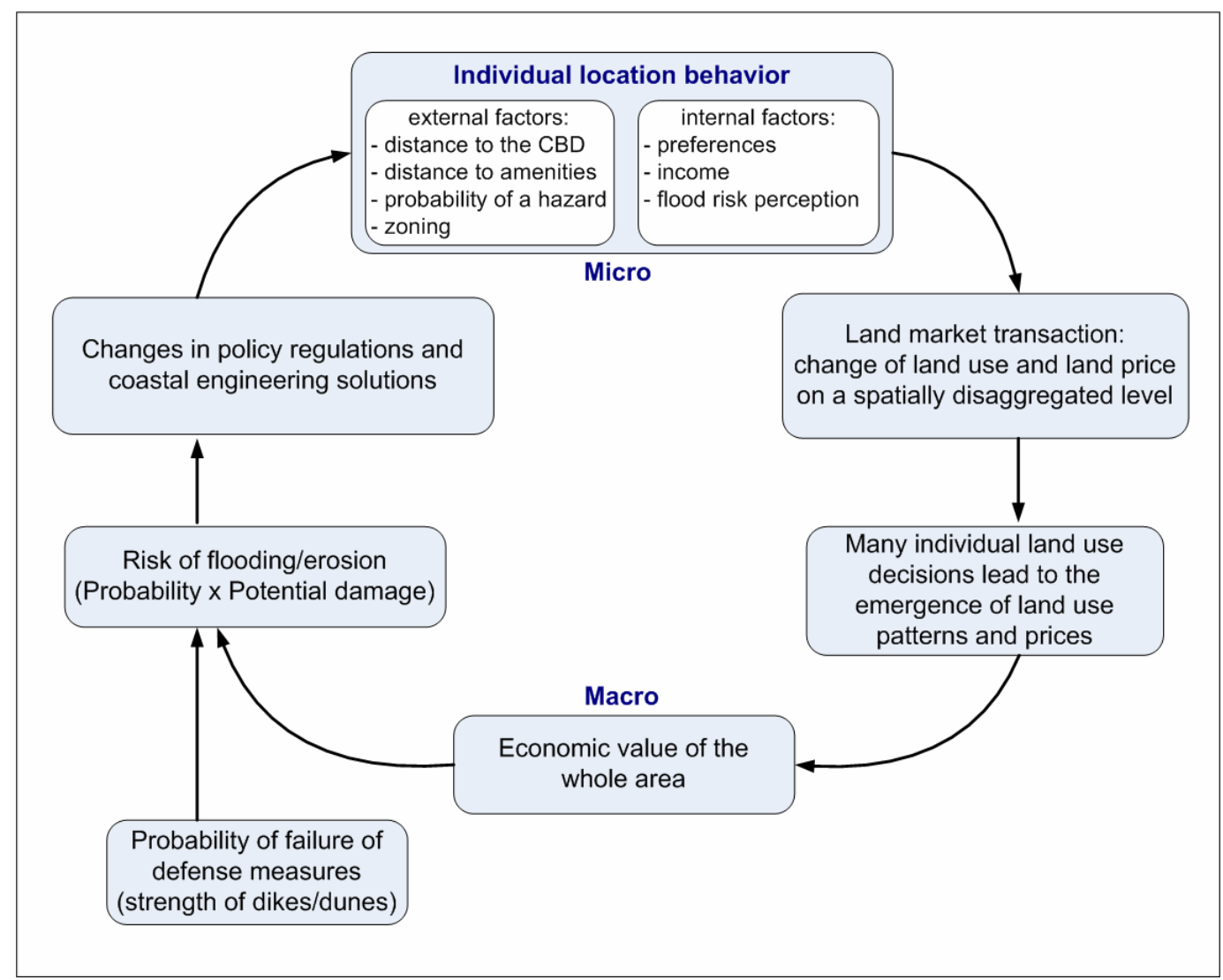

Figure 1.1: Conceptual model of feedbacks between microeconomic behavior and coastal risk management on macro-level (CBD - central business district)

At the micro-level economic agents choose a location, which is characterized by certain spatial attributes (external factors), by maximizing their utility or profit function (i.e. based on their internal factors). A successful transaction on a land market leads to the conversion of the sold piece of land from one use to another or change in its price. Many individual interactions on a land market lead to the emergence of spatial patterns and land prices that impact the economic value of the area at the aggregated level. The risk of flooding is determined based on the new economic value of the area (i.e. potential direct damage) and the probability of defense measures failure. Changes in total potential flood risk in the area drive changes in coastal policy at the macro-level 
(possibly, changes in the safety standards or spatial planning) providing new conditions, in which individuals make their microeconomic location decisions. The iterative nature of this process may be taken into account while developing coastal risk management strategies.

Currently, policy decisions, including coastal policies, are supported either by a general equilibrium model (based on representative agent and driven by aggregated statistical data for averages) or econometric predictions (based on the estimated demand curve of a representative agent or the probability that a representative agent will exercise a particular land use). This thesis will explore how the introduction of heterogeneity among agents and direct modeling of their market and spatial interactions might affect economic macro-outcomes, on the basis of which policy decisions are made. Therefore, the "growing" of economic macro-phenomena in space from bottom-up might serve as a useful laboratory to examine macro-outcomes of many interacting heterogeneous agents reacting to changes in macro-environment including changes in policy options.

\subsection{Goals, objectives and research questions}

\subsubsection{Goal and objectives}

The main goal of the study is to get insight into the aggregation issue in economics in a spatially explicit context. Specifically, this thesis seeks to identify traceable connections between micro and macroeconomic scales applied to a hypothetic city, which replicates the structure and complexity of a typical Dutch coastal city. This puts the results in a practical context and highlights their applicability for decision making. To achieve this purpose the following objectives were defined:

- Provide theoretical insights into the connections between microeconomic spatial location decisions, and macroeconomic outcomes and coastal risk management policy;

- Define a potential method to capture these connections;

- Develop a model capable of incorporating the economic concepts of land markets in the spatial context;

- Start with a simple model, and then gradually add details comparing it to economic theory and to the available empirical data;

- Explore what practical applications the model results may have for policy makers and give some considerations for coastal flood risk management. 


\subsubsection{Research questions}

To reach the goal, the following research questions were formulated:

Q1: How do micro-level preferences and perceptions (e.g. flood risk awareness) of economic agents affect macroeconomic spatial outcomes and how can policy-makers use these micromacro links for coastal risk management?

Q2: How can a land market be modeled in a spatially explicit way and what are the challenges arising from transforming an economic equilibrium framework into a dynamic spatial context?

Q3: How comparable are the results of a land market with homogeneous agents where the centralized equilibrium price determination mechanism is replaced by the spatially distributed bilateral trading to the results of the conventional monocentric urban model?

Q4: What are the results (e.g. land rent gradient, size of the city, welfare metrics) of a spatially explicit land market if spatial heterogeneity (e.g. amenities and disamenities) and agent heterogeneity are introduced?

Q5: How might land markets respond (in terms of changed land prices, city size, and amount of urban developments under risk) to an increasing probability of flooding or erosion? How variations in individual perceptions of erosion probability affect aggregated patterns of development?

Q6: What are the real-world individual location preferences and perceptions of flood risk in the Netherlands? What are the outcomes of a spatially explicit land market where the distribution of economic agents' perception of risk of flooding is parameterized with real-world survey data?

\subsection{Thesis outline}

The current study consists of eight chapters. After this Introduction, Chapter 2 focuses on the market mechanism, through which probability of flooding enters the microeconomic choice of location and on why it matters for coastal risk management. The effects of changes in individual flood risk awareness upon land prices and spatial patterns are discussed and a short review of the recent surveys of coastal flood risk perception conducted in the Netherlands is presented. Consequences of low individual flood risk awareness in coastal land markets are discussed together with the policy instruments to increase flood risk awareness.

Chapter 3 reviews the existing approaches to modeling of land markets and explores various spatial micro-simulation models. The justification is provided for the choice of the methodology, that is agent based modeling. We outline the challenges related to the equilibrium economic 
approach, the problems with the choice of economic agents participating in a land market and their pricing behavior, and propose some approaches to resolve the challenges.

Chapter 4 presents the first implementation of a spatially explicit agent-based land market model (ALMA), in which equilibrium price determination mechanism is replaced by a series of bilateral trades. Experiments reproducing conventional analytical monocentric urban model with homogeneous agents are performed (structural validation). Also, the effects of different pricing strategies are presented.

In Chapter 5 the monocentric urban model is extended to account for more than one spatial attribute (beyond traditional distance to the CBD). The chapter presents a spatially explicit land market model for a coastal city (ALMA-C) where economic agents make trade-offs between coastal amenities (seaside view) and disamenities (the probability of flooding or erosion). The effects of agents' heterogeneity with regards to spatial characteristics on aggregated outcomes are investigated.

Chapter 6 considers how macro-patterns change due to changes in spatial characteristics, rather than in agents' preferences as was the case in Chapter 5. This example shows the potential dynamics in the land market if the probability of flooding or erosion changes as a result of climate change (e.g. 'erosion line' shift). Results of experiments of the ALMA-C model with homogeneous and heterogeneous agents are discussed.

Chapter 7 discusses the results of a 2008 survey conducted in the Netherlands, which explores coastal flood risk perception and location choices. The analysis of micro-level data provides insight into how people actually make decisions about buying properties in flood-prone areas. As a next step, the survey results on individual flood risk perceptions are used to parameterize economic agents in the ALMA-C model.

Chapter 8 presents the conclusions in line with the research questions and the main goal of the study. The achievements and drawbacks of the current research along with directions for future work are presented. In addition, considerations on practical applicability of research results for coastal flood management in the Netherlands are outlined. 


\title{
2 Coastal risk management: how to motivate individual economic decisions to lower flood risk?
}

\begin{abstract}
Coastal flood risk is defined as a product of probability of event and its effect, measured in terms of damage. The focus of this paper is on how to decrease risk by decreasing potential damage. We review socio-economic literature to show that total flood damage depends on individual location choices in the housing market and on individual flood risk awareness. Low flood risk awareness leads to inefficient spatial developments and increased flood risk. We show that personal experience, risk communication, financial instruments like insurance from flooding and technical instruments like building on high elevations, are factors that increase individual risk awareness. Evidence that these factors indeed affect housing prices and land use patterns is provided. We discuss proactive instruments that can be used in coastal zone management in the Netherlands to increase individual risk awareness. We argue that policy-makers may create incentives giving individuals a possibility to make location choices that lead to less total flood risk in the coastal zone area.
\end{abstract}

\subsection{Introduction}

Worldwide the amount of capital in coastal zones susceptible to flooding ${ }^{4}$ is increasing. According to the IPCC the damage from natural disasters in Europe has rapidly increased over the past decades, mainly because of the growth of capital accumulated in flood-prone areas (Nicholls et al., 2007). In the Netherlands where about $70 \%$ of the Gross National Product is earned in the areas below sea level (Veraart et al., 2007), the issue of decreasing flood risk attracts a lot of attention. Risk of flooding in European water management is defined as a function of the probability of a flood event and its potential effect (in terms of monetary damage and human causalities) (Rijkswaterstaat, 2005a). This implies that lower flood risk can be achieved either by decreasing probability of flooding, or by decreasing potential damage from flooding or by combining the two. In Dutch water management traditionally the focus has been on reduction the probability of flooding by means of engineering defense constructions (i.e., strengthening dikes and dunes) (Rijkswaterstaat, 2002; Smits et al., 2006; Bucx et al., 2008). However, the decrease in total flood risk due to lowered probability of flood defense failure is vanished if the economic value of the area continues to grow in zones vulnerable to flood. Flood risk can be really reduced only if engineered coastal defense measures are complemented with an economic use of a flood zone that ensures less potential damage.

\footnotetext{
${ }^{3}$ This Chapter is also a paper co-authored with J.P.M. Mulder and A.van der Veen "Coastal risk management: how to motivate individual economic decisions to lower flood risk?" Submitted to Ocean and Coastal Management.

${ }^{4}$ Flooding, which is caused either by a break of a dike or high water levels, has two physical effects: inundation and erosion. Here when we say flooding (or flood) we assume both effects.
} 
The extent of flood damage depends on spatial patterns of residential and commercial areas and their values (Rijkswaterstaat, 2005d). Both patterns and prices are the outcomes of many individual interactions in the urban land market. Due to several reasons economic developments occur in proximity to old economic centres, which originated close to water ways or harbours. First, production and business companies benefit from clustering (Fujita and Thisse, 2002). Second, households are attracted to economically developed areas because of employment opportunities. Third, in addition to these economic factors coastal zones provide important environmental amenities, which are highly valued by households (Bin et al., 2008). Thus, all economic forces work to promote growth of capital in flood prone areas.

In coastal zones another vital factor in the decision to buy property or to invest is individual flood risk awareness (MacDonald et al., 1987). Low risk awareness leads people to buy properties in the zones vulnerable to flooding at higher prices and in higher amounts than would be beneficial for a society as a whole. It was shown that people who underestimate flood probability drive urban

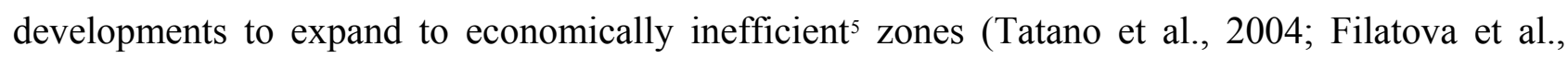
Under review). In the case of the Netherlands, where it is the society as a whole that pays for flood protection measures, individuals can take advantage of that and contribute to increasing flood risk. Since safety is assumed to be a governmental responsibility, water management provides no mechanisms for individuals to act in a more sustainable way in the light of climate change and sea level rise. This paper explores stimuli to motivate individuals to make microeconomic decisions at the housing market in the Netherlands that lead to less flood risk at the aggregated level. At the same time we highlight the aspects of shared responsibilities between government and individuals with regard to flood risk.

We focus on two research questions: 1) How do individuals make economic decisions at the housing market if there is a probability of flooding? 2) What instruments may policy-makers use to promote outcomes of a housing market that would lead to less flood risk? First, we outline the challenges associated with the current water management in the Netherlands. Next, from the review of economic studies we provide both theoretical and empirical evidence of the influence of flood probability on land prices and spatial patterns and explore the role of individual risk awareness. Third, the results of surveys aimed to elucidate individual coastal flood risk awareness in the Netherlands are reviewed. We then discuss four factors that increase risk awareness in coastal zones, and have a direct measurable effect on land use patterns and housing prices and, thus, on potential flood damage. Finally we draw conclusions on the effectiveness of these factors and possibilities to use them in water management.

\footnotetext{
${ }^{5}$ Economic outcome is considered to be economically efficient if no single person can be made better off, without making somebody else worse off. Inefficiency means that somebody made it better off by means of making another person worse off.
} 


\subsection{Challenges for flood risk reduction in the Netherlands}

In the Netherlands, at the macro-level the government took on the responsibility to minimize flood risk. Today the country is protected by a system of dike rings with different safety levels, which standards are enforced by law (Wet op de Waterkering, 1995). The dikes and dunes in the provinces of North and South Holland are supposed to withstand a storm surge with a probability of occurrence of once in 10000 years. Although the probability that a disaster may happen is low, the consequences will be dramatic ( $€ 300$ billion for the "Centraal-Holland" dike ring along in prices of 2000 (Kok et al., 2002)). The present safety standards, related to probabilities of flooding, are based on the guidelines developed by the first Deltacommissie (1960). The spatially differentiated probabilities have been defined taking into account the number of people living in a certain area and the economic value of the area. The second Deltacommissie (Deltacommissie, 2008) has proposed to increase the current safety levels by decreasing the probability level by a factor 10 .

However, by only decreasing probability levels one shadows some important hidden feedbacks between micro (individual) and macro (policy) decisions in the process of risk reduction. The higher the density of population and economic value of a territory (boxes I. and II. in Figure 2.1) the more reasons the government has to minimize the probability of flooding (box III. in Figure 2.1). However, there is a clear danger of a positive feedback here. The safer it becomes to live in the potentially vulnerable areas, the more people and businesses are attracted to settle and to invest there (box IV. in Figure 2.1). Moreover, economic forces work to attract more business and households seeking jobs to the existing economic clusters in coastal zones. The economic value of the territory increases even more (boxes V. and I. in Figure 2.1) and again may motivate the government to increase the safety in this area (boxes III. in Figure 2.1).

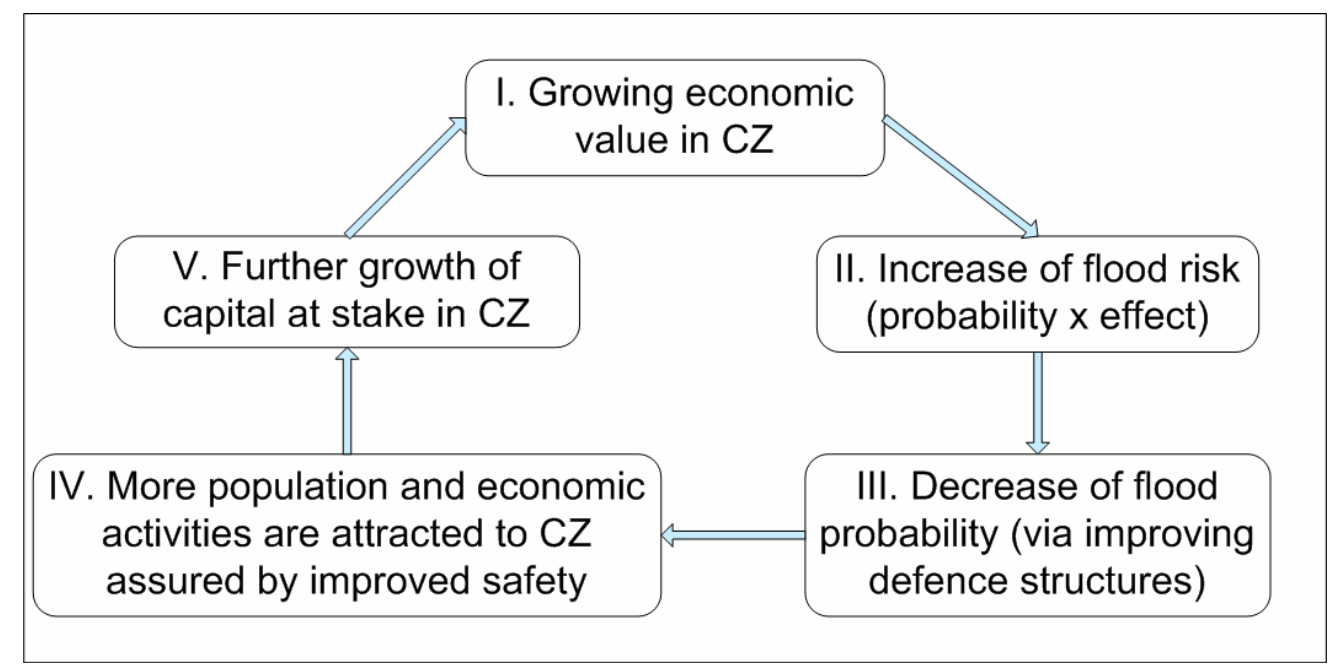

Figure 2.1: Self-reinforcing loop that fuels the growth of flood risk in coastal zones (CZ) 
It is a self-reinforcing cycle that has a negative effect on flood risk: the safer it becomes to live somewhere, the more economic agents would like to live and work there, and the more the state should invest to increase overall safety standards. Eventually, a cost-benefit analysis (CBA) calculating the cost of technical protection measures and the benefits of avoided risk - will indicate whether the cycle may continue. The key question is what will happen at the critical point in time when the CBA will appear to be negative. In order to postpone or even prevent this point in time, it seems worthwhile to investigate ways to interrupt the self-reinforcing cycle and turn it into a positive direction of maintaining or even decreasing flood risk.

With respect to damage reduction the following aspects deserve special attention:

1. Damage from a flood event is calculated as a sum of direct and indirect economic damage and damage from business interruption (Rijkswaterstaat, 2005a; Rijkswaterstaat, 2005d). Both spatial patterns and prices of properties play an essential role in the potential direct damage. In the Netherlands spatial patterns of development are strictly controlled by the government via spatial planning (Rijkswaterstaat, 2002). Housing prices, however, are the outcomes of market allocation of land between competitive uses where individual choice plays the main role. Thus, the risk of flooding is related to land/housing market outcomes, i.e. to individual demands for particular locations.

2. Safety from flooding is a public good. Formally in the Netherlands the government has an overall responsibility to decrease flood risk along the coast. However, individual location decisions create capital at stake making citizens partly contributing to the increased risk of flooding in the coastal zone. The present system of water management does not have mechanisms to account for these shared responsibilities. There are no incentives at the individual level to make housing decisions that would lower potential flood damage.

Characteristics of the traditional approach to flood safety in the Netherlands, as described above, is the dominant role of the government, no active mechanisms for individuals to make land market decisions leading to less flood damage and the emphasis on technical measures including technical expressions of safety levels. Even though, technically speaking, the probability of a dike failure is not zero, this water management practice has created a feeling of absolute safety amongst the population (see Section 2.4) and of absolute trust in the government taking care of the safety. Can a change in this attitude contribute to a reduction in flood risk?

We state that if individuals who buy properties in the land market are aware of risks that they are taking when settling in a vulnerable zone (box IV in Figure 2.1), then flood risk in coastal zone 
decreases. We argue that this measure can reduce the growth of flood risk in coastal zones even if the safety standards (probabilities of disaster occurrence) (Wet op de Waterkering, 1995) remain constant. To support our argument we first prove that individual risk awareness influences land prices and spatial patterns and, consequently, flood risk. Second, we discuss possibilities to increase individual risk awareness, which affects individual location decisions, so that flood risk in coastal zones can be decreased.

\subsection{Land use and housing values in flood prone areas: how does probability of flood enter into economic decisions at housing market?}

\subsubsection{Theory: Urban economics and economic decisions under risk}

The functioning of markets is well studied in economics (Varian, 1992). Economic agents in a land market have preferences for properties, from which the demand for land can be determined. The supply of housing depends on geographical conditions, spatial planning, and the structural density at which developers supply residential or commercial buildings. Conceptually, the price of a spatial good (i.e. a house or land) is the intersection point of the aggregated demand and supply curves. This is a very simplified view on a housing market; however, it gives us some powerful insights into how everything is interconnected. If demand for properties goes up then prices also increase (Buurman et al., 2001). For a coastal city this also implies that potential direct damage from flooding will increase. For example, if households have strong preferences for a seaside view, then demand for coastal properties increases and so do prices. Alternatively, if economic agents are aware of the risk of flooding in the locations close to the seaside, then the proximity to the coast might serve as a repulsive factor. The aggregated demand for land is likely to decrease pushing land prices down.

Consequently, the lower the demand for some locations, the lower the property price and the lower is the direct economic damage from flooding. As a matter of fact, in the Netherlands an average price of properties at the coast is higher than the average for coastal provinces. Specifically, in the province of Zuid-Holland the difference between average property prices along the coast and those more landward, was $€ 99400$ in 2005 (VLIZ, 2005). This may indicate that coastal amenities and economic attractiveness of the Dutch coast exhibit much stronger influence on individuals than potential flood damage.

Urban economics studies location decisions of individual households and firms in a city and aggregated urban features such as land prices and spatial structure. The majority of urban models 
are based on the monocentric urban model (Alonso, 1964). Households search for a location that maximizes their utility under budget constraint. Firms search for a location that maximizes their profits. This standard urban model was extended to account for several employment centers (Fujita and Thisse, 2002), as well as for the influence of environmental amenities (such as a seaside view) (Wu and Plantinga, 2003).

Under conditions of uncertainty, such as when buying properties in an area potentially vulnerable to flood or erosion, people maximize expected utility (expected profit). Thus, a choice between locating in a flood-prone coastal area and a safe area, might be seen as maximization of Von Neumann-Morgenstern utility function (Varian, 1992). The specific characteristic of the Dutch coastal zone is that the probability of flooding is very low. At the same time, benefits of locating close to the economically most developed area and coastal amenities are very appealing, which causes urban developments in the coastal zone to expand.

Moreover, economic agents may hold subjective beliefs about the probabilities, causes, and effects of flood events in the future. These beliefs depend on their experience, income, education and other personal factors. As discussed in literature (Slovic, 1987; Varian, 1992; Sjoeberg, 2000) economic agents have subjective perceptions of a flooding probability and associated risk. Experimental economics has proven that subjective risk perceptions very much depend on how the risky situation is framed or presented to an individual decision maker (Kahneman and Tversky, 1979). Subjective probabilities of an event are updated whenever a hazard event occurs and become lower if it does not occur for a long time. Empirical studies also reveal that the perception of risk increases after an event (Kaiser et al., 2004) and gradually reduces in the long-term, if an event does not happen periodically (Chivers and Flores, 2002).

Tatano et al (2004) proposed an urban model, in which the probability of a disaster was integrated as a qualitative characteristic of land. This model borrows much from the traditional monocentric model, except for the fact that a city is divided into two zones: a safe zone and a zone vulnerable to a natural disaster. Households are assumed to have some "perception bias" for the chance of a disaster. Equilibrium urban spatial pattern and land prices depend on individual risk perceptions of a natural disaster. The authors concluded that if risk perception biases exist, then an efficient allocation of land in the city is not possible.

\subsubsection{Empirical evidence: Hedonic analysis of housing prices in flood-prone areas}

The influence of risk of flooding on the land prices is also empirically justified by hedonic studies (MacDonald et al. 1987; IWR 1998; Daniel et al. 2007). In hedonic price studies a spatial good is considered as a differentiated market good with specific quantitative and qualitative attributes 
(Rosen, 1974). The probability of flooding is an important characteristic of the quality of a spatial good and it contributes to the overall property price. To be willing to locate in an area vulnerable to natural disaster, economic agents have to receive some compensation for accepting potential future losses. This compensation capitalizes in housing prices, meaning that property prices normally decrease in the vulnerable areas. The property price discount depends on the perceived loss and probability of a disaster (MacDonald et al., 1987). It develops in the competitive markets with perfectly informed buyers and sellers. However, information asymmetry, risk perception bias, and expectations that the government fully provides public safety, add to the complexity of market dynamics (IWR, 1998).

Using property transaction data, hedonic price researchers estimate the monetary value of every significant characteristic of a spatial good. In this case, the probability of flooding will have a negative value, which might reduce the total value of a spatial good in the market. Numerous studies trying to identify the discount of the housing prices caused by flood risks, were done in the USA. The common finding is that a probability of flood decreases property values (Table 2.1).

Table 2.1: Hedonic estimations of the housing price discount in the flood hazard areas

\begin{tabular}{|l|l|l|c|}
\hline $\begin{array}{l}\text { Authors, year of } \\
\text { publication }\end{array}$ & Case-studyarea & $\begin{array}{l}\text { Type of } \\
\text { natural } \\
\text { disaster }\end{array}$ & $\begin{array}{l}\text { Housing price reduction in } \\
\text { the } \begin{array}{c}\text { flood-prone } \\
\text { compared to the safe area }\end{array}\end{array}$ \\
\hline $\begin{array}{l}\text { MacDonald, Murdoch, } \\
\text { and White (1987) }\end{array}$ & Monroe, Louisiana & $\begin{array}{l}\text { Spring river } \\
\text { flooding }\end{array}$ & $2.8 \%-2.9 \%$ \\
\hline Speyrer and Ragas (1991) & $\begin{array}{l}\text { New Orleans, } \\
\text { Louisiana, USA }\end{array}$ & Flooding & $4,2 \%-6,3 \%$ \\
\hline Shultz and Fridgen (2001) & $\begin{array}{l}\text { Fargo, North Dakota } \\
\text { and Moorhead, } \\
\text { Minnesota, USA; }\end{array}$ & $\begin{array}{l}\text { Spring river } \\
\text { flooding }\end{array}$ & $8,8 \%$ \\
\hline $\begin{array}{l}\text { Daniel, Florax, and } \\
\text { Rietveld (2007) }\end{array}$ & North Carolina, USA & $\begin{array}{l}\text { River } \\
\text { flooding }\end{array}$ & $7 \%-13 \%$ \\
\hline $\begin{array}{l}\text { Bin, Kruse and Landry } \\
(2008)\end{array}$ & North Carolina, USA & $\begin{array}{l}\text { Coastal } \\
\text { flooding }\end{array}$ & $6.2 \%-7.8 \%$ \\
\hline
\end{tabular}

In the Netherlands, the hedonic price method rarely has been applied to evaluate flood effects on housing values. To our knowledge there is only one study applying it to river flooding (Daniel et al., 2007). The results of this hedonic price analysis for the dwellings in the floodplain of Meuse River, showed that local housing markets in the Netherlands are sensitive to flood risk. The housing sales during the period from 1990-2004 were analyzed and the result was that the prices of houses located in an area inundated in 1993, were ex-ante 7\% lower than a similar house located in a safe zone, and went down by $14 \%$ after the flood. 
River flooding is a more frequent event than coastal flooding in the Netherlands; people are more aware of river flood risks and react accordingly in the housing market. This makes the situation different from coastal flooding, which is rarer.

To summarize the economic literature, we outline three important facts:

1. Individual decisions matter: Land prices and land use patterns (on which flood risk depends) are determined by the total demand and supply of land/housing in the region. The latter two are formed by aggregating individual supplies and demands (i.e. individual preferences for locations and financial possibilities);

2. Probability of flood matters: There are attractive and repulsive forces, which influence individual decisions on where to locate or to invest, i.e. the individual demand for location. These forces are formed by preferences of economic agents over characteristics of spatial environment. Probability of flooding, if integrated in location decisions, affects housing prices and land use patterns;

3. Risk awareness matters: Individuals have subjectively perceived probability of the hazardous event, which cause economically inefficient biased aggregated outcomes such (i.e. land use patterns and land prices).

\subsection{Perception of risk of coastal flooding in the Netherlands}

Water managers operate with probabilities, but people very poorly understand probabilistic risks (Slovic, 1987). Especially when an event has a low probability, such as coastal flood in the Netherlands, people hardly integrate risk into their decisions (Camerer and Kunreuther, 1989; Bin and Kruse, 2006). Risk perception is shaped by socio-economic, demographic and cultural factors and by previous individual experience of the hazardous event, and may differ from region to region (Williams et al., 1999; Kaiser et al., 2004; Raaijmakers et al., 2008).

Several surveys, which investigate the level of coastal risk awareness, were carried out in the Netherlands. Three of them are at the stage of result analysis (Bočkarjova et al., 2008; Krywkow et al., 2008; Terpstra and Gutteling, 2008). The main conclusion from these surveys is that individual flood risk perception in the Netherlands is low. To our knowledge there are two other surveys that have been completed. In 2000 there was a survey conducted in six Dutch coastal towns (Berg et al., 2002). The main purpose of that survey was to understand the willingness of coastal residents to accept flood risks. The sample was very small and included only 12 households (and 48 for the set of questions concerning alternative policies). The main conclusion of the survey was that citizens of the coastal towns felt themselves safe and had trust in the defense measures designed by the government. The most common answer to the question "Do you think that flooding could happen in 
the area where you live?" was negative (see (Berg et al., 2002) p. 20) although each of the towns is certainly prone to flooding.

Another survey was conducted under the umbrella of the COMRISK ${ }^{6}$ project (Kaiser et al., 2004). It covered several European countries in the North Sea region, including the Netherlands. One of the objectives was the analysis of the present state of public perceptions of flood and flood defense. About $22.3 \%$ of the 400 questionnaires distributed were returned (making the sample group of about 89 respondents). Although 34\% of respondents had experienced coastal flooding, $74 \%$ of them considered the probability of coastal flooding as "low" and "very low". Also, 95\% of respondents did not take any personal measures to be prepared for a storm flood. The survey suggested that knowledge about the probability of disaster did not imply awareness about consequences.

It is surprising to conclude that in the Netherlands where $70 \%$ of the territory is below sea level, citizens have very low coastal flood risk awareness. One possible explanation for this, may go back to the history of floods and water management in the Netherlands. The experience of a disaster and the time since it occurred strongly influences perceptions of risk (Kaiser et al., 2004). The last coastal flood happened in the Netherlands in 1953. That event took away over 1800 human lives, destroyed 3000 houses and 300 farms, over 40000 houses and 3000 farms were damaged. The inundation of almost 200000 hectares of land caused an enormous material damage of 3.1 billion discounted Dutch guilders (Marchand et al., 2006). After this tragedy the Dutch government promised to improve flood defense, so that such a disaster would not happen again (Deltacommissie, 1960). The enormous Delta works resulted in construction of a strong wall against the sea in the south-west of the country. Coastal engineering constructions, which made the Netherlands a country with the highest flood safety standards in the world, have been considered as 'the' solution to the flood problem and have created a feeling of absolute safety. Perhaps, feeling safe behind strong flood defenses, the Dutch society has started to experience an effect of dissonant perception, i.e. a perception of the past hazardous event as a coincidence, and a conviction that this is unlikely to happen again (Kaiser et al., 2004). Dissonant risk perception is attributed to people who have much material wealth and have to live their day-to-day lives with a chance of a major disaster (Smith, 2001).

Another explanation for low awareness of coastal flooding in the Netherlands might be the fact that the threats along the Dutch coast are actually not visible for ordinary citizens. Indeed with the decision to maintain the coastline in the 1990 position (Rijkswaterstaat, 1990), coastal nourishments fix the erosion that happens during winter storms. The idea to maintain the coastline

\footnotetext{
${ }^{6}$ http://comrisk.hosted-by-kfki.baw.de/index.html
} 
was an appropriate decision; it certainly prevents dune erosion to spread landward. However, it may exacerbate a false feeling of safety and further decrease individual risk awareness.

\subsection{Increasing individual flood risk awareness as a complementary measure to reduce flood risk.}

Following the logic outlined in the previous sections (see Figure 2.2) we argue that in order to decrease risk of flooding in coastal zones, an important option is to increase individual coastal flood risk awareness. In this section we discuss how risk awareness can be positively influenced by personal experience, risk communication, financial mechanisms and technical engineering solutions. We focus on the measurable effect of an increased risk awareness by one of these factors, on individual location choices and consequently on land prices and on overall damage from flooding in the vulnerable areas.

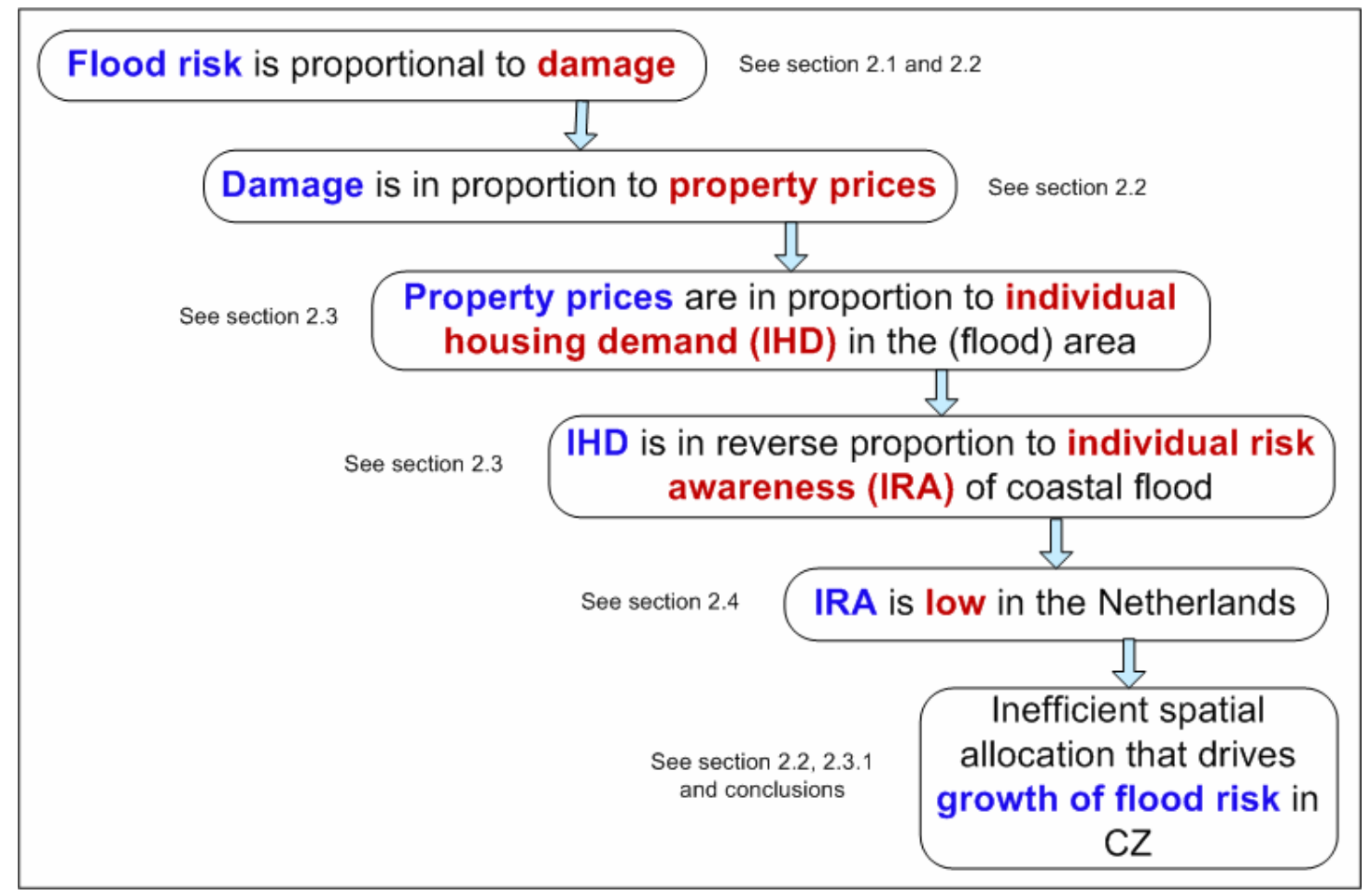

Figure 2.2: Conceptual links between flood risk, housing market and individual risk awareness (CZ - coastal zone)

\subsubsection{Personal experience of a disaster and risk awareness}

Perceived risk and experience of disaster are closely related. People who have ever experienced flooding themselves, are likely to have higher flood risk awareness than those who never did (Lave and Lave, 1991; Kaiser et al., 2004). There is clear evidence that risk awareness, increased by a natural disaster, can change individual location decisions. 
Example (effect of a hurricane on a housing market): Hallstrom and Smith (2005) evaluated whether the prices of properties known to be in risky locations, have adjusted in response to the information provided by the hurricane Andrew in Florida, USA. In 1992 this area experienced the strongest storm over the last 20 years. This hurricane "nearly missed" Lee County and passed the area 75 miles to the south without any damage to Lee County. However, the hurricane provided information about the effect of the natural disaster. The housing prices in the flood hazard areas went down by $19 \%$ after the "nearly-missed" hurricane. This shows how people perceive risk implying that home buyers and sellers appear to have incorporated the risk in their decisions in the housing market, not just because the actual disaster happened to them, but even because the disaster 'nearly' happened. It was not damage from flooding that made housing prices go down. People's flood risk awareness was affected and they responded at the housing market with lower housing prices in the risk-prone zone.

Economically speaking, if subjective probability of flooding is updated to the actual probability level, then the individually expected utility from a location that is vulnerable to flood, decreases. Thus, the demand for urban land in vulnerable zone decreases followed by decrease in property prices and in potential direct flood damage.

Conclusion 1: If individual flood risk awareness increases, then spatial patterns and land prices in vulnerable areas may change. These changes decrease potential economic damage from flooding and thus total flood risk.

Examples above show that personal experience is indeed an important factor in increasing flood risk awareness. However, stimulating floods in order to promote personal flooding experiences, of course is not a reasonable policy instrument. Nevertheless, broadcasting and visualizing these previous experiences may be an important component of a risk communication strategy.

\subsubsection{Risk communication and risk awareness}

By applying a chain-of safety approach ${ }^{7}$, European water management, in the first place, aims at proactive measures. Increased risk awareness is essential to achieve this. Not only does increased risk awareness lead to changes in location behavior and decrease of total flood risk in the area, as discussed above; it is also an expression of the willingness of people to respond or accept proactive

\footnotetext{
${ }^{7}$ The chain of safety is an approach to flooding disaster prevention aimed to provide proaction, prevention, preparation, response and recovery strategies to minimize the casualties and damage caused by coastal flooding. See details at http://www.chainofsafety.com/
} 
actions of government. For example, citizens will be more likely to accept "room for the river" as a flood management strategy, if they are aware that river floods can happen. Thus, increasing flood risk awareness is not only a proactive measure in itself; it also creates ground for acceptance of other proactive flood protection initiatives of government. Consequently, the government needs to find a proper flood risk communication tool or another way to increase individual risk awareness (Rijkswaterstaat, 2005b).

Decision-makers in water management operate with a technical notion of risk. This, however, is quite different from the notion of the general public about risk (Plough and Krimsky, 1987; Raaijmakers et al., 2008) (see Table 2.2 for the differences between technical and cultural rationality). Following a need to communicate different types of risks (health risk, risk from natural disasters, industrial risks, risk from genetically modified food and so on) to people, a new scientific field has emerged (Plough and Krimsky, 1987). The main challenge in risk communication is that the public perception of hazards is inconsistent with the objective information. The question is how to present information to the public in order to gain its understanding and acceptance for policy decisions. Thus, increasing risk awareness is all about presenting information in a way acceptable for the public, specifically, addressing it's feelings (Baker, 1990). However, informing about potential flood risks and not providing real instruments for individuals to act upon this risk, does not provide a ground for a shared responsibility for risk elimination between government and individuals.

Table 2.2: Factors relevant to the technical and cultural rationality of risk (After (Plough and Krimsky, 1987))

\begin{tabular}{|l|l|}
\hline \multicolumn{1}{|c|}{ Technical Rationality } & \multicolumn{1}{c|}{ Cultural Rationality } \\
\hline $\begin{array}{l}\text { Trust in scientific methods, } \\
\text { explanations; evidence }\end{array}$ & Trust in political culture and democratic process \\
\hline Appeal to authority and expertise & Appeal to folk wisdom, peer groups, and traditions \\
\hline Risks are depersonalized & Risks are personalized \\
\hline $\begin{array}{l}\text { Emphasis on statistical variation and } \\
\text { probability }\end{array}$ & $\begin{array}{l}\text { Emphasis on the impacts of risk on the family and } \\
\text { community }\end{array}$ \\
\hline
\end{tabular}

Risk communication strategies can be based on different theories; for example organizational theory (Chess, 2001) or mental model approaches (Kolkman et al., 2007; Wagner, 2007). Special attention is paid to the communication of the risk of natural hazards (Baker, 1990; Lave and Lave, 1991). In particular, Baker (1990) provides a detailed 8-step guide on how to transfer information about environmental risks from experts to a non-expert public.

\footnotetext{
8 'Room for the River' is a package of measures concerning the spatial planning key decisions in the Netherlands. In particular, it aims to create more space for rivers to flood in the zones where the least damage is expected to occur (e.g. part of agricultural land along the rivers is being transferred into the 'planned' flood plains). For details see http://www.ruimtevoorderivier.nl/
} 
Risk communication and increase of risk awareness is a very complex and long-term process since it has to deal with promotion and establishment of new social or public norms or opinions in a society. Bier (2001) reviewed several empirical studies and inferred positive and negative lessons learned. There are many obstacles to effective risk communication, including some external and internal barriers inside a governmental agency or ministry (such as inadequate resources, lack of time, special interests or internal politics) (Johnson and Chess, 2006).

Example (effect of media coverage of risk on a housing market): Risk is communicated by providing information about a hazardous event. With new information, individual beliefs about risk are updated. McCluskey and Rausser (2001) tried to measure the evolution of risk perception due to information people obtain from the media. Particularly, they have analyzed the effect of news about a hazardous waste site published in a local newspaper, on changes in risk perception. The hypothesis was that "if the media affects the public perception of risk, then media coverage of environmental damage should be a significant factor in determining property values". They concluded that media coverage increases perceived risk, which in turn decreases property prices. Gayer, Hamilton and Viscusi (2000) analyzed changes in perceived risk of cancer from hazardous waste sites, due to newspaper coverage, and effect of these changes on the housing market. The analysis showed that newspaper publicity about the local hazardous waste sites had a negative effect on housing prices.

Conclusion 2: If a flood risk communication strategy is designed in an appropriate way, it may increase individual risk awareness of environmental hazards. With increased risk awareness economic agents are likely to integrate flood risk in their location decisions, which might be reflected in decreased land prices and decreased flood risk for the area.

\subsubsection{Insurance against flooding as a measure to increase coastal flood risk awareness}

Dikes and insurance are two totally different measures of flood protection. The former reduces the probability of a disaster, and the latter reduces the individual damage from flooding. Insurance against flooding has been implemented for flood-prone areas in several countries, such as France, Germany, the UK and the USA, but not in the Netherlands. Compulsory flood insurance is supposed to improve the economic efficiency of the use of the flood-prone areas (Chivers and Flores, 2002). One of flood insurance's primary purposes is to guarantee premiums proportional to risk for individuals in vulnerable areas (Krutilla, 1966). Botzen and van den Bergh (2008) discuss the feasibility of flood insurance as a risk-sharing mechanism in the Netherlands.

Yet, in addition to risk-sharing, flood insurance may serve another objective, which seems to be ignored in the discussions over its implementation in the Netherlands: in areas where people 
ignore risks, which is often the case for low-probability high-impact events such as coastal floods in the Netherlands, insurance may serve as a measure to communicate this risk and to persuade people to integrate it in their decision making. As noted by Chivers (2002) "even if people do not appreciate the risk they face by locating in the flood plain for whatever reason, compulsory insurance, ... will force them to face the social cost of locating in the flood plain". If compulsory flood insurance is present, then risk of flooding becomes explicitly known to people making a choice to buy a house or to invest. Since the late 1960s the federal government in the USA has emphasized flood insurance as a primary tool for improving location behavior in flood-prone areas (Lave and Lave, 1991). To make insurance work as both risk-sharing and risk-communication device, information asymmetry should be avoided (Bin and Polasky, 2004) and spatial discrimination of risk and its accurate prices should be emphasized.

In practice insurance implies that individuals and government share the responsibility in the case of disaster. As for any public good, safety from flooding may cause a discussion about who has to pay for its provision. In the Netherlands, traditionally the government and Water Boards are responsible for building and maintaining flood protection structures and guaranteeing a certain safety level. All citizens, independently of the fact whether they live in flood-prone or in safe areas, have to pay their share of taxes to finance flood protection measures for vulnerable zones. As such there is a collective responsibility for flood protection.

There is an important difference between collective and shared responsibility. Collective responsibility means that society as a whole is responsible, but nobody in particular. In this case flood defense measures are financed via the tax system, which does not differentiate between risk levels in the location of taxpayers and actual tax payment. Shared responsibility means that society as a whole (represented by a government decision-maker) and individuals, both play active roles in risk reduction. Insurance is an example of a shared responsibility arrangement. Insurance payment discriminates on a risk of a natural hazard and individuals can actually choose whether to take it. However, since the introduction of an insurance against flooding implies a partially individual responsibility for flood risk, the Dutch are very reluctant to it.

Nevertheless, nowadays insurance against flooding is being discussed by policy makers and scientists in the Netherlands. The issue of redistribution of responsibilities for damage between government and individuals entered the decision-making process of the Dutch Ministry of Public Works and Water Management, when risk management strategies for coastal towns under flood risk were discussed (Rijkswaterstaat, 2005b). Each of the strategies included a set of options with respect to coastal defense measures, spatial planning, insurance options and risk communication. Three of the four proposed policy options implied an establishment of a pool of insurers. For some 
coastal towns under risk, including the ones described in Chapter 6, insurance if supported by government seems feasible (Kok, 2005).

An option to extend insurance coverage for coastal flood risks at the scale of the whole Netherlands is argued to be unattractive due to the potential high damage from flooding and impossibility to cover all insurance claims (Kok et al., 2002). However, it might be attractive to use in coastal cities under risk, such as discussed by Poelmann commission (2005). For large-scale flooding in the Netherlands the reinsurance schemes should obviously be offered, probably involving the global private insurance market discussed in literature (Bouwer and Vellinga, 2002); this offers new products to effectively transfer risk. Botzen and v.d. Berg (2008) proposed a set of insurance arrangements for the Dutch situation. They argue that varying risk premiums across risk classes, introducing deductibles, co- and re-insurance and upper limits on coverage, will not only make flood insurance feasible in the Netherlands, but will also increase economic efficiency.

Example (flood insurance and decreased housing values): housing markets in the countries where flood insurance is mandatory, reveal a decrease of prices due to insurance pressure on individual budgets. Flood insurance largely explains housing price discounting in flood-plains where mandatory insurance has been introduced (Speyrer and Ragas, 1991). Shultz and Fridgen (2001) showed that flood insurance premiums account for about $80 \%$ of a house price decrease in a flood-plain. They also associated the decrease in housing prices with increased flood risk awareness. Bin et al (2008) reported that the value of flood insurance premiums capitalized into housing prices. They concluded that flood insurance conveyed risk information to participants in the coastal housing market.

Conclusion 3: If mandatory flood insurance is introduced, it serves as a flood risk communication device that helps to integrate flood risk in the urban land market. Capitalization of flood insurance leads to a house price discounting, leading to less direct damage from flooding to an area as a whole. Prices in vulnerable zones go down, as it should be from the viewpoint of market efficiency. Where possible, Dutch water management needs to apply market mechanisms to reduce flood risk in coastal zones.

\subsubsection{Building on higher elevation levels as a measure to increase risk awareness}

Coastal engineering solutions have significantly decreased flood probability but have made people unaware of coastal risk (Smits et al., 2006; Wesselink, 2007). There are also engineering solutions that can decrease risk of flooding without creating a false feeling of safety. Currently in the Netherlands, an option of raising ground level for new spatial developments is discussed as one of the adaptation strategies to climate change (Bucx et al., 2008). Under the framework of EU project 
ComCoast there is a pilot project "Perkpolder", that aims to develop a new area with housing and a hotel to be built on elevated grounds in the Dutch province of Zeeland ${ }^{9}$.

Building new developments at higher ground levels does not only decrease potential damage from flooding. We claim that it also makes people living in the neighborhood aware of flooding since it creates a visible sign that houses are in the vulnerable zone. The traditional methodology to increase individual risk awareness is to educate people about risk as discussed in Section 2.5.2; which means talking about a problem and making people think about a problem. In combination with traditional hydraulic engineering measures, a traditional way of increasing risk awareness is emphasizing "water as a threat": basically a negative message that is given a positive twist by the appeal "to live with water" 10 . Contrary to that, an alternative engineering measure like building on higher ground levels, offers the opportunity to communicate a positive message: it is about building, instead of being liable for erosion; it is about being protected instead of being threatened. Moreover, the 2008 Deltacommissie ((2008), p52) refers to the idea of building on high elevations as to one of the options to decrease damage due to high water levels.

Example (lessons from Dutch «Terpen»): Artificial mounds or terpen were used in the Netherlands back in 500 B.C. ${ }^{11}$ and even earlier ${ }^{12}$. Back in the middle ages terpen, on which villages were built, could reach up to $5.5 \mathrm{~m}$ above NAP (mean sea level) (Groenendijk, 1997). The fact that in the Netherlands in the past there were developments on artificially elevated grounds implies that people were aware of flood risk. It illustrates that "higher is safer" is easy to understand, which makes developments on terpen a perfect flood risk communication instrument. From this point of view, terpen not only provide means to reduce actual flood risk, but also increases the awareness of people about this risk. Individuals searching for houses to buy and being aware that floods occur in the area, will more likely prefer to choose a location at higher elevation. By choosing between a house in the elevated and safe area or in the low and vulnerable place, individuals share a responsibility with their government with respect to flood risk reduction. Due to their image of a cultural and historical heritage, terpen "do not score badly in the Netherlands" (Groenendijk, 1997). It is likely that the average Dutch person will have a positive attitude towards buying a house on a terp. The more developments in the zone vulnerable to flood occur on manmade mounds, the less the potential risk is.

Example (lessons from Hurricane Katrina): The analysis of the consequences of Hurricane Katrina led to many recommendations. In addition to calls for better governmental reaction, for

\footnotetext{
9 http://www.comcoast.org/

${ }^{10}$ See Communication strategy Nederland leeft met Water ( Netherlands Living with water) of the Netherlands Ministery of Transport, Public Works and Watermanagement (http://www.nederlandleeftmetwater.nl/)

11 Rijkswaterstaat, an official web site of the Directorate-General for Public Works and Water Management, http://www.rijkswaterstaat.nl/themas/bescherming tegen het_water/hoe beschermt_rws/terpen/index.aspx

12 An official web site of Friesland province in the Netherlands http://www.friesland.org/red/n terpen.htm
} 
strengthening the levees, and for individual preparedness and evacuation plans, there are also recommendations for future urban development. Waugh and Smith (2006) mention that plans for New Orleans' redevelopment assume that new developments are built at higher elevation. Specifically, redevelopment plans included elevated residences and an elevated rail system between the city and the airport. According to Rodiek (2007) urban planners should consider landscape reconfiguration by creating topographic terraces of varying height with commercial and residential developments at the highest level. Naturally, the areas of New Orleans that were on higher ground had less physical damage (Cigler, 2007).

Conclusion 4: Constructing new developments on higher grounds not only decreases direct damage in the case of flooding. It also serves as a persistent flood communication signal that reminds that flooding may happen, thus reviving individual risk awareness.

\subsection{Discussions and overall conclusions}

Risk of coastal flooding is an important issue in the Netherlands, where the majority of economically developed areas is below sea level. Risk, defined as a product of probability and damage, can be best reduced by decreasing both multipliers. While most of the effort so far has been on reducing probability, in this paper we have been discussing policy options to decrease potential damage. We are trying to achieve that, and consequently to define options to reduce flood risk in the coastal zone of the Netherlands, by affecting microeconomic decisions in the housing market. Changes in flood risk happen due to changes in individual demand for land in flood-prone areas, which affects property prices and consequently potential direct damage. With the Dutch government being totally responsible for safety, there are no real mechanisms for individuals to make choices in the housing market that would lead to less potential damage. Thus, there are no instruments to share the responsibility for flood risk reduction between government and individuals, although in practice individual choices do affect potential damage.

Economic theory and empirical evidence show that individual risk awareness affects individual location choices. Property prices and spatial patterns change due to increasing risk awareness, leading to a decrease in direct damage from coastal flooding. However, results of recent surveys on coastal flood risk perception show that risk awareness is low in the Netherlands. It leads to inefficient economic land use outcomes. Thus, for water management policy it is important to find ways of increasing individual flood risk awareness.

By reviewing literature and experience in different countries we found four factors that influence risk perception and have measurable effects on property prices: 1) personal experience, 2) risk communication, 3) financial and 4) technical instruments as risk communication devices. We 
showed evidence of the effects of these four factors on individual risk perception and location behavior. Our main and general conclusion is that if individual flood risk awareness is increased, then it is likely that coastal flood risks are integrated in the individual economic decisions at the housing market. In this case the housing market reacts by changing spatial patterns and housing prices leading to less total flood risk in the area. Thus, we argue that coastal flood risk can be reduced by increasing individual coastal flood risk awareness.

Personal experience of a disaster increases risk awareness and has a strong effect on individual location choices and, consequently, can change flood risk in the area. However, being a factor that increases awareness, it cannot be used directly by policy makers. Nevertheless, personal experiences may play an important role in communicating risk through outreach and education.

Risk communication, financial and technical mechanisms, can be used by policy makers as complementary instruments to increase individual risk awareness and decrease coastal flood risk. Risk communication is an important but a long-term process, requiring a change in social norms. Both insurance and building on higher elevation have direct measurable effects on individual location choices and, consequently, on flood risk reduction. Moreover, these two instruments give individuals an opportunity to act, in contrast to risk communication where an individual remains passive. They also create a ground for shared responsibility between government and individuals for flood risk reduction. There have to be possibilities for individuals to act upon communicated risk. Insurance schemes allow individuals to choose to pay different premiums depending on different risks in different locations. Similarly, developments built at higher elevation will give individuals a choice to live either at, or below, or above sea level, even in the coastal provinces in the Netherlands.

Mandatory flood insurance is an effective risk communication tool. It increases economic efficiency of land use in coastal zones. However, it is a forced action and due to the cultural and historic background, Dutch citizens might be reluctant to accept it. An advantage and at the same time a drawback of this measure is that it may drive investments to more safe areas. On the one hand it implies less flood risk in the areas prone to flooding. On the other hand, however, it means a loss of investment for some coastal municipalities and lower housing prices for house owners. A solution to overcome the negative side of this financial instrument might be to set affordable insurance premiums with the aim to discriminate among different flood risk levels.

Building new developments on higher elevation levels is an effective engineering instrument which also increases risk awareness. In addition, it decreases potential flood damage in the elevated areas. Nevertheless, attention has to be paid to potential negative effects on flood risk in the surrounding, not elevated area. Another problem is the financial feasibility of new spatial 
developments at high elevation. Both concerns can be addressed by designing a long-term gradual introduction of surface accretion, which will slowly (in, say, 100 years time) decrease risk in elevated areas. Regarding to the financial aspects, preliminary estimates show that the cost of raising surface levels of planned new developments will constitute only about $2 \%$ of total current Dutch building investments (Meulen et al., 2007). The major advantage of this technical instrument to increase risk awareness is that it does not deter investments from coastal zones. Instead it creates extra space, safe from flooding, in the coastal zone. Moreover, the government does not need to force people to buy houses that are at higher levels, it just needs to provide opportunities for them to make this choice. The more aware people become about coastal flood risk, the more they may choose to prefer locations at higher elevations. Increasing demand for land uphill will provoke land market forces to come into play driving up housing prices on high ground and making it appealing to developers to invest more in the elevated houses. The more developments occur on higher ground, the more individuals become aware of flood risk and the less potential damage is going to occur. This is potentially a self-reinforcing cycle with a positive effect of decreasing flood risk. In this case not only the government achieves its goal of decreasing flood risk, but also individuals and private investors benefit. It has the potential to make microeconomic behavior working in line with policy-goals and thus to exploit the capacity of shared responsibilities for flood risk reduction between the government and the citizens. 



\title{
3 A conceptual design for a bilateral agent-based land market with heterogeneous economic agents ${ }^{13}$
}

\begin{abstract}
This paper presents a conceptual design for an agent-based bilateral residential land market. The design includes interactions between multiple buyers and sellers (household agents, developers, and rural land owners) and two local feedbacks to land value-price expectation formation based on local neighborhoods and spatial externalities. To address the methodological challenges inherent in the transition from equilibrium-based analytical models to agent-based simulation, we combine traditional deductive optimization models of behavior at the agent level with inductive models of price expectation formation. Relative to previous models, our proposed model is more closely linked to urban economics; contains a wider range of drivers of land use (LU); and addresses alternative models of division of gains from trade and determination of transaction prices, including models of bid and ask price formation. Our proposed approach is also closely linked to geographic cellular LU models, potentially uniting the strengths of these two disciplinary perspectives.
\end{abstract}

\subsection{Introduction}

Land-use change (LUC) is influenced by interactions between social and biophysical landscapes, with economic development, demographic growth, and shifting social conditions occurring concurrently with land-cover and climate change. Land itself has many roles: property or investment, an administrative unit, soil, a store of mineral resources, or terrain for ecosystems functions (Randall and Castle, 1985). Consequently, different disciplines attempt to explain drivers of LUC from their own perspectives, and within disciplines, LUC is modeled using a variety of approaches: theoretical and empirical, spatial and aspatial, micro and-macro-scale. The result is a diversity of explanations of LU development and prescriptions of optimal policies for LU.

The economic perspective investigates how scarce resources such as land can be allocated efficiently between competitive uses, and the land market (LM) is viewed as the main allocation mechanism. Yet, many models of LUC exclude economic drivers and/or LM interactions. This deficit may occur because of the difficulties inherent in integrating static equilibrium-based aspatial economic land market models (LMM), with the dynamic, heterogeneous spatial environments of LUC models.

This paper presents a conceptual design for an agent-based bilateral residential LM that includes multiple heterogeneous and interacting buyer and seller agents. We outline a proposed set of approaches to address the methodological questions that are raised in the transition from

\footnotetext{
${ }^{13}$ This Chapter is also published as paper co-authored with D. C. Parker "A conceptual design for a bilateral agent-based land market with heterogeneous economic agents." Computers, Environment and Urban Systems 32: 454-463, 2008
} 
equilibrium-based analytical theoretical models to an agent-based simulation. Relative to previous work in economics and cellular modeling, our proposed model is more closely grounded in urban economics, but moves that perspective further from equilibrium-based modeling. Although we begin from the perspective of economics, our modeling framework emphasizes local spatial interactions and linkages between local processes and heterogeneous patterns of LUC, opening the possibility for coupling the LMM with other spatially explicit, process based socioeconomic and ecological models. While we focus narrowly on modeling LMs, we hope that the discussion will be of interest to the broader community of LU modelers, whose activities represent and integrate a diversity of disciplinary perspectives and research applications (Nelson and Geoghegan 2002; Benenson and Torrens 2004; Veldkamp and Verburg 2004; Crawford et al. 2005; Klosterman and Pettit 2005; Brown and Xie 2006; Koomen et al. 2007; Turner II et al. 2007; Koomen et al. 2008; Walsh and McGinnis 2008). Our paper lays out a series of open questions and a set of proposed approaches, which we hope will stimulate discussion, debate, and new work by the LU modeling and spatial economics communities.

The paper proceeds as follows. We briefly review related literature, including analytical equilibrium-based and cellular simulation models of urban systems and other agent-based market models. Next, we discuss LMs in the context of agent-based modeling (ABM). We then present the conceptual bilateral ABM of residential LMs. First, trading agents and their interactions are defined. Next, approaches to modeling agents' underlying values for buying or selling, the potential deviations between those values and their bid or ask prices, and the determination of a transaction price are discussed. A conceptual model of developers' profit maximization behavior is presented. We conclude with a discussion of a potential path for transferring the model to an empirical context.

\subsection{Previous residential land market models}

\subsubsection{Land in economic theory}

The concept of land rent is central to different economic schools studying land (Randall and Castle, 1985). In theory, in a LM, the transaction price for land reflects the highest value of any agent in the market, the land rent. Under the assumptions of homogeneous land and a representative agent, the amount of land consumed for a particular use and its market price can be modeled as an a-spatial equilibrium of demand and supply (Arnott et al., 1999; Buurman et al., 2001) (Figure 3.1). 


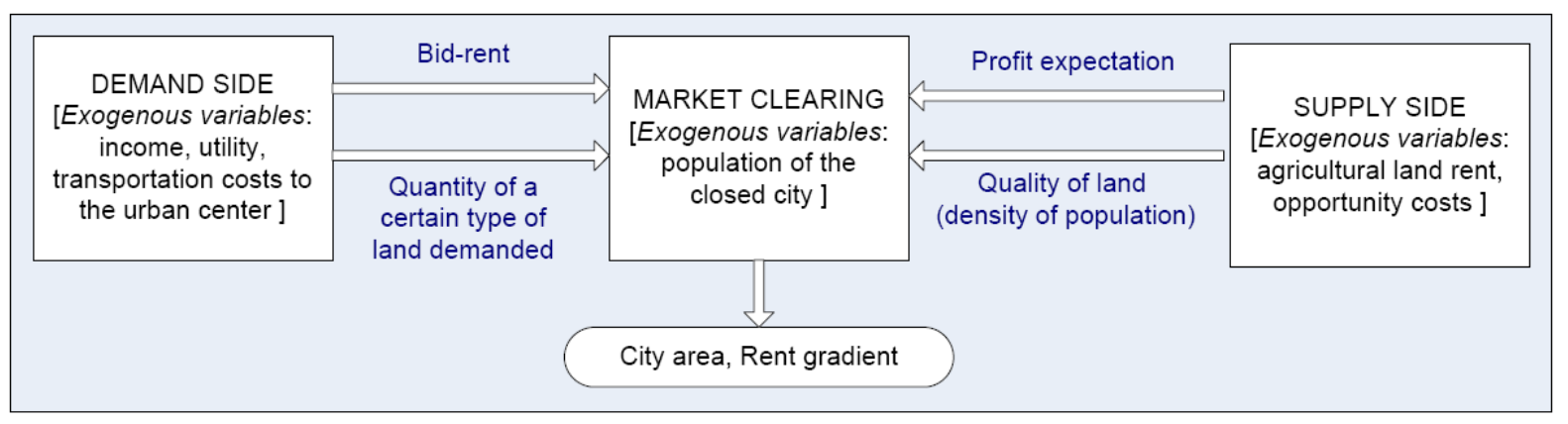

Figure 3.1: Schematic structure of the land market model in economics

Classic economic theory treated land as a factor of production in addition to capital and labor. Later Ricardo (1821/2001) formalized the relationship between the quality (fertility) of land and land rent, with higher rents for higher-quality/productivity land. Following Randall and Castle (1985) the Ricardian rent $(\Psi)$ can be expressed as:

$$
\Psi_{i}(F)=p_{i} \cdot \alpha_{i} \cdot f(L, F)-\omega \cdot L
$$

where $F$ stands for fertility, $p_{i}$ is the market price for the agricultural good produced using labor input $(\mathrm{f}(\mathrm{L}, \mathrm{F})), \omega$ is the wage level per unit of labor, and $\alpha_{i}$ is a proportionality factor characterizing the particular crop growth.

The model of von Thünen (1826/1966) formalizes the relationship between transportation costs for agricultural goods to the central business district (CBD) and land rents, demonstrating how the location of agricultural activity (in terms of distance $\left(d_{i}\right)$ from the market located at the CBD) depends on the cost of production $\left(c_{i}\right)$, transportation costs $\left(t_{i}\right)$ and market prices $\left(p_{i}\right)$ for an agricultural good $(i)$. The per-acre bid price for land is:

$$
\Psi_{i}\left(d_{i}\right)=\frac{\left(p_{i}-c_{i}-t_{i} \cdot d_{i}\right)}{s_{i}}
$$

where $s_{i}$ is the acre of agricultural land a farmer occupies. The model assumes that land will be allocated to the highest bidder, with the extensive margin at which a bid for one crop exceeds the next-lowest valued crop defining locations of bands of crop types in concentric circles around the CBD.

The Von Thünen model was extended for urban LU by Alonso (1964). According to his bidrent theory, households choose locations at a certain distance from the CBD based on the utility they receive from land and other consumption goods under their budget constraint. The Muth-Mills housing model extends the Alonso model to account for density at each location (by introducing a housing producer who decides the structural density of development) in addition to the rent gradients (see Strazsheim (1987) for review). Other spatial analytical models have been developed 
to examine the effects of open-space amenities and spatial externalities on land rents $(\mathrm{Wu}$ and Plantinga, 2003; Caruso et al., 2007; Parker, 2007).

\subsubsection{Cellular spatial simulation models}

The limitations of analytical models for representing neighborhood effects and two-dimensional patterns have led to the development of cellular spatial simulations. These models (including cellular automata, spatial econometrics models and ABMs) represent economic and market influences to varying degrees.

Cellular automaton models represent transportation and neighborhood influences through calibrated parameters, which reflect socioeconomic influences only implicitly (White and Engelen, 1993; Batty et al., 1999; Jantz et al., 2003; Benenson and Torrens, 2004; van Delden et al., 2007). Econometric models calibrate transition coefficients based on relationships between socioeconomic drivers and land prices, and may use these calibrated models for simulation modeling to produce spatially explicit outcome maps (Irwin and Bockstael, 2002). The estimated coefficients of such models reflect but do not directly represent interactions between supply and demand measured at some point in time.

Several cellular models include hypothetical LMs, but with primary emphasis on the demand side. The SOME and SLUCE models allow agents to choose the property that maximizes their utility without competition from other sellers and assume that the locating agent will outbid the current use (Brown et al., 2008). Caruso et al. (2007) develop a sophisticated model of residential demand, allowing relocation by renters and a competitive rental market. However, the supply price of rural parcels is taken as fixed, and renters are assumed to capture all gains from trade. Parker and Meretsky (2004) represent demand a-spatially through a fixed demand curve, and model the land conversion decisions of a hypothetical parcel manager. Benenson (1998) uses a simple adaptation mechanism to establish the price of houses, in which the price of an occupied house adapts to reflect the wealth of the occupant and the average value of neighboring houses. These factors, along with the cultural identity of neighborhoods, affect the dissonance of residents, which in turn may motivate them to move. Diappi and Bolchi (2008) model supply-side redevelopment decisions of landlords and developers, using an exogenous potential land rent function, but endogenous capitalized land rents based on the state of upkeep of the property. Ettema et al (2007) developed a model that includes location decisions of households and firms modeled as discrete choice and regression models. Heckbert and Smajgl (2005) use discrete-choice theory to simulate the demand side of a residential market where agents optimize their utility function and estimate property affordability. Miller et al (2004) propose two approaches to modeling commercial and residential 
LMs. In each, supply and demand offers are made by heterogeneous buyers and sellers. The first adjusts zonally based prices when markets do not clear. The second determines prices through bilateral transactions. Price expectations in the next round are influenced through an estimated hedonic price function. McNamara and Werner (2008) model the hotel property market using an adaptive model of profit expectation formation by developer agents who supply and sell hotels. Hotel owners bid to acquire properties based on expected profits, with the highest bidder winning the property. Torrens (2007) models LM interactions with dynamic price updating on both the demand and supply side, but the offer prices of residences are not formed based on market conditions or agent preferences.

Several models of agricultural LMs model both demand and supply decisions (Berger, 2001; Happe et al., 2006; Polhill et al., 2008). While these models are becoming increasingly more sophisticated, they do not model differences between the buyer's willingness to pay (underlying utility or payoffs for the land) and her bid or offer price for the land; nor do they model differences between the seller's willingness to accept (opportunity cost of the sale) and his ask price.

\subsection{Agent-based models, markets, and land-use change}

\subsubsection{Why model markets with ABMs?}

Driven by the desire to better represent and explore complex economic systems, applications of $\mathrm{ABM}$ to economics and market interactions are increasing (Epstein and Axtell, 1996; Arthur, Durlauf et al., 1997; Lux, 1998; Kirman and Vriend, 2001; LeBaron, 2006; Tesfatsion and Judd, 2006). In spite of rapid growth, the field of ABM market modeling is still relatively new. Current application areas include financial markets, markets for pollution emissions, auctions for the electro-magnetic spectrum, electricity markets, and on-line e-markets (Marks, 2006). These ABMs relax traditional restrictive assumptions of economic models:

1. The concept of equilibrium is central to most economic models. However, economic markets are dynamic adaptive systems (Tesfatsion, 2001) and may be out of equilibrium (Arthur, 2006). The dynamic path to equilibrium can be modeled in greater detail and out-ofequilibrium properties more fully explored using agent-based market modeling.

2. Many economic models take a representative agent approach, in which the demand curve of one agent is extrapolated to represent the demand for the particular good in the whole economy. The limitations of this approach, discussed by (Kirman, 1992), can be overcome through ABMs' ability to represent diverse agent types. 
3. In standard economic models, agents are assumed to be rational and have perfect information about environment. In reality agents have bounded computational ability, memory, and perception (Marks, 2006).

4. Standard economic models exclude most agent-agent and agent-environment interactions (Epstein and Axtell, 1996; Tesfatsion and Judd, 2006). Market interactions in ABMs occur during price formation and price negotiation. Non-market interactions include externalities, information transfer, and social networks.

\subsubsection{Agent-based market models in practice}

Market design for ABM is discussed at length by Marks (2006). The logic of the ABM market mechanism is described by Mackie-Mason and Wellman (2006) in three steps (Figure 3.2).

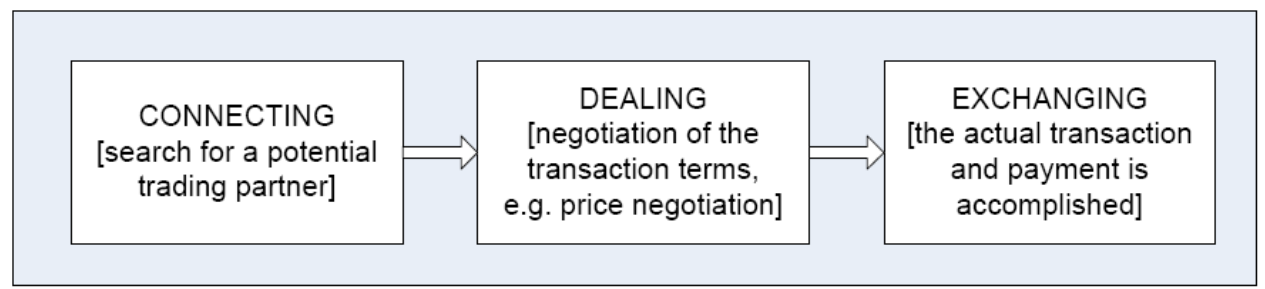

Figure 3.2: Main steps of a market transaction, the core of market mechanism (Summarized from MackieMason and Wellman (2006))

LeBaron (2006) outlines fundamental questions that need to be answered when designing markets, including what kind of good will be traded, how the preferences of individuals will be formalized, what kind of mechanism will be used to determine prices, whether agents can learn, whether information is private or public, how information is presented and processed, and finally what benchmark/criteria will be used to track the operation of a market. Reviewing previous work in financial ABM markets, LeBaron identifies several approaches to modeling determination of the market clearing price, including price adaptation based on the difference between supply and demand, numerical clearing, auction mechanisms, and random connection of trading partners, with trades occurring when gains from trade are positive. In many ABM market models, reinforcement learning algorithms at the individual agent level are used to establish price expectations and bid/ask prices for individual agents (Arthur, 2006; LeBaron, 2006; Tesfatsion, 2006).

\subsubsection{Why model land markets using ABM?}

The advantages of applying ABM in ecological-economic systems are widely discussed (Bousquet and Le Page, 2004; Grimm and Railsback, 2005). The rationale for modeling LUC using ABM laid out by Parker et al (2003) can be carried forward to argue that ABMs are appropriate for modeling LMs. Because land differs from other market goods, ABM market models developed for other 
applications must be further adapted to model LMs. Drawing on previous research on LMs and our own analysis, we summarize the unique features of LMs that motivate development of a new variety of agent-based market model.

\section{A heterogeneous commodity traded by heterogeneous agents: Every property (land} parcel/house) is immobile and has unique attributes (soil, slope, neighborhood characteristics, accessibility) (Buurman et al., 2001). There are several types of buyers and sellers participating in the LM. For example, potential sellers include farmers selling agricultural land, developers supplying new residences, and relocating households. ${ }^{14}$ These types of sellers may have different motivations, opportunity costs, types of behavior and pricing strategies. ${ }^{15}$ Within the same type, buyers and sellers differ in their location preferences, motivations, resources, and information.

Spatial and agent-agent interactions: The use of a property affects the use and value of the surrounding properties through spatial externalities and local price expectation feedbacks. Agents operating in an LM are involved in both market and non-market interactions (Grevers, 2007).

Importance of non-equilibrium dynamics: LMs are cyclic and are rarely in equilibrium. Housing market growth, decline, and bubbles are everyday news. These out-of-equilibrium dynamics can be effectively explored with an ABM LM. However, LMs have slower dynamics than other markets. The supply of land is fixed or restricted by regulation in the short run (Smith et al., 1988), limiting adjustment of the LM. Moreover, the purchase of land is an infrequent, high transaction cost, long-term investment ${ }^{16}$, often requiring an extensive search for buyers. As a result, relatively few market transactions occur as compared, for example to financial markets. Thus, price expectation formation and learning about the behavior of other traders are slower, and traders usually form strategic responses based on dynamic market conditions. Sellers and buyers leave the market after a successful trade, and rarely interact again with the same trading partner. This complicates the implementation of price learning algorithms used in commodity ABM markets.

An ABM LM that incorporates the heterogeneity, interactions, and non-equilibrium dynamics of real-world LMs can be useful in many ways. ABM LMs can be used to explore the effects of heterogeneous agent-level drivers of LUC, such as incomes, interest rates, social preferences, and credit availability. As discussed by Polhill et al (2008), by providing information about

\footnotetext{
${ }^{14}$ In practice government often plays an important influential role in the LM. Spatial planning policy and zoning regulations directly affect the elasticity of land and housing supply. Taxes and subsidies applied to the area under local government jurisdiction exert influence upon buyers and sellers choices.

15 There is a distinction between behavior of buyers and sellers in landownership market and tenants and landlords in rental markets. These two types of LMs are interconnected because the market price of land and houses influence the rental price of those. However, different models to explain location choice and market prices are used for rental and ownership markets. In our paper we focus on ownership LMs rather than on rental markets. We also do not distinguish between land and property markets; implicitly, LMs refer to the market for individual residences.

${ }^{16}$ The fact that housing is a long-term investment implies that agents' discount rates and access to capital affect land purchase decisions. While we do not include discounting explicitly in the framework presented here, the equations could easily be modified to include intertemporal considerations.
} 
heterogeneous land rents (private shadow values), ABM LMs may reveal areas where growth pressure is high and deviations between private and public shadow values of land. ${ }^{17}$ Finally, ABM LMs can be designed to reflect buyer and sellers' boundedly rational price expectations and explore the effects of adaptive price expectation updating mechanisms.

\subsection{Designed land markets}

\subsubsection{Conceptual scheme: tradable good and traders in the land market}

Our conceptual model of an artificial LM combines rules adapted from standard urban economics with a cellular spatial simulation model. We move beyond previous work by implementing agents' heterogeneity, a spatially explicit setup, and direct modeling of price formation and market transactions. Both demand and supply sides are represented in detail, facilitating model experiments focused on the drivers of each. Our approach leads to the emergence of heterogeneous land rent patterns without restrictive assumptions to identify prices in equilibrium. Results from the first implementation are reported in Filatova et al (2007), and further model analysis is ongoing.

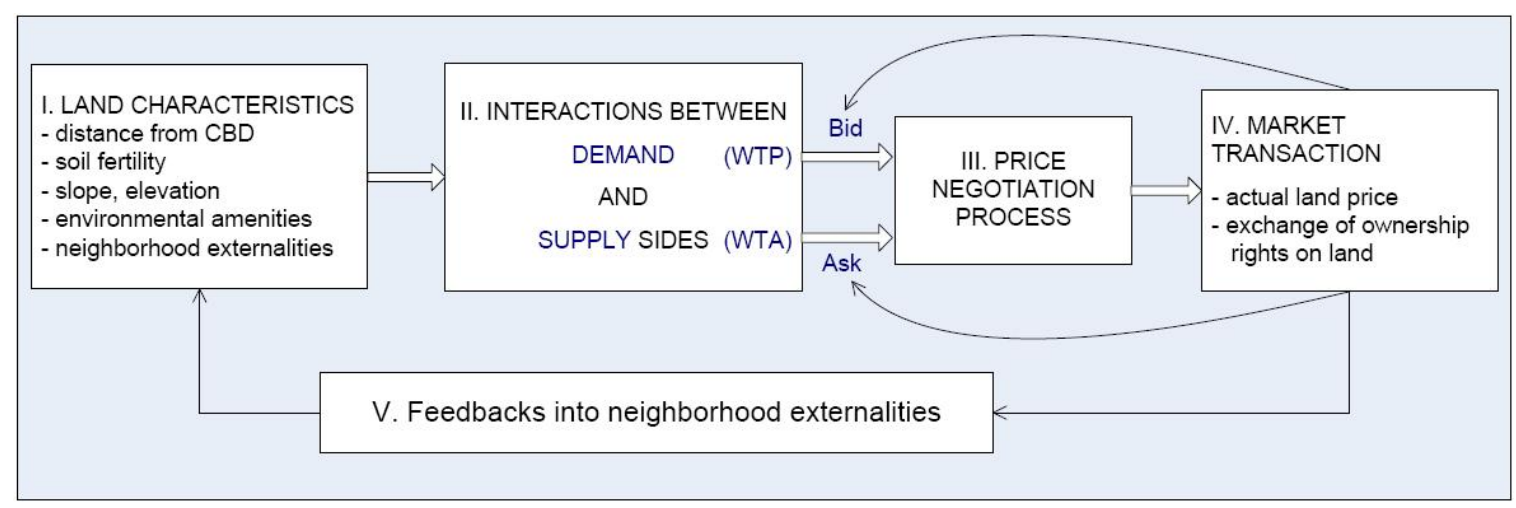

Figure 3.3: Conceptual scheme of the agent-based land market

Figure 3.3 represents the logic of our model. Essentially, the agent level interactions illustrated in Boxes III and IV replace the top-down market clearing conditions that define equilibrium in traditional models (Figure 3.1). Based on land characteristics (Box I) and individual preferences, buyers and sellers form bid and ask prices for properties, which are functions of their willingness to pay (WTP) and willingness to accept (WTA) (Box II), and negotiate with potential traders over a transaction price (Box III). If negotiation is successful, then the market transaction takes place (Box IV). Current transaction prices influence bid and ask prices in the next time period. Moreover, as a property is converted, the altered LU feeds back into the spatial neighborhood (Box

\footnotetext{
${ }^{17}$ The shadow value of a resource reflects the increase in payoffs at the margin that would be provided by an additional unit of the resource. The private shadow value reflects the increase in individual utility or profits; while the public shadow value reflects the value to society as a whole.
} 
V), through, for example, changes in density, availability of open space, or the social characteristics of the neighborhood.

Extensive previous theoretical and empirical research has been conducted to identify the drivers of land value as outlined in Boxes I and V (Anas et al., 1998; Irwin and Bockstael, 2002; Lambin and Geist, 2006). However, many open questions remain regarding translation of the assumptions of analytical theoretical models into spatially explicit dynamics as represented in Boxes II-IV. We therefore focus on these dynamics and refer to previous literature for the other aspects of the conceptual model.

The first step in analysis of a market is to define the participants. Several agent types participate on both the supply and demand side (Box II, Figure 3.3), including households, developers and rural land owners as seen in Figure 3.4. The market behavior of each actor in the LM is discussed below.

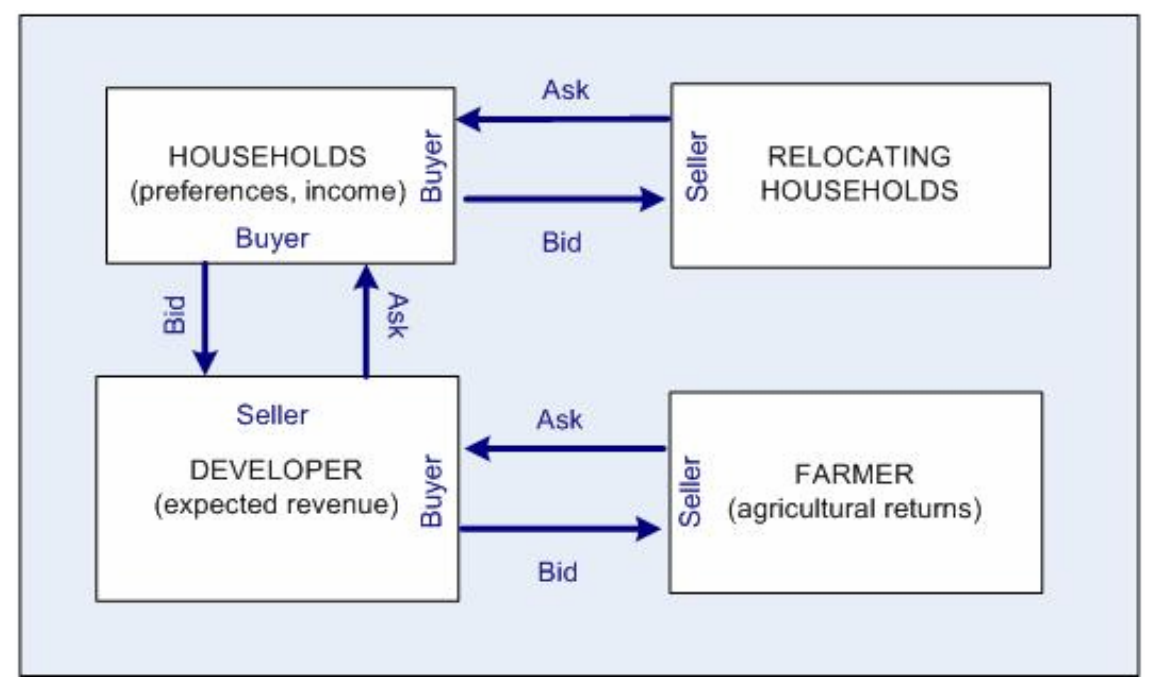

Figure 3.4: Interaction between demand and supply side, Box II of Figure 3.3

\subsubsection{Reservation prices, bid and ask prices, and gains from trade}

WTP and WTA for land are reservation prices for land - the maximum price a buyer is willing to pay for a good, and the minimum price at which a seller is willing to sell (Figure 3.5). Economic theory suggests that reservation prices depend on preferences for characteristics of the spatial good (accessibility, availability of environmental amenities, neighborhood characteristics, etc.) and agents' financial resources.

The difference between the WTP and WTA defines the gains from trade (GFT) - the economic surplus that can be captured from the market transaction, and the realized transaction price defines the division of the GFT between the buyer and seller. The realized transaction price depends on bid and ask strategies and perceived market conditions. Current theory simply bounds, but does not directly identify, that transaction price. In representative agent models of a 
homogeneous good, the equilibrium market-clearing price is assumed to be the price for all realized transactions. However, residential land is generally sold through bilateral bidding and negotiation. In this case, a clear distinction should be made between WTP and bid price, and WTA and ask price. Since economic agents try to maximize their GFT, a buyer tends to set a bid price lower than her WTP (by $\varepsilon_{b}$ ), and a seller sets his ask price higher than his WTA (by $\varepsilon_{s}$ ) (Equation 3.3 and Figure 3.5).

$$
P_{b i d}=W T P-\varepsilon_{b} ; \quad P_{a s k}=W T A+\varepsilon_{s}
$$

Neither $\varepsilon_{b}$ nor $\varepsilon_{s}$ can exceed the total GFT $\bar{\varepsilon}_{b}$, if a transaction is to be feasible. For example, in Figure 3.5, if the buyer sets her bid price lower than the seller's WTA, the transaction will not occur. The buyer's strategic incentive is to set her bid price as close to the seller's WTA as possible, but still above. The seller has complementary incentives; he wants to set the ask price as close as possible to the buyer's WTP, but still below.

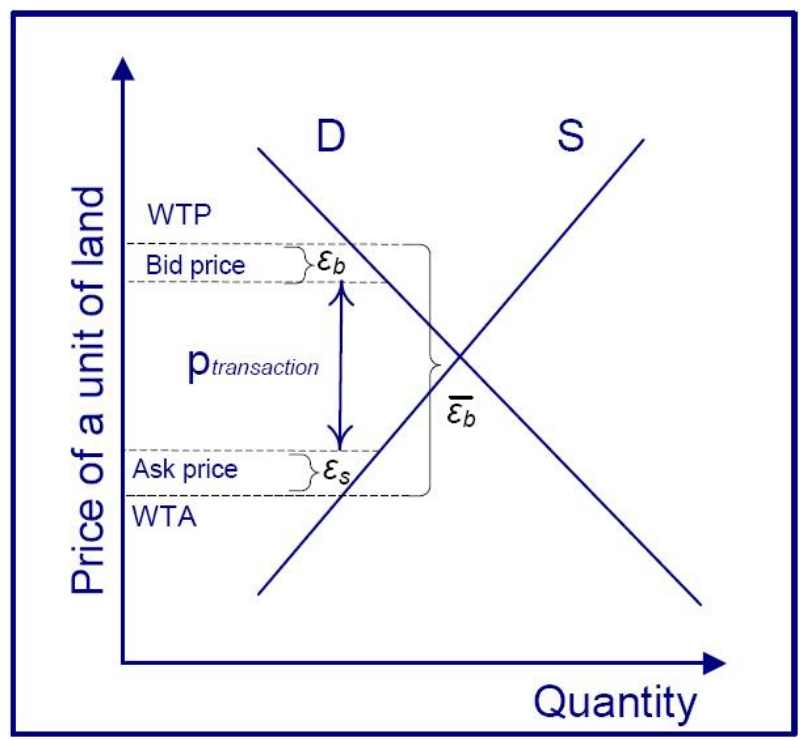

Figure 3.5: Price negotiation and division of gains from trade

In the LM, agents are heterogeneous according to their behavior (e.g. the goal is to maximize or satisfy utility vs. profit), their resources (income-constrained households vs. financial capital constrained developers), and in the type of land they seek to buy or sell (existing dwellings for individual households and rural residential parcels for developers and rural land owners). Thus, agents' WTP and WTA formation varies by sector (household/developer/ rural land owner). In the following sections, we review theoretical research regarding reservation and bid/ask price formation for different types of agents and propose strategies for calculation of reservation prices. 


\subsubsection{Buyer households (residential use)}

As a starting point to model a household's reservation price, we return to the classical theoretical models of residential location based on the framework proposed by Alonso (1964; Strazsheim, 1987). The conventional economic approach to find a willingness to pay for a housing unit is to solve the budget constrained budget-constrained utility maximization problem: $\max U(z, s, d)$, s.t. $z+s \cdot R(d)=Y-T(d)$, where, $z$ is a composite good, $s$ is the quantity of land/housing purchased, $d$ is the distance from the city centre, $R(d)$ is the distance-dependent land/housing price, $Y$ is the household's budget, and $T(d)$ is commuting cost at distance $d$. The demands for the composite good and for housing as well as land rent $\left(R^{*}(d, u)\right.$, Equation 3.4) are derived simultaneously by applying market-clearing conditions (assuming that demand is equal to supply at equilibrium) and assuming that utility is equal for all agents in the city.

$$
R^{*}(d, u) \equiv R^{*}[Y-T(d), u]=\max _{z, s}\left\{\frac{(Y-T(d)-z)}{s} \quad \text { s.t } \quad \mathrm{U}(\mathrm{z}, \mathrm{s})=\mathrm{u}\right\}
$$

This traditional method to identify the households' willingness to pay at each point in space, or bid-rent function, relies on assumptions of representative agents and market equilibrium.

Economic agent-based LU models in agricultural contexts often represent the choice problem of agents as a resource-constrained maximization problem, with agents substituting boundedly rational inductively estimated or dynamically evolving prices for expected prices formed through some rational expectations mechanism (Berger, 2001; Happe et al., 2006). We pursue a similar approach, staying conceptually close to the analytical budget-constrained utility maximization Alonso modifications that include open-space amenities, but noting that, in the absence of restrictive equilibrium conditions that identify land rent, individual households cannot solve for their WTP. We therefore arrive at:

Open Question 1: How can the standard equilibrium-based Alonso model be translated for application to heterogeneous agents in a dynamic spatial environment?

We propose four potential approaches to the problem, moving from the least to most complex.

Approach 1: Following Gode and Sunder's (1993) ABM markets for homogeneous goods, assume a WTP function for each agent type, and draw randomly from that function to define a population of trading agents. Their "Zero-Intelligence traders" form bids by subtracting some random value from their exogenously assigned WTP. The disadvantage of this approach for a good with heterogeneous characteristics, such a spatial good, is that WTP is the same for goods with different quality. Thus, the bid price does not reflect location-specific amenities. This approach may suffice for highly abstract computational experiments, but the potential for translation into a realworld context is limited. 
Approach 2: As in approach 1, heterogeneous WTP functions, which depend on agent's preferences and income, are assigned to agents. Approach 2 essentially assumes a set of exogenous individual-level demand curves for housing, allowing property-specific values to reflect agent-level income and preferences.

Approach 3: This approach assumes an explicit utility function for housing that reflects preferences for proximity to the $\operatorname{CBD}(P)$ and green amenities $(A)$ and a fixed, exogenous optimal expenditure share for the property $Y=Y_{\text {housing }}-T \cdot d$ (the share of an exogenous total housing and transport cost budget spent on the property). Preferences can be formalized using a Cobb-Douglas utility function (Wu and Plantinga, 2003). We then define the following WTP function:

$$
W T P=\frac{Y \cdot U^{n}}{b^{n}+U^{n}}
$$

which bounds WTP by the budget constraint, and exhibits the qualitative properties of a traditional demand function. The parameter $b$ is a proxy for the prices of other goods. A buyer decides which house to bid on by randomly selecting a subset of houses that are affordable under her budget constraint. She then chooses to bid on the house that gives her maximum utility, with her WTP given by Equation 3.5. In applications of the first model implementation, we implement agent heterogeneity in this context by varying the utility weights of each good or the budget constraint for housing, and we implement spatial heterogeneity by varying amenity levels across space (Filatova, Parker et al., 2007). This approach may be appropriate in highly regulated housing markets, where loans are made based on monthly payments that represent a fixed proportion of income, and where this constraint is binding for most agents.

Approach 4: We propose to implement an Alonso-style approach by replacing the land price defined through equilibrium assumptions with a parametric adaptively estimated land rent $\hat{r}$, whose estimation may reflect the boundedly rational price expectations of heterogeneous buyer agents. Following traditional models, each agent solves a budget-constrained utility maximization problem (Equation 3.6), in which the value of a residence $s$ increases with amenity level $A$ and decreases with distance from the CBD $d$.

$$
\max U(z, s(A, d)) \text { s.t. } Y=p_{z} \cdot z+\hat{r} \cdot s(A, d)+T \cdot d
$$

The solution to this maximization problem provides optimal demands for the composite good and attributes of the spatial good (amenity levels and accessibility). These optimal solutions can be used to derive an analytical demand curve (WTP) for housing as a function of estimated land rent and, from that, an optimal housing budget. 
The challenge in this approach comes from the need to initialize $\hat{r}$. We propose two solutions. First, the model could be initialized using the bid-rent values from analytical solutions to a simplified version of the model ${ }^{18}$. Second, the landscape could be initialized with plausible selling prices, given agent utility functions. Agents would form an expected rent by sampling properties selling for between $25-40 \%$ of their income (a standard budget metric for lenders) and estimating prices through a hedonic regression model (similarly to the model proposed by Miller et al. (2004)). Either method would be likely to induce some path dependence in model outcomes, which should be formally explored.

Expected rent must be dynamically updated. A new class of "Real Estate Agents," who might possess differential levels of knowledge and estimation strategies, could estimate $\hat{r}$ through learning algorithms (Arthur, 2006; Tesfatsion, 2006). As the model runs and price levels change, expected land rent could be updated either according to a fixed (each time the agent is active) or event driven time schedule. (For example, a buyer may update price expectations following a given number of unsuccessful bids.) Each time price expectations are updated, she will re-solve her utility maximization problem, alter her optimal budget share for housing and shift her demand curve. This approach promises to endogenously model expectation-driven price dynamics that are a prominent feature of real-world housing markets, in which budget shares on housing increase even as incomes and preferences remain fixed. This is accomplished while still maintaining a theoretically grounded WTP and budget share for housing.

\subsubsection{Modeling a buyer's bid price}

A buyer's strategy for setting her bid price will likely depend on her WTP and expectations for future prices. To our knowledge, few theoretical models of these prices expectations exist. The relationship between bid and ask prices are often dependent on the state of the housing market. In perceived "sellers"” markets (when demand exceeds supply), bid prices are often higher than ask prices. Buyers compete against each other, raising their bids in the hope capturing a desirable property. In "buyers"” markets, bids are often below ask prices, and ask prices are often lowered over time in the hopes of attracting a buyer. These dynamic relationships between bid and ask prices likely drive cyclical housing market dynamics, but also ideally should be endogenous to our model.

These dynamics lead us to the first of several questions:

\footnotetext{
${ }^{18}$ In the case of homogeneous agents and a homogeneous landscape, this initialization should imply that the model would quickly converge to that analytical solution. This could be an important robustness test for the model. However, we anticipate that this model will be used primarily to analyze heterogeneous agents and landscapes.
} 


\section{Open Question 2: Given a theoretical WTP, how are bid prices set?}

Drawing in part on ABMs of financial markets, we propose two approaches for setting bid prices, which could be combined. However, they should be tested independently as well as in combination, since they may have comparable effects on market dynamics. If effects are comparable, the simplest approach is justified.

Approach 1: In the current model implementation, the WTP of a buyer is adjusted depending on whether it is a buyers' or a sellers' market. We introduce a variable $\varepsilon$, which serves as a proxy for the state of the market (Equation 3.7).

$$
P_{b i d}=P_{W T P} \cdot(1+\varepsilon)
$$

where $\varepsilon=(N B-N S) /(N B+N S) ; \mathrm{NB}=$ number of buyers and NS $=$ number of sellers. If the number of buyers and sellers are equal, $\varepsilon=0$ and buyers bid their willingness to pay. If there are more buyers than sellers, buyers are in a less favorable situation, and bids will increase. Conversely, bids will decrease when sellers exceed buyers.

This approach is easy to implement in a programming context and potentially leads to endogenous cyclical price variations. Based on information available through the web, Realtors and housing market analyses, real-world agents are likely to perceive the state of the market and the direction of market trends. A disadvantage of this approach is the assumption that agents' bids may exceed their theoretical WTP. This could be remedied by normalizing the bid to fall between WTP and an estimated WTA (consistent with Figure 3.5).

Approach 2: Modification to WTP can be based on information about recent comparable sales, average days on the market, and the rate of change of prices. These three pieces of information are readily available to buyers. Information on recent sales could be used to estimate an expected sales price for the property, which could be used to modify the agent's bid relative to the ask price. The bid could also be modified up or down depending on whether prices were rising or falling. Days on the market and the rate of change of prices would be proxies for the buyer's perception of competition among buyers. Essentially, Approach 2 can be viewed as a strategic approach to pricing by the buyer. She forms her best estimate of the highest other bid that the seller is likely to receive, and bids no higher than this amount.

\subsubsection{Modeling a seller's decision to relocate}

In the case of a single residential seller, his willingness to accept will be determined by his opportunity cost of keeping the residence---the utility that he might gain by selling and moving. Several studies investigate household mobility (Kan, 2002; van der Vlist et al., 2002; Clark et al., 2003). In a comprehensive overview of the theory of household relocation behavior, Clark and Van 
Lierop (1987) distinguish between inter-urban and intra-urban migration. They argue that main reasons for intra-urban migration are transitions to a new life cycle stage, development of more attractive housing options elsewhere, changes in the neighborhood, and a desire for greater accessibility to central locations. Inter-urban migration is mainly motivated by employment changes. Clark and van Lierop describe relocation behavior as a two-stage process. A household first decides to move (for one of the reasons mentioned above), and then it searches for the location for which the expected utility net of moving costs exceeds the expected utility of staying. Other spatially explicit urban simulation models focus in more detail on households' mobility due to ethnic sorting (segregation with respect to the nationality or ethnic group) (Schelling, 1978) and wealth preferences (clustering with respect to income) (Torrens, 2007). This background leads us to:

Open Question 3: How should the decision to relocate be modeled?

We propose three approaches (consistent with urban economic theory) to modeling relocation behavior, each of which is likely to apply to different agent types.

Approach 1: An agent becomes dissatisfied with his neighborhood (due to a change in racial/ethnic balance, income disparities, a decline in green amenities or public services (for example school quality), or an increase in congestion or commute times, with two possible action thresholds for relocation:

1. An agent's current utility level $\left(U_{i t}\right)$ has fallen below the level that he had when he first purchased the house $\left(U_{i}^{*}\right)$, (probably by a certain threshold) $U_{i t}<U_{i}^{*}$;

2. The utility of some other location $\left(\tilde{U}_{i}\right)$ that household $i$ could purchase given his housing budget is higher than the utility of the current location $\left(U_{i t}\right)$ net of the utility of moving $\left(U_{m}\right), \widetilde{U}_{i}>U_{i t}-U_{m}$;

Approach 2: Household life-cycle: At thresholds defined by household age and size, agents may form their own households, seek an independent residence, then seek a larger residence (more bedrooms) or higher levels of open space, neighborhood safety, or school quality. Agents at later life stages may seek smaller residences, easier access to local amenities, high-amenity locations, or proximity to extended family.

Approach 3: Job-following migration: If employment locations are included in the model, then household workers may follow shifts in employment. (Note that if employment locations shift within the city for a given agent, the commuting times faced by that agent may change, leading to dissatisfaction with the neighborhood as discussed in point one.) 


\subsubsection{Modeling seller's WTA and ask price}

Open Question 4: How should WTA be determined for selling households?

Compensation for the costs paid for the current residence is likely to determine the minimum reservation price for most sellers, barring bankruptcy. Households relocating in the same area, however, wish to increase their utility. Thus, their WTA will be given by the sales price that allows them to purchase the house that achieves the minimum utility increase required to relocate; their WTA, thus, is derived from their WTP for another house. A seller agent has an incentive to set an ask price as high above his WTA as the market will bear, leading to:

Open Question 5: How do seller households set their ask prices?

Approach 1: Sellers may also respond to the perceived market power of buyers by adjusting their ask price upwards in the case of a sellers' market, and downward in a buyers' market. (Equation 3.8 with $\varepsilon$ from Equation 3.7)

$$
P_{a s k}=W T A \cdot(1+\varepsilon)
$$

Approach 2: The WTA is adjusted upward or downward based on the difference between the WTA and prices in the seller's neighborhood, dependent on a coefficient of sensitivity $\chi \in[0 ; 1])$. (Equation 3.9)

$$
P_{A s k}=W T A+\chi \cdot \Delta, \text { where } \quad \Delta=P_{\text {averageNeighborhood }}-W T A
$$

This approach, implemented using Moore neighborhoods, incorporates local spatial price feedbacks, and will reinforce the positive price effects of location-specific amenities (Filatova, Parker et al., 2007). As in Approach 2 in Section 3.4.2.2, a disadvantage is that sellers may price their houses below their WTA, which contradicts economic theory. A modified approach maintains links to economic theory, while incorporating local price feedbacks. (Equation 3.10)

$$
P_{\text {Ask }}=\operatorname{Max}\left(W T A, P_{\text {averageNeighborhood }}\right)
$$

Approach 3: Rather than basing their decision on current sales prices, sellers (or their real estate agents) may attempt to forecast a probable sales price, as would buyers, using information about recent comparable sales, average days on the market, and the rate of change of prices. A variety of reinforcement learning or inductive statistical models could be used to represent this process. Obviously, if the same methods were used by both buyers and sellers, bid and ask prices would be identical, and the dynamics of bidding up and falling prices would not occur unless driven by pure differences in reservation prices (which are likely to occur given heterogeneous agents). This leads to:

Open Question 6: How can differences in bid and ask prices be modeled? 
Ask price formation might rely most heavily on recent activity in the physical neighborhood of the residence, whereas bid prices formation might be more dependent on opportunity costs of bidding on residences in different neighborhoods. Sellers might have private information that they try to conceal through a too-high ask price. Sellers and buyers may have heterogeneous degrees of urgency for achieving a transaction. Finally, differences in bid and ask prices may arise from the differential experience of boundedly rational real estate agents who advise buyers and sellers. If however, theoretical and empirical models indicate that bid and ask prices can be assumed to be the same, then the process of negotiation need not be modeled explicitly; rather, in trades where GFT are positive, the estimated bid/ask price can be used as the transaction price, thereby defining the division of GFT.

\subsubsection{New home production--Developer agents}

\subsubsection{Developers}

Developers (housing producers) serve as an intermediary between farmers willing to sell agricultural land and households willing to buy a house. They buy undeveloped land, convert it to residential land, and sell housing (see Figure 3.4), meaning that they form an WTP for the agricultural land and WTA for new residential units. In the Muth-Mills modification of the Alonso model (Brueckner, 1987; Strazsheim, 1987) developers act as housing producers, maximizing profit by combining land $L(d)$ and capital $K(d)$ to supply housing $H(d)$ at location $d$ (Equation 3.11).

$$
H(d)=H\{L(d), K(d)\}
$$

The land price $R(d)$ is determined endogenously as a solution of maximization problem of a developer (Equation 3.12) and defines the developer's WTP for agricultural land in the analytical problem. The developer's profit maximization problem is:

$$
\max \pi_{d x}=p(d) \cdot H(d)-R_{a g}(d) \cdot L(d)-i \cdot K(d)
$$

where $\pi_{d x}$ is the profit of developer $x$ at location $\mathrm{d}, p(d)$ is the willingness to pay of households for a unit of housing at location $d, R_{a g}(d)$ is a price for agricultural land, and $i$ is the interest rate. Developers are assumed to be price takers with respect to the price for housing. Thus, their price expectations are based on derived demand from the households, which itself comes from the theoretical bid-rent functions derived from an Alonso-type model (Equation 3.6).

In theory, the increased WTP of households nearer to CBD resulting from lower commutes leads to a higher optimal density of residences (size and proximity of residences and height of buildings) for developers closer to the CBD (Brueckner, 1987; Kraus, 2006). Assuming constant returns to scale, the housing producer's theoretically optimal structural density $(S D=K / L$, 
capital-land ratio) and the developer's WTP for agricultural land $\left(R_{a g}\right)$ are derived by maximizing profit (Equation 3.13).

$$
\max \pi_{d x}^{\text {per unit of land }}=p(d) \cdot H(S D ; 1)-R-i \cdot S D
$$

Since the price for housing $(p(d))$ is a function of a households' preferences, income, distance from CBD and travel costs, the structural density also depends on these drivers (Brueckner, 1987).

Empirical research suggests that developers are motivated by market demand for housing (preferences of new-home buyers) and are constrained by policy regulations (Levine, 2006). Evidence also exists that developers specialize in particular kinds of development, each of which provide different levels of private and public open-space amenities (Vigmostad, 2003).

Regardless of the complexity with which developers' profit maximization decisions are modeled, again a familiar challenge presents itself---that of modeling price expectation formation for households' WTP when developers face heterogeneous buyers, leading to a pair of questions:

Open Question 7: How should the profit-maximizing choice of development type be modeled?

Approach 1: For abstract theoretical models, the translation of the Muth-Mills model with optimal density could be used to differentiate housing types by density, with a pool of developer agents created who specialize in particular development densities. This approach does not, a-priori, account for agent heterogeneity.

Approach 2: Models of market segmentation under monopolistic competition (in which sellers offer slightly specialized versions of a good that is homogeneous in some basic characteristics) could be adapted to reflect heterogeneous preferences of agents for open-space amenities, commute times, and property characteristics (Dixit and Stiglitz, 1977; Singh and Xavier, 1984).

Either of these approaches would require developers to estimate consumers' heterogeneous WTP functions for different development types, leading to:

Open Question 8: How should the willingness to pay of particular groups of individual buyers that appears in developers' profit function be estimated?

Approach 1: The urban economics literature provides some examples of equilibrium-based models of a developer who is able to differentiate among different groups of housing consumers (Henderson and Thisse, 1999). The underlying assumption is that potential customers have different incomes and WTP for housing, which the developer may be able to extract by providing both private and public goods. ${ }^{19}$

\footnotetext{
${ }^{19}$ We do not discuss migration motivated by local public goods (Tiebout, 1956) here. A discussion of pricing decision of developer in the framework of Tiebout model can be found elsewhere (Pines, 1991).
} 
Approach 2: Similarly to Approach 3 for seller ask price formation, boundedly rational developers estimate inductive hedonic demand curves based on information about agent characteristics and recent sales. Developers likely have access to a wide range of resources and information to estimate demand - in fact, they may have a staff of economists dedicated to that task. While the WTP of individual buyers is private information, accepted bid prices are public information. Thus, a hedonic demand curve for each homogeneous housing product could be estimated through recent sales data. Given that developers would know these estimates reflect interactions between supply and demand, they may set ask prices higher than estimated WTP, then reduce housing prices if they remain unsold.

\subsubsection{Developers' WTP for agricultural land}

Open question 9: How should developers' WTP (expected price) for agricultural land be determined?

Approach 1: An exogenously set inter-temporal opportunity cost for agricultural production can be used as the developer's expected price for rural land, assuming that the developer will be able to capture all GFT from the transaction, perhaps accurate only when the supply of conversion land is abundant. This approach is simple, but also grounded in economic theory.

Approach 2: In equilibrium-based models, the price for undeveloped land is assumed to be derived from developers' profit function (Equation 3.12). ${ }^{20}$ Again, the equilibrium problem could be translated into an ABM context by implementing an inductively estimated expected price for agricultural land, based on recent sales.

\subsubsection{Price negotiation and the land transaction price}

The process of determining sales prices and executing trades (Boxes III and IV in Figure 3.3) raises several questions. First:

Open Question 10: How should sellers decide which bid to accept?

Sellers status and ask prices are public information, available easily to all buyers. Buyer's bids may be above or below the ask price, as discussed earlier. Two approaches are possible:

Approach 1: The seller can accept the first bid that is at or above his ask price.

Approach 2: The seller can gather bids over a certain time frame, then accept the highest bid that is above his WTA. That time frame may also be endogenous, depending on average local time on the market and rates of change of prices. To avoid the complication of buyers withdrawing

\footnotetext{
${ }^{20}$ The theoretical literature presents more complex strategic models of price negotiation with landowners from whom housing producers buy undeveloped land. A game-theoretic approach (Asami \& Teraki, 1991) analyzes the outcome of sequential pairwise negotiations between a single developer and several landowners over the price to be paid for land.
} 
during this interval, the seller agent could collect bid prices simultaneously at a "Sunday open house," then decide which, if any, bid to accept at the end of the round. A buyer then may issue a revised bid based updated estimation of WTP and/or a bid price in the next round, if her first bid were rejected. In either of these approaches, the accepted price defines the transaction price. However, when both buyers and sellers offer their true reservations prices (WTP/WTA), another question must be answered:

Open Question 11: How should the gains from trade from the transaction be divided?

Researchers have taken several approaches to this problem, most involving some algorithmic division of GFT. Happe et al. (2006) divide the GFTs using the geometric mean of WTP and WTA, and Polhill, Parker, and Gotts (2008) impose a Vickery auction so that the auction winner pays the bid of the second-highest bidder. (An overview of types of auctions and their applicability to ABM is provided in Wooldridge (2002).) Arsenault, Nolan, and Schoney (2007) compare the results of several alternative auction mechanisms in their rural LM model, and find that the model results are not sensitive to the auction mechanism, suggesting that in simple circumstances, models may not be sensitive to assumptions regarding division of GFT.

A decision about whether/how to model bid and ask prices and division of gains from trade may depend on whether cyclical housing dynamics are an important part of the research question. In the case of irreversible conversion of open space driven by spikes in housing demand, they may be essential to explaining observed dynamics. However, if the purpose of the model is comparison to other abstract, theoretical models of effects of open space on property values, a simpler approach may suffice.

\subsection{Confronting the conceptual model with the real world: next steps}

\subsubsection{Benchmarks for land markets}

Replication of benchmark theoretical models through simplified versions of an ABM is an important strategy for structural model validation (LeBaron, 2006) one that we pursue in related work (Parker and Meretsky, 2004; Filatova, Parker et al., 2007). We used a set of economic and spatial metrics to compare conventional model and ABM LM. Strategies for model calibration, verification, and validation appropriate for our model are discussed elsewhere (Parker et al. 2003; Grimm and Railsback 2005; Lambin and Geist 2006). 


\subsubsection{Empirical modeling}

In principal empirical ABM offer two advantages over traditional reduced-form statistical empirical models of land conversion. The first is that demand and supply can be modeled separately, based on structural representations of utility and profit functions, to which multiple statistical models may contribute. The second is that the dynamics of price formation are explicitly represented, allowing for endogenous evolution of land rents in response to shifts in factors that influence supply and demand, relocation decisions, and in-migration by new agents.

The major challenge to translating this framework into an empirical context, however, is to empirically parameterize those structural utility and profit functions, so that WTP and WTA functions can be derived and dynamically updated. The problem is compounded by the fact that utility functions are not observable or directly measurable. Further, while data are available on bid and ask prices, we expect that those prices will be lower (higher) than actual WTP and WTA. Finally, while data on real estate transactions are available, these data represent the result of interactions between demand and supply 8 and are rarely easily matched to the demographic characteristics of buyers or sellers.

Several approaches are possible, however, to construct empirical analogs of theoretical willingness to pay functions for buyers and willingness to accept functions for sellers.

Approach 1: Experimental/conjoint analysis: Although there are fundamental problems related to parameter and functional form identification, experimental approaches have been used to identify potential parameter weights for utility functions. In an experimental setting, agents could be endowed with budgets based on fixed prices and allowed to trade housing "goods" with particular characteristics. Alternatively, in a survey setting agents could be allowed to choose among housing options based on their actual budgets.

Approach 2: Revealed preference approaches through statistical models that combine household and spatial survey data: In theory, demand and supply curves can be estimated if survey data are available that link the characteristics and preferences of buyers/ sellers to actual sales transactions. Data on the characteristics of the residence are often linked to transaction/tax assessment records, and data on the spatial characteristics of the neighborhood of the house could be derived through GIS. Resident surveys can capture information about buyers who currently reside in the house. These data provide sufficient information to estimate a demand curve. Obtaining similar data on sellers, and linking that data to homes purchased as well as homes sold, would require a seller survey and would pose greater challenges for gathering GIS data on sellers' new residences. 


\subsection{Conclusions}

In this paper, we have outlined a detailed conceptual model of a LM with interactions between heterogeneous agents-buyer households, relocating seller households, and developers. Our proposed model moves beyond existing work by modeling interactions between multiple agent types, modeling the process of bid and ask price formation, and proposing agent decision models that combine deductive optimization with inductive models of price expectation formation. Our discussion is well grounded in economic theory, but also is closely linked to previous cellular models of LU originating in geography. Thus, we hope that our presentation will be of interest to both urban/environmental economists and cellular spatial modelers and will serve to bring these two groups closer together in knowledge and perspective.

Because restrictive assumptions and equilibrium solutions need not be imposed on ABMs, many — perhaps too many! — choices are available to modelers. We have outlined a series of open questions that are inherent in making the transition for theoretical equilibrium- based urban economic models to agent-based residential LMM, and we have proposed solutions to each of them. We plan next to compare the effects of the alternative proposed solutions within our simulation model. We also welcome feedback on these proposed solutions, comparative modeling to explore their implications, and suggestions for additional alternatives. 


\title{
4 Agent-based urban land markets: agent's pricing behavior, land prices and urban land use change ${ }^{21}$
}

\begin{abstract}
We present a new bilateral agent-based land market model, which moves beyond previous work by explicitly modeling behavioral drivers of land-market transactions on both the buyer and seller sides; formation of bid prices (of buyers) and ask prices (of sellers); and the relative division of the gains from trade from the market transactions. We analyze model output using a series of macro-scale economic and landscape pattern measures, including land rent gradients estimated using simple regression models. We first demonstrate that our model replicates relevant theoretical results of the traditional Alonso/Von Thünen model (structural validation). We then explore how urban morphology and land rents change as the relative market power of buyers and sellers changes (i.e., we move from a "sellers' market" to a "buyers' market"). We demonstrate that these strategic price dynamics have differential effects on land rents, but both lead to increased urban expansion.
\end{abstract}

\subsection{Introduction}

Housing markets are dynamic. Not only housing prices but also the spatial form of the city are the result of market allocation of urban land between competing users. Aggregate urban economic indicators and the morphology of the city are determined by the adaptive behavior of individual agents. Equilibrium-based urban models omit the exploration of urban dynamics. However, real world phenomena, such as housing market bubbles, are a manifestation of the cyclic dynamic nature of urban markets. We are interested in understanding how the replacement of a centralized equilibrium price determination mechanism by decentralized bilateral agent trading dispersed in time and space influences morphology and land prices in the city. In the real world, housing prices for comparable housing differ in sellers' and buyers' markets. It is often observed that prices grow unjustifiably in a housing market favoring sellers. We argue that economic agents react to the state of the housing market (i.e., buyers' or sellers' market) in their pricing strategies. Moreover, if buyers are saturated with information about a shortage of properties on the market, they generally respond with a willingness to raise their bids.

This paper presents an agent-based bilateral residential land market model, with a particular focus on the formation of WTP/WTA (willingness to pay/ willingness to accept) versus bid/ask price for land as well as the division of gains from trade. We apply agent-based modeling (ABM) to study land markets in a dynamic way. The ABM allows for spatially explicit modeling and creates

\footnotetext{
${ }^{21}$ This Chapter is also published as paper co-authored with D. C. Parker and A. van der Veen "Agent-Based Urban Land Markets: Agent's Pricing Behavior, Land Prices and Urban Land Use Change", Journal of Artificial Societies and Social Simulation, $12(1) 3<$ http://jasss.soc.surrey.ac.uk/12/1/3.html>
} 
the opportunity to visualize the impacts of different factors (such as different preferences for the attributes of spatial environment and pricing strategies) on a 2D landscape.

Representative analytical, cellular, and agent-based models of residential development are reviewed by Parker and Filatova (2008). Applications of ABMs to land use (LU) problems are quite diverse (Parker et al., 2002; Parker et al., 2003) and include modeling of simplified urban (Otter et al., 2001) and semi-urban (Sasaki and Box, 2003) systems without land markets. A discussion of the rationale for explicit modeling of land markets in land use models can be found elsewhere (Polhill et al., 2005; Parker and Filatova, 2008; Polhill et al., 2008). Several models study the effects of hypothetical land markets, but with primary emphasis on the demand side. The SOME and SLUCE models allow agents to choose the parcel that maximizes their utility without competition from other sellers, assuming that the locating agent will outbid the current use (Brown and Robinson, 2006). The micro-simulation model of Miller et al (2004) simulates both commercial and residential land markets. Terán (2007) models location behavior of forest landowners who bid for desirable parcels. However, price determination within this land market is not explained in the paper. Other models of agricultural land markets deal both with demand and supply decisions (Balmann and Happe, 2000; Berger, 2001; Happe, 2004; Polhill et al., 2008). The MADCM model provides a welfare analysis of the simulated urban land market but considers space to be heterogeneous in one aggregated characteristic called "quality" (Grevers and van der Veen, 2008). These models are becoming increasingly more sophisticated and can certainly serve as a basis for further attempts to include land markets in LU modeling.

Our model moves beyond previous work in several aspects. First, both demand and supply sides are represented in detail, facilitating model experiments focused on the drivers of each. Second, to explore welfare effects of land market outcomes, we explicitly model differences between the buyer's WTP and her bid price for the land, and differences between the seller's WTA and his ask price. Finally, we show how the division of gains from trade and spatial patterns depend on whether there is a buyers' or sellers' market.

We proceed as follows. First, the economic approach to modeling residential land markets and the value added of an ABM are outlined. Second, the bilateral ABM of a residential land market, including the assumptions and technical details of our new ALMA-v1.0 model, is presented. Then, we present a series of experiments that first replicate results of the conventional Alonso urban model, and then explore the implications of interactions between traders and differences between WTP/WTA and the actual bid/ask price. We conclude with a summary of the model results and a discussion of their implications and future directions for the model. 


\subsection{The traditional economic approach to modeling urban land use and value added of $A B M$}

Agent-based modeling should be viewed as a way to supplement traditional scientific methods and expand the boundaries of science to test hypotheses and undertake experiments, rather then as a substitute for traditional methods (Parker et al., 2002; Parker et al., 2003). Thus, we develop our agent-based land market based on knowledge from urban economics, with the goal of expanding the scope of questions that can be investigated through modeling. As discussed in greater detail in Parker and Filatova (2008), many traditional models of urban land markets find their roots in the monocentric urban model of W. Alonso (1964). According to his bid-rent theory, households choose locations at a certain distance from the central business district (CBD) by means of maximizing utility they get from the joint consumption of a spatial good (land lot or house) and a composite good (all other goods) under their budget constraint (income less transportation costs). Applying market-clearing conditions (assuming that demands derived from the consumer's first order conditions are equal to supply at equilibrium) and assuming that utility is equal for all agents in the city, one derives the equilibrium land rent $R^{*}(d, u)$. In this case equilibrium rent is the maximum rent per unit of land that the representative consumer is willing to pay at distance $d$ while enjoying a given utility level $u$ (Fujita and Thisse, 2002). The outcome of the bid-rent model is a set of rent gradients (i.e., land prices at different distances from the city center).

As is typical in economics, certain restrictive assumptions are made to solve for equilibrium conditions in traditional urban economic models. In general these assumptions can contradict real world phenomena, and they have created controversy and raised substantial criticism. These assumptions fall into four general areas, each of which has a representative example in urban economics:

1. Limitations of the representative agent approach (Kirman, 1992): each agent in the model is assumed to be homogeneous with respect to preferences for proximity, open-space amenities, resources, and behavior;

2. Limitations of assumptions of economic rationality, which in urban economic models include assumptions of complete information and perfect foresight;

3. Traditional analytical models do not account for interactions among agents. However, the importance of social interactions (Manski, 2000; Brock and Durlauf, 2001) and the effects of spatial externalities on land-use patterns (Irwin and Bockstael, 2002; Parker and Meretsky, 2004) have been recognized; 
4. Equilibrium is assumed to occur instantaneously, leaving no space for analysis of out-ofequilibrium dynamics and adaptation (Arthur, 2006; Tesfatsion, 2006).

These drawbacks of neoclassical economics are discussed elsewhere in greater detail in general (Epstein and Axtell, 1996; Arthur, Durlauf et al., 1997; Axtell, 2005; Tesfatsion and Judd, 2006), and in application to land markets in particular (Parker and Filatova, 2008). For the purposes of this paper, we relax assumption 2 by a small extent, assuming that agents consider only a subsample of all available properties. We relax assumption 3 by explicitly modeling bilateral trading between agents (analysis of spatial externalities is left for future work). We relax assumption 4 by allowing market equilibrium to emerge in a step-wise fashion, based on sequential rounds of trading. In line with the objective of this paper we formulate the following research questions:

1. How comparable are the results of the spatially explicit land market, where the centralized equilibrium price determination mechanism is replaced by spatially distributed bilateral trading, to the results of the benchmark analytical monocentric urban model?

2. How do different price setting strategies of buyers and sellers influence the morphology of the city, the micro and macroeconomic outcomes and, particularly, the division of gains from trade?

To answer these questions we constructed an ABM of residential land markets - ALMA (Agent-based Land MArket). By modeling spatial and market interactions between buyers and sellers explicitly, ALMA allows us to obtain spatial patterns and land prices endogenously as economic theory does (Question 1, addressed by the experiments in Section 4.4.2). The bilateral market allows us to analyze the evolution of path-dependent land transaction prices, which depend on the number of successful transactions in the previous time period and the resulting relative power of buyers and sellers in the marketplace (Question 2, addressed by the experiments in Section 4.4.3).

\subsection{An Agent-based Land Market (ALMA)}

Our Agent-based Land MArket (ALMA) model explicitly simulates micro-scale interactions between buyers and sellers of spatial goods and macro-scale feedbacks of market transactions. The main agents in the ALMA model are land users operating in an urban area (households, who buy land, and farmers, who sell land). The main good they exchange via market mechanisms is a spatial 
good, which can be viewed as a plot of land or a house. The ALMA model ${ }^{22}$ was programmed in NetLogo (Wilensky, 1999). The model presented in this paper intends to replicate a monocentric urban model. We denote this version of our model as ALMA version 1.0 (ALMA-v1.0).

The land market structure we are proposing borrows much from existing research on spatial economics. However, differences show up in the implementation of a spatially explicit setup, and direct modeling of price formation and market transactions. Figure 4.1 shows the logic of the land market model discussed in this paper. Figure 4.1 is a simplified version of a more general figure representing a comprehensive $\mathrm{ABM}$ market model described elsewhere (Filatova, Parker et al., 2007; Filatova, van der Veen et al., 2007; Parker and Filatova, 2008).

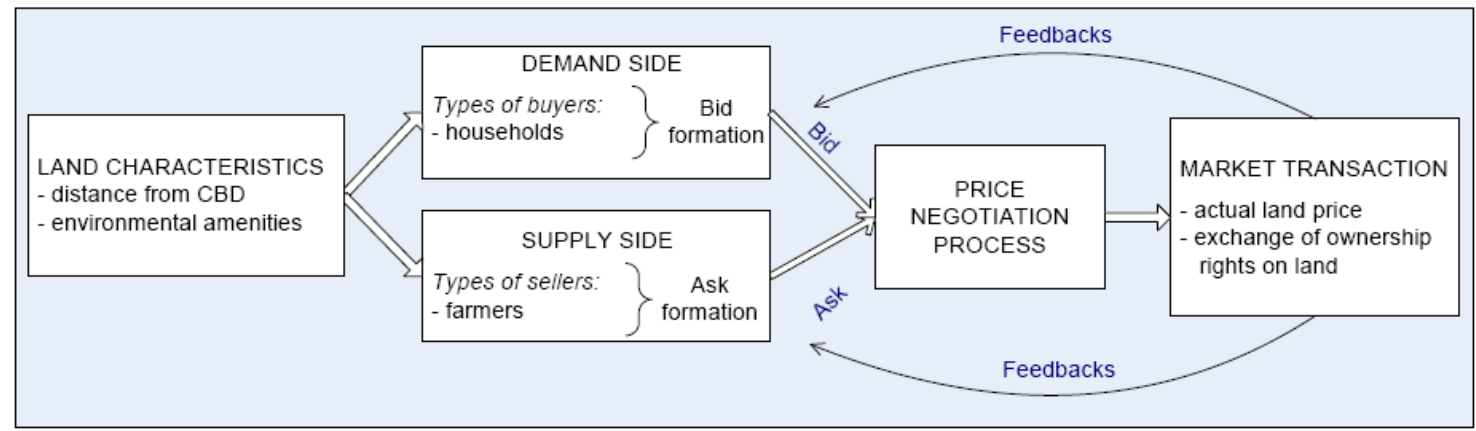

Figure 4.1: Conceptual scheme of the land market

The land market in ALMA is represented as a two-side matching market. Our goal in this paper is to present a somewhat simplified version of the standard monocentric urban model (Alonso, 1964). Therefore, each spatial good is characterized by distance to the CBD, and by uniformly distributed environmental amenities. Buyers form their bid prices for land depending on the distance to the $\mathrm{CBD}$, their preferences for commuting, budget constraints, and potentially market conditions. Sellers form their ask prices based on a fixed opportunity cost, and potentially market conditions. When two trading partners are able to agree upon transaction of a spatial good, the land is transferred to the new user. Thus, ALMA-v1.0 produces urban land patterns and land prices (land rent gradients) as a result of market allocation of land between competitive users. The environment and main entities of ALMA-v1.0 are shown in Figure 4.2.

The code of the ALMA model also provides the possibility a) to represent heterogeneous environmental amenities and disamenities, b) to account for spatial externalities that serve as feedbacks from the changed spatial structure of a neighborhood when a spatial good changes its owner, and c) to endow agents with heterogeneous preferences for environmental amenities and proximity to the CBD (Filatova, Parker et al., 2007; Filatova and van der Veen, 2007; Filatova, van der Veen et al., 2007). For the purposes of this paper this capacity is not utilized.

\footnotetext{
${ }^{22}$ The NetLogo code for ALMA 1.0 will be made publicly available following the defense of the PhD thesis by T. Filatova at the University of Twente, the Netherlands.
} 


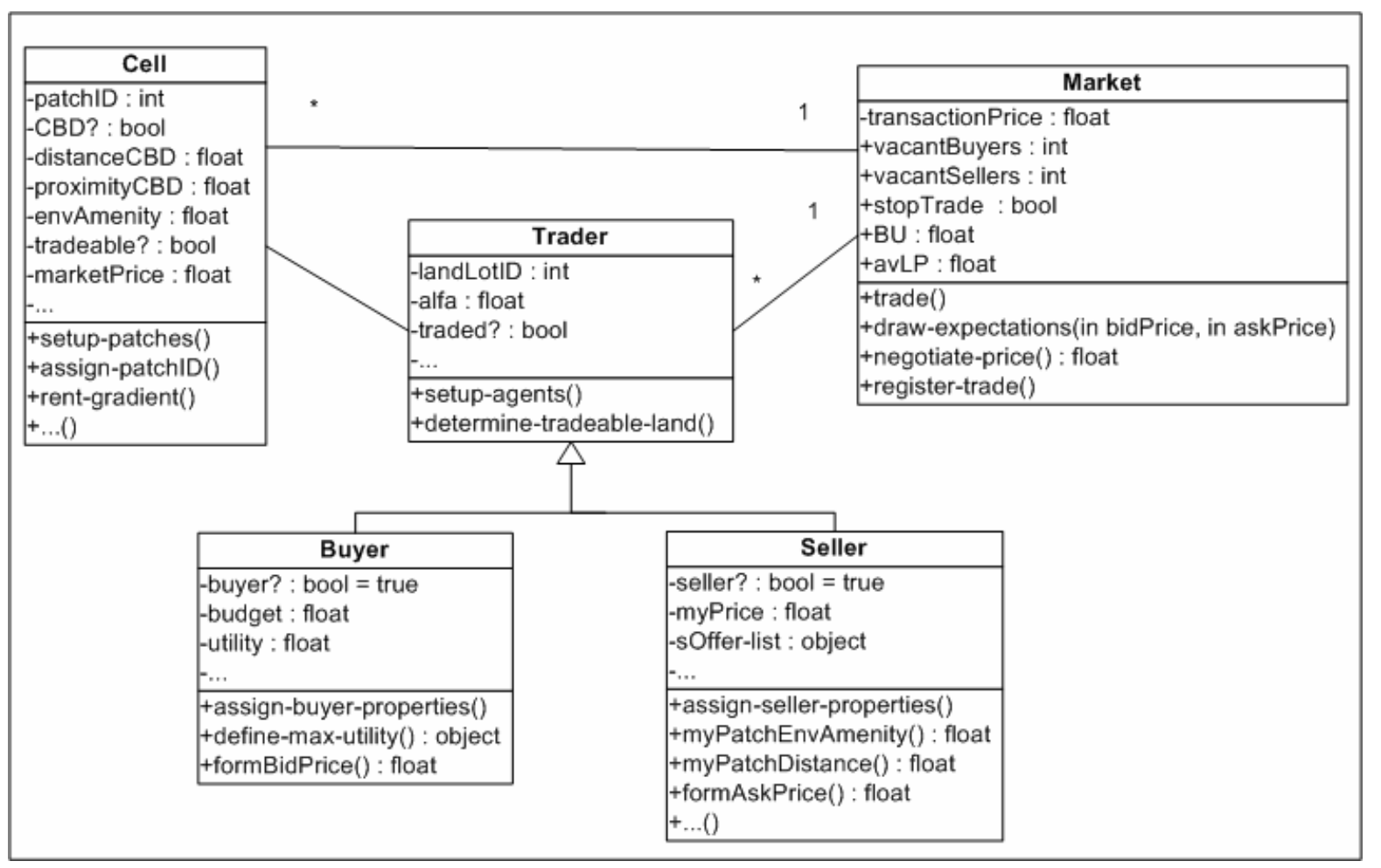

Figure 4.2: UML class diagram of the ALMA-v1.0 metamodel ${ }^{23}$

We proceed with the description of ALMA-v1.0 following the MR.POTATOHEAD framework (Parker, Brown et al., 2008). First, the spatial environment will be described in detail, then we will explain the behavior of economic agents. We conclude with a description of the land exchange mechanism.

\subsubsection{The spatial environment}

Space is an essential component of any land market. ALMA-v1.0 has an explicit spatial representation of model dynamics (i.e., the location of the $\mathrm{CBD}$ and relative transportation costs affect model dynamics and the spatial pattern of land rents resulting from market trades). Space is represented by a grid of equal cells, each of which can be owned by one economic agent. Each cell can be viewed as a separate spatial good, e.g. property unit, characterized by several parameters (see Figure 4.2). In ALMA-v1.0 each cell has two characteristics: distance from the CBD and level of green amenities. In principle, cells can be parameterized with more characteristics if needed.

\footnotetext{
${ }^{23}$ This UML diagram shows that classes "Buyer" and "Seller" inherit from "Traders". In the actual NetLogo code inheritance is not presented exactly as in the tradition of the object-oriented programming. In particular, to differentiate among buyers and sellers we do not create "breeds" of different traders. We rather introduce a Boolean attribute "buyer?" and "seller?" whose value can change during the model run. This feature is used in the extended version of ALMA model, where buyers who have acquired some property in the previous time steps might decide to move because of the changed neighborhood structure. Thus, they need to become sellers. In ALMA-v1.0 this procedure is not activated. So, buyers and sellers agents actually can be viewed as separate classes with one parent class.
} 
The position of the city center (CBD) is exogenous and is in the center of the 2D lattice, i.e. it is a point with coordinates $(0 ; 0)$ in a Cartesian coordinate system. A distance of each cell $(D)$ is measured as a Pythagorean distance from the center of coordinates. We also estimate relative proximity to the $\mathrm{CBD}$ (relative meaning that it is compared to the maximum distance in this city) as a measure inverse to distance (Equation 4.1). Here $D_{\max }$ is a distance from the CBD of the most remote cell in the simulated landscape, dependent on the extent of the landscape as set by the user. In this paper, we run the model on a 29x29 lattice, but the landscape extent may be extended as needed. Thus, relative proximity for distance $D$ is given by:

$$
\bar{P}=D_{\max }+1-D
$$

Further, when agents estimate their utility for a certain property unit, they use a normalized value of proximity:

$$
P=\bar{P} / \bar{P}_{\max }
$$

The standard monocentric model assumes that households choose a location in the city as a result of the tradeoff between land price and transport costs. Transport costs are assumed to be a linear function of distance: $T(D)=t c u * D$, where $t c u$ are transport costs per unit of distance.

\subsubsection{The demand side of the land market (acquires of land)}

Buyers are households searching to buy a house/land lot. At model initialization, the number of buyers is defined by the user.

Budget: As we discussed earlier, in traditional urban economic models households search for a location to maximize their utility under their budget constraint. While transferring the equilibrium economic framework into an $\mathrm{ABM}$ market, we have to make a few assumptions, which arise when one attempts to transfer the traditional budget-constrained utility maximization framework to an agent-based model (Parker and Filatova, 2008). In ALMA-v1.0, we first assume that the housing choice is separable---i.e. the buyer has already decided what portion of her income to spend on housing and non-housing goods. This assumption is consistent with traditional real estate markets, where in general about $1 / 3$ of household monthly income is spent on housing (i.e, the mortgage payment). Thus, we assume that household agents have already estimated their disposable budget for housing and transportation before they come to the land market. The budget constraint of a buyer is the disposable budget for housing ( $Y_{\text {housing, }}$, i.e. "budget" attribute of buyers on Figure 4.2) net of transport costs at a certain distance $D$ :

$$
Y=Y_{\text {housing }}-T(D)
$$


Second, at this point of the model development it is assumed that each seller owns only one spatial good (i.e., one cell) and each buyer is interested only in buying one property unit. We leave for future work the question of the amount of floor space/land lot area demanded.

Utility: Thus, the task of a house buyer is reduced to a) a choice of the housing good that gives maximum utility under her budget constraint, and b) estimation of her WTP. Households' utility depends on the qualitative characteristics of a spatial good, which depend on its location, and is assumed to have a Cobb-Douglass functional form (Equation 4.4). Here $A$ is the uniformly distributed amenity, $P$ is normalized relative proximity estimated according to Equation $4.2, \alpha$ and $\beta$ are preferences for green amenities and proximity respectively, and $\alpha+\beta=1$. For the model experiments presented here, we assume that $\beta>0.5$. As in the original Alonso model (1964) distance is included directly in the utility function because it represents not only the travel costs but also the disutility of commuting time to the $\mathrm{CBD}$, which decreases the overall utility of a remote location.

$$
U=A^{\alpha} \cdot P^{\beta}
$$

Bid price: Given her utility function and budget constraint, a buyer chooses which property to bid on by sampling $N$ spatial goods, offered for sale in the current market, that are affordable given her budget constraint. She then calculates the utility of each spatial good, and chooses to bid on the one for which her utility is the highest (see Figure 4.3).

In standard economic theory, the relationship between individual WTP and qualitative characteristics of housing is given by the demand curve of a household ${ }^{24}$. WTP is assumed to be a function of utility, individual income and prices of all other goods (Varian, 1992). We propose to describe these dependencies with the help of the following function ${ }^{25}$ :

$$
W T P=\frac{Y \cdot U^{2}}{b^{2}+U^{2}}
$$

Here, $Y$ and $U$ are calculated according to Equations 4.3 and 4.4 respectively, and $b$ is a constant. The WTP function is monotonically increasing approaching $Y$ as $U \rightarrow \infty$, meaning that individual WTP increases with utility but does not exceed her budget. The value of parameter $b$ controls the steepness of the function. As $b \rightarrow \infty$ the function in Equation 4.5 becomes flatter, and at $U=b, W T P=Y / 2$, reaching half of its possible value. We can think of $b$ as a proxy of the affordability of all other goods to reflect their relative influence on the WTP for housing. As shown

\footnotetext{
24 Traditionally the demand curve shows the relationship between price and quantity demanded. In our case it is assumed that an individual wants to buy only 1 unit of housing. However, because each spatial good is of different quality, then an individual actually makes choice of how much quality to buy at a certain price. The amount of quality that the good provides to the individual is measured by utility she obtains from its consumption.

25 This function is known as a Michaelis-Menten function in kinetics or Monod function in biology (Voinov, 2008)
} 
in Appendix A, the WTP function (4.5) exhibits the main qualitative properties of the neoclassical demand function.

We differentiate between WTP and a final bid price of a buyer, and between WTA and a final ask price of a seller (Parker and Filatova, 2008). In the bilateral trading and negotiation of a land market, buyers try to maximize their gains from trade (the difference between their WTP and their bid price), as do sellers. Therefore, they will set a bid price below their initial WTP, but they will attempt to keep their bid above the WTA of a seller. However, agents are likely to perceive the negotiating power of their trading partners depending on whether it is a sellers' or a buyers' market. In a sellers' market, demand exceeds supply, and sellers obtain more market power to influence the final transaction price, while buyers have to compete more intensely to be able to obtain needed goods. In this case the buyer's bid price is likely to grow in order to increase the chance that they will outcompete other buyers and obtain the desired good. In contrast, in a buyers' market when supply exceeds demand, buyers have more market power to influence prices, and sellers must reduce their relative ask prices in order to be able to sell. We believe that these market feedbacks, at least partly, explain cyclical dynamics in the housing market. Price adjustments depending on demand or supply excess in financial ABM markets are commonly modeled (LeBaron, 2006). We translate this conceptual framework into housing market dynamics using the following strategy to adjust bid and ask prices depending on the relative market power of buyers and sellers. In ALMA$\mathrm{v} 1.0 \mathrm{a}$ bid price of a buyer is estimated as follows:

$$
P_{\text {bid }}=W T P \cdot(1+\varepsilon), \text { where } \varepsilon=(N B-N S) /(N B+N S)
$$

where $N B$ is the number of buyers and $N S$ is the number of sellers. Both variables indirectly depend on land prices and the number of successful transactions in the previous time step, since if prices are beneficial for both buyers and sellers, they participate in successful trades and leave the land market. If an imbalance of buyers and sellers remains, bid or ask prices will adjust to correct the imbalance. At the beginning of each time step, the variable $\varepsilon$ is updated and pricing behavior changes (See Figure 4.3).

Properties of $\varepsilon$ : If the number of buyers exceeds the number of sellers (i.e., it is sellers' market) then $\varepsilon>0$, and $P_{b i d}$ increases, as buyers compete to be able to buy the spatial good they want. Correspondingly, if $\varepsilon<0$, then sellers compete for the buyers, and buyers in their turn are willing to pay relatively less and sellers may accept lower bids.

The relative change in bid price will also depend on the total number of buyers and sellers in the marketplace, reflecting the logic that a small number of buyers and/or sellers will increase the market power of the participants. If total number of traders is small, $(N B+N S) \rightarrow 0$, and the absolute value of $\varepsilon \rightarrow 1$. In this case, a change in the relative number of buyers and sellers will cause a 
relatively large change in bid prices, leading to relatively large change in transaction prices. This situation can be viewed as an oligopoly (a market dominated by a few suppliers of a good) or an oligopsony (a market dominated by a few buyers), where each dominant agent can influence prices significantly. If the total number of traders is large, $(N B+N S) \rightarrow \infty$, and $\varepsilon \rightarrow 0$. This situation can be viewed as the case of monopolistic competition, where there are many buyers with heterogeneous preferences and many sellers who offer heterogeneous goods. In this case, a change in the relative number of buyers and sellers will lead to relatively small changes in bid prices and transaction prices. One individual has little influence on land prices as possibilities for substitution are high, and the average market price for land changes slowly with time. Thus, in summary, the numerator of $\varepsilon$ determines whether the final bid price will decrease or increase, and the denominator defines the magnitude of the change.

Bounded rationality: In our model, as in the neoclassical model, agents are assumed to maximize utility by choosing the optimal location under the budget constraint. However, there are two important distinctions from the neoclassical utility-maximization problem. Neither buyers nor sellers account for their future benefits, and in that sense they are myopic, as they do not calculate the optimal time to enter the market. Moreover, economic agents are not fully-informed. The search for the optimal transaction in any market is costly. This search involves information, time and monetary costs, meaning that a global optimum is not likely to be located in real-world housing markets. As well, humans have limited computational abilities: even if they might have full information about all houses on the market, it is not a trivial task to find a maximum (of utility) on this $\mathrm{n}$-dimensional space (where $\mathrm{n}$ is the number of attributes of a spatial good). In other words, replicating the limitations imposed on real-world traders by this computational complexity we make economic agents in the ALMA model boundedly rational. ${ }^{26}$

\subsubsection{The supply side of the land market (suppliers of land)}

Sellers represent owners of agricultural land. At model initialization, the user defines the number of sellers NS. The model experiments presented in this paper have a fixed number of sellers equal to the number of cells in the initial landscape. Each seller owns one land lot. Consistent with the monocentric urban model, in ALMA-v1.0, the supply side is assumed to be willing to give up its land at the fixed price of agricultural land, which is the same everywhere in the city $\left(P_{a g}\right.$ is equal 200 in our experiments). However, sellers try to capture economic surplus from converting land to

\footnotetext{
${ }^{26}$ The assumption of limited information will be relaxed in a future version of the model in order to explore its implications. The computational capabilities of Netlogo prevent us, for this version of the model, from having agents sample from all affordable parcels. However, sensitivity analysis indicates that model results are not highly sensitive to the number of parcels sampled. We attribute this result to the uniform spatial amenities imposed on this model.
} 
urban use. Therefore, we assume that they set their WTA 25\% higher than their reservation price but still the same everywhere in the city $(W T A=250)$.

As widely discussed in our earlier paper (Parker and Filatova, 2008), in general, the ask price is expected to differ from a seller's WTA. When sellers form their ask price, they may account for the market situation:

$$
P_{a s k}=W T A \cdot(1+\varepsilon)
$$

The variable $\varepsilon$ is estimated as in Equation 4.6. In the case of a buyer's market, when sellers decrease their ask price $\left(P_{\text {ask }}\right)$, we impose a condition that the ask price cannot go below agricultural reservation price $\left(P_{a g}\right)$.

\subsubsection{Price negotiation and market transactions (land exchange mechanism)}

Land exchange rules: The algorithm that artificial traders follow is presented in Figure 4.3. Location choice and the price for the desirable site are determined jointly. Thus, the decision of an agent to buy a house is divided into two stages: a) finding a spatial good that maximizes her utility (step III. and IV., Figure 4.3) and b) determining transaction land price (steps V.- IX.). The seller gathers all bids for his property offered during the current time step and selects the highest of these bids. Nevertheless, the market transaction will only take place if the terms of trade are favorable to both the buyer and the seller (see box VIII.). If, however, the buyer's bid price is higher than the seller's WTA, meaning that gains from trade are potentially positive for both traders, there are several possible ways to determine the actual transaction price for the spatial good. Price negotiation mechanisms in existing market $\mathrm{ABMs}$ vary from simple arithmetic or geometric average of bid and ask prices (Berger, 2001) to sophisticated algorithms, such as auctions (Miyake, 2003; Polhill et al., 2008). For simplicity at this stage of the ALMA model, the price negotiation procedure (step IX.) is implemented as a calculation of the arithmetic average of the seller's price and the highest offer-bid of a buyer. A successful trade is registered by ALMA-v.1.0 (step IX.), both buyer and seller update their status (the seller will not sell in the next period, the buyer will not search for a land lot to buy, and they will not be counted in the estimation of NB and NS in Equation 4.6), the ownership rights on the spatial good are transferred from seller to buyer, and the transaction price is registered as the actual price for this specific land lot. Both the exchange of land and recording of the market transaction are fulfilled by a "Market" agent (Figure 4.4) and are saved in a *.csv (comma separated) file. The numbers of buyers and sellers remaining in the market after the transaction will influence the determination of bid and ask prices in the next time step via the variable $\varepsilon$ (see Equations 4.6 and 4.7). The model stops running when no more transactions occur, 
i.e. all the submitted bids are lower than ask prices ${ }^{27}$. Implicitly we assume that households (i.e., buyers) not settling in this city will search for a location in another city and leave the simulation environment, as in the open city model (Strazsheim, 1987; Anas et al., 1998).

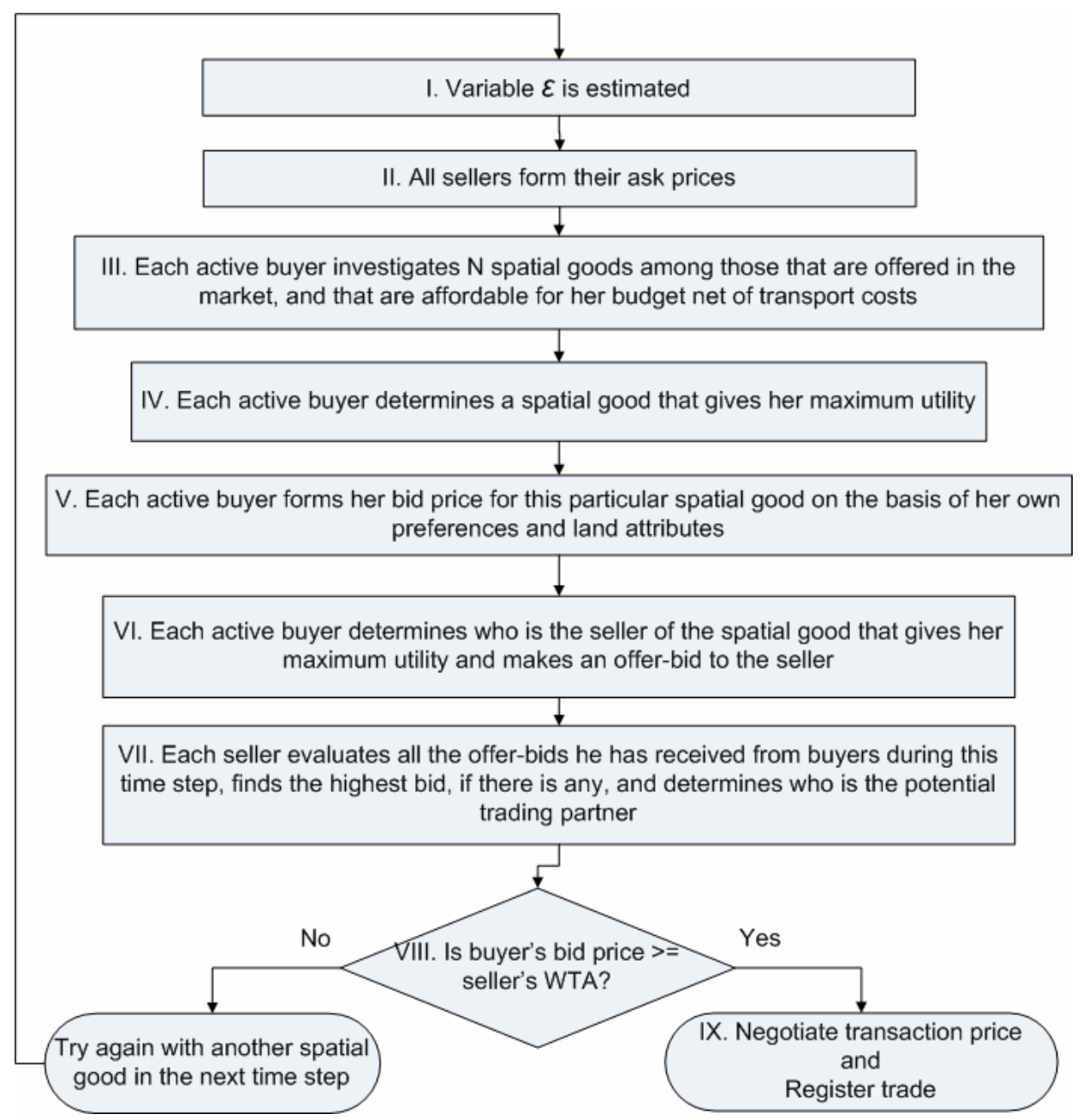

Figure 4.3: Conceptual algorithm of trade

Event sequencing mechanisms: In any given time step, Netlogo activates agents in a random, but fixed, sequence. In the first time step of any model run, a preset number of buyers and sellers are initialized. Below, we present experiments with and without activation of $\varepsilon$ (realized via assigning "Pure WTP/WTA" or "Market-oriented" pricing behavior to traders). In the "Pure WTP/WTA" case, all buyers are activated in each time step. In the "Market-oriented" case, all buyers may not be activated in each time step, but instead will become active in the market at some user-defined rate. Epsilon is calculated using all the initialized buyers and sellers who have not yet successfully traded, not only those who are active in trading in a given round. The number of buyers who are active in the market in each time step (buyers from previous time periods who have not successfully purchased properties plus newly activated buyers) affects the speed at which $\varepsilon$ is

\footnotetext{
${ }^{27}$ We are aware that in real world a transaction may happen even if a bid price is lower than an ask price (sellers may accept lower bid price if for example the property has been on the market for a long time or if they anticipate that prices will fall further). However, implementation of such type of algorithms is left for the future work.
} 
updated (see Experiments 4.3-4.6). The lower the number of buyers active in the land market during the time step, the more often $\varepsilon$ is updated. Buyers and sellers who have not completed a successful transaction remain active in the next time period. The model continues to run until no more transactions occur.

The sequence of events in ALMA-v1.0 is presented in Figure 4.4 below. The scheme is quite straightforward and all the components were discussed above.

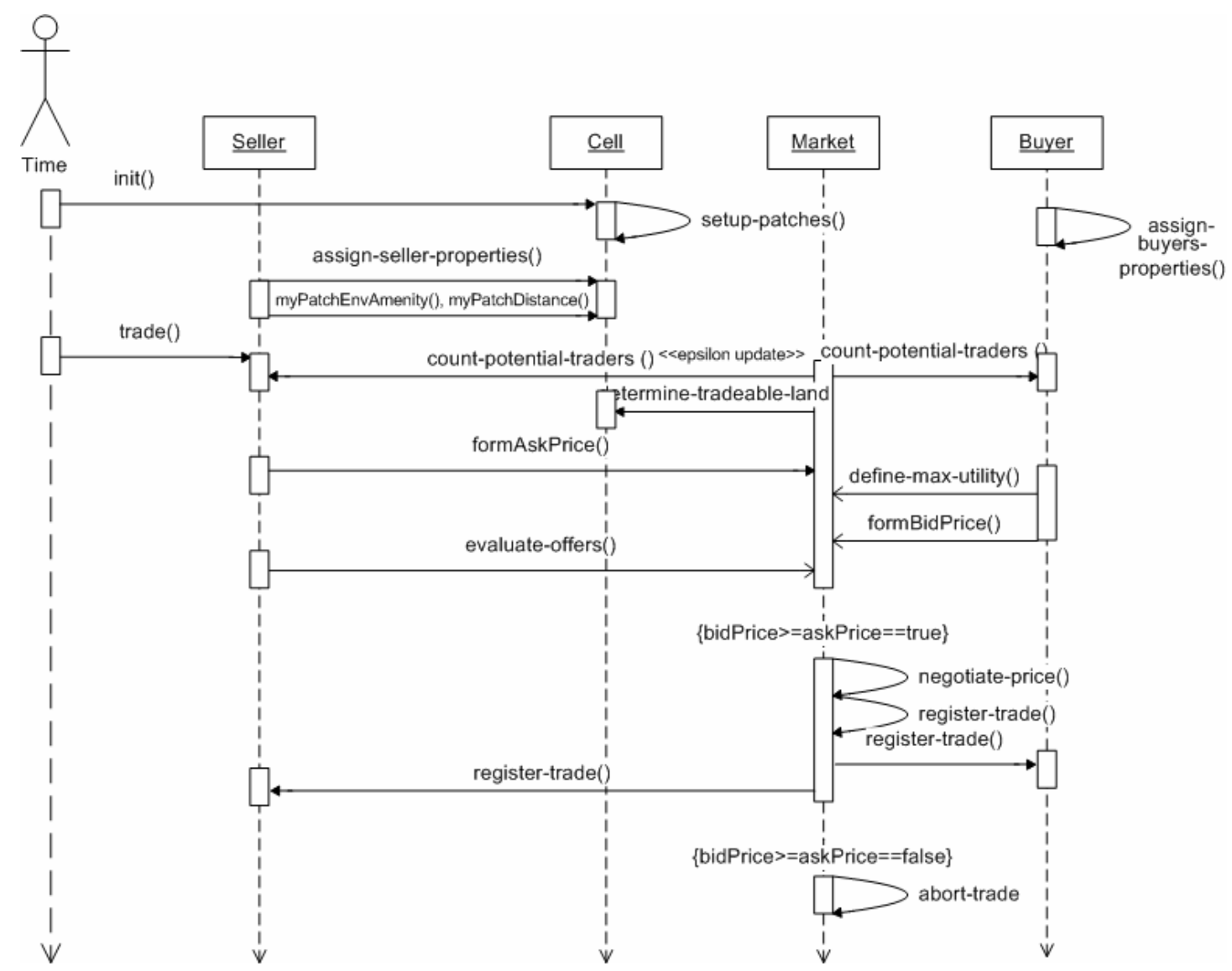

Figure 4.4: UML time sequence diagram

Innovations of ALMA: The ALMA model allows us to study the division of gains from trade in the land market, since there is a differentiation between ask price and WTA, and bid price and WTP. A consumer's (producer) surplus is the amount she (he) benefits from being able to buy (sell) a good at a price below her WTP (above his WTA). In the traditional equilibrium framework, the price at which everyone buys (sells) is assumed to be the price determined at equilibrium by some hypothetical auctioneer, and this price is used to calculate consumer and producer surplus. In our $\mathrm{ABM}$ market, there is no one unique price for everyone in the market; rather, there is a set of individual transaction prices determined by each set of trading partners separately. Consumer (and producer) surplus is calculated by comparing WTP (WTA) with the individual transaction price (not an equilibrium one). The total economic surplus is the sum of consumer and producer surplus. In 
contrast to the approach taken to calculating consumer and producer surplus in the SLUDGE model (Parker and Meretsky, 2004), this approach allows us to examine how consumer and producer surplus, influenced by relative market power, change as market conditions change.

\subsection{Simulation Experiments}

We performed several experiments with the ALMA model. The model produces spatially explicit rent gradients (i.e., land prices at different distances from the city center) and land patterns. We are mainly interested in how changes in buyers' and sellers' characteristics, environment, and trading strategies affect economic indicators and the spatial morphology of the city.

\subsubsection{Macro-scale outcome measures}

In addition to graphical representations, we also present a set of metrics to analyze micro and macroeconomic and spatial outcomes, including:

- Individual utility: the average individual satisfaction from the consumption of a good of a certain quality (characterized by certain parameters such as distance or environmental amenity), estimated as an average of individual utilities from Equation 4.3;

- Aggregated utility: the total utility of all individuals settled in the city, estimated as the sum of the utilities of urban inhabitants (excluding agricultural users). This metric is often used as a measure of social welfare;

- Buyer's bid price: the average bid price for urban land, estimated as an average of individual bid prices (Equation 4.6). This metric allows us to analyze how bid prices change depending on pricing strategy;

- Urban land price: the average transaction price in the city. The transaction price for the bilateral trade is an arithmetic average of a bid and an ask price. We are interested in how the transaction price changes depending on whether buyers or sellers account for the market situation;

- Average surplus (for both buyers and sellers): the average amount that buyers (sellers) benefit by buying (selling) a good for a price that is lower (higher) than their WTP (WTA). It is calculated as an average difference between the transaction price and buyer's WTP (seller's WTA). Comparison of the relative proportion of surplus captured by buyers and sellers allows us to analyze how the division of gains from trade changes depending on the market situation. Total economic surplus (i.e., the sum of a buyer's and a seller's surpluses) is also often used as a measure of social welfare; 
- Total property value: the sum of urban land prices in the city. Total property value is important for policy analysis, particularly with respect to property taxes rates and receipts, funding of public goods from property taxes or estimation of the damage from extreme events such as flooding;

- City size: the number of urban inhabitants (excluding agricultural users). City size is a typical characteristic of urban spatial structure often analyzed in urban economics (Strazsheim, 1987);

- Distance at which city border stops: the distance from the CBD of the most remote urban cell, or urban extent. Urban extent is also a typical characteristic of urban spatial structure used in urban economics. In the experiments presented here (with no open-space amenities), it will be closely correlated with city size;

- Estimated land rent gradient: an equation that quantitatively characterizes the realized transaction price at a given distance from the city center, estimated using linear regression analysis. The land gradient is another typical characteristic of urban spatial structure that is analyzed both theoretically and empirically in both urban economics and geography (Strazsheim, 1987; Anas et al., 1998).

All the model experiments presented in this paper were performed on a 29x29 cell landscape. Each experiment was performed 30 times to check the robustness of the simulated results against random effects using a t-test. The ALMA parameters that remain unchanged for all model experiments are listed in Table 4.1; those that were varied between the 6 experiments are listed in Table 4.3. A brief summary of each experiment is presented in Table 4.2. The setup and objective of each experiment are discussed below. Tables 4.4 and 4.5 compare the experiments' outcomes in terms of macro and microeconomic and spatial measures. Metrics for each experiment in Tables 4.4 and 4.5 are average estimates of 30 runs. Outcomes of each on the 30 runs in one parameter space do not change qualitatively. In particular, the standard deviation of total property values between the 30 runs in Exp 4.1-4.2 is equal to 0 and the standard deviation of total property values between the 30 runs of Exp 4.3-4.6 varies from $0.01 \%-0.04 \%$.

Table 4.1: Values of parameters unchanged in the simulation experiments

\begin{tabular}{|l|l|c|l|c|c|c|}
\hline Symbol & $\mathbf{Y}$ & $\mathbf{A}$ & $\mathbf{b}$ & $\mathbf{N}$ of cells & $\mathbf{P}_{\mathbf{a g}}$ & WTA \\
\hline Meaning & $\begin{array}{c}\text { Individual } \\
\text { budget }\end{array}$ & $\begin{array}{c}\text { Level of } \\
\text { green } \\
\text { amenities }\end{array}$ & $\begin{array}{c}\text { A } \\
\text { constant } \\
\text { in (5) }\end{array}$ & $\begin{array}{c}\text { Number of } \\
\text { spatial } \\
\text { goods in a } \\
\text { city }\end{array}$ & $\begin{array}{c}\text { Reservation } \\
\text { price for } \\
\text { agricultural } \\
\text { land }\end{array}$ & $\begin{array}{c}\text { WTA for } \\
\text { agricultural land } \\
\text { without } \\
\text { consideration of the } \\
\text { market situation }\end{array}$ \\
\hline Value & 800 & 1 & 70 & 841 & 200 & 250 \\
\hline
\end{tabular}


Table 4.2: Description of the performed experiments

\begin{tabular}{|l|l|}
\hline Experiment \# & Tested hypothesis \\
\hline Exp4.1 & $\begin{array}{l}\text { An agent-based ALMA model with distributed price determination } \\
\text { mechanisms reproduces the conventional analytical model behavior given } \\
\text { similar assumptions, i.e. structural validation holds. }\end{array}$ \\
\hline Exp4.2 & $\begin{array}{l}\text { Increased tolerance for commuting among buyers (changes in preferences for } \\
\text { distance - } \beta \text { ) causes urban expansion. }\end{array}$ \\
\hline Exp4.3 & $\begin{array}{l}\text { In the case of a "sellers' market" gains from trade will not be divided equally } \\
\text { and the city will expand, assuming that buyers adapt their bid prices based on } \\
\text { the market situation. }\end{array}$ \\
\hline Exp4.4 & $\begin{array}{l}\text { The more often buyers are faced with information about market conditions, } \\
\text { the more likely they are to "panic" and to offer higher bids. }\end{array}$ \\
\hline Exp4.5 & $\begin{array}{l}\text { In the case of a "buyers' market" gains from trade will mostly be captured by } \\
\text { buyers, assuming that sellers adapt their ask prices based on the market } \\
\text { situation. }\end{array}$ \\
\hline Exp4.6 & $\begin{array}{l}\text { The more often sellers are faced with information about market conditions, } \\
\text { the more likely they are to "panic" and to offer lower ask prices. }\end{array}$ \\
\hline
\end{tabular}

Table 4.3: Values of parameters changed in the simulation experiments

\begin{tabular}{|l|l|c|c|c|c|c|c|}
\hline Symbol & \multicolumn{1}{|c|}{ Meaning } & Exp4.1 & Exp4.2 & Exp4.3 & Exp4.4 & Exp4.5 & Exp4.6 \\
\hline NB & number of buyers & 841 & 841 & 925 & 925 & 757 & 757 \\
\hline NS & number of sellers & 841 & 841 & 841 & 841 & 841 & 841 \\
\hline MB & market behavior & $\begin{array}{c}\text { Pure } \\
\text { WTP/ } \\
\text { WTA }\end{array}$ & $\begin{array}{c}\text { Pure } \\
\text { WTP/ } \\
\text { WTA }\end{array}$ & $\begin{array}{c}\text { Buyers: } \\
\text { Market } \\
\text { oriente } \\
\mathrm{d}\end{array}$ & $\begin{array}{c}\text { Buyers: } \\
\text { Market } \\
\text { oriente } \\
\mathrm{d}\end{array}$ & $\begin{array}{c}\text { Sellers: } \\
\text { Market } \\
\text { oriente } \\
\mathrm{d}\end{array}$ & $\begin{array}{c}\text { Sellers: } \\
\text { Market } \\
\text { oriente } \\
\mathrm{d}\end{array}$ \\
\hline Betta & $\begin{array}{l}\text { preference for } \\
\text { proximity to the } \\
\text { CBD }\end{array}$ & 0.85 & 0.7 & 0.85 & 0.85 & 0.85 & 0.85 \\
\hline $\begin{array}{l}\text { N- } \\
\text { buyers } \\
\text { in trade }\end{array}$ & $\begin{array}{l}\text { number of buyers } \\
\text { activated each trade } \\
\text { period, i.e. the } \\
\text { speed of epsilon }(\varepsilon) \\
\text { updating }\end{array}$ & all & all & all & 5 & all & 5 \\
\hline TCU & $\begin{array}{l}\text { transport costs per } \\
\text { unit of distance }\end{array}$ & 1 & 1 & 1 & 1 & 1 & 1 \\
\hline
\end{tabular}


Table 4.4: Economic and spatial metric outcomes of the ALMA experiments

\begin{tabular}{|c|c|c|c|c|c|c|}
\hline Parameter & $\operatorname{Exp} 4.1$ & Exp4.2 & $\operatorname{Exp} 4.3$ & Exp4.4 & $\operatorname{Exp} 4.5$ & Exp4.6 \\
\hline Individual utility: & 65.48 & 66.61 & \multicolumn{2}{|c|}{63.51} & \multicolumn{2}{|c|}{62.19} \\
\hline St.dev & 12.56 & 12.6 & \multicolumn{2}{|c|}{13.29} & \multicolumn{2}{|c|}{13.8} \\
\hline Aggregate utility & 30448.82 & 38431.14 & \multicolumn{2}{|c|}{32836.11} & \multicolumn{2}{|c|}{34391.27} \\
\hline \multirow{2}{*}{$\begin{array}{l}\text { Buyers' bid price: } \\
\text { Mean } \\
\text { St.dev }\end{array}$} & 363.72 & 369.97 & 371.99 & 374.82 & 342.24 & 342.26 \\
\hline & 73.92 & 73.53 & 80.21 & 80.53 & 83.99 & 83.98 \\
\hline \multirow{2}{*}{$\begin{array}{l}\text { Urban land price: } \\
\text { Mean } \\
\text { St.dev }\end{array}$} & 306.86 & 309.98 & 311 & 312.41 & 286.35 & 285 \\
\hline & 36.96 & 36.77 & 40.11 & 40.27 & 44.99 & 45.17 \\
\hline \multirow{2}{*}{$\begin{array}{l}\text { Average surplus } \\
\text { \%:Buyers' } \\
\text { Sellers' } \\
\end{array}$} & $50 \%$ & $50 \%$ & $39.58 \%$ & $38.19 \%$ & $60.59 \%$ & $62.06 \%$ \\
\hline & $50 \%$ & $50 \%$ & $60.42 \%$ & $61.81 \%$ & $39.41 \%$ & $37.94 \%$ \\
\hline $\begin{array}{l}\text { Total property } \\
\text { value }\end{array}$ & 142690.2 & 178860.2 & 160785.6 & 161494.5 & 158350.8 & 157587.1 \\
\hline $\begin{array}{l}\text { City size (urban } \\
\text { population) }\end{array}$ & 465 & 577 & \multicolumn{2}{|c|}{517} & \multicolumn{2}{|c|}{553} \\
\hline $\begin{array}{l}\text { Distance at which } \\
\text { city border stops }\end{array}$ & 12.08 & 13.45 & \multicolumn{2}{|c|}{12.81} & \multicolumn{2}{|c|}{13.15} \\
\hline
\end{tabular}

Table 4.5: Linear regression estimation results of the ALMA model generated data (the transaction price is a dependent variable)

\begin{tabular}{|c|c|c|c|c|c|c|}
\hline Parameter & Exp4.1 & Exp4.2 & Exp4.3 & Exp 4.4 & Exp 4.5 & Exp4.6 \\
\hline $\mathrm{R}^{2}:$ & 0.9905 & 0.9858 & 0.9913 & 0.9899 & 0.982 & 0.982 \\
\hline \multirow{3}{*}{$\begin{array}{l}\text { Intercept: } \\
\text { St error } \\
\text { t-Value }\end{array}$} & 410.76 & 413.2 & 423.9 & 425.68 & 412.39 & 411.57 \\
\hline & 0.09 & 0.1 & 0.09 & 0.1 & 0.14 & 0.14 \\
\hline & 4498.96 & 4136.46 & 4710.81 & 4360.21 & 2936.39 & 2917.12 \\
\hline \multirow{3}{*}{$\begin{array}{l}\text { Distance to CBD: estimate } \\
\text { (slope) } \\
\text { t-Value }\end{array}$} & -12.81 & -11.43 & -13.2 & -13.25 & -14.25 & -14.31 \\
\hline & 0.01 & 0.01 & 0.01 & 0.01 & 0.01 & 0.02 \\
\hline & -1207.2 & -1096.0 & -1330.8 & -1230.6 & -951.96 & -951.55 \\
\hline
\end{tabular}

\subsubsection{Replication and sensitivity analysis of Alonso model}

In this set of experiments we explore how the dynamic land market model behaves. We mainly focus on the tasks raised by research question 1 in Section 4.2 above.

Experiment 4.1: The purpose of this paper is first to replicate the benchmark case of the analytical Alonso model (i.e. perform structural validation), and then, moving from this comparison baseline, to demonstrate the valued added from the agent-based approach. Summarizing the baseline assumptions of ALMA-v1.0, buyer agents have homogeneous preferences for proximity to the $\mathrm{CBD}$ and bid their willingness to pay, which is based on their preferences for proximity, their 
budget, and the transport cost to their preferred cell. Sellers, i.e. owners of agricultural land, each offer land at the same fixed price. Neither buyers nor sellers account for the market situation (i.e., for epsilon). The main difference between this simulation experiment and the analytical model is that the centralized land price determination mechanism is replaced by a series of spatially distributed bilateral trades. However, since agents are homogeneous and no market situation is accounted for while bidding, our model reproduces the standard Alonso pattern of land rents predicted by the analytical equilibrium, meaning that transaction prices are equal for all cells at equal distance from the CBD. The results from the replication of the Alonso model are presented in column "Exp4.1" of Table 4.4. The spatial form of the city and urban land rent gradient are presented in Figures 4.5.a and 4.5.b respectively.

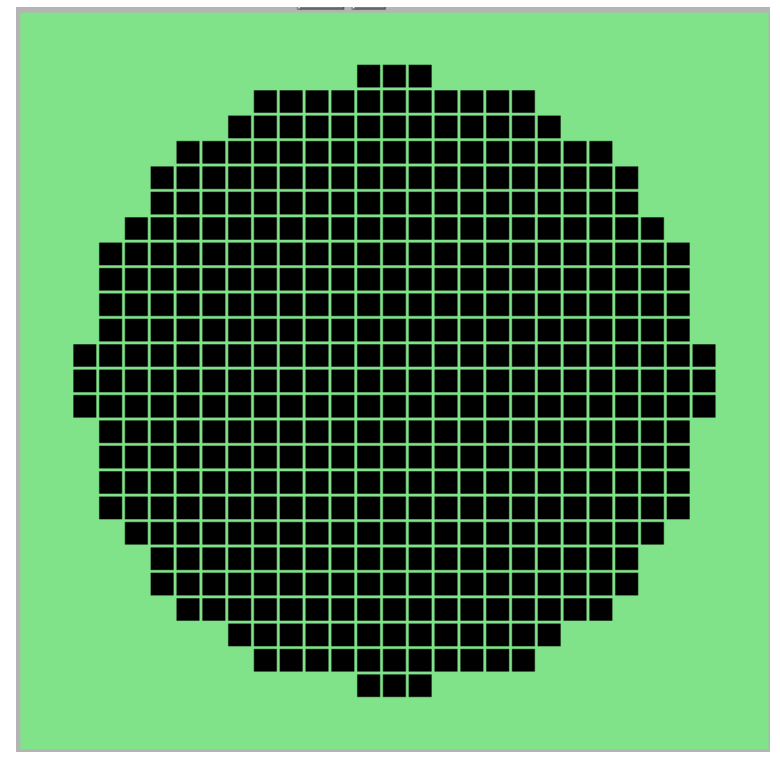

a: Spatial form of a city

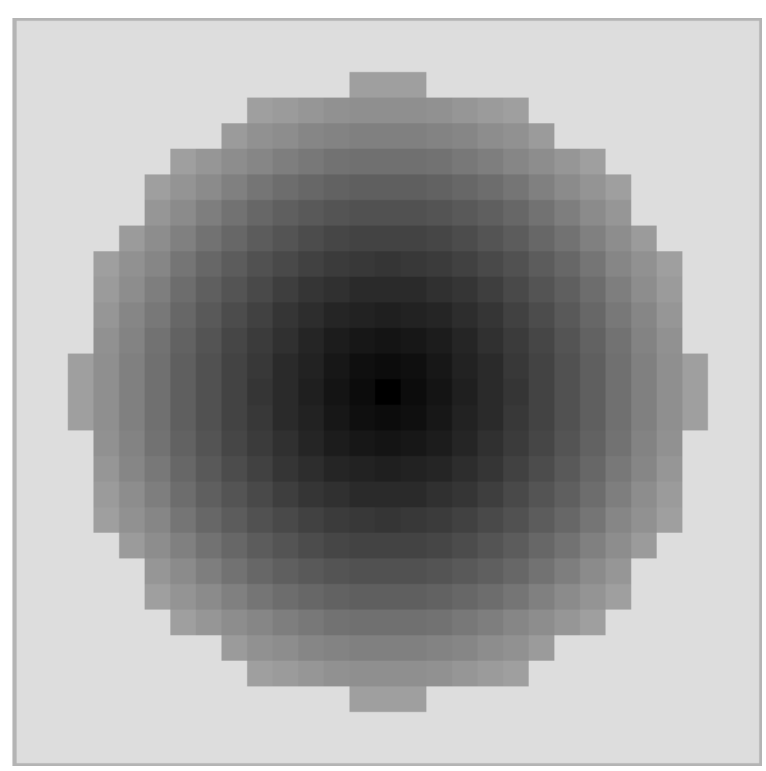

b: Land rent gradient

Figure 4.5: Exp4.1, Replication of the Alonso model

The green area in Figure 4.5.a represents agriculture and the black is urban area. The intensity of grey color in Figure 4.5.b symbolizes the value of land: the darker the color, the higher the land price. As in the benchmark case of a theoretical monocentric urban model, land prices are higher closer to the CBD, and the land rent gradient is decreasing with distance. The urban land price is equal for cells that are equidistant from the CBD (as seen in Figure 4.5.c). The city expansion stops at the location where bid price of a buyer falls below the agricultural rent $\left(\mathrm{P}_{\mathrm{ask}}=250\right)$. The lightestgrey area in Figure 4.5.b shows the beginning of the agriculture area (urban-rural fringe) and symbolizes the city border. Note that not all of the buyers in the model ultimately purchase properties (only 465 of the 841 buyers engage in transactions). The parameter settings for Exp4.1, then, replicate an open city model, where buyers are assumed to have the opportunity to purchase a property in another location, if their WTP for available properties in this region is below the WTA 
of the current landowners. We did other experiments with the ALMA model, such as changes in income or increase in transportation costs - traditional tests performed with analytical urban models. As in the base case described in Exp4.1, the ALMA model reproduces qualitative results of the conventional equilibrium model.

We estimated a functional representation of the rent gradient through a linear regression analysis of the model-generated data. We tried several functional forms including linear, log-log (both sides of the equation are in logarithms), semi-log (the dependent variable is in logarithm and the right hand side is in linear forms) and inverse semi-log form (the dependent variable is linear and the right hand side is in logarithms). The $\mathrm{R}^{2}$ values from these four model specifications are $0.9905,0.9764,0.8599$ and 0.8236 respectively. ${ }^{28}$ The results of the linear regression model, which showed the best fit, are presented in Table 4.5 and in Figure 4.7. The graphic of the regression line together with the transaction data from Exp4.1 is presented in Figure 4.7 (the blue line and scatter points).

Experiment 4.2: We now wish to conduct a sensitivity analysis of how buyer preferences influence our proposed metrics (Table 4.4) and change the slope of a rent gradient (Table 4.5 and Figure 4.7). The setup Exp4.2 is identical to Exp4.1 (see Table 4.3), but with a lower preference for proximity to the CBD for buyer agents (particularly $\beta=0.7$ instead of 0.85 ), which can also be interpreted as a higher tolerance for commuting. The first difference in results from Exp4.1 manifests itself in the spatial morphology of the city, as seen from comparison of Figures 4.6.a and 4.5a. The city border has expanded (shifted from 12.08 spatial units in Exp4.1 to 13.45 in Exp4.2), and the urban population has increased (from 465 to 577) as can be seen from Table 4.4. The land rent gradient (Table 4.5) is decreasing with distance as in Exp4.1. However, the prices of cells at the same distance from the CBD in Exp4.1 and Exp4.2 differ due to the difference in preferences (compare land prices in Figures 4.5.c and 4.6.c). The price of the most central cell is the same (due to the normalization of distance in the utility function), but the prices of more remote cells are higher in Figure 4.6.c than in Figure 4.5.c — with a higher tolerance for commuting, the buyers' willingness to pay for remote cells has increased. Moreover, the price difference between two experiments increases with the distance from the CBD, which is consistent with the concavity of the utility function with respect to proximity (See Figure 4.6 as well). This result demonstrates the advantage of including a preference for proximity in the utility function, as was the case with the original Alonso model, rather than simply using transportation costs as a proxy for commuting disutility. Average land price is higher in Exp4.2 than in Exp4.1 (explained by the higher rent

\footnotetext{
${ }^{28}$ Although the linear model is the best fit for these data, it is clear from Figure 4.8 that the data-generating process is not exactly linear. Identification of an exact functional form representing the data-generating process is an agenda item for future work. For the purposes of this paper (comparison and discussion of the qualitative properties of the generated land rent gradients), the fit of the linear model is sufficiently good.
} 
gradient), and total property value in the city is also higher (explained by the greater urban expansion) (see Table 4.4). The result is statistically significant at the $99 \%$ confidence level as confirmed by the t-test (see Appendix B). Since buyers have a higher tolerance for commuting they are more willing to buy land in the remote areas. Thus, buyers in Exp4.2 are willing to pay more for housing at a given distance from the CBD than are buyers in Exp4.1 at the same location, and they also can offer bids higher than sellers' ask prices on properties at higher distances from the CBD. The result is higher average bid prices in Exp4.2 (the average bid price is 363.72 and 369.97 in Exp4.1 and Exp4.2, respectively).

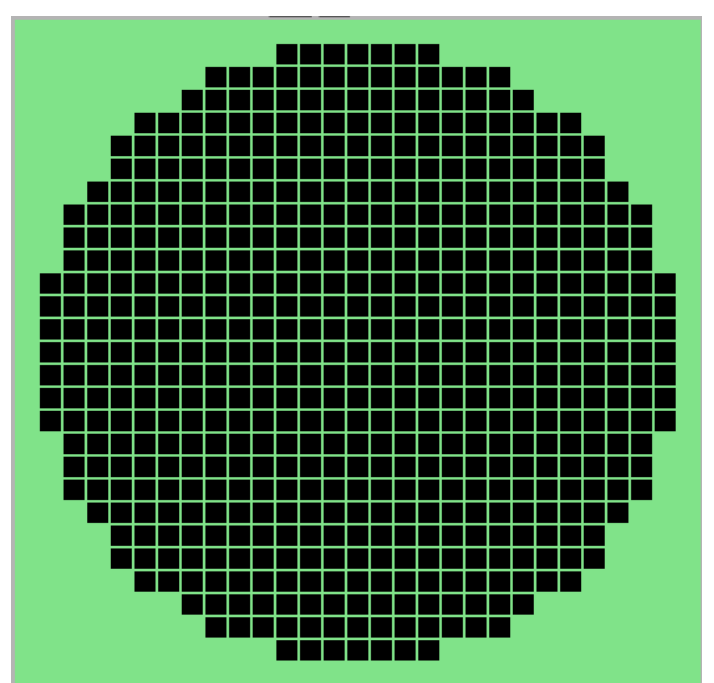

a: Spatial form of a city

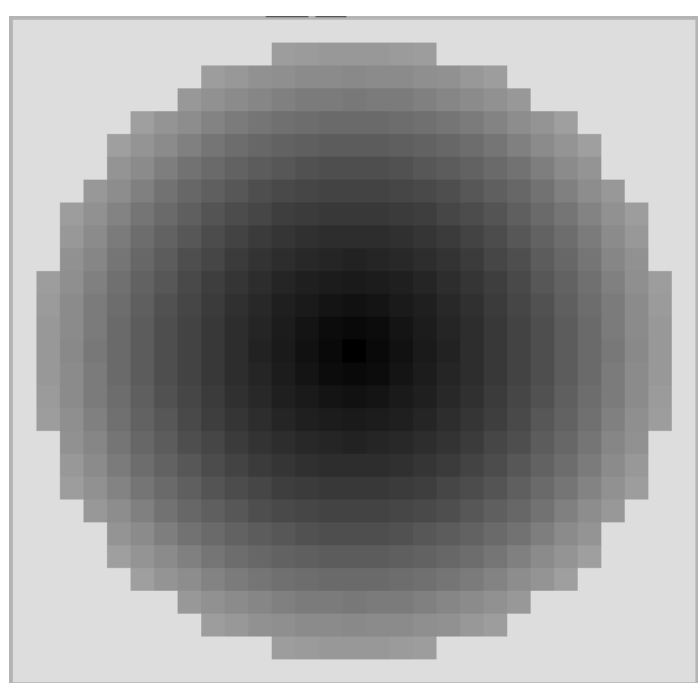

b: Land rent gradient

Figure 4.6: Exp4.2, Preferences for proximity are lower than in Exp4.1 in Figure 4.5

To compare the land rent gradients between Exp4.1 and Exp4.2, we again estimated the land rent gradient for the computer-generated data from Exp4.2. The linear regression model again showed the best fit in comparison to other functional forms (the $\mathrm{R}^{2}$ is 0.9858 in comparison to 0.9696, 0.8430 and 0.8061 of $\log -\log$, semi-log and inverse semi-log forms respectively). Consistent with the results described above, the regression coefficients in Table 4.5 for Exp4.1 and Exp4.2 differ. A visual comparison of a regression analysis of the computer generated data (Table 4.5) from Exp4.1 and Exp4.2 is presented in Figure 4.7. The supply curve of agricultural agents is a constant line (equal to 250 in our settings) parallel to the axes $O X$. The point at which the regression line and the line $y=250$ cross shows the distance at which city expansion stops, i.e. at which the transaction price is lower than sellers' ask price. Both estimated rent gradients are downward slopping, meaning that land price is deceasing with distance from the CBD, as in the Alonso bid rent theory. However, as expected, the slope of the rent gradient (the regression coefficient for distance to the CBD) for Exp4.1 is higher in absolute value than the slope of the rent gradient from Exp4.2 (Table 4.5); i.e. the bid rent curve in Exp4.1 is steeper than in Exp4.2. The gap between the estimated rent gradients also increases with distance from the CBD, consistent with the explanation 
presented above--at higher distances from the CBD the more commuting-tolerant buyers will always bid higher than the people with strong preferences for proximity to the CBD.

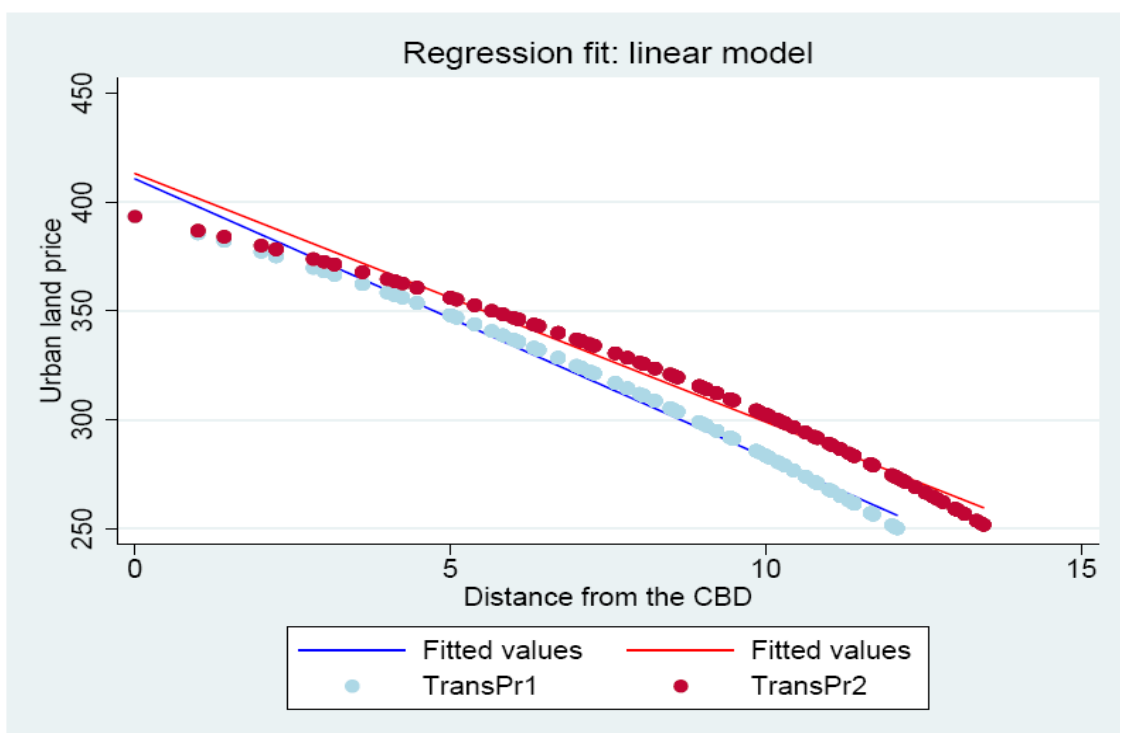

Figure 4.729. Land rent gradients for Exp4.1 and Exp4.2, linear regression fit of the computer generated data

TransPr1(2) - actual land transaction prices from Exp4.1(Exp4.2 - lower preferences for proximity), Fitted value - estimated land rent gradient

\subsubsection{Market-oriented buyers and sellers}

In the previous experiments, we have run ALMA-v1.0 with traders who do not account for the relative power of buyers and sellers, i.e. for epsilon in Equations 4.6 and 4.7. Both householdbuyers and agricultural sellers thus revealed their true WTP and WTA while submitting bids and asks to the market (see Figures 4.1 and 4.2). In the next few experiments, we implement another market behavior: instead of revealing their pure WTP/WTA, agents adjust their bids and asks depending on whether it is a sellers' or a buyers' market-in other words, they become marketoriented. In order to answer the second research question from Section 4.2 above, we analyze macro-scopic model outcomes from experiments that implement different pricing strategies at micro-level. We increase or decrease the number of buyers in the land market to replicate buyers' or sellers' markets, activating $\varepsilon$ in Equation 4.6 when the number of buyers exceeds the number of sellers, and activating $\varepsilon$ in Equation 4.7 when the number of sellers exceeds the number of buyers. Code verification using the parameter settings for Exp4.1, but de-activating $\varepsilon$ (so that agents submit bids and asks without accounting for the market power of each other) confirmed that unequal numbers of buyers and sellers at the land market did not affect outcomes for homogeneous agents, as expected.

\footnotetext{
${ }^{29}$ The graph shows the comparison of estimated rent gradients of two representative runs of Exp 4.1 and Exp 4.2
} 
Experiment 4.3: In this experiment we investigate how the morphology of the city and economic indicators will change if buyers change their bidding strategy in a "sellers' market" environment. We assume that while forming their bid price, buyers account for the market situation (i.e., account whether it is a buyers' or a sellers' market). We run ALMA-v1.0 with a higher number of buyers (10\% more than sellers; see Table 4.3 for parameter settings). In this case, buyers realize that sellers have relative market power and that buyers have to compete for the spatial good, since there are more buyers willing to buy the good than there are goods on the market. Per Equation 4.6, they therefore increase their bid price above their initial willingness-to-pay in response (but still do need exceed their budget constraint). Agricultural sellers set their ask price at the price of agricultural land, i.e. equal to 250 as in previous experiments. The land rent gradient and spatial form of the city are shown in Figure 4.8. The simulated land rent gradient is reported in Table 4.5 and illustrated in black in Figure 4.10.

Over the time steps of the model run, buyers incrementally raise their bid prices and are willing to buy land further from the CBD even if they originally (in Exp4.1) would value it less then the $P_{a s k}$. This temporal increase in the bid price can be viewed as an emergent model outcome, since it is the result of interactions between bidding agents. While the behavioral rule that bid prices will depend on buyer/seller ratios operates at an individual level, the implementation of this behavioral rule depends on the previous decisions of other agents (on the global state of the system). The average bid price (not to be confused with the final transaction price) has increased by 8.27 monetary units in comparison to the average bid price in Exp4.1 (see Table 4.4). The result is statistically significant at the $99 \%$ confidence level as confirmed by the t-test (see Appendix B). As a result of sellers' market power and buyers' competition, there is a significant change in the relative proportion of buyers' and sellers' surplus. In the case when buyers bid only on the basis of their utility (Exp4.1-Exp4.2), the proportions of surplus captured by buyers and sellers are equal. However, when sellers have more market power, they capture a higher proportion of gains from trade $(60.42 \%$ vs. $39.58 \%)$, making themselves better off.

In comparison with the outcome of Exp4.1, the city has expanded (compare Figures 4.5.a and 4.8.a). The city border has shifted from 12.08 spatial units to 12.81 in Exp4.1 and Exp4.3 respectively. The urban population has increased by $11.2 \%$. The total value of the property in the city increased as well. The land rent gradient still follows the Alonso predictions, i.e. the rent decreases with the distance. However, the structure of the land rent gradient differs from Exp4.1; prices for land at the same distance from the CBD are not always equal, since buyers bid for the parcels at different time steps, each having a different market structure (different value of $\varepsilon$ ). Thus, if equilibrium in the land market is not achieved in one shot but is rather distributed (prices are 
determined in the bilateral trades in different moments in time), and if market participants respond to the relative market power of other participants, then prices for spatial goods with the same characteristics might not be homogeneous, even with homogeneous traders. This result differs from that of the traditional equilibrium-based theoretical model that assumes a centralized price determination mechanism such as a Walrasian auctioneer, which will predict that prices for a good of equal quality consumed by homogeneous economic agents will be the same. Sensitivity analysis (not presented here) demonstrated also that the larger the gap between the number of buyers and sellers in the market the larger the deviation of land prices in Exp4.3 (Figure 4.9.b) from Figure 4.5.c.

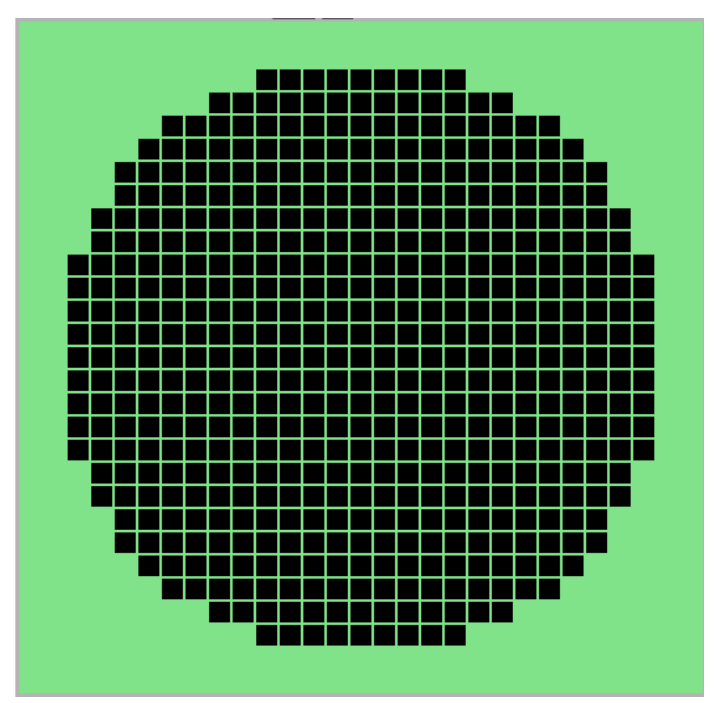

a: Spatial form of a city

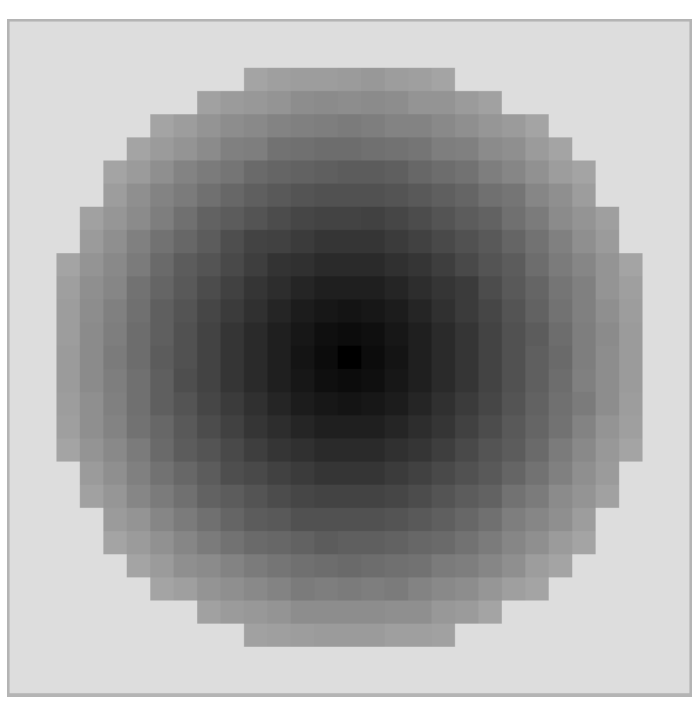

b: Land rent gradient

Figure 4.8: Exp4.3, Buyers competition in a sellers' market

Experiment 4.4: Now we would like to show how the speed of $\varepsilon$ updating (from Equation 4.6) influences the model outcome. Our hypothesis is that the frequency with which agents received updated information concerning the market situation will affect the evolution of prices. The setup for this experiment is basically the same as in Exp4.3 except for changes in the buyer activation regime. In Exp4.3, all the buyers initialized in the model can participate in the market (see Section 4.3.4 for discussion) in the first time step of the model. The value of $\varepsilon$ is updated once per time step (see Figures 4.3 and 4.4), using the total number of buyers and sellers participating in a market (the original number of each, minus the number of each who have successfully completed a transaction in the last time step). In Exp4.4, we allow fewer buyers to participate in market transactions in each time step. This means that the variable $\varepsilon$ will be updated more frequently. In other words, buyers will have access to more accurate information regarding excess demand. More significantly, buyers have more frequent opportunities to update their bids to reflect new market conditions. (Note, however, that the number of buyers who are searching for properties (NB) is different than the 
number of buyers activated in each time step.) This situation could be viewed as that of a seasonal market, where some buyer agents enter earlier than others, and later buyers form bids based in part on their perception of current market conditions. Essentially, market prices are path dependent in the market-oriented pricing situation - the bid in a particular time period depends on the market situation in the previous time period. We run Exp4.4 with only 5 buyers activated per time step. The results of this experiment run are presented in column Exp4.4 of Table 4.4.

The spatial form and spatial metrics of the city stay exactly the same as in Exp4.3 (see Figure 4.8.a and Table 4.4 column for Exp4.3), as does average individual utility in the city. (Intuitively, utility is separate from bid price: having paid more for the property, the buyer still receives the same level of utility.) The differences between the experiments are manifested in land prices. Land prices again are decreasing with distance to the CBD but even less gradually than in Exp4.1 and Exp4.3. Figures 4.9.a and 4.9.b show land prices as the outcome of Exp4.3 and Exp4.4 respectively. All the parameters stay the same in these two experiments except for the speed of information provision to the buyers. As a result, buyers in Exp4.4 were willing to bid higher prices for the same houses as in Exp4.3. For example the most central land lot in Figure 4.9.b (from Exp4.4) was purchased for 409 monetary units in Exp4.4 in contrast to 406 in Figure 4.9.a (from Exp4.3). The price for almost every cell in Figure 4.9.b is higher than in Figure 4.9.a. As a result, the aggregate economic measures in Table 4.4, such as average bid price and urban transaction land price, are higher in Exp4.4 than in Exp4.3. The result is statistically significant at the $99 \%$ confidence level as confirmed by the t-test (see Appendix B). Most important, the division of gains from trade has changed: now sellers capture even more of the total economic surplus from the transaction than in Exp4.3.

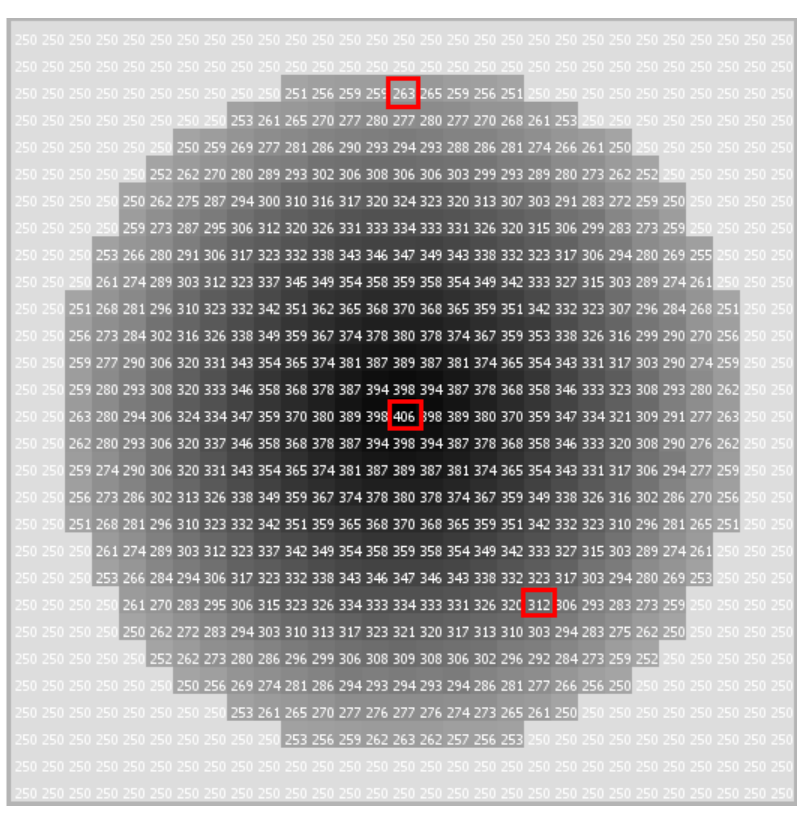

a: Land prices, Exp4.3

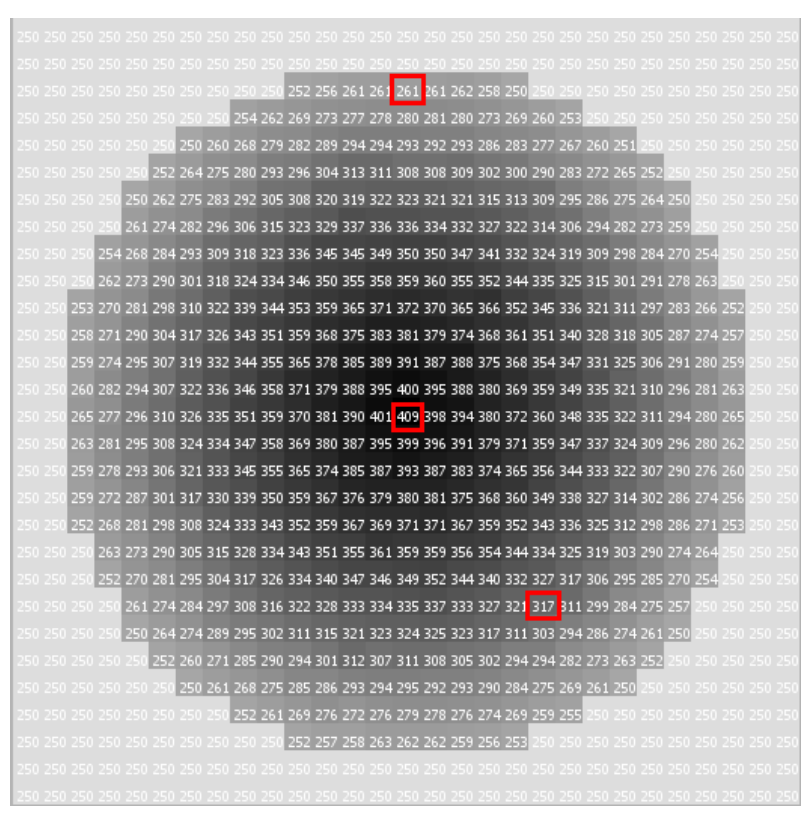

b: Land prices, Exp4.4

Figure 4.9: Influence of the speed of $\varepsilon$ updating on the land prices at a sellers' market 
Figure 4.10 shows land rent gradients estimated using the simulated data from Exp4.4 (Estimates in Table 4.5). The red dots and red line represent the transaction prices and estimated land rent gradient, respectively, in Exp4.4. We compare the estimated land rent gradient to those from Exp4.3 (the black line) and Exp4.1 (the blue line). Both land rent gradients from Exp4.3 and Exp4.4 are much higher than the land rent gradient from Exp4.1, meaning that buyers bid higher at all distances from the CBD in Exp4.3 and Exp4.4. At the same time, we can see that the black line is a bit below the red line; i.e. buyers from Exp4.4 would outbid buyers from Exp4.3. The only reason for this is the increased speed of information about the market situation provided to buyers at the moment of their bid formation, and the corresponding increased speed of updating of bids.

Interestingly, one of the conclusions from this experiment might be that if there is a sellers' market and information about this fact is provided more often to the buyers (e.g. via newspapers or by real estate agents) then buyers will increase their bids for the same type of house, raising housing prices in a kind of "artificial panic". So, simply news of a high demand excess can create the effect of a housing bubble, causing prices to rise without an underlying economic rationale. This implies a certain set of incentives for real estate agents. If they want to increase the final transaction price (and the share of it they capture as their fee) they might want to emphasize that there is a demand excess in a particular housing market. In early presentations of ALMA, we received many comments about the importance of real estate agents to the dynamics of bid and ask price formation. This updating mechanisms, and the conclusions that it implies, is a first step toward more formal exploration of their potential role in housing market dynamics

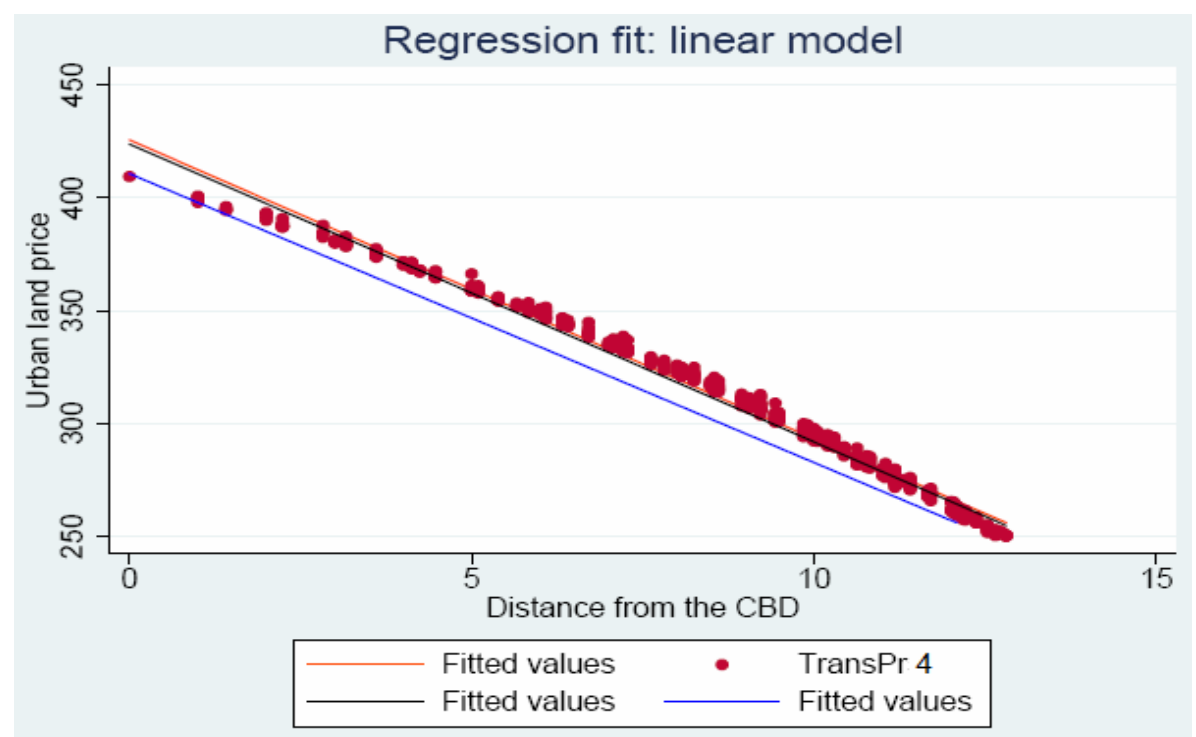

Figure 4.10 ${ }^{30}$. Land rent gradients for Exp4.1, Exp4.3 and Exp4.4, linear regression fit of the computer generated data TransPr4 - actual land transaction prices from Exp4.4, Fitted value - estimated land rent gradient: blue - for Exp4.1, black - for Exp4.3, red - for Exp4.4

\footnotetext{
${ }^{30} 30$ The graph shows the comparison of estimated rent gradients of two representative runs of Exp4.1, Exp4.3 and Exp4.4
} 
Experiment 4.5: In the previous experiment, we assumed that the number of buyers was higher than the number of sellers. Here we investigate the opposite situation: there are more sellers than potential buyers. Thus, buyers have market power in this land market. Now sellers are competing, and in order to be able to sell their agricultural lots they adjust their ask price depending on the market situation (i.e., $\varepsilon$ in (7); again note that $\varepsilon$ is activated only on the seller side). The economic metrics are presented in Table 4.4 and the spatial form of the city as well as land rent gradient are shown in Figure 4.11. The estimated land rent gradient is illustrated in Figure 4.12 and reported in Table 4.5 .

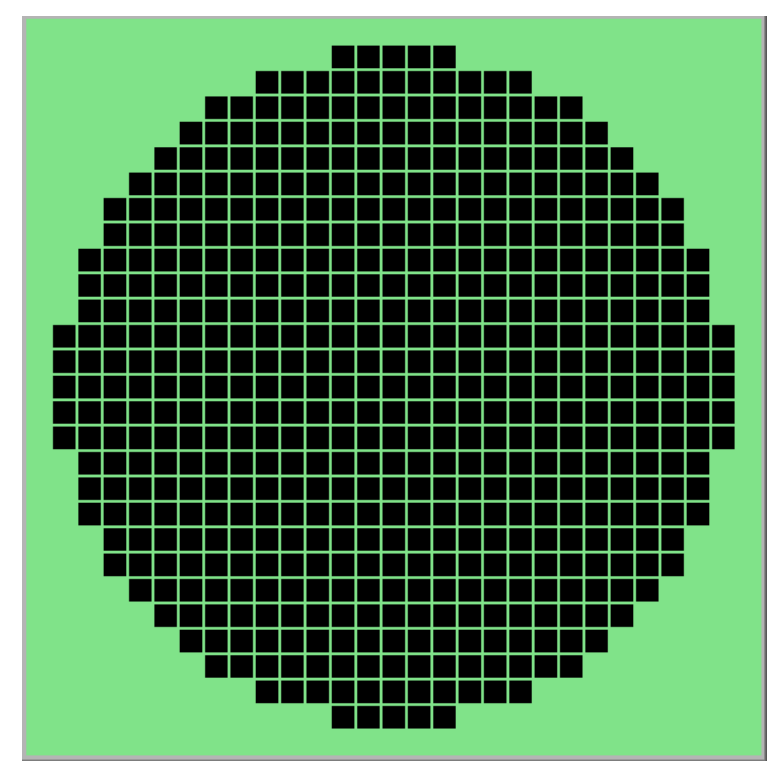

a: Spatial form of a city

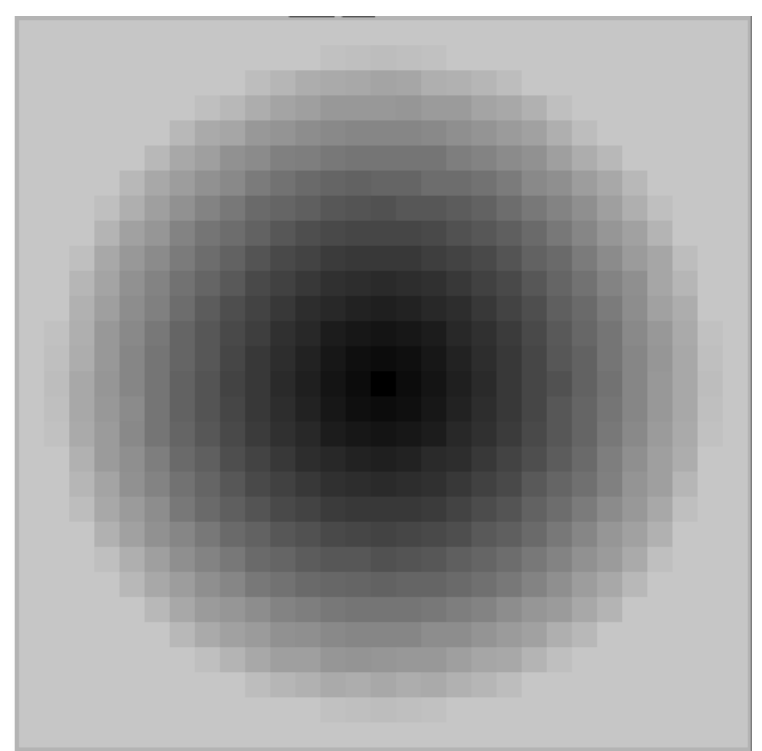

b: Land rent gradient

Figure 4.11: Exp4.5, Sellers' competition in buyers' market

In this market regime, sellers gradually decrease their ask price until it reaches agricultural land price. Since ask prices decrease, land at higher distances becomes more affordable for buyers. Thus, remote areas are converted into urban use, and city expands in comparison to Exp4.1 (compare Figures 4.11.a and 4.5.a). The city border expands as long as the buyers' highest bid is above sellers' reservation price. The average transaction price for land has decreased by $5.9 \%$ in comparison to Exp4.1 data (see Table 4.4). The decrease in land prices can also be seen in Figure 4.11.b, where the colors of land rent gradient became less intense in comparison to Figure 4.5.b. The result is statistically significant at the $99 \%$ confidence level as confirmed by the t-test (see Appendix B). Buyers have more market power in this situation and land prices are determined in their favor. As a result, average seller's surplus has decreased significantly in comparison to Exp4.1 (60.59\% to buyers and $39.41 \%$ to sellers). As we can see from the estimated land rent gradients from Exp4.1 and Exp4.5 (Figure 4.12) the latter is lower than the former (see Table 4.5 for quantitative measures). 


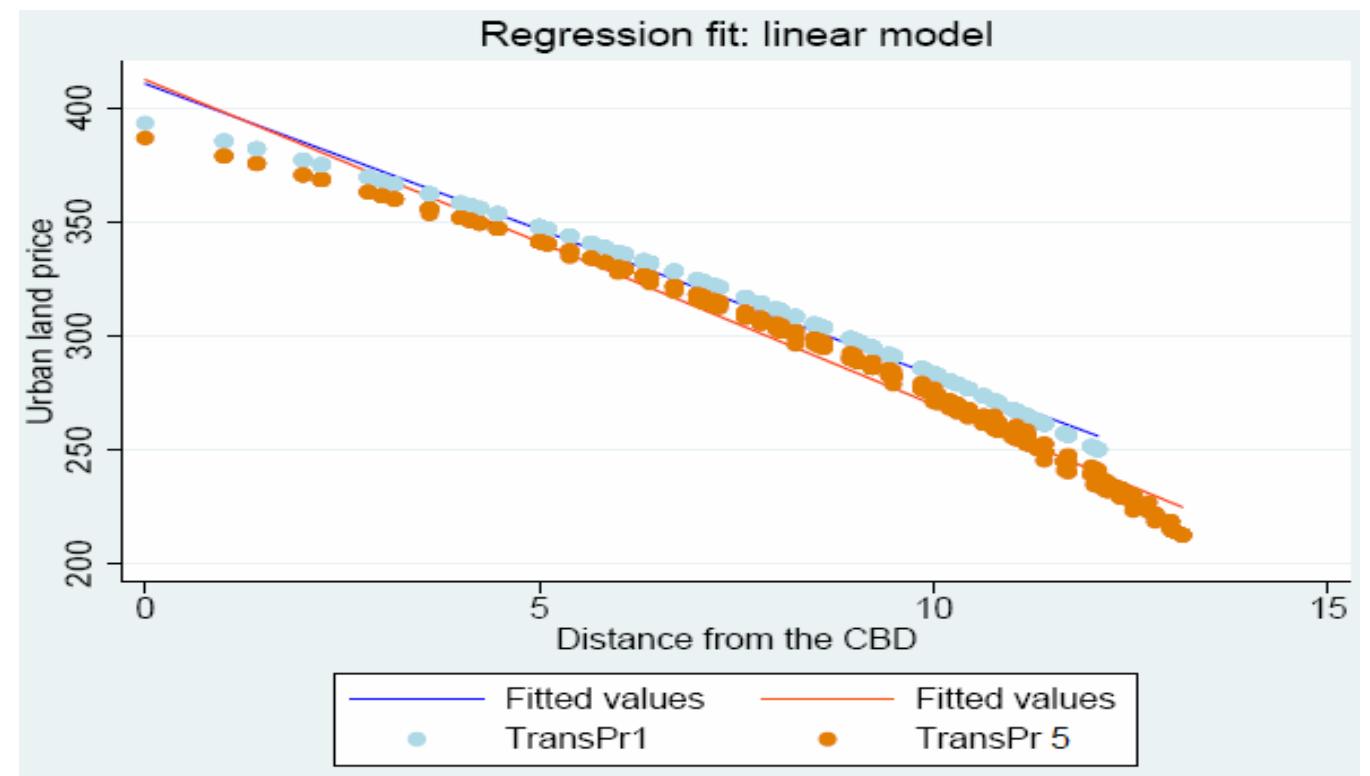

Figure 4.12 ${ }^{31}$. Land rent gradients for Exp4.1 and Exp4.5, linear regression fit of the computer generated data

TransPr 5 - actual land transaction prices from Exp4.5,

Fitted value - estimated land rent gradient: blue - for Exp4.1, orange - for Exp4.5, dark green - for Exp4.6

Experiment 4.6: Finally, we ran ALMA with the same settings as in Exp4.5 but with a changed activation mode, replicating the logic of Exp4.4. Basically, we changed the number of buyers activated each time step in order to increase the speed of $\varepsilon$ updating (from Equation 4.7). We explore a buyers' market again but assuming that sellers more frequently update information about the market situation and integrate this information while forming their ask prices.

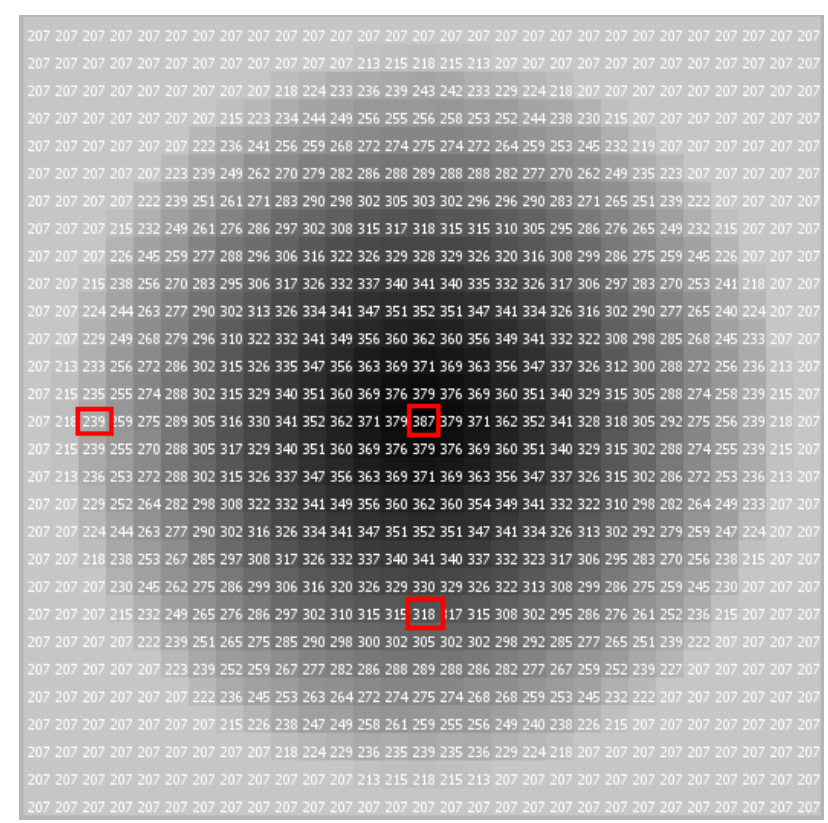

a: Land prices, $\operatorname{Exp} 4.5$

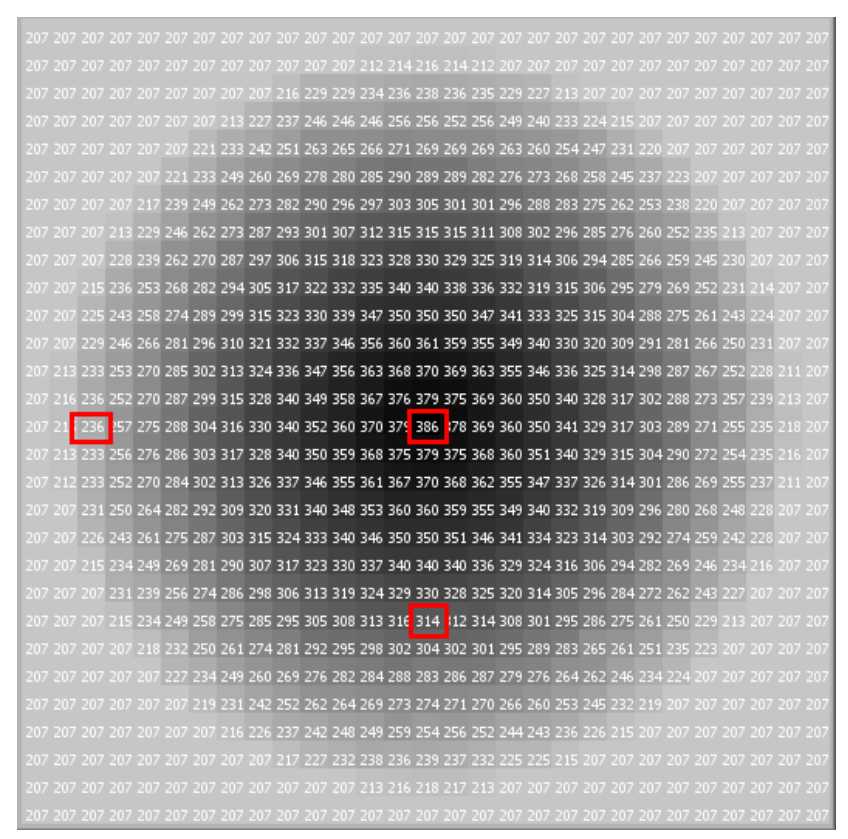

b: Land prices, Exp4.6

Figure 4.13: Influence of the speed of $\varepsilon$ updating on the land prices at a buyers' market

\footnotetext{
${ }^{31}$ The graph shows the comparison of estimated rent gradients of two representative runs of Exp4.1, Exp4.5 and Exp4.6
} 
The spatial form of the city stays exactly the same as in Exp4.5, but the land rent gradients change. Prices become even lower than in Exp4.5 (see Table 4.4 and Figures 4.13.a and 4.13.b for comparison). The estimated land gradient for Exp4.6 is a bit below the one from Exp4.5 (compare green and orange lines in Figure 4.12, see Table 4.5 for quantitative measures). The result is statistically significant at the $99 \%$ confidence level as confirmed by the t-test (see Appendix B). Thus, when sellers receive a consistent flow of information that it is a buyers' market and update frequently in response, they decrease their ask prices to attract potential buyers. Again, experiments with the speed of $\varepsilon$ updating highlight the importance of the role of the role of information in the market and reinforce our interest in future exploration of the role of real estate agents, who serve as information providers for both sellers and buyers.

\subsection{Discussions and conclusions}

In this paper, we have presented an agent-based land market model that, in its simplest form, replicates the qualitative properties of the standard equilibrium-based monocentric urban market model. We have demonstrated that both micro-scale and macro-scale model behaviors conform to the qualitative behaviors of the standard model. The WTP of buyer agents follows traditional rules, increasing with income, the relative prices of other goods, and the utility gained from the housing good, and decreasing with transportation costs. The model reproduces the standard result that when homogeneous traders operate in a homogeneous landscape, transaction prices (land rents) are the same at locations equidistant from the $\mathrm{CBD}$, and land rents decline monotonically as distance from the CBD increases. The land rent gradient is estimated through regression analysis, using our generated transaction prices as the dependent variable, and distance as the independent variable. The extent of the urban area is determined by the location where the bid of the highest-value buyer is just equal to the willingness-to-accept of the seller (the opportunity cost of land in a non-urban use).

This replication exercise can be viewed as a sensitivity analysis or structural verification, ensuring that the model operates as intended, through comparison to an existing alternative theoretical model. We anticipate that the added value of the modeling effort will be seen as we move forward from this point. In, fact, it is the features of the model that relax the restrictive assumptions of traditional equilibrium models that will provide its utility. Moving beyond traditional models, our model separates the underlying valuation of buyers and sellers (their WTP and WTA) from their bid and ask prices, facilitating modeling of strategic pricing behavior, and analysis of the division of gains from trade under different market circumstances. The movement away from a pure optimization framework allows us to explore boundedly rational formation of bid 
and ask prices, as influenced by inductive updating of price expectations (see Parker and Filatova (2008) for more details). The ability to generate realized transaction data that can be used to estimate rent gradients through regression analysis allows us to more closely link our theoretical models to real-world data. Essentially, we have created a computational laboratory in which we have a full understanding of the agent-level and spatial factors that influence bid prices, ask prices, and realized transactions. This laboratory lets us explore the statistical predictions that emerge from these models, creating an opportunity for greater understanding of the potential processes that have generated the transaction data that we observe in the real world.

In this paper, we explore the implications of the model's ability to separate WTP (WTA) and bid price (ask price) formation for urban morphology and land prices. Starting from a baseline case where both buyers and sellers bid their true valuations, and gains from trade for successful transactions are evenly divided, we model bid and ask prices as depending on the relative market power of buyers and sellers. In this model, bid and ask prices adapt as market conditions change. We demonstrate that this process of price adaptation results in heterogeneous transaction prices over time for properties of the same quality (distance from the CBD in this simple case). It also results in conversion of properties that would not have been converted in the previous situation (more urban expansion). Finally, it results in a higher proportion of the gains from trade from transaction accruing to the market agents who have relative market power.

We then decrease the number of market participants in each time step (or, effectively, increase the speed at which participates update their bids). We show that this more frequent updating again increases prices for properties the same distance from the CBD. It also increases the proportion of gains from trade that accrue to the agents with relative market power. This result implies that more frequent provision of information to buyers and updating of bid prices leads to higher prices, creating an obvious incentive for agents in the market who benefit from higher prices to increase the intensity of provision of market information.

One interesting result of our analysis is that market-oriented pricing behavior on either the buyer or seller side leads to expansion of the urban area, although in one case land prices increase relative to the baseline (the sellers' market), and in the other they decrease. This result underlines the importance of modeling bid and ask price dynamics, rather than just assuming an equilibrium price that would result in the capture of equal gains from trade by both market participants. When either side has some relative market power, the result of the decreased bargaining power on the other side leads to more market transactions, and expansion of the city. Given the irreversible effects of conversion of rural land to urban uses, this finding is significant, although its full implications deserve more detailed consideration. 
We plan several future directions for this model, including:

- Exploration of the effects of open-space amenities, including interactions between heterogeneous agent preferences and spatial heterogeneity;

- Modeling price expectation formation based on rates of change of prices (globally and within neighborhoods), as described in Parker and Filatova (2008; 2008);

- Modeling the decision of buyers and sellers to enter and leave the land market. The current model, ALMA-v1.0, is focused mainly on the exploration of land market dynamics and changes of economic and spatial macro-outcomes depending on the changes in microsettings. There is an extensive literature on triggers for urban relocation (Clark and Van Lierop, 1987; van der Vlist et al., 2002). These motives could be included in the ALMA model;

- Modeling the optimal time to enter the land market and the dependence of agents' desire to sell or to buy a spatial good on agent-level factors (financial, social tension etc);

- Introduction of a "real estate" agent. This may be a natural way to model the process of learning about prices (Kirman and Vriend, 2001; LeBaron, 2001; Nicolaisen et al., 2001; Tesfatsion, 2006) in a land market context. It will also afford an opportunity to further explore the influence of information on the pricing strategies of traders. 


\subsection{APPENDIX A: Properties of the demand curve}

In what follows, we would like to explore the properties of the buyer's willingness to pay (WTP, from Equation 4.5) and to compare these properties to the properties of the traditional demand curve from microeconomics. This process serves two purposes. First, it allows us to gain a better understanding of the operation of our model at the micro (agent) level. Second, in keeping with our goal of replicating a standard economic analytical model, it ensures that the micro-level behavior of our model is consistent with the micro-level behavior assumed by the Alonso model. To derive some predictions of how our WTP function changes as its exogenous parameters change, we performed "comparative statics" analysis by estimating first-order derivatives of Equation 4.5 with respect to each parameter, while holding all others constant. The sign of the derivative describes the qualitative response of the WTP function to a change in the exogenous parameter. If negative, WTP falls; if positive, it increases.

1. Income effect: Microeconomic theory predicts that for normal goods an increase in income results in an increase in willingness to pay (demand).

$$
\frac{\partial W T P}{\partial Y}=\frac{u^{n}}{b^{n}+u^{n}}>0
$$

This result is in line with microeconomic demand theory, in which an increase in income results in a positive change in the WTP, i.e. the demand curve shifts up. This fact means that if a buyer's purchasing power increases, her WTP also increases.

\section{Changes in total utility:}

Although a buyer's level of utility is not observed in the real world, willingness to pay for the good is often used as an observed indicator to represent people's choices, for example in environmental economics. In theory, consumers are willing to pay more for those goods that bring them higher utility. Thus, a buyer's WTP for a spatial good that provides a higher level of utility should be higher than that for a spatial good that offers a lower level of utility. Certainly, this level of utility depends on other factors such as the level of the attributes given by the spatial good, and the buyer's preference weights for these attributes. We examine the effects of the preference weights below. However, to ensure the generality of the model, we first confirm that WTP is increasing with the utility provided by a particular good.

$$
\frac{\partial W T P}{\partial U}=\frac{n \cdot Y \cdot b^{n} \cdot U^{n-1}}{\left(b^{n}+U^{n}\right)^{2}}>0
$$

WTP increases as the utility of the good increases. An individual is willing to pay less for a spatial good that brings her lower utility and more for the one that brings her higher utility.

3. Preference for proximity effect: Again, in the real world, individual preferences, as well as utility itself, are unobserved. Nevertheless, intuition would predict that higher relative consumer preferences for an attribute of a good lead to a higher WTP for a good with relatively high levels of this attribute. 


$$
\frac{\partial W T P}{\partial \beta}=\frac{Y n\left(P^{\beta} A^{1-\beta}\right)^{n} b^{n}(\ln (P)-\ln (A))}{\left(b^{n}+\left(P^{\beta} A^{1-\beta}\right)^{n}\right)^{2}}=\left\{\begin{array}{l}
<0, \text { if } A>P \\
=0, \text { if } A=P \\
>0, \text { if } A<P
\end{array}\right.
$$

The result shows that WTP behaves differently depending on the characteristics of the spatial good. This result depends on the form of the Cobb-Douglas utility function (Equation 4.4), which assumes a substitution effect between different characteristics of spatial quality (proximity to the CBD and environmental amenities). So, a buyer's WTP grows as preferences for proximity to the CBD increases if the proximity value of the good is higher than the amenity value of the good $(P>A)$. In other words, as a buyer's preference for proximity increases, her willingness to pay for goods that provide more proximity than amenities increases, meaning that she will bid higher for a property closer to the CBD.

4. Effect of distance: One of the main properties of the demand for land function in the monocentric city model is that land price decreases as distance from the CBD increases. Alonso explained this result by the fact that both disutility of commuting and travel costs increase with distance from the CBD (Alonso, 1964), p 71. Our WTP function should behave the same way, for the same reasons.

$$
\frac{\partial W T P}{\partial D}=\frac{\beta n Y\left(\left(D_{\max }+1-D\right)^{\beta} A^{\alpha}\right)^{n} b^{n}}{\left(b^{n}+\left(\left(D_{\max }+1-D\right)^{\beta} A^{\alpha}\right)^{n}\right)^{2}\left(-D_{\max }-1+D\right)}<0
$$

The derivative is negative because the expression $(-D m a x-1+D)$ is always negative. This means that WTP decreases with distance to the CBD. Thus, it mimics the downward-sloping bid-rent function from the monocentric urban model.

5. Effect of $b$ : The willingness to pay for a spatial good depends among other factors on the prices of all other goods (i.e. composite good). We do not include a composite good directly into the utility function due to the factors explained in (Parker and Filatova, 2008). However, the parameter $b$ can be interpreted as a proxy for the prices of all other goods.

$$
\frac{\partial W T P}{\partial b}=-\frac{Y \cdot U^{n} \cdot n \cdot b^{n-1}}{\left(b^{n}+U^{n}\right)^{2}}<0
$$

Demand for housing decreases as $b$ increases. Since the prices for non-housing goods increase while income remains constant, then the share of budget for housing decreases because of the additional expenses for non-housing goods. With the decrease in money available for housing, the WTP for housing also decreases. 


\subsection{APPENDIX B: Results of the t-test between different experiments' runs}

To check statistical significance of the differences between experiments' results, we performed ttest to compare the two means. Each experiment was run 30 times. The outcomes of all 30 runs were recorded in one file and mean value of each of the macro-metrics (Table 4.4) between 30 model runs in the same parameter space were calculated. Then, the mean values between two different experiments of interest were compared. All claimed differences are statistically significant at the $99 \%$ confidence interval. The results of the t-tests of the most important metrics are reported below. The mean ask price remains unchanged in every experiment except 5 and 6 , so we report ttest results for it only in the last two comparisons. Utility changes only between experiments 1 and 2 , so it is reported only in the first test.

\begin{tabular}{|c|c|c|c|c|c|c|c|c|}
\hline \# & $\begin{array}{l}\text { Experiments } \\
\text { compared }\end{array}$ & Metrics & t value & $d f$ & $p$ value & \multicolumn{2}{|c|}{$\begin{array}{l}\text { Confidence } \\
\text { interval }\end{array}$} & Comment \\
\hline \multirow[t]{3}{*}{1} & \multirow{3}{*}{$\begin{array}{l}\text { Exp4.1 vs } \\
\text { Exp4.2 }\end{array}$} & \multirow{3}{*}{$\begin{array}{l}\text { Individual } \\
\text { utility } \\
\text { Bid price } \\
\text { Transaction } \\
\text { price }\end{array}$} & -7.852 & 29897 & 0 & -1.492 & -0.755 & significant \\
\hline & & & -7.442 & 29796 & 0 & -8.406 & -4.083 & significant \\
\hline & & & -7.442 & 29796 & 0 & -4.203 & -2.042 & significant \\
\hline \multirow[t]{2}{*}{2} & \multirow{2}{*}{\begin{tabular}{|l} 
Exp4.1 vs \\
Exp4.3
\end{tabular}} & Bid price & -9.212 & 29441 & 0 & -10.587 & -5.96 & significant \\
\hline & & $\begin{array}{l}\text { Transaction } \\
\text { price }\end{array}$ & -9.212 & 29441 & 0 & -5.293 & -2.98 & significant \\
\hline \multirow[t]{2}{*}{3} & \multirow[t]{2}{*}{$\begin{array}{l}\text { Exp4.3 vs } \\
\text { Exp4.4 }\end{array}$} & Bid price & -3.093 & 31015 & 0.002 & -5.174 & -0.472 & significant \\
\hline & & $\begin{array}{l}\text { Transaction } \\
\text { price }\end{array}$ & -3.093 & 31015 & 0.002 & -2.587 & -0.236 & significant \\
\hline \multirow[t]{2}{*}{4} & \multirow{2}{*}{$\begin{array}{l}\text { Exp4.1 vs } \\
\text { Exp4.5 }\end{array}$} & Ask price & 349.698 & 16589 & 0 & 19.401 & 19.689 & significant \\
\hline & & $\begin{array}{l}\text { Transaction } \\
\text { price }\end{array}$ & 43.74 & 30522 & 0 & 19.304 & 21.72 & significant \\
\hline \multirow[t]{2}{*}{5} & \multirow[t]{2}{*}{$\begin{array}{l}\text { Exp4.5 vs } \\
\text { Exp4.6 }\end{array}$} & Ask price & 33.038 & 33011 & 0 & 2.498 & 2.92 & significant \\
\hline & & $\begin{array}{l}\text { Transaction } \\
\text { price }\end{array}$ & 2.721 & 33175 & 0.007 & 0.072 & 2.622 & significant \\
\hline
\end{tabular}





\title{
5 Land market interactions between heterogeneous agents in a heterogeneous landscape-tracing the macro-scale effects of individual trade-offs between environmental amenities and disamenities ${ }^{32}$
}

\begin{abstract}
Heterogeneity in both the spatial environment and economic agents is a crucial driver of land market dynamics. We present an agent-based land market model that combines the microeconomic demand, supply, and bidding foundations of urban economic models with the spatial heterogeneity of spatial econometric models in a single methodological platform. Heterogeneous agents exchange heterogeneous spatial goods via simulated bilateral market interactions. We model a coastal city where both coastal amenities and flooding or erosion disamenities drive land market outcomes, facilitating separate analysis of the effects of each driver on land rents and land development patterns. We also analyze the implications of homogeneous vs. heterogeneous but unbiased perceptions of the probability of flooding. Since buyers with perceptions of flood probability drive market outcomes, spatial development under heterogeneous probability perceptions differs qualitatively, with more expansion into risky areas. Our results highlight the shortcomings of policy models based on representative agent assumptions and the importance of including agent-level data in empirical modeling.
\end{abstract}

\subsection{Introduction}

Land development in coastal cities is shaped by several spatial influences: the attractive forces of the amenity value of the coast and proximity to the central business district (CBD) and the repulsive force of the risk of flooding and erosion. Empirical data suggest that economic agents participating in coastal urban land markets may have heterogeneous perceptions of the probability of a coastal hazard, i.e. individual beliefs about the probability of flooding or erosion. Thus, land market transactions and resulting development patterns in coastal cities occur in the context of heterogeneous agents operating in a heterogeneous spatial environment, influenced by both amenities and disamenities. In this paper, we present a theoretical model and series of experiments designed to address two related research questions. First, how do spatially coupled amenities, such as a coastal view, and disamenities, such as the risk of flooding or erosion, influence patterns of urban land use and land rents? Second, within this context, what role do heterogeneous perceptions of flooding probability play in shaping land market outcomes, and what land-use and rent patterns emerge from the interactions of heterogeneous buyers? To address these questions, we develop a theoretical model of a coastal urban land market that includes several sources of spatial

\footnotetext{
32 This Chapter is also a paper co-authored with D. C. Parker and A. van der Veen "'Land market interactions between heterogeneous agents in a heterogeneous landscape-tracing the macro-scale effects of individual trade-offs between environmental amenities and disamenities" in Canadian Journal of Agricultural Economics, Under revisions
} 
heterogeneity, while also allowing for agent heterogeneity. Our theoretical modeling approach relies on traditional microeconomic decision models at the agent level, and also generates spatially explicit transaction data that preserve information on the agent-level characteristics of buyers and sellers. Thus, our approach creates closer linkages between theoretical urban economics modeling and empirical spatial econometric analysis than has been achieved through previous modeling approaches.

Econometric research efforts have provided evidence that spatial heterogeneity is a crucial determinant of spatial patterns of development and land rents. Models have successfully estimated the effects of spatial amenities on both property prices and land patterns (Irwin and Bockstael, 2004; Wu et al., 2004). Hedonic price analysis has demonstrated that negative attributes of the spatial environment (such as pollution, noise, hazardous waste sites and etc.) also affect spatial patterns of residential developments and are capitalized in property prices (see Bin et al. (2008) for review). For a coastal city, price discounts dependent on the probability of flooding or erosion are seen in flood-prone areas (MacDonald et al., 1987). Attributes of the spatial environment that create repulsive or attractive incentives for agents participating in the land market are often spatially linked (for example, proximity to the $\mathrm{CBD}$ and noise or traffic pollution, living close to the forest and risk of forest fires, waterfront amenities and erosion) and need to be studied together. When positive and negative amenities are spatially correlated, the price discount due to a disamenity can exceed the capitalization value of the environmental amenity (Bin et al., 2008).

In spite of this growing body of empirical evidence, theoretical spatial economics has been lagging behind in including spatial heterogeneity in land market models. The reasons are understandable: introduction of too much of diversity in a spatial landscape prevents analytical identification of market equilibrium quantities, pattern, and prices of developed land. Several urban economics models have, however, departed from the traditional monocentric model (Alonso, 1964) and its assumption of the featureless plain landscape by adding a second attribute of quality of land in addition to distance from the CBD: environmental amenities ( $\mathrm{Wu}$ et al., 2004; Caruso et al., 2007), local public goods (Henderson and Thisse, 1999) or disamenities (Tatano et al., 2004). However, to our knowledge there is no analytical theoretical urban model that accounts for more than two sources of spatial heterogeneity.

There are many diverse agents with different roles, resources, and preferences operating in the land market (Parker and Filatova, 2008). However, traditional economic market models assume a representative agent or a group of identical agents. If heterogeneity among agents is modeled, the spatial environment is often assumed to be homogeneous, since again, the combination of both factors creates analytical intractability. Currently, spatial economics is able to track the 
dependencies between agents' preferences and incomes at the micro-level and macro-level equilibrium market outcomes, but is unable to accommodate real world heterogeneity. Yet, microeconomic theory predicts that capitalization of different spatial attributes depends on agents' incomes and preferences for spatial attributes. In the real world, individual land users in the coastal zone may have different preferences for amenities and subjective heterogeneous perceptions of the probability of flooding.

Econometric analysis is often based only on spatial data: a dependent variable based on land transaction prices or transitions and independent variables that represent land suitability, neighborhood effects, and travel cost distance (Bell and Irwin, 2002). These models estimate either the demand curve of a representative agent for land or the probability that a representative agent chooses a specific land use in a specific location. Although these models account for spatial heterogeneity, they provide only a snapshot of a market at a certain moment in time, which may not be robust if agents' preferences and incomes or the quality of supplied land change. When used for policy analysis, these models cannot be used to explore the effects of agent heterogeneity or resources on land-use values and transitions. Some statistical analyses include both spatial and agent-level data, such as that conducted by Lynch and Lovell (2003). However, these models may be analyzed under the assumption of a representative agent, using statistical data on average agent characteristics (income, education, liquidity, etc.) to produce guidelines for policy-making. Thus, policy decisions may be based on analysis of representative behavior while the real-world population is very diverse. We all know that a model is a simplification of reality. But what is the price of some of our simplifications, whether motivated by modeling challenges or by lack of data?

Current modeling methods cannot answer this question. An important gap remains - the gap between spatial analytical theoretical models, which effectively explore linkages between the resources and incentives of land market agents and equilibrium land rents, but fail to incorporate spatial heterogeneity, and spatial econometric models, which provide empirical evidence of the net importance and magnitude of spatial drivers, but fail to analyze the empirical structural drivers of land-market outcomes. A theoretical platform is needed to merge the knowledge from these two economic sub-disciplines in order to more effectively explore the effects of agent-level drivers of land market activity and landscape-level patterns of land value and land-use change.

In this paper we propose an approach to accommodate multi-dimensional heterogeneity of the spatial environment while maintaining links between micro-economic agents' characteristics and macro-level land market macro-outcomes. As a second step, we introduce heterogeneity across agents' preferences for spatial attributes, particularly heterogeneous perceptions of the probability of flooding or erosion. We build an agent-based land market model, which borrows heavily from 
the spatial and environmental economics and agent-based computational economics (ACE) perspectives. ACE is used to explore complex adaptive economic systems (Axtell, 2005; Tesfatsion and Judd, 2006). It has been widely applied to a variety of market settings, including financial, electricity, commodity and labor markets (Arthur, Durlauf et al., 1997; Kirman and Vriend, 2001; LeBaron, 2006; Marks, 2006; Tesfatsion, 2006). ACE methodology allows for modeling and exploration of key issues not possible in traditional analytical models: out-of-equilibrium dynamics (Arthur, 2006), agent heterogeneity (Kirman, 1992), bounded rationality (Simon, 1997), and interaction between agents (Axtell, 2005). This is accomplished by replacing centralized price determination mechanisms (i.e. equilibrium conditions motivated by a story of a Walrasian auctioneer) by decentralized bilateral trading among agents. Agent-based models (ABM) have been widely applied to modeling land-use change (Parker et al., 2002). The applicability of ABM to both market modeling and spatially explicit land use simulations makes it an ideal tool to model land markets (discussed in detail by Parker and Filatova (2008)).

The paper proceeds as follows. First, the empirical context of the research is presented. Second, the model structure and assumptions are briefly discussed. Next, three model experiments with increasing degrees of complexity are presented: the land market with the decentralized price determination mechanism in a city with coastal amenities, the same market with the addition of the flood risk disamenity, and last, the market with both spatial factors and the inclusion of heterogeneous perceptions of the probability of flooding. We conclude by summarizing the main results and their application to real-world land markets and policy-making.

\subsection{Trade-offs and individual heterogeneity in the real-world}

Coastal areas are rich in environmental amenities including beaches, dunes and natural habitat for many species. At the same time, the risk of flooding or erosion presents a constant threat. Our research is motivated by the case of coastal cities. In the Netherlands, both factors influence land market activity in regions with high population densities, meaning high potential economic damages and risks to public safety. Safety standards in the Netherlands are high in most areas, designed to reduce the probability of flooding to as low as 1 in 10,000 years. However, there are 13 coastal towns deemed "risk towns" (Rijkswaterstaat, 2002), where protection levels are lower and development is allowed beyond a legally protected zone (i.e. outside of dikes). The chance of flooding or erosion in this areas is unknown but obviously higher than in the protected zone. It is up to individuals to decide whether they want to locate in this unprotected area, bearing their own risk (Poelmann Commissie, 2005). Insurance from coastal flooding or erosion does not exist in the Netherlands. Thus, individual economic agents face a trade-off: to enjoy the high-amenity 
waterfront and bear the risk or to have lower level of environmental amenities in exchange for a higher safety level. Within this context, policy makers would like to understand the likely spatial evolution of development, the total economic value of the area, and the extent and value of development in the unprotected zones.

Empirical data provide two important observations about the location preferences of Dutch people. First, the average price of property on the coast is higher than the average in the coastal province, signalizing the high amenity value of the coast. Specifically, in the province of ZuidHolland the difference between average property prices along the coast and landward properties was €99 400 in 2005 (VLIZ, 2005). Second, the survey concerning individual coastal flood awareness showed that people estimate the probability of coastal flooding as low (Kaiser et al., 2004). Notably, individual risk awareness is quite dispersed: $37 \%$ of respondents considered the probability of coastal flooding as very low, another $37 \%$ considered it to be low and $22 \%$ of the sample stated that it is high. This heterogeneity of responses means that people are unequal in their perceptions of the probability of coastal flooding and some are likely to underestimate it. However, spatial policies are generally formulated assuming a representative agent who perceives risk objectively. Thus, policy makers face an additional challenge- how to understand the influence of heterogeneous beliefs about the probability of flooding on the distribution of land development and land values in the protected and unprotected areas of the coastal cities, where both preferences for amenities and probability of a hazard influence development decisions and land values.

\subsection{Model description}

As discussed in Section 5.1, there are no ready-to-use economic tools to analyze the problem outlined in Section 5.2. To address this challenge, we have designed and implemented an agentbased computational model of a land market, ALMA (Agent-based Land MArket model). A detailed description of the conceptual model and literature context can be found in Parker and Filatova (2008). Details of model mechanisms and operation, summarized here, are found in Filatova et al. (2009), and two additional model applications are described in Filatova et al. (2007; 2008). Our description here focuses in particular on the price setting algorithm for sellers, which differs from that used in Filatova et al. (2009).

Our Agent-based Land MArket model for the Coast (ALMA-C) simulates the emergence of urban land patterns and land prices as a result of micro-scale interactions between buyers and sellers of land with application to a coastal city. ALMA-C borrows much from the analytical monocentric urban model (Alonso, 1964) and its application to a coastal city with amenities (Wu, 2001). 
Differences show up in the implementation of a spatially explicit setup, direct modeling of price formation, and heterogeneity of both agents and the spatial landscape.

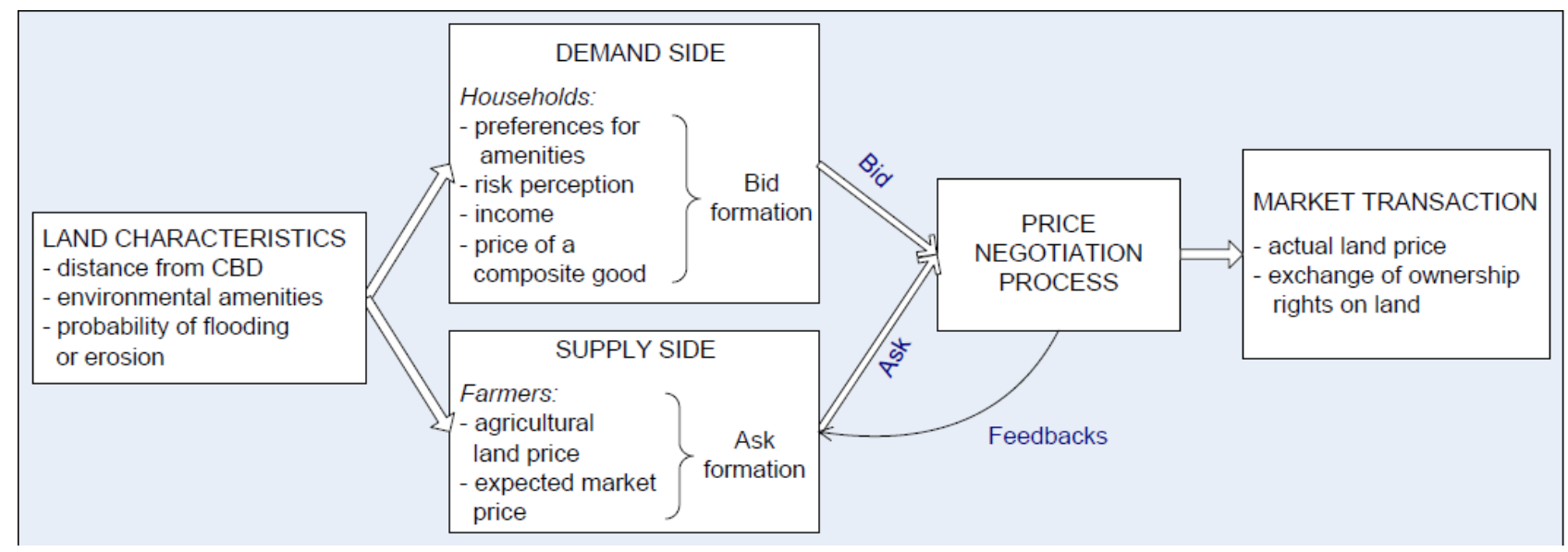

Figure 5.1: Conceptual scheme of a land market

Figure $5.1^{33}$ shows the logic of the land market model discussed in this paper. The main agents in the ALMA-C model are land market participants operating in a coastal urban area (economic agents, specifically households who buy land and agricultural land owners who sell land). In line with the assumptions of the analytical model, ALMA-C assumes that each spatial good is differentiated by distance $\left(D_{c b d}\right)$ from the CBD (or its inverse measure-proximity Prox = Dmax $+1-D)$, the level of environmental amenities $(A)$ (estimated as a normalized distance to the coast) and a distant-dependent objective probability of flooding or erosion $\left(P F_{o b j}\right)$ (see Equation 5.1).

$$
P F_{o b j}=\frac{C_{P F 1} * C_{P F 2}^{8}}{C_{P F 2}^{8}+D_{\text {coast }}^{8}}
$$

The probability of flooding falls with the distance to the coast $D_{\text {coast }}$ starting from the bounding maximum probability defined by $C_{P F 1}$. $C_{P F 2}$ determines the speed at which the flood probability falls. (See Table 5.1 in Section 5.4 for the coefficient values used in this paper.) Other attributes of land can be easily added if needed. In ALMA, the centralized price determination mechanism of the standard analytical model is replaced by a set of bilateral trades, as summarized below.

Buyer's behavior Buyer households search for the location that maximizes their expected utility (Equation 5.2, where and are individual preferences for green amenities and proximity correspondingly) and is affordable under their disposable budget for housing net of transport costs (Y). This logarithmic utility functional form is adapted from (Wu et al., 2004).

\footnotetext{
${ }^{33}$ Figure 5.1 is a simplified version of a more general figure representing a comprehensive ABM land market model described elsewhere (Parker and Filatova, 2008; Filatova et al., 2009)
} 


$$
\begin{aligned}
& U=\alpha \cdot \ln (A)+\beta \cdot \ln (\text { Prox }) \\
& E(U)=P F_{i} \cdot U \cdot\left(1-C_{d a m}\right)+\left(1-P F_{i}\right) \cdot U
\end{aligned}
$$

where $C_{\text {dam }} \in[0 ; 1]$ is a damage coefficient denoting the loss from flood or erosion and $P F_{i}$ is the probability of flooding as perceived by an agent $i$. This subjective probability is determined by the deviation of the agent's belief about the flood risk $\left(R P_{d e v}\right)$ from its objective probability (Equation $5.3)^{34}$.

$$
P F_{i}=P F_{o b j} \pm R P_{d e v}, \quad P F_{i} \in[0 ; 1]
$$

A buyer first identifies the property that gives her maximum utility. Her willingness to pay (WTP) for the property is a function of her expected utility $E(U)$, her individual budget net of travel costs $(Y)$ and the prices of all other goods (the influence of which is expressed by a constant $b$ that determines the convexity of the WTP for housing).

$$
P_{W T P}=\frac{Y^{*} E(U)^{2}}{b^{2}+E(U)^{2}}
$$

This function exhibits the same qualitative properties (comparative statics) as a standard demand function (Filatova et al., 2009). In this paper we assume that agents form their bid price equal to their true WTP, $P_{b i d}=P_{w t p}$. The effects of other pricing strategies on the division of gains from trade are discussed elsewhere (Filatova et al., 2009). Having identified their optimal property and bid price, buyers submit their offer-bids to the sellers.

Seller's behaviour: The minimum willingness to accept (WTA) of a sellers, or reservation price, is equal to the agricultural land price $\left(P_{a g}\right)$. Following the strategic pricing approach proposed in Parker and Filatova (Parker and Filatova, 2008), we assume that in order to maximize his gains from trade, a seller will set an ask price based on his expectation of a buyer's WTP, as determined by Equation 5.4, which depends on the attributes of the spatial good. His ask price will be the highest of this estimate and his WTA, $P_{a g}$. Since in this setting the seller would capture all the gains from trade, he is the one who has the space to adjust his price. If a seller cannot sell his spatial good during $\mathrm{N}$ time steps he decreases his ask price by $3 \%$, with a floor of his agricultural WTA. Sellers accept the highest offer-bid that is greater than or equal to their ask price. The final transaction price is an arithmetic average of the ask price and the highest bid price.

Event sequencing and dynamics: ALMA-C is a dynamic model. At initialization, all land is assumed to be under agricultural use, and the CBD is exogenously set. In this implementation, all buyers and sellers are initially active in the market. Market interactions start when sellers announce their ask prices and buyers enter the market to search for the best deal. As sellers accept bids,

\footnotetext{
${ }^{34}$ In this paper, we set the range of $P F_{o b j}$ and $R P_{d e v}$ such that $P F_{i} \in[0 ; 1]$.
} 
transactions are registered, land changes ownership, and the associated buyer and sellers leave the market. The model continues in the next round with a reduced number of buyers, sellers, and properties on the market. Unsuccessful buyers and sellers continue to participate in the next round of the market. The model stops running when no more transactions occur, i.e. all the submitted bids are lower than ask prices. Essentially, consistent with the standard story of the operation of an invisible hand in the marketplace, market equilibrium is reached when all gains from trade are exhausted.

\subsection{Simulation experiments with ALMA-C}

In many situations economic agents operating in an urban land market need to make trade-offs between positive and negative characteristics of the spatial environment. Below we perform two experiments with the ALMA-C model to study these trade-offs in a coastal urban land market. In the third experiment we show the effect of substituting a set of heterogeneous agents for a representative agent in the land market.

The ALMA-C simulations produce spatially explicit rent gradients (i.e., realized land transaction prices at different distances from the city center), land patterns, and a set of economic and spatial metrics (bid, ask and transaction prices, average individual utility, total welfare of the urban population, urban size, and urban extent). In addition to reporting these metrics, we use our simulated transaction price data to econometrically estimate land rent gradients for each experiment. Our simulated transaction data provide a spatial data set structurally similar to realworld data used to estimate spatial hedonic models and empirical rent gradients. Transaction prices serve as our dependent variable, and the spatial attributes of each property (distance from the CBD and amenity values) and individual attributes of buyers (perceptions of the probability of flooding in this application) provide the independent variables for the regressions. Our modeling approach thus provides a direct link between theoretical urban analytical models and empirical spatial econometric models not made in previous modeling work.

\subsubsection{Experimental setup}

The three experiments presented in this paper were performed on a 35x63 cell landscape, initialized with 1890 buyers and 1890 sellers. Given the parameter settings used in these experiments, not all buyers will find properties to buy. Thus, our model essentially follows an open city model, where buyers are assumed to have an opportunity to locate in another community. Agents are 
homogeneous with respect to their preferences for green amenities and incomes ${ }^{35}$ but can be assigned heterogeneous perceptions of the probability of flooding. The model parameters used in all 3 experiments are listed in Table 5.1.

Table 5.1: Values of the parameters in the simulation experiments

\begin{tabular}{|l|l|c|c|c|}
\hline \multicolumn{1}{|c|}{ Symbol } & \multicolumn{1}{|c|}{ Meaning } & Exp 5.1 & Exp 5.2 & Exp 5.3 \\
\hline $\mathrm{Y}$ & Individual budget & 800 & 800 & 800 \\
\hline $\mathrm{P}_{\mathrm{ag}}$ & Price for agricultural land & 200 & 200 & 200 \\
\hline $\mathrm{TCU}$ & Transport costs per unit of distance & 1 & 1 & 1 \\
\hline $\mathrm{b}$ & Constant in WTP-WTA formula & 70 & 70 & 70 \\
\hline$\alpha \dot{\alpha}$ & Individual preference for green amenities & 0.6 & 0.6 & 0.6 \\
\hline $\mathrm{C}_{\mathrm{dam}}$ & Flood damage coefficient & $\mathrm{NA}^{37}$ & 0.16 & 0.16 \\
\hline $\mathrm{C}_{\mathrm{PF} 1}$ & Coefficient in the Equation 5.1 & $\mathrm{NA}$ & 0.7 & 0.7 \\
\hline $\mathrm{C}_{\mathrm{PF} 2}$ & Coefficient in the Equation 5.1 & $\mathrm{NA}$ & 4 & 4 \\
\hline $\mathrm{RP}_{\mathrm{dev}}$ & $\begin{array}{l}\text { Individual flood probability perception } \\
\text { deviation }\end{array}$ & $\mathrm{NA}$ & 0 & {$[-0.15 ; 0.15]$} \\
\hline $\mathrm{avRP}$ & Mean $R P_{\text {dev }}$ in the traders population & NA & 0 & 0 \\
\hline $\mathrm{PF}_{\mathrm{obj}}$ at the coast & Probability of flooding & NA & 0.7 & 0.7 \\
\hline
\end{tabular}

Each of the three experiments was repeated 50 times with a different random seed to check the robustness of the model results. The random seed affects both the distribution of the individual perceptions of the probability of flooding and the order of activation of agents. The statistical significance of differences of land prices and welfare measures between model experiments was confirmed by t-tests.

\subsubsection{Experiment 5.1: introducing environmental amenities in the bilateral land market}

We first model a monocentric city located along the coast, with spatial amenities provided by proximity to the coast and the probability of flooding $P F_{o b j}$ and agents' probability perception deviation $R P_{\text {dev }}$ in Equation 5.3 set to zero. Thus, $E(U)=U$ from Equation 5.2. This experiment reproduces the benchmark analytical urban model of a coastal city by $\mathrm{Wu}$ (2001). ALMA-C departs from the analytical model by replacing the centralized land price determination mechanism with a series of spatially distributed bilateral trades as described in Section 5.3 above. The results provide structural validation of the theoretical foundations of our ABM.

\footnotetext{
${ }^{35}$ Our earlier work explored preference heterogeneity related environmental amenities (Filatova, Parker et al., 2007), proximity to the CBD (Filatova, van der Veen and Parker, 2008) and income (Filatova, van der Veen and Voinov, 2008)

${ }^{36}$ See Chapter 4 for the details of WTP-WTA estimation

${ }^{37} \mathrm{NA}$ - not applicable
} 
Table 5.2: Economic and spatial metric outcomes of the ALMA-C experiments

\begin{tabular}{rrrr}
\hline & Exp1 & Exp2 & Exp3 \\
\hline Utility indiv, mean & 43.02 & 42.53 & 42.67 \\
Utility $_{\text {indiv }}$, st.dev & 1.20 & 0.99 & 1.30 \\
Aggregate util & 26756.61 & 18754.48 & 24918.40 \\
Bid price, mean & 216.08 & 212.93 & 213.67 \\
Bid price, st.dev & 9.72 & 8.17 & 10.42 \\
Ask price, mean & 216.08 & 212.93 & 209.65 \\
Ask price, st.dev & 9.72 & 8.17 & 9.37 \\
Transaction price, mean & 216.08 & 212.93 & 211.66 \\
Transaction price, st.dev & 9.72 & 8.17 & 9.75 \\
Total land value in the city & 134398.95 & 93902.49 & 123611.73 \\
City size & 622.00 & 441.00 & 584.00 \\
City border & 26.93 & 22.09 & 25.09 \\
Urban cells seaward from safety contour & NA & 0.00 & 38.66 \\
\hline
\end{tabular}

Visualizing the simulated rent gradient: The macro-outcomes of micro-interactions in the land market are presented in Table 5.2. Column "Exp.5.1" reports the welfare and spatial metrics of this experiment. A snapshot of the spatial distribution of urban land prices (realized transaction prices) is presented in Figure 5.2. The dark line on the left represents the ocean and the white circle in the middle is the CBD. The intensity of gray color symbolizes the value of land: the darker the color, the higher the land price. Exp.5.1 reproduces the qualitative properties of the standard analytical equilibrium model of a coastal city if homogeneity among agents is assumed. Land rents have the same pattern as in the benchmark model. Specifically, transaction prices decrease monotonically with distance from the $\mathrm{CBD}$ and distance from the environmental amenity, and cells equally close to the $\mathrm{CBD}$ and the coastline have the same price.

Property prices are highest in the area closest to the coastline and the CBD. The city's expansion stops at the location where the bid price of a buyer falls below the ask price of a seller-the reservation price of returns to agricultural land. The lightest-gray area in Figure 5.2 shows the city border and symbolizes the the urban-rural fringe. Given the high value for amenities relative to value of proximity to the CBD used in these simulations, the highest land values occur along the coast itself. However, the value of proximity to the CBD is seen in the fact that the form of the city and realized land rent gradient is not perfectly linearly spread along the coast. Land rent at the CBD is higher than land rent at points along the coast that are the same distance from point $\mathrm{C}$ as the CBD. 


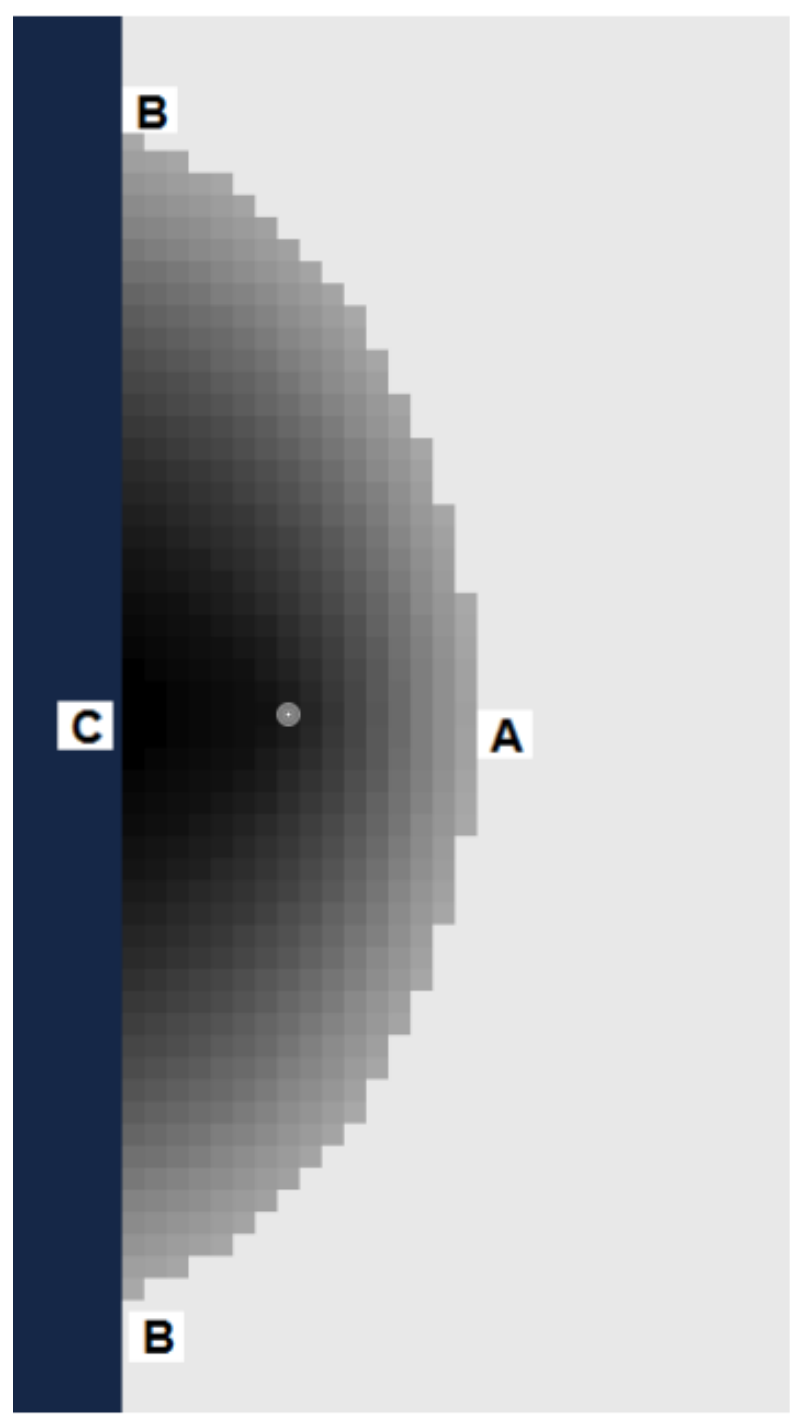

Figure 5.2: Rent gradients, Exp.5.1: only environmental amenities

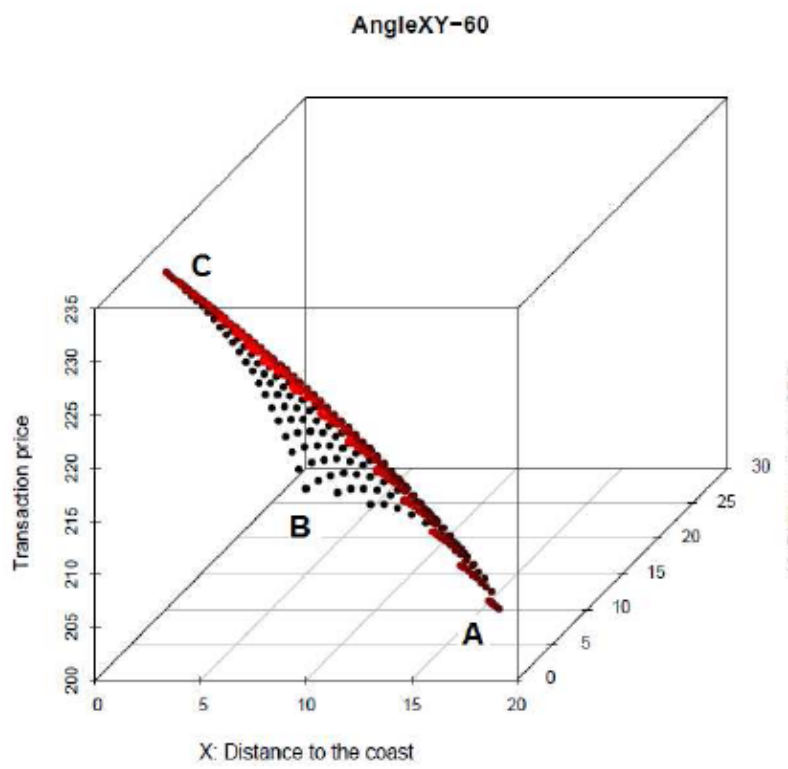

Traditionally, the rent gradient, which represents the urban land price as a function of distance to the $\mathrm{CBD}$, is a curve in $2 \mathrm{D}$ space. In a landscape where not only proximity to the CBD but also proximity to an environmental amenity affects prices, the rent gradient becomes a surface in a $3 \mathrm{D}$ space. A 3D scatterplot of the transaction data from Exp.5.1 is presented at different angles in Figure 5.3. The urban land price is on the vertical axis, so higher dots represent higher land prices. The two horizontal axes are distance to the coast and distance to the CBD. Note that this is not a $3 \mathrm{D}$ representation of the landscape, but a 3D visualization of a realized land rent gradient. For reference, compare points $\mathrm{A}, \mathrm{B}$ and $\mathrm{C}$ in Figure 5.2 and Figure 5.3. Again, land rent is highest at the coastal location closest to the $\mathrm{CBD}$, and land rents at points $\mathrm{A}$ and $\mathrm{B}$, the extensive margins of urban development, are equal to the returns from agricultural land. The simulated land rent gradient is convex and declines monotonically, as would be expected in an analytical model.

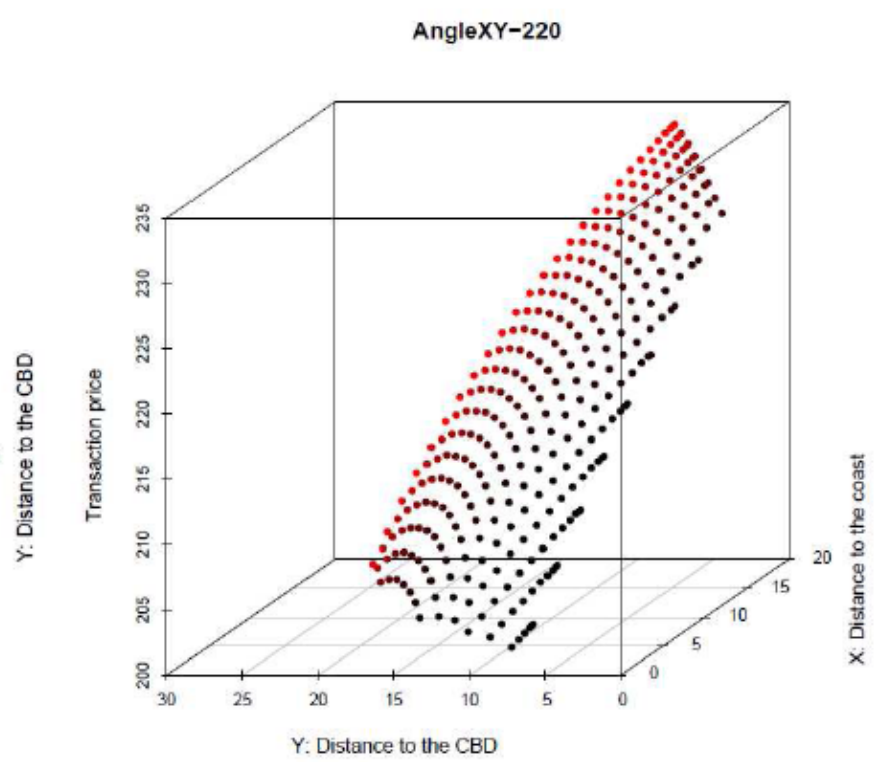

Figure 5.3: 3D scatterplot of transaction prices for Exp.5.1: only environmental amenities 
Estimating the rent gradient: To have a quantitative measure of the land price distribution and facilitate comparison between experiments, we estimated the land rent gradient equation via a cubic regression using the simulated transaction prices as the dependent variable and distance to the $\mathrm{CBD}$ and distance to the coast as the two independent variables. The estimated rent gradient is presented in the first column of Table 5.3. In the case of homogeneous agents, the variation in land prices is completely explained by these two spatial attributes, as expected $\left(\mathrm{R}^{2}\right.$ is 1$)$.

Table 5.3: Cubic regression of simulated land prices

(Notations: Estimate(st.error / t-value), Exp1 is Exp.5.1 and Exp2 is Exp.5.2)

\begin{tabular}{rllll}
\hline & Exp1 & Exp2 & Exp3A & Exp3B \\
\hline R_sqr & 1 & 0.9636 & 0.8663 & 0.9105 \\
Intercept & $243.43(0.01 / 36651.1)$ & $171.51(0.44 / 392.5)$ & $180.47(0.52 / 345.8)$ & $177(0.55 / 322.9)$ \\
$D_{a m}$ & $-1.5(0 /-990.9)$ & $19.89(0.11 / 174.4)$ & $15.68(0.11 / 142.2)$ & $14.79(0.11 / 133.7)$ \\
$D_{a m}^{2}$ & $-0.01(0 /-75.53)$ & $-2(0.01 /-194.01)$ & $-1.4(0.01 /-150.08)$ & $-1.31(0.01 /-152.84)$ \\
$D_{a m}^{3}$ & $0(0 /-350.06)$ & $0.06(0 / 175.6)$ & $0.03(0 / 103.3)$ & $0.03(0 / 115.8)$ \\
$D_{c b d}$ & $-1.15(0 /-970.14)$ & $-1.59(0.06 /-25.77)$ & $0.01(0.09 / 0.11)$ & $-0.42(0.09 /-4.88)$ \\
$D_{c b d}^{2}$ & $0.003(1 \mathrm{e}-04 / 41.1)$ & $0.047(0.004 / 13.1)$ & $-0.015(0.005 /-2.7)$ & $0.011(0.005 / 2.4)$ \\
$D_{c b d}^{3}$ & $-7 \mathrm{e}-04(0 /-485.4)$ & $-3 \mathrm{e}-04(1 \mathrm{e}-04 /-3.9)$ & $3 \mathrm{e}-04(1 \mathrm{e}-04 / 3.1)$ & $-2 \mathrm{e}-04(1 \mathrm{e}-04 /-1.7)$ \\
$D_{a m}^{2} * D_{c b d}$ & $-2 \mathrm{e}-04(0 /-37)$ & $0.007(3 \mathrm{e}-04 / 18.9)$ & $0.015(4 \mathrm{e}-04 / 34.2)$ & $0.011(4 \mathrm{e}-04 / 28.8)$ \\
$D_{a m} * D_{c b d}^{2}$ & $0(0 / 3.3)$ & $-0.007(2 \mathrm{e}-04 /-33.3)$ & $-2 \mathrm{e}-04(3 \mathrm{e}-04 /-0.8)$ & $-0.002(2 \mathrm{e}-04 /-6.2)$ \\
$D_{a m} * D_{c b d}$ & $0.004(1 \mathrm{e}-04 / 26.3)$ & $0.021(0.008 / 2.5)$ & $-0.271(0.012 /-23.5)$ & $-0.18(0.01 /-18.2)$ \\
$R P$ & - & - & - & $-41.23(4.21 /-9.8)$ \\
$R P^{2}$ & - & - & - & $196.93(21.94 / 8.98)$ \\
$R P^{3}$ & - & - & - & $-232.29(72.12 /-3.22)$ \\
$R P * D_{a m}^{2}$ & - & - & - & $-0.07(0.03 /-2.23)$ \\
$R P^{2} * D_{a m}$ & - & - & - & $-14.68(1.52 /-9.66)$ \\
$R P * D_{c b d}^{2}$ & - & - & - & $0.05(0.01 / 3.69)$ \\
$R P^{2} * D_{c b d}$ & - & - & - & $-3.6(1.1 /-3.28)$ \\
$R P * D_{a m}$ & - & - & - & $1.15(0.6 / 1.91)$ \\
$R P * D_{c b d}$ & - & - & $-0.66(0.34 /-1.93)$ \\
\hline
\end{tabular}

To visualize these results in the form of a traditional 2D rent gradient, we plot a cross section of this 3D graph along the perpendicular axis between the CBD and the coastline (segment AC in Figure 5.2), translating each of the two independent variables into distance from the coast. This estimate is shown by the red line in Figure 5.4). The extent of this line (and the others plotted similarly) is determined by the realised urban transaction data; thus the line also shows the extent of the simulated urban area. The dashed black line shows the position of the CBD. Consistent with the transaction data used to estimate the model, the highest land values occur along the coast. Estimated land rent declines monotonically. To the left of the CBD, the decrease in land value associated with decreased amenity value is partly offset by the value of increased proximity to the CBD. Conversely, estimated land rent falls off more steeply to the right of the CBD, where both effects of distance are negative. 


\section{Cubic regression fit}

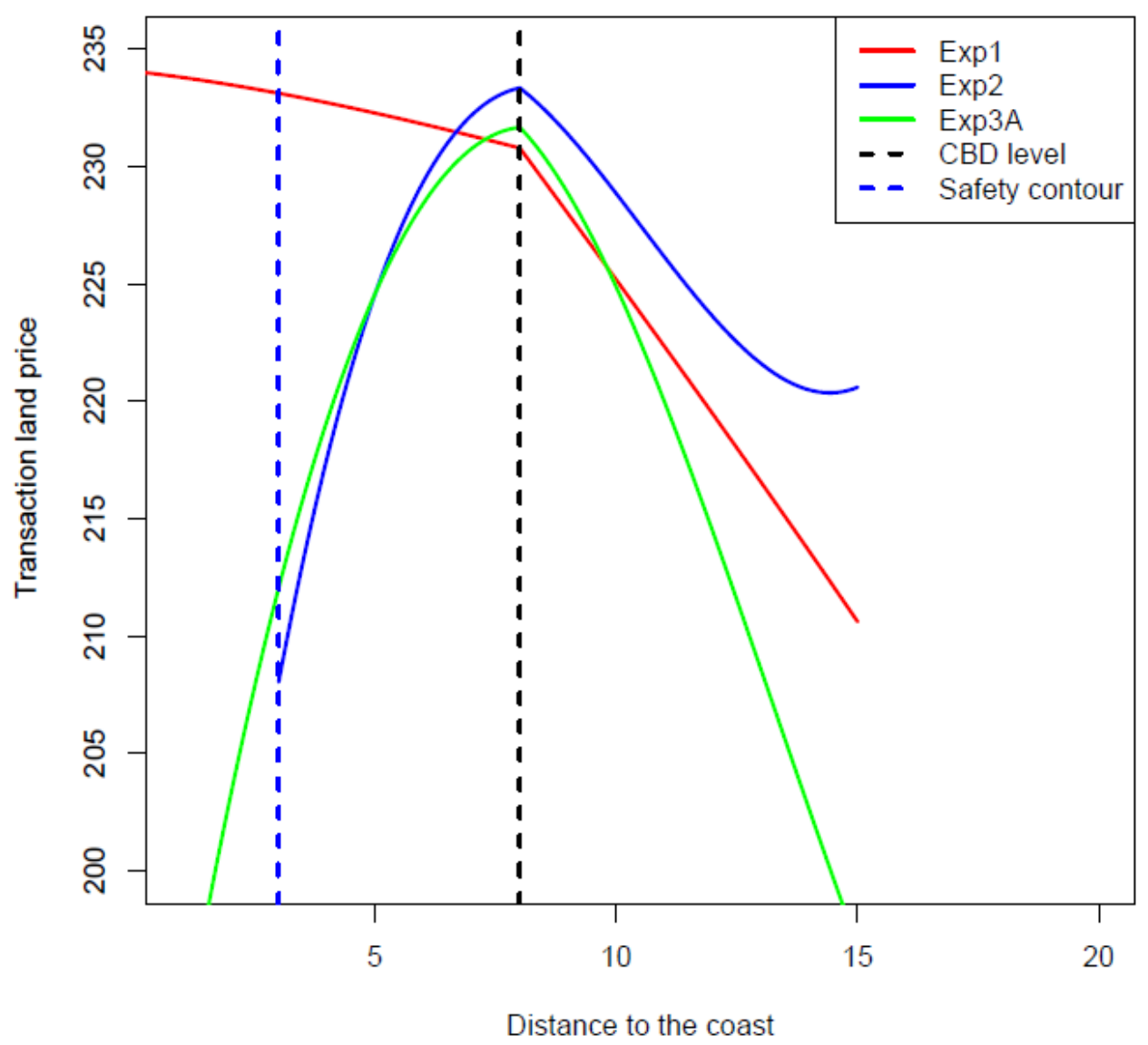

Figure 5.4: 2D cross section of rent gradient

\subsubsection{Experiment 5.2: trade-offs between amenities and disamenities}

In Exp.5.2 we instantiate the ALMA-C model with a spatial disamenity, specifically a flood probability that declines with distance from the $\operatorname{coast}^{38}$. Homogeneous economic agents perceive the flood probability objectively, meaning that $R P_{d e v}=0$ in Equation 5.3. Given this constant flood probability, agents maximize expected utility according to Equation 5.2 in Section 5.3. These economic agents have to make a trade-off between the amenity value of the coast and the disamenity of increased flood risk. This trade-off affects both the individual choice of a desirable spatial good in urban land market and its price, i.e. spatial patterns of development and the rent gradient.

Figure 5.5 shows the new simulated rent gradient. The main change in the spatial morphology of the city is seen in the lack of urban development along the coastline. The city border has shifted landwards. Agents' expected utility is quite low in the primary zone along the coast due to the high

\footnotetext{
${ }^{38}$ Future experiments will explore the effects of heterogeneous flood protection, representing the real-world case of the "risk towns."
} 
flood probability, reducing their WTP below the sellers' ask price ${ }^{39}$. For future reference, we will refer to the line at which the city's left seawards border has stopped as the "safety contour".

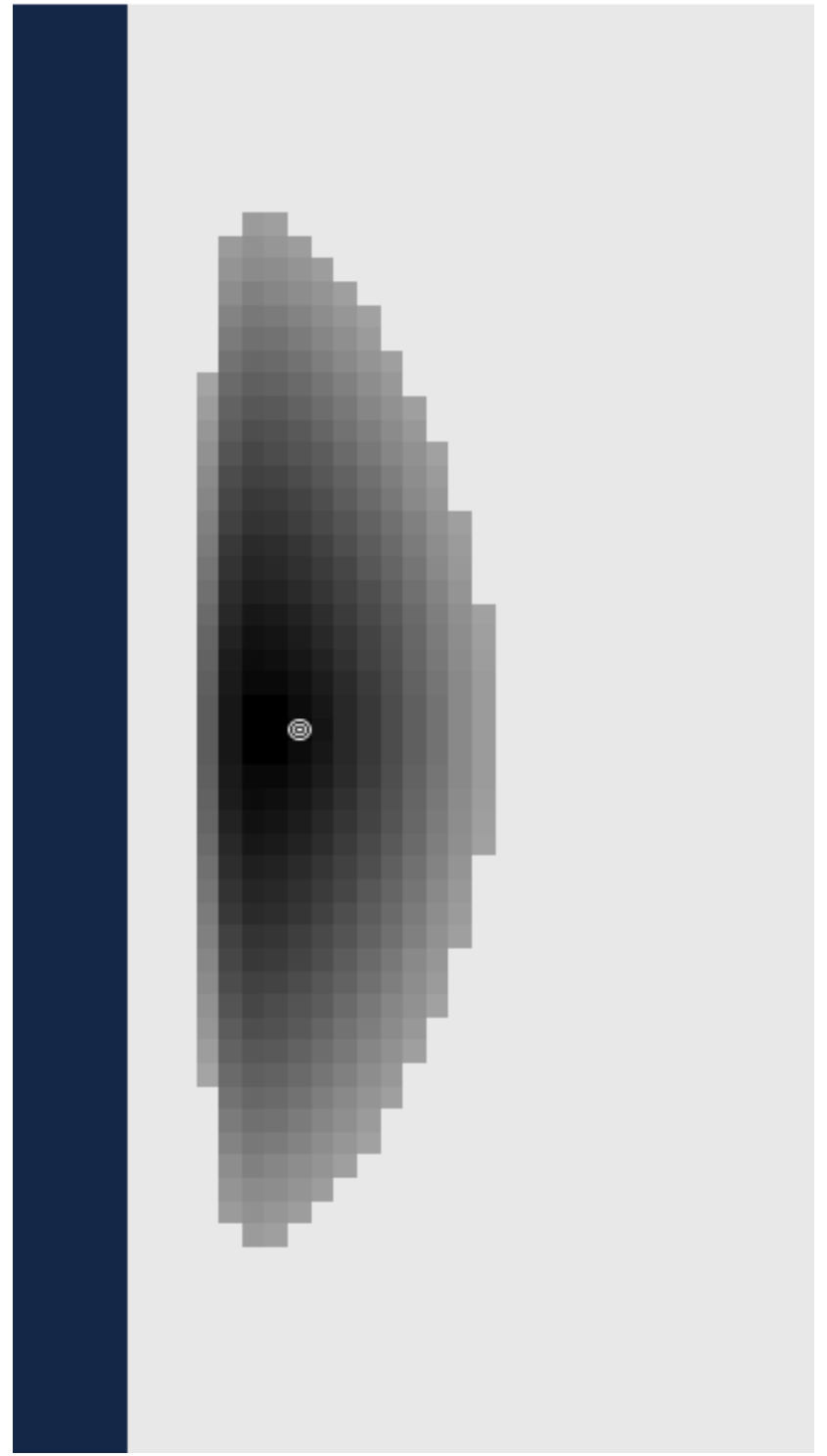

Figure 5.5: Rent gradients, Exp.5.2: both spatial amenities and disamenities are present)
The city extent and total urban area have also declined (e.g, the city border has shifted from 26.93 spatial units in Exp.5.1 to 22.09 in Exp.5.2, and urban area is reduced from 622 to 441 cells) as seen in Table 5.2, Section 5.4.2. This result is due to the assumption of the open city and the fact that, with positive flood risk everywhere, expected utility is lower everywhere than in Exp.5.1. The average transaction price is lower (compare columns 1 and 2 in Table 5.2 in Section 5.4.2), as expected. Average utility has also declined (compare 42.53 to 43.02 in Table 5.2). A t-test confirms that these differences are statistically significant between experiments at the $0.99 \%$ confidence level.

Figure 5.6 shows a 3D scatter plot of the land prices in the city. Land prices decreased intensively closer to the coast; however, because the coastline also provides environmental amenities, it still attracts some development. This line of development facing the coast is seen in curve that stands separately

from the others. The gradient is still convex, as before.

Using regression analysis of land price as a function of distance to the CBD and distance to the coast (the amenity/disamenity source), we estimated the land rent gradient for Exp.5.2 (see column 2 in Table 5.3 in Section 5.4.2). The fit for the cubic regression is good ( $\mathrm{R}^{2}$ is 0.9636$)$. The estimated coefficients on distance from the coast now reflect the net amenity affects of the coastline (amenity value plus flood risk), as they would in an empirical model using real-world data.

In order to visualize how the estimated rent gradient has shifted, these regression coefficients are plotted in the blue line in Figure 5.4. The left dashed blue line represents the "safety contour", at

\footnotetext{
39 This result is consistent with the "optimal distance" from a distance-dependent spatial disamenity demonstrated in an analytical model by Parker (2007).
} 
which city stops. No developments occurred beyond it in any of the 50 repetitions of this experiment. In contrast to the peak of the estimated rent gradient at the coast in Exp.5.1, the estimated rent gradient clearly drops down closer to the coast where the risk of flooding is the highest, and estimated rent is highest at the CBD. Estimated rent declines more steeply to the right of the CBD, as before.
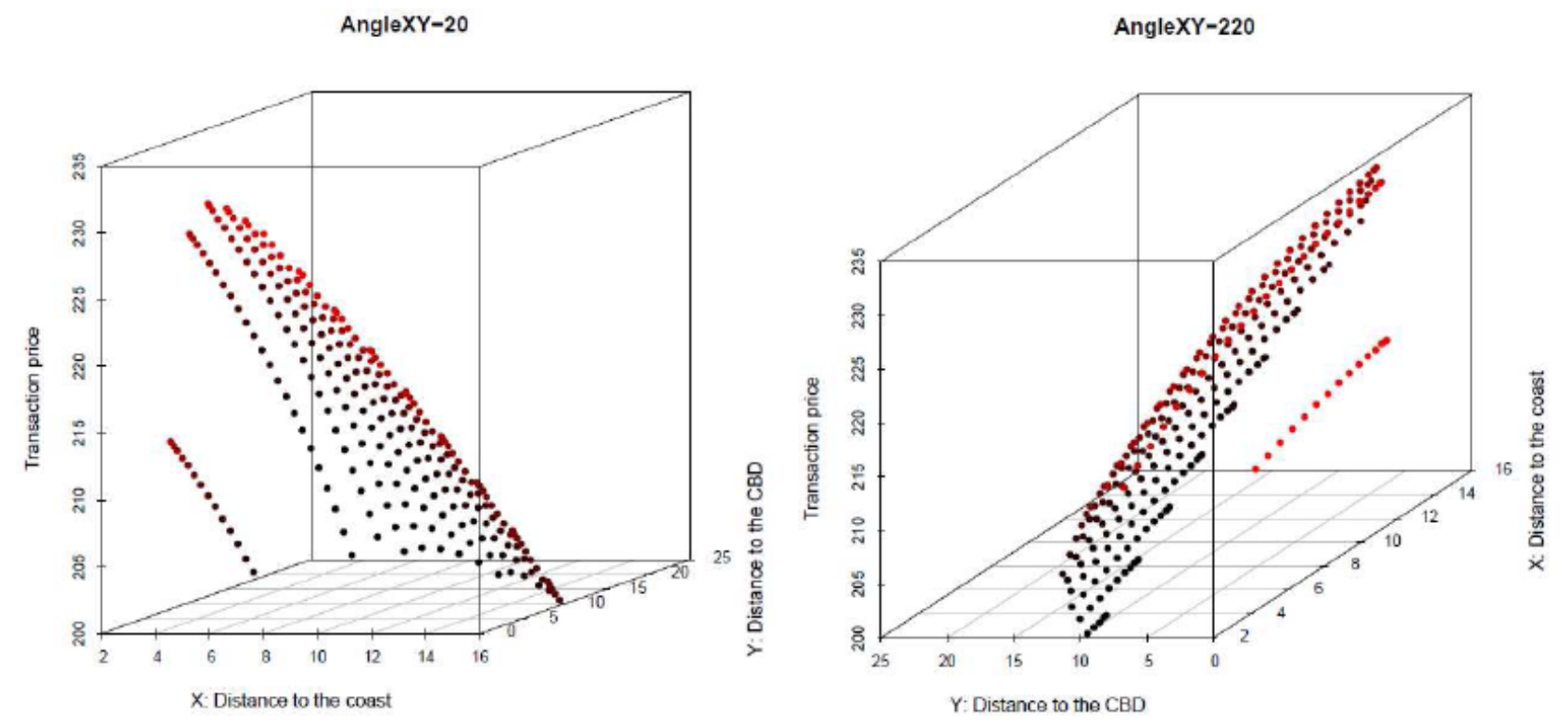

Figure 5.6: 3D scatterplot of transaction prices for Exp.5.2: both spatial amenities and disamenities are present

\subsubsection{Experiment 5.3: heterogeneity among agents}

The case-study of Dutch coastal towns tells us, however, that people do not perceive the probability of flooding objectively. Experiment 5.3 is designed to address our second research question and shed some light on the micro-economic interactions of heterogeneous agents in a land market with heterogeneous spatial goods. Agents in Exp.5.3 are heterogeneous in their beliefs about the probability of flooding. To avoid statistical bias and make Exp.5.3 comparable to Exp.5.2, the average perception of the probability of flooding is set equal to the objective probability of flood: $E\left(P F_{i}\right)=P F_{o b j}$. (See Equation 5.3 and Table 5.1 in Section 5.4.1 for more details). Agents' RP deviation $R P_{d e v}$ follows a uniform distribution with mean zero and deviations $[-0.15 ; 0.15]^{40}$. Thus, on average, agents perceive the flood probability risk objectively. In essence, this experiment compares the outcomes of representative agent behavior (Exp.5.2) with the outcomes of behavior of heterogeneous agents who are on average the same as the representative agent. Given our twodimensional landscape, multiple repulsive and attractive spatial influences on land rents, and

\footnotetext{
${ }^{40}$ The results of the model run with the normal distribution of RP are qualitatively the same.
} 
heterogeneous agent population, this experiment would be quite difficult (and has not been successfully performed to our knowledge) using an analytical model.

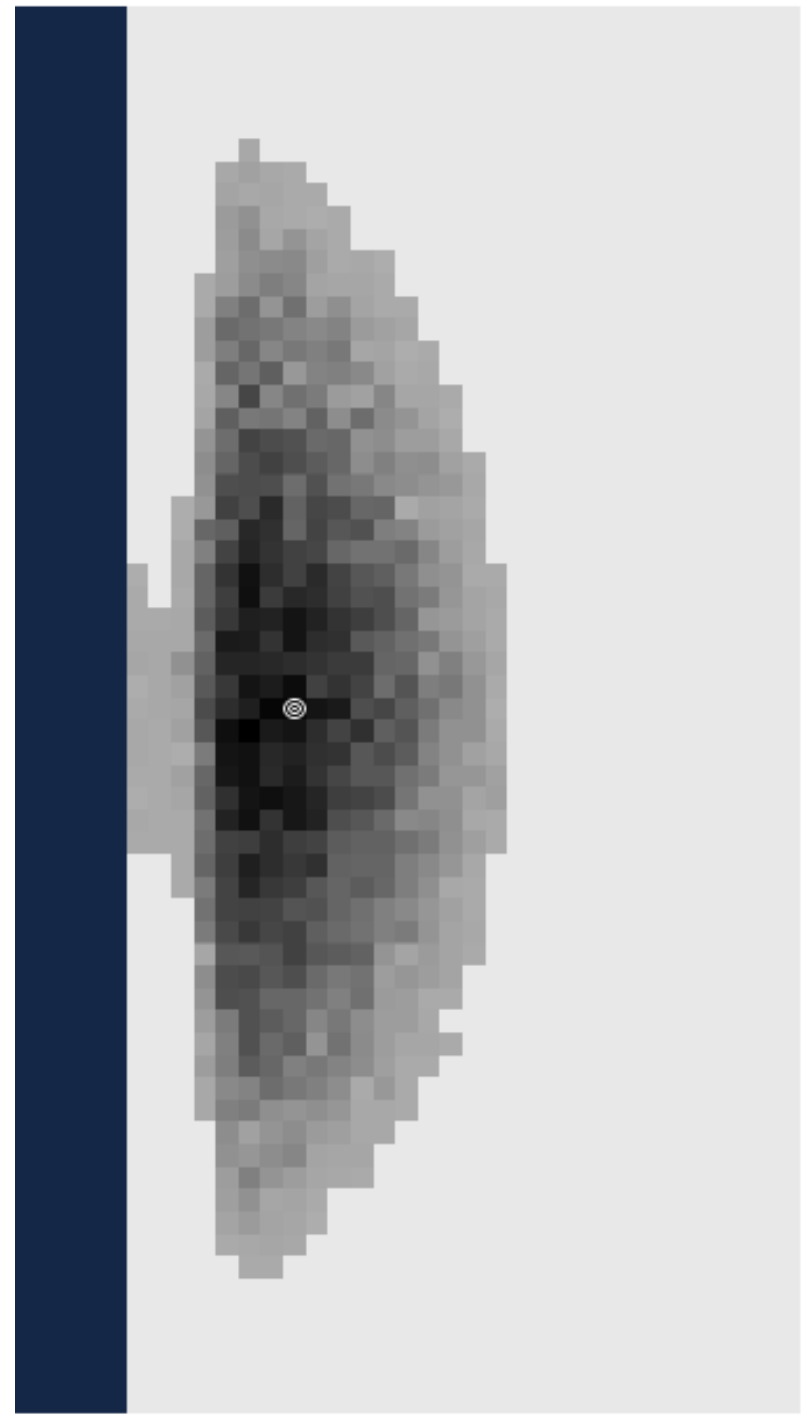

Figure 5.7: Rent gradients, Exp.5.3: heterogeneous agents
Land market outcomes with heterogeneous agents (Figure 5.7) differ substantially from those with homogeneous agents (Figure 5.5). Intuition might suggest that outcomes would be similar to the homogeneous risk case, since on average, buyer's bids are equal in both cases. However, since land market outcomes are determined through multilateral bidding between buyers and sellers, model outcomes contradict that initial intuition. The results of the simulations, however, are easily understood by recognizing the role that downward-biased perceptions of the probability of flooding have in the land market. Basically, those with the lowest perceptions of the probability of flooding have the highest WTP for higher-risk properties, and thus they are more likely to capture the property in competitive bidding. In short, those with the lowest risk perceptions are driving the market outcomes.

As a result, the spatial patterns of land use differ between Exp.5.2 and Exp.5.3. First, buyers settle closer to the coast. In Exp.5.3 about 7\% of urban developments lie seaward from safety contour (Table 5.2 in Section 5.4.2), where representative agents in Exp.5.2 found it too risky to locate. Agents who underestimate risk have relatively high expected utility from these locations to the left of the "safety contour". They are thus able to offer a bid price high enough to meet the ask price of sellers. These developments can be considered economically inefficient, since the true expected value of development is below the agricultural returns. This is not a random outcome. Exp.5.3 was reproduced 50 times with different random seeds and the result is consistent: agricultural land is converted into urban use seaward from the "safety contour" in a land market with heterogeneous agents.

The city border has expanded and the urban population has increased compared to the homogeneous agent case (see Exp.5.2 and Exp.5.3 in Table 5.2). Again, development occurs in 
areas where the objective returns from development are below the agricultural opportunity cost. Additionally, the previous symmetry of land use and land rent is lost. Agents with different $R P_{d e v}$ value land at the same location (with its associated amenity value, flood risk, and distance to the CBD) differently. Thus, even though prices are still in general higher in proximity to the CBD, they no longer decline monotonically. The city also no longer expands uniformly in all directions. Comparing Figure 5.7 to Figure 5.5, more cells are converted at the extensive margin of development closest to the coastal areas. The heterogeneity and non-monotonicity of land rents is also clearly seen in the 3D scatter plot of the transaction data in Figure 5.8, mirroring the heterogeneity found in real-world data. Essentially, heterogeneity in individual attitudes toward spatial characteristics of land leads to heterogeneity and asymmetry in realized land rent patterns. However, although the transaction data from Exp.5.3 are quite dispersed, they still follow the trend of the homogeneous case (compare Figure 5.8 and Figure 5.6). The dispersion (essentially, heteroskedasticity) arises from the agents' heterogeneity.
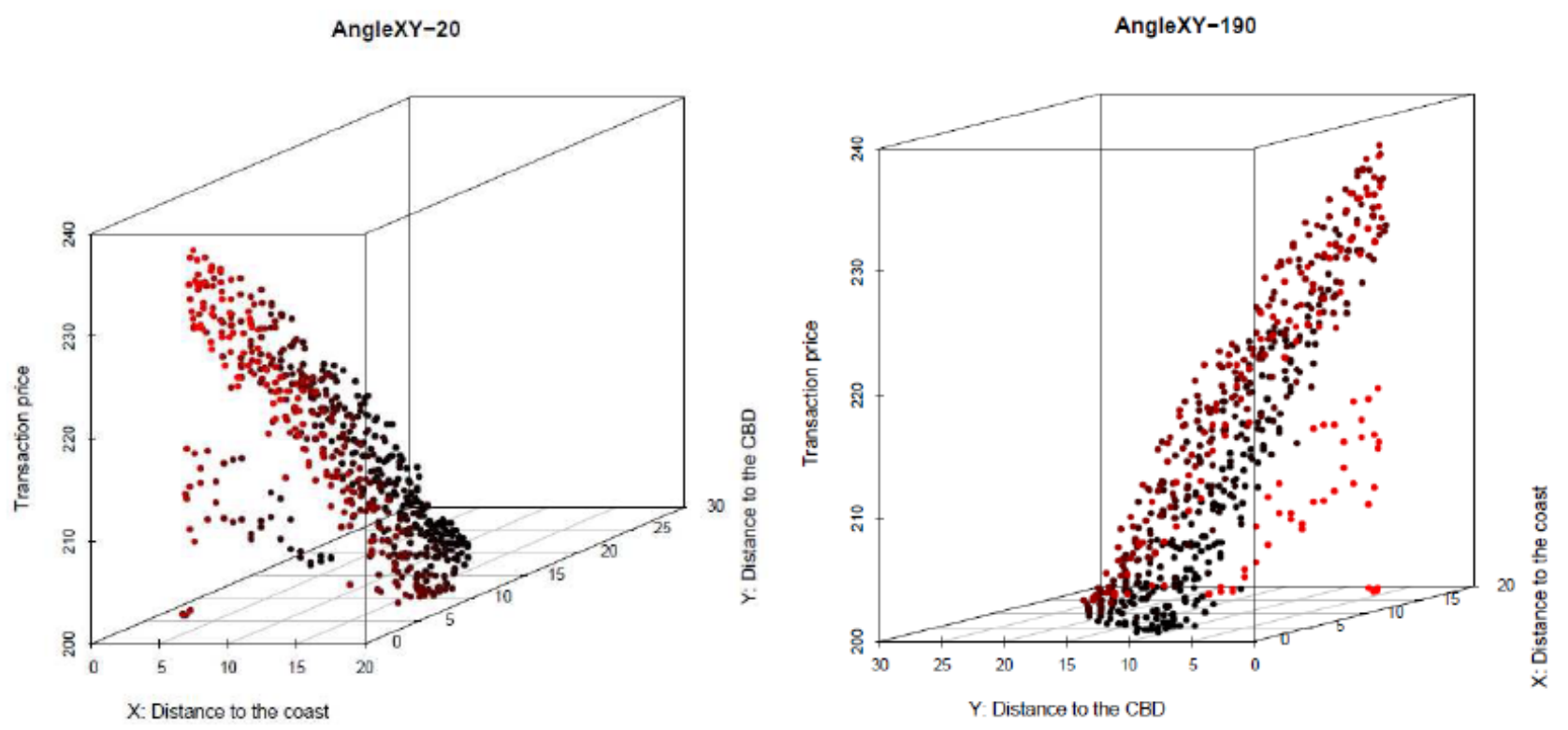

Figure 5.8: 3D scatterplot of transaction prices for Exp.5.3: heterogeneous agents

Standard econometric theory explains the presence of the error term in part through unobserved heterogeneity. When this heterogeneity is due to systematic differences in the characteristics of buyer agents, the result is bias due to the omitted variable of preference heterogeneity. The willingness to pay of the buyers depends on their preferences for spatial amenities and their perceptions of the probability of flooding — both unobservable in the real-world. However, the beauty of agent-based modeling is in the ability to control agent-level characteristics and account for them in analysis of macro-outcomes of the data generated by simulations. Having spatial characteristics, individual preferences and probability perceptions recorded together with the land transaction data generated by ALMA-C, we gain the opportunity to systematically explore the 
potential effects of the omitted variable bias in the land price regression analysis. We thus estimate two regressions. The first includes the two spatial variables traditionally used in hedonic econometric models, also included in the regression from Exp.5.2. This regression essentially assumes that individual perceptions of the probability of flooding are constant across the landscape. The second includes a third independent variable, the probability perception deviation of the buyer agent.

The results of the land rent gradient estimation for Exp.5.3 are presented in Table 5.3. Column "Exp.3A" shows the results of a cubic regression of land price based on the observed spatial data, and column "Exp.3B" reports the results of the same regression where the individual RP is also included in the set of explanatory variables. As expected, regression "Exp.3B" explains more of the variability in transaction prices than "Exp. $3 \mathrm{~A}^{\prime}\left(\mathrm{R}^{2}\right.$ is 0.9105 vs. 0.0 .8663$)$. The estimated coefficients on the other independent variables have also changed, consistent with omitted variables bias. For instance, in "Exp.3A" the effects of distance to the CBD are close to zero, and the statistical significance is low. In "Exp.3B”, the rent gradient from the CBD is significantly negative, as expected ${ }^{41}$. This simple modeling exercise illustrates that observed variation in real-world transaction prices may arise from non-spatially-uniformly distributed unobserved agent-level characteristics rather than from unbiased random error. Thus, rent gradient estimates that do not control for agent-level heterogeneity are likely to be systematically biased.

The green line in Figure 5.4 shows the 2D cross section of the estimated rent gradient that excludes probability perception deviation ("Exp.3A"). The rent gradient goes beyond the "safety contour" (left dashed blue line), while in the representative agent case all land transactions stay to the right of this line. The estimated rent gradient lies above the representative agent outcome (the blue line representing Exp.5.2) closer to the coast, then below it as distance from the coast increases.

To graphically analyze the effects of the omitted variable bias and the effects of different levels of individual flood probability perception on the unbiased estimated land rent gradient, we plotted the same estimated land rent gradient from "Exp.3A" along with the estimated land rent gradient from "Exp.3B", evaluated at three different levels of probability perception (minimum “Exp3B:low RP”, average “Exp3B:avRP”, and maximum “Exp3B:high RP”) in Figure 5.9.

\footnotetext{
${ }^{41}$ Given that the fit of the model is not perfect, the cubic regression may not be the ideal functional form for this simulated data. However, it allows us to compare cleanly between the three experiments, and the model fit is still fairly good.
} 


\section{Cubic regression fit}

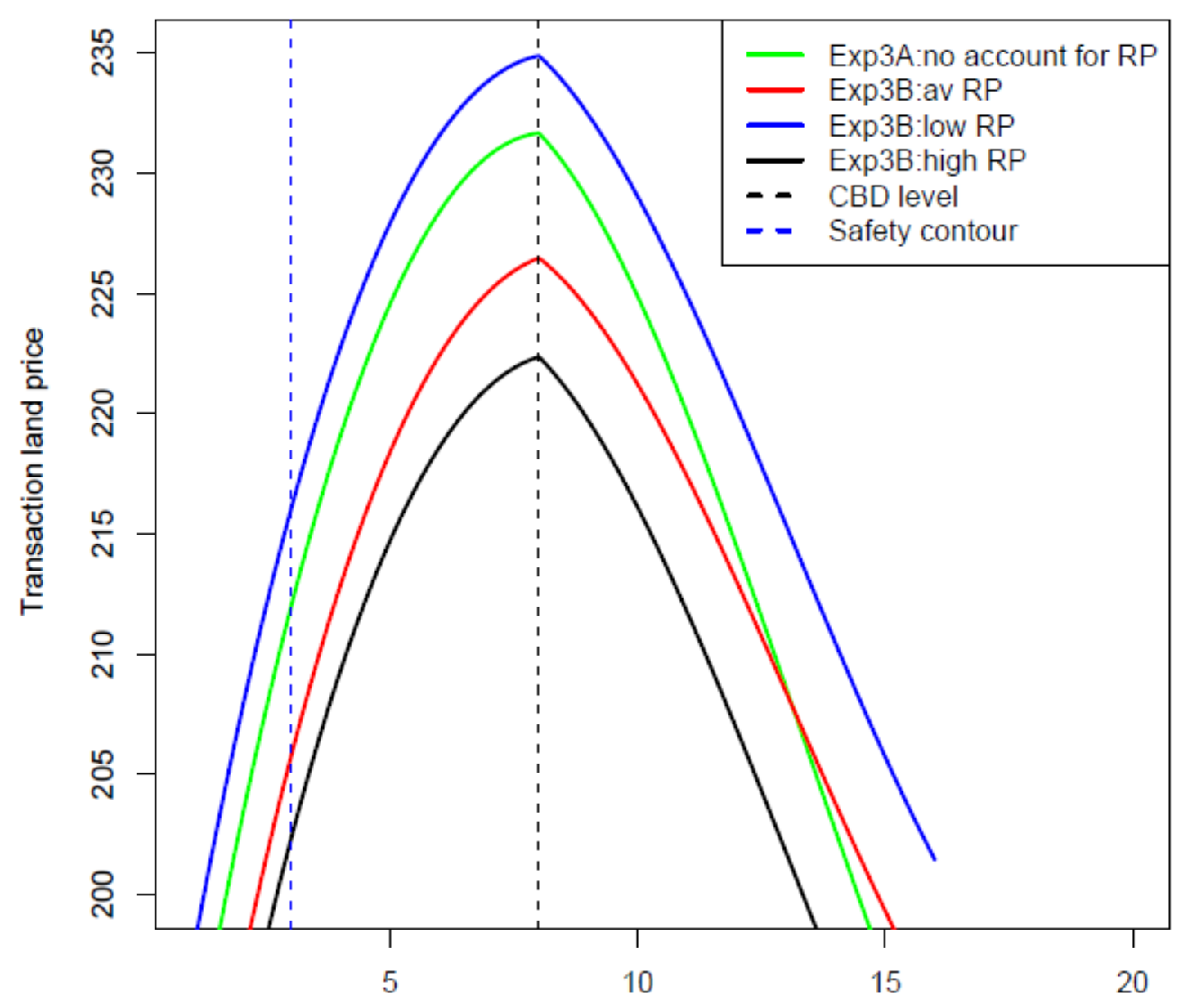

Distance to the coast

Figure 5.9: Rent gradients of agents with different levels of flood probability perception trading in a coastal urban LM

Several points are worth noting. First, as discussed above, agents who underestimate risk inevitably bid higher, as seen by the fact that the low RP rent gradient lies above and beyond the others everywhere. This is consistent with their offering higher bids for a given risky property and bidding on properties seen as too risky by other bidders, causing the city to expand beyond the efficient level under homogeneous perception of the probability of flooding.

Second, as probability perception shifts linearly, estimated land rents shift non-linearly. This result is consistent with the risk aversion of the modeled agents. At the CBD, the increase in estimated land rent for an decrease in risk from average to high is approximately twice as large as the increase for a risk reduction from low to average.

Finally, the rent gradient from "Exp.3A" lies above the gradient from "Exp.3B" estimated for an agent with average perception of the probability of flooding. The regression from $3 \mathrm{~A}$ has produced a biased estimate of the land rent gradient generated by a buyer with correct perceptions 
of probability. The "real" land market participant with correct perceptions of the probability of flooding is in fact more conservative in her WTP for risky land than estimated by 3A. The regression results in "Exp.3A" are biased upwards by the transactions that the low perception of the probability of flooding buyers captured through the bidding process. Again, by not accounting for the way in which the low perception of probability buyers are driving the market outcomes, researchers and policy makers may obtain a biased quantitative understanding of the drivers of land rents, if they base their analysis only on observed spatial data.

\subsection{Discussions and conclusions}

The empirical problem that motivated our analysis was the need to model the land market in a coastal town where both an amenity (the coastal view) and a disamenity (the probability of flooding) are present and agents exhibit heterogeneous perceptions toward the latter. The paper presents a land market model-ALMA-C - that is able to account for both heterogeneity in the spatial landscape and among economic agents interacting in the land market. The centralized price determination and land allocation mechanism of traditional analytical models is replaced by a set of bilateral trades. Structural validation (Exp.5.1 in Section 5.4.2) demonstrated that under the assumption of homogeneous agents, ALMA-C produces results qualitatively identical to an analytical equilibrium model $(\mathrm{Wu}, 2001)$. Using the ABM methodology, we were able to move beyond these traditional results to analyze the effects of multiple spatial factors and agents' heterogeneity, building a land market model that includes more real-world heterogeneity than conventional economic models. The results of our experiments have important implications:

The value of modeling multiple spatial drivers: We argue that both spatial amenities and disamenities need to be included in land market modeling, especially if they are spatially correlated. By modeling these factors separately, we can now easily perform sensitivity analysis of spatial patterns and land prices to agent attributes and the distribution of spatial amenities and disamenities in a controlled environment. Not only can the effects of different spatial attributes on land prices then be studied separately, researchers can develop a deeper understanding of the processes that generated observed spatial data, which could potentially improve the design and structure of spatial econometric models.

The importance of agent-level heterogeneity: To support policy decisions, often either a general equilibrium model (based on representative agent and fed with average statistical data) or econometric predictions (based on the estimated demand curve of a representative agent or the probability that a representative agent will perform particular land use) is used. We have demonstrated that the introduction of heterogeneity at the micro-level produces qualitatively 
different behavior at the macro-level than a representative agent approach. It is important to note that the population of heterogeneous agents was set up to be on average the same as a representative agent, i.e. their expectations are unbiased. However, when the representative agent is replaced by heterogeneous agents, not only does the land price distribution differ, but urban development expands into the zone that a representative agent considers economically inefficient. For a coastal city, it would mean that development could occur in a zone vulnerable to erosion or flooding in which a conventional model with a representative agent would not predict development. This implies that potential damage from natural hazards in a coastal town will grow beyond the level anticipated by policy makers.

The importance of agent-level data: For the heterogeneous agent case, we estimated land rent gradients using our model-generated data. The land price variation was explained in two stages: first using only the spatial attributes of the environment (the data usually available for econometric analysis) and second, including data on the individual agent characteristics of buyers, specifically flood probability perception (usually unobservable directly in the real-world). Comparison of the two regressions showed that estimates based only on spatial data may give policy-makers a biased picture of land market dynamics. Thus, it is very important to include individual data when possible. We are conscious that agent-level data (for example, a survey about preferences or perception of the probability of flooding) are difficult to obtain, especially when coupled with land transaction data. It is possible that some proxy for preferences could be developed for statistical estimation of the demand function. At the very least, we should be conscious regarding potential biases in predictions due to missing agent-level data. An agent-based land market model such as the one we present can be used as a computational laboratory to understand the potential implications of missing data.

Risk perceptions as a driver of land market activity: There is an important, and quite significant for today's US housing market situation, link between land prices and individual risk perception. The ALMA-C model shows that people who underestimate risk drive land market dynamics, causing the city to expand into a high risk zone. Although this paper focuses on the risk of natural hazards, the results can be expanded to other types of risks. Real-estate economics views a house as an asset, and there are financial risks involved in investment in different properties. If property investors/home buyers have heterogeneous perceptions of financial risks, it can lead to the conversion of rural land into urban use at locations and in amounts that are economically inefficient. Given that conversion of land to urban use is largely irreversible, our work implies important linkages between misperceived financial risks of land investments and urban sprawl. In short, an 
additional causality of the current housing and financial crisis is likely economically inefficient, irreversible expansion of our city boundaries.

In summary, heterogeneity of both land and individual preferences are crucial determinants of land market behavior. Our agent-based land market links the micro-characteristics of agents and macro-market outcomes, serving as a laboratory where spatial characteristics of the landscape and individual perception of those spatial attributes are coupled in a dynamic modeling environment to produce simulated land transaction data. With this information, one can easily derive new estimated rent gradients, spatial patterns of allocation and spatial distributions of land prices over a 2D landscape. This complement of economic, econometric and agent-based models could help to improve analysis to support policy making and planning. 


\section{Response of economic agents in a land market to changed erosion risks in coastal towns}

\subsection{Introduction}

The coastal area, which provides ecosystem functions such as erosion control, and sediment retention, is also a very lucrative area for urban developments. On one hand, coastal areas exhibit great pressure from human systems: up to two thirds of the world's population live there (Costanza et al., 1999), and demand for coastal land is only growing. On the other hand, the pressure from the global changes in natural system is also growing. Climate change is likely to produce more extreme events, such as severe storms or hurricanes in addition to a gradual rise of the sea level (Nicholls et al., 2007). As a result one should expect an increased probability of flooding or erosion in the coastal area. Human and physical (or climatic) pressures lead to the effect known as a 'coastal squeeze'. Coastal squeeze is the situation observed in the coastal margin, which is squeezed between fixed landward boundary and the rising sea level (Schleupner, 2008) shrinking the areas available for natural coastal processes to take place. To confront the threats of the coastal squeeze, some of the forcing factors (i.e. land use, erosion, sea-level rise) should be affected. However, controlling global pressure of nature (sea-level rise and erosion) on a local spatial scale is either not likely in the short-term or is very costly. Moreover, permanent hard flood defenses only accelerate coastal squeeze ${ }^{42}$ (Sterr, 2008). In contrast, the human component contributing to the coastal squeeze seems to be more manageable. At least, the drivers, which underlie human pressure, should be investigated with the potential to affect them in the desirable way.

This chapter explores the drivers of human pressure on the coast. In particular, we are interested in the response of economic developments to the increased global climate change pressure, e.g. risk of coastal erosion. The central research question is how coastal land markets react (in terms of changed land prices, city size, and amount of urban developments under risk) to an increasing probability of flooding or erosion. In addition, we are interested in how variations in individual perceptions of erosion probability affect aggregated patterns of development and coastal squeeze. To pursue this task the spatially explicit land market model — ALMA-C — discussed in details in previous chapters, is applied. The power of the ALMA-C model is in its ability to register how land markets may respond to the changes in the spatial environment under different assumptions about individual economic behavior.

\footnotetext{
${ }^{42}$ It happens because hard coastal flood defenses affect natural habitat for species and natural processes such as sediment transport..
} 
The chapter proceeds as follows. We first demonstrate the situation in Dutch coastal towns and discuss how global physical and human pressure affects the determination of legally stipulated flood defence line. Second, we briefly describe the assumptions of the agent-based land market model. The model is similar to the one presented in Chapter 5 except for the assumption of the increased probability of erosion. Third, the results of the ALMA-C model run are presented. In this experiment agents are assumed to perceive the probability of erosion objectively, as a conventional economic model would assume. Next, the aggregated outcomes of the land market where agents have heterogeneous ${ }^{43}$ beliefs about probability of erosion are analyzed. Finally, the discussions and conclusions are outlined.

\subsection{Dutch coastal towns under risk}

The coast in the Netherlands is protected by a system of dikes and dunes, which have certain safety levels defined by law (Wet op de Waterkering, 1995). However, some 13 coastal towns in the Netherlands (see Figure 6.1) have areas, which are situated on or seawards of the flood defenses, and consequently are not protected in compliance with the legal safety standards, such as probability of erosion/flood 1:10000 (Rijkswaterstaat, 2002). Each town is divided into two zones: legally protected one (on the right from the black line in Figure 6.2) and a zone where the government cannot guarantee any safety level (Rijkswaterstaat, 2005c). The zone on the left side of the flood defence line does not have legally stipulated safety standards and is often referred to as 'unprotected' or 'outside the dikes' area (buitendijks gebied).

The flood defence line is based on the physical erosion line estimated by morphological models (van der Burgh et al., 2007). The erosion line shows how far landwards the erosion will go if there will be a storm of such a strength, which is predicted to happen only once in 10,000 years. However, it should be noted that the flood defence line in Figure 6.2 is a politically determined line (Rijkswaterstaat, 2005c). Specifically, it is a political decision whether to shift this line landwards following the pressure of the natural system or move it seawards under the pressure of the human system. For example, the flood defence line at the top of Figure 6.2 abruptly turns landwards, although in reality the physical erosion line ${ }^{44}$ goes parallel to the coast. This happens because the area north of the city is a natural park. The political decision was to allow natural coastal processes there because it is important for the maintenance of coastal ecosystems. In contrast, if the area outside the dikes contains buildings of a high economic value, then policy-makers might decide to

\footnotetext{
${ }^{43}$ Agents' heterogeneous beliefs are statistically unbiased, i.e. the population of agents on average has zero deviation of their beliefs about probability of erosion. In other words, it is the same as a representative agent with objective knowledge about probability of a coastal hazard.

${ }^{44}$ Erosion line is not in Figure 6.2
} 
shift the flood defence line seawards from the position of the erosion line. This decision implies that additional money should be invested to strengthen the dunes, so that the politically-determined flood defence line coincidences with the physical erosion line. This interplay of natural and human interests and priorities in the process of determining the position of flood defence line is yet another illustration of the coastal squeeze.

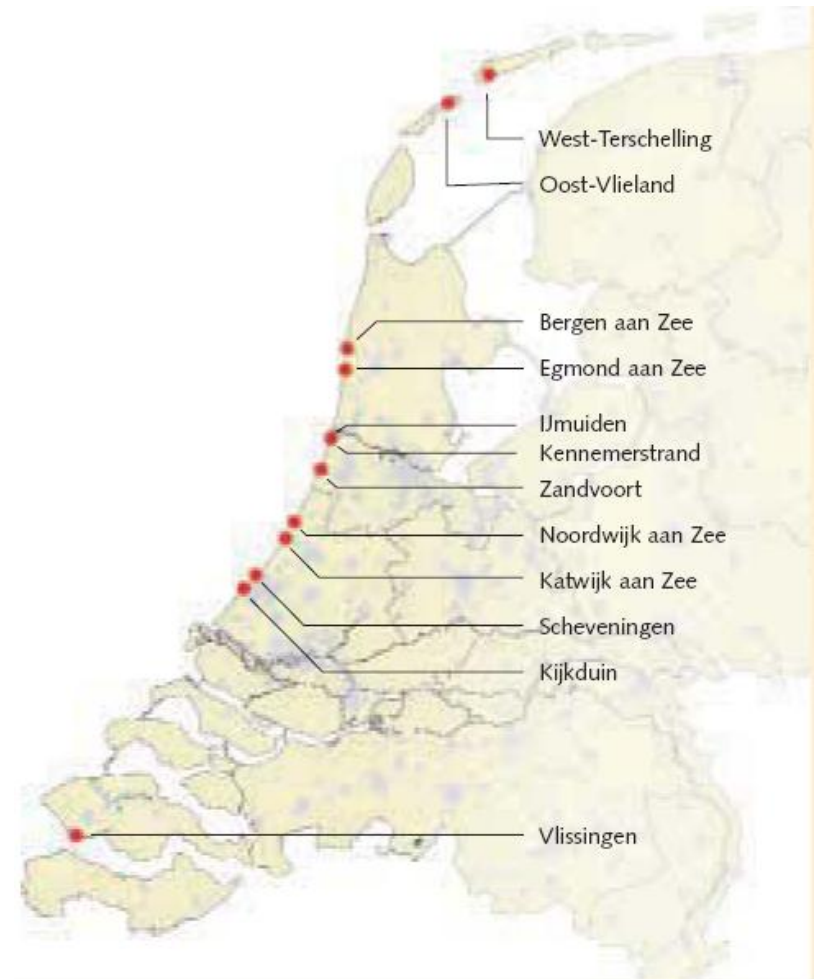

Figure 6.1: Risk towns, i.e. coastal cities with outside the dikes areas

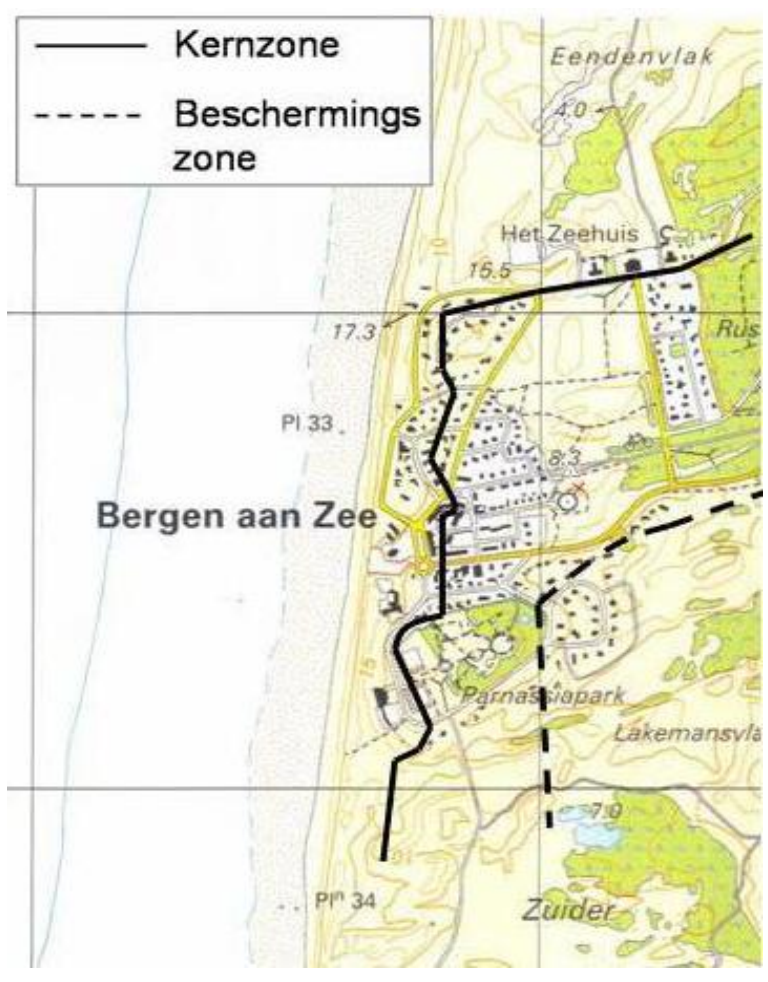

Figure 6.2: Flood defence line (Kernzone) that divides a city into the legally protected and unprotected zone

Figures are from (Rijkswaterstaat, 2005c)

All the 13 Dutch coastal towns have urban developments in the area outside the dikes. As can be seen from Figure 6.2 there are quite a few buildings situated in the unprotected area. Thousands of individuals live beyond the dikes in the Netherlands (Rijkswaterstaat, 2002). The total potential damage for the unprotected areas for 13 coastal towns was estimated at $€ 6.607$ millions $^{45}$ (Rijkswaterstaat, 2005c). In October 2005 the Commission of Poelmann published an official recommendation to the government concerning the future of these coastal cities under risk. The Commission advised to allow future developments in the areas beyond the flood defence line at the risk of individuals (Poelmann Commissie, 2005). Thus, it would be possible to invest in the unprotected areas but individuals should be responsible for the risks they take. However, there is a concern that individuals seem largely unaware of the risks involved (Kaiser et al., 2004; Bočkarjova

\footnotetext{
45 The estimation is done with the help of "Economic GIS" (Huizinga, 2003) based on the HIS-KSM method (Rijkswaterstaat, 2005d) using from 1995, 1997 and 1999 data ((Rijkswaterstaat, 2005c), p61).
} 
et al., 2008; Krywkow et al., 2008; Terpstra and Gutteling, 2008). Moreover, what once was considered as unlikely (once in 10,000 years event) can become a much more probable scenario under the conditions brought by changing climate and increasing frequency and severity of storms with risen sea levels. This can very well cause the erosion line to shift landwards increasing the risk of damage in the areas seaward of the flood defence line.

In what follows we demonstrate how the economic system might respond to the shift of the erosion line and the effect such factors as individual perception of erosion probability may have on the urban developments along the coast.

\subsection{Experimental setup of the ALMA-C model}

One of the benefits of the ALMA-C model is that it shows how individual preferences are aggregated to produce land prices and spatial patterns for land in a coastal city. ALMA is an abstract theoretical model, however its main advantage in allowing the connections of micromotives of individuals operating in a heterogeneous spatial landscape to macro-indices at the aggregated level of a city. If individual preferences or perception of a probability of a coastal hazard change, then land prices and spatial patterns also change as a result of multiple interactions between agents in a land market. There is empirical evidence of this happening (see Chapter 2), and ALMA is able to capture this process (as shown in Chapter 5).

Similarly, if spatial environmental conditions change (such as erosion probability), these changes enter the decision making process of individual economic agents and have effects in the macro-level (see Figure 1.1 in Chapter 1). Land market outcomes depend not only on the individual preferences of economic agents but also on the quality of spatial goods, i.e. land itself. If the quality of land (expressed in the availability of environmental amenities or, in this case, level of erosion or flood risk) changes, then individual utility from its consumption also changes, leading to changes in aggregated demand for land in the area.

In the situation when risk of investing in some areas increases, for example due to the shift of the erosion line, economic agents operating in an urban land market re-estimate their expected utility from locations, possibly modifying the aggregated demand for land. In the experiment below we first simulate a shift of the erosion line in a stylized coastal city where all agents perceive erosion and flood risk objectively. The second experiment shows how land prices and spatial patterns will look like if some agents have lower or higher awareness of coastal risk. Thus, first experiment assumes that individuals are rational and are all alike (as a representative agent assumed 
by conventional economic models) and perceives probability of erosion as it is, i.e. objectively ${ }^{46}$. The second experiment assumes that some individuals might underestimate or overestimate the actual probability of erosion, i.e. perceive it subjectively (a deviation in agents' perceptions of actual probability implies that agents are heterogeneous).

Experiment 5.2 from Chapter 5 serves as a base case for the two experiments presented here. Particularly, buyers and sellers behave as described in section 5.3 in Chapter 5. Sellers form their ask price based on the expected WTP of buyers but this ask price cannot be lower than the opportunity costs of the agricultural land price. Buyers maximize their expected utility and form bid price for land based on their true WTP. Sellers choose the highest bid-offer, and whenever it is above their WTA, the transaction takes place. Otherwise, both buyer and seller stay in the land market and participate in the bidding process in the next time step. The model stops running when no more transactions occur, i.e. when all the submitted bids are lower than WTAs of sellers.

Shift of erosion line in the model: For simplicity let us assume that the actual objective probability of erosion $\left(P F_{o b j}\right)$ is distance-dependent ${ }^{47}$ :

$$
P F_{o b j}=\frac{C_{P F 1} * C_{P F 2}^{8}}{C_{P F 2}^{8}+D_{\text {coast }}^{8}}
$$

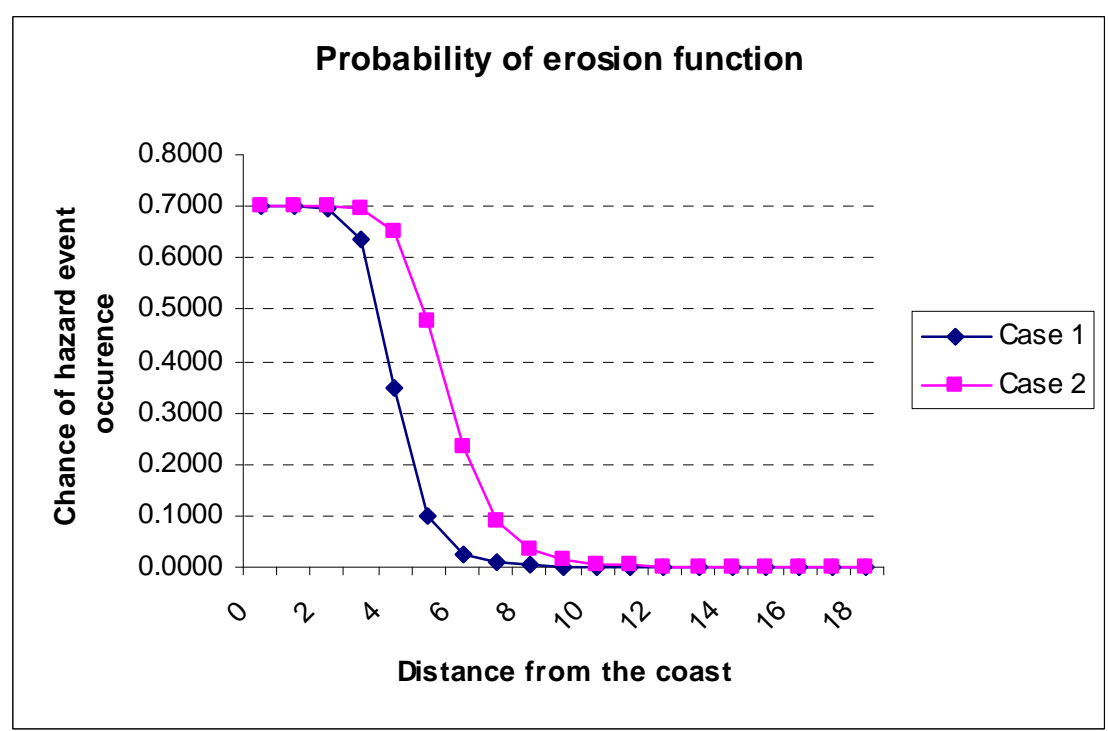

Figure 6.3: The probability of erosion as function of the distance from the coast. Case 1 is used in Exp.6.1 and Case 2 is for Exp.6.2
Obviously, probability of flooding or erosion at a certain location should be estimated in a much more advanced way taking into account frequency of storms, form of the coastline, elevation, geomorphology, etc. This, however, goes beyond the scope of the study since at this time topography is not considered in the ALMA model. Technically ALMA-C could integrate a vertical gradient (height relative to sea level) to account for these factors. However, this

\footnotetext{
${ }^{46}$ An assumption of a representative agent does not necessary imply that he perceives the probability objectively. As it will be shown in Chapter 7, a representative agent can underestimate probability or risk of a coastal hazard.

${ }^{47}$ This function is an inverted form of the Michaelis-Menten function in kinetics or Monod function in biology (Voinov, 2008)
} 
simplified version of the model uses a homogeneous height to check the pure effect of the shift of erosion line. Currently, in ALMA-C we estimate the impact of erosion by assuming that the chance of erosion depends on the distance from the coastline, and use the function from Equation 6.1, shown in Figure 6.3.

On the coast $\left(D_{\text {coast }}=0\right)$ the probability of a hazard is quite high but then it goes abruptly down reaching the value of 0.0001 (probability of 1:10000). This function in the two cases presented below drops to this lower value at different distances from the coast. This is controlled by the coefficient $C_{P F 2}$ (see Equation 6.1), which is equal to 4 in case 1 and 5.5 in case 2. In this way we represent the shift of the erosion line in our experiments. Other ALMA-C parameters are the same in all model experiments as listed in Table 6.1.

Table 6.1: Values of parameters in the simulation experiments

\begin{tabular}{|l|l|c|c|c|}
\hline \multicolumn{1}{|c|}{ Symbol } & \multicolumn{1}{|c|}{ Meaning } & Exp 5.2 & Exp 6.1 & Exp 6.2 \\
\hline $\mathrm{Y}$ & Individual budget & 800 & 800 & $800 \mathrm{~s}$ \\
\hline $\mathrm{P}_{\mathrm{ag}}$ & Price for agricultural land & 200 & 200 & 200 \\
\hline $\mathrm{TCU}$ & Transport costs per unit of distance & 1 & 1 & 1 \\
\hline $\mathrm{b}$ & Constant in WTP-WTA formula & 70 & 70 & 70 \\
\hline$\beta$ & Individual preference for green amenities & 0.6 & 0.6 & 0.6 \\
\hline $\mathrm{C}_{\mathrm{dam}}$ & Flood damage coefficient & 0.16 & 0.16 & 0.16 \\
\hline $\mathrm{C}_{\mathrm{PF} 1}$ & Coefficient in the Equation 4.1 & 0.7 & 0.7 & 0.7 \\
\hline \hline $\mathrm{C}_{\mathrm{PF} 2}$ & Coefficient in the Equation 4.1 & 4 & 5.5 & 5.5 \\
\hline $\mathrm{RP}_{\mathrm{dev}}$ & $\begin{array}{l}\text { Individual erosion probability perception } \\
\text { deviation }\end{array}$ & $\mathrm{NA}$ & $\mathrm{NA}$ & $\begin{array}{c}\text { Uniform distribution } \\
{[-0.15 ; 0.15]}\end{array}$ \\
\hline $\mathrm{avRP}$ & Mean RPdev in the traders population & 0 & 0 & 0 \\
\hline $\mathrm{PF}_{\mathrm{obj}}$ at the coast & Probability of flooding & 0.7 & 0.7 & 0.7 \\
\hline
\end{tabular}

The two experiments (Exp 6.1 and Exp 6.2) were repeated 30 times with a different random seed to check the robustness of the model results. Experiment 5.2 was also run multiple times as discussed above in Chapter 5. The random seed affects both the distribution of subjective perceptions of a coastal hazard probability and the order of agents' activation. The differences in the aggregated indices among experiments are statistically significant at $0.99 \%$ confidence interval.

\subsection{Model results}

\subsubsection{Experiment 6.1: shift of erosion line in a coastal city where individuals perceive erosion probability objectively}

In this experiment we explore the changes in the macro-outcomes of a coastal land market if probability of erosion changes (according to Figure 6.3). Specifically, we seek to understand how land prices and spatial patterns of a city change due to the landward shift of erosion line. Exp 5.2

\footnotetext{
${ }^{48}$ See Chapter 4 for the details of WTP-WTA estimation

${ }^{49}$ See Chapter 4 for Equation 4.1
} 
from Chapter 5, that we use as a base case, models a monocentric city located along the coast, with spatial amenities $(A)$ provided by proximity to the coast, and with the probability of flooding $P F_{o b j}$ (Equation 6.1). Economic agents' erosion probability perception deviation $R P_{\text {dev }}$ in Equation 5.3 (see Chapter 5) is set to zero meaning that individuals perceive erosion risk objectively and are making rational decisions on a land market. Exp 6.1 deviates from the base case by assuming that the erosion line shifts due to climate change (see Figure 6.3 and Table 6.1). As before, economic agents have to make a trade-off between coastal amenity and disamenity associated with the increased coastal risk. By shifting the erosion line we now increase the risk of locating closer to the otherwise attractive coast.

The macro-outcomes of these changes in the spatial landscape that drive the microinteractions in the land market are presented in Table 6.2. The second column "Exp 6.1" reports the welfare and spatial metrics of this experiment, the first column "Exp 5.2" reports the metrics of the base case reported in Chapter 5.
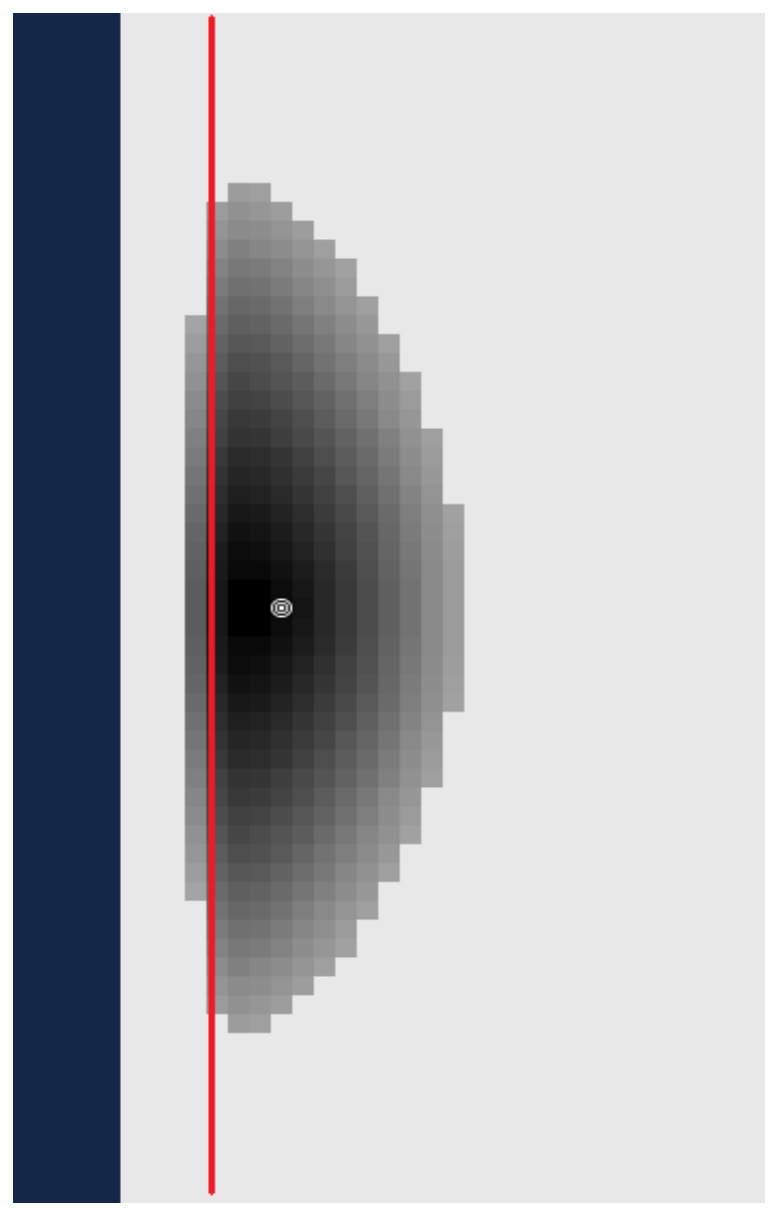

Figure 6.4: Rent gradients, Exp 5.2, i.e. base case There are some developments beyond the 'safety contour', i.e. the seawards border of a town from Exp 6.1 (when erosion line shifts)
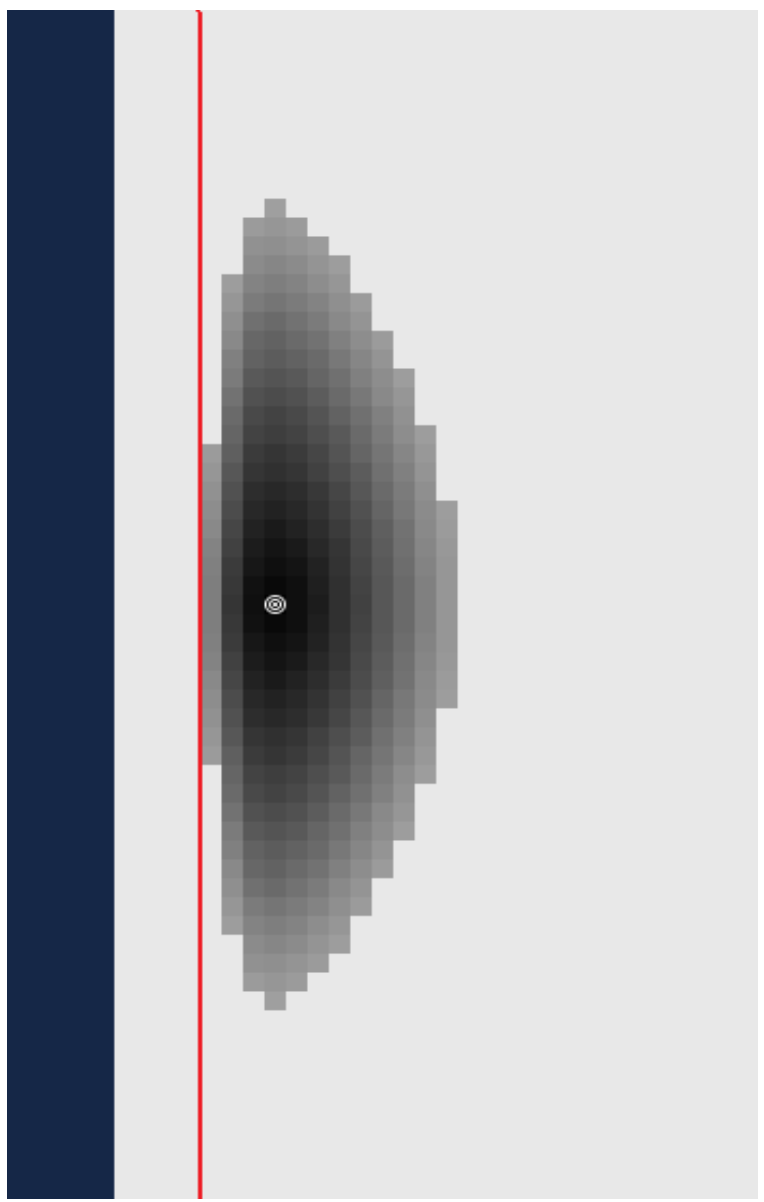

Figure 6.5: Rent gradients, Exp 6.1 Increased probability of erosion pushes the city further away from the coast, making the area in general less attractive and therefore shrinking the size of the whole city. 
Table 6.2: Welfare and spatial metric outcomes of the ALMA-C experiments

\begin{tabular}{|c|c|c|c|c|c|}
\hline \multicolumn{3}{|c|}{ Parameter } & $\operatorname{Exp} 5.2$ & $\operatorname{Exp} 6.1$ & $\operatorname{Exp} 6.2$ \\
\hline \multirow[t]{2}{*}{ Individual utility: } & \multirow[t]{2}{*}{ Mean } & \multirow{3}{*}{ St. dev. } & 42.53 & 42.25 & 42.32 \\
\hline & & & 0.99 & 0.88 & 0.97 \\
\hline Aggregate utility & & & 18754.48 & 15634.32 & 17426.57 \\
\hline \multirow[t]{2}{*}{ Urban transaction price: } & Mean & \multirow{3}{*}{ St. dev. } & 212.93 & 211.11 & 210.6 \\
\hline & & & 8.17 & 7.3 & 7.87 \\
\hline \multicolumn{2}{|l|}{ Total property value } & & 93902.49 & 78110.13 & 86725.16 \\
\hline \multicolumn{3}{|c|}{ City size (urban population) } & 441 & 370 & 411.8 \\
\hline \multicolumn{3}{|c|}{ Distance from CBD at which city border stops } & 22.09 & 21 & 22 \\
\hline \multicolumn{3}{|c|}{ Urban cells seawards from the safety contour } & 31 & 0 & 4.3 \\
\hline
\end{tabular}

A snapshot of the spatial distribution of urban land prices (emerged via interactions on a land market in ALMA-C) is presented in Figure 6.5. For comparison Figure 6.4 shows urban land prices from Exp 5.2. As before, the dark area on the left represents the ocean and the white circle in the middle is the CBD. The intensity of gray color symbolizes the value of land: the darker the color, the higher the land price. As can be seen from these figures, the city has shrunk from the seaward side (also see Table 6.2 for decreased spatial metrics). We refer to the line at which the city's seawards border has stopped in Exp 6.1 as the 'safety contour'. Since the erosion line has shifted, parts of the previously (Exp 5.2) comparatively safe area have become more risky to invest in. Assuming that economic agents make rational decisions, meaning that they evaluate erosion risk correctly, they would no longer be willing to pay much for the land along the coastline. In this case their bid prices will not be high enough to cover sellers' reservation price. Thus, a larger area along the coast would remain undeveloped. In other words, if economic agents make rational decisions in a land market, then the city would shift landwards with the increased probability of erosion.

Not only the size of the city shrunk but also utility of individuals settled in the city went down. Aggregated utility decreased by $16.6 \%$ (see Table 6.2) compared to Exp 5.2. So did the land prices (total economic value in this city dropped by $16.8 \%$ ). In other words, if people do perceive increased environmental risks associated with climate change, then they would make market decisions that lead to less potential damage at the aggregated level, making future investments in coastal zones and coastal cities in a less risky way.

The major strength of the agent based modeling is that we do not need to have all agents be the same, be representative. In reality individuals are all different, and have different ideas about risk, values, and costs. In the subsequent experiment we investigate the effects of the variability in agents' beliefs about probability of erosion. 


\subsubsection{Experiment 6.2: shift of erosion line in a coastal city where agents have}

heterogeneous perception of erosion probability

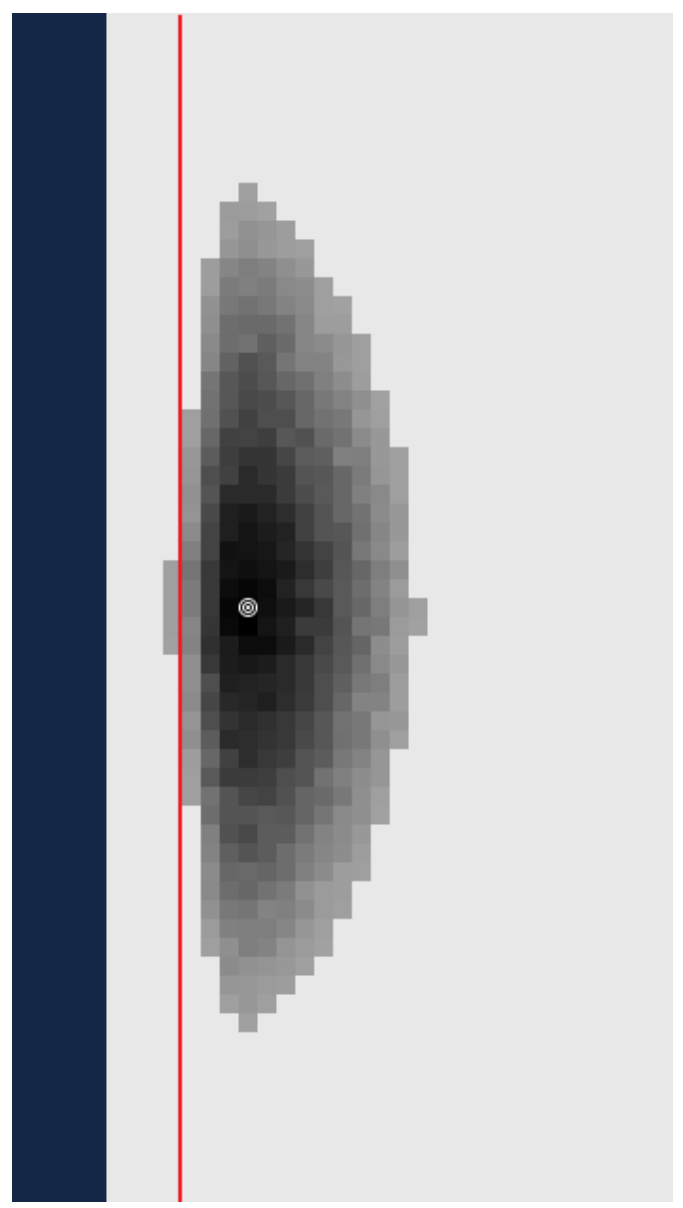

Figure 6.6: Rent gradients, Exp 6.2 (increased probability of erosion in the city where agents have heterogeneous perception of a coastal hazard probability)
Exp 6.1 above assumes that all economic agents perceive erosion risk objectively. This is usually also the assumption that coastal policy-makers make while considering that people are aware of risks, which they are taking. However, people have difficulty perceiving probabilistic risks (Slovic, 1987). Often they have subjective perceptions of erosion probability, which differs among individuals. Consequently, the more realistic assumption is that individual perceptions of the probability of erosion are subjective and nonhomogeneous. So, for Exp 6.2 we make the hazard probability perception deviation $R P_{d e v}$ (see Equation 5.3 in Chapter 5) for agents to follow a uniform distribution with values varying within the interval $[-0.15 ; 0.15]$ and the mean equal to zero. This is done to avoid statistical bias and make Exp 6.1 comparable to Exp 6.2. So, individual hazard perception is not becoming lower or higher in the Exp 6.2: on average, hazard probability perception is equal to the objectively perceived probability of erosion, i.e. $E\left(P F_{i}\right)=P F_{o b j}$.

Urban land prices generated in Exp 6.2 are shown in a spatially explicit way in Figure 6.6. Comparing Figure 6.6 to Figure 6.4 and 6.5 and looking at results in Table 6.2, we can still observe that the shift of erosion line causes developments to move landwards leaving a larger area along the coast undeveloped (developed areas seawards from the safety contour in Exp 6.2 are just 14\% of those in Exp 5.2). However, there is one important qualitative difference between the Exp 6.1 and Exp 6.2: we do find urban developments beyond the safety contour if individuals have heterogeneous perceptions of erosion probability. Individuals who underestimate erosion risk would still get high expected utility in this area (see Equation 5.2 in Section 5.3 of Chapter 5 and note the slight increase in utility between Exp 6.1 and Exp 6.2 in Table 6.2). They will be willing to make sufficiently high bids to cover sellers' ask prices. Thus, people with low risk awareness drive the city to expand to the area where representative agents (in this case an agent with objective perception of erosion probability) would not find if economically efficient 
to locate. On average over 30 runs of Exp 6.2, the total property value of urban developments beyond the safety contour is 840.54 monetary units. This implies that even if only a part of the population has low perception of a probability of coastal hazard, there will already be economically unjustifiable investments done in the erosion-prone area.

\subsection{Discussions and conclusions}

This chapter demonstrates how changes in the physical conditions of the spatial environment affect the aggregated land market outcomes. In a coastal town one of the main attributes of land is the probability of coastal hazard: flooding or erosion. For many coastal towns in the Netherlands it is the probability of erosion in particular that is important. Erosion points can be estimated based on different scenarios of sea level rise and frequency of coastal storms. Consequently, the erosion line may move to a different position depending on whether climate change and other factors are taken into account or not. The land markets would react to the increase in such global physical pressure by changing land prices and patterns and other aggregated metrics.

The model presented here pursues an explorative purpose to show the development trend in land/spatial economic systems. The simulation was motivated by a real-world situation in Dutch coastal cities. The results of the ALMA-C runs for a city with the shift of erosion line landwards (Exp 6.1), i.e. representing increased probability of erosion due to climate change for example, were compared to a base case (Exp 5.2). The general conclusion is that, if the probability of erosion increases (erosion line shifts landwards), then individual expected utility from a location in this coastal city decreases and urban developments move away from the coast. This is what a conventional economic analysis, assuming a representative economic agent in a land market, could predict as well. If homogeneity among economic agents is assumed, and if they perceive probability of erosion objectively, then the seawards city border ("safety contour") shifts landwards.

In reality, people are not always rational and their perceptions of some hazard may vary. Often they do not perceive risks objectively. In fact, individuals have subjective perception of erosion probability, which often depends on person's socio-economic and demographic characteristics and previous experience of a hazardous event (Sjoeberg, 2000; Kaiser et al., 2004). As a result, in realworld land markets there may be individuals who overestimate or underestimate a hazardous event. Using the additional functionality of an agent-based modeling framework we explore the effect of introducing heterogeneity among agents. As it was shown in Chapter 2, low flood risk awareness at the individual level affects aggregated land market outcomes. Therefore it is of interest to compare the results of the coastal land market where agents have homogeneous erosion perceptions to a market where agents are with heterogeneous perceptions of erosion probability. We see that if 
subjective heterogeneous perceptions of a hazard are present at micro-level, then urban developments will go beyond the economically efficient allocation (for detailed discussion see also Chapter 5). The ALMA-C model with heterogeneous agents shows that even with the landward shift of the erosion line, there still will be some urban developments beyond the "safety contour". Consequently, for the coastal zone policy context it means that if there are some people who underestimate erosion probability (which is the case in the Netherlands - see Chapters 2 and 7 for the results of the recent flood risk perception surveys) they will locate in risky area and contribute to the increase of capital at risk and to the increase of coastal squeeze.

What would this imply for the case of Dutch coastal towns where part of the town lies beyond erosions line (i.e. coastal towns with "buitendijks gebied") and to which the recommendations of the Poelman Commission apply? What will happen is that, ceteris paribus, individuals, with low coastal hazard risk awareness would underestimate the risk of coastal erosion and will locate in the unprotected zone. In other words, economic agents who are assumed to make their location decisions on their own risk may locate in the areas where rational decision-maker with objective perception of a coastal hazard would find it inefficient to invest. Yet, if risk is on individuals then why would policy-makers care about these irrational decisions of people with low risk awareness? The problem is that if the newly built properties in the unprotected areas would spread and bear a high economic value, then those people become important stakeholders. Following the coastal policy principle of protecting certain areas on the basis of the concept of risk, defined as probability times effect, the coast-benefit analysis at some point might show that these areas outside of the dikes are too valuable to lose. Since areas with high economic value in the Netherlands are protected from flooding and erosion by means of governmental funds, the government might eventually choose to take responsibility for the developments, which were supposed to be at the risk of individuals. Obviously, risk communication and other financial and technical mechanisms to increase individual flood risk awareness discussed in Chapter 2 could be used to educate individuals about actual coastal risks and to avoid accumulation of the economic capital in the erosion-prone areas.

The differences between the two experiments (one with homogeneous agents with objective perception of the probability and the other one with heterogeneous agents with subjective beliefs about it) are demonstrated in a qualitative visual (Figures 6.4-6.6) and quantitative (Table 6.2) way. Note, that the representative agent model, which underestimates the potential damage from coastal hazards, is what is currently used for policy scenario analysis and decision support. Although these experiments with the ALMA-C model do not aim to draw predictions, they could be very useful for explorative analyses. Certainly more experimental and empirical information will be needed to 
make ALMA-C estimates quantitative and reliable for real policy decisions. However the simulations clearly demonstrate the potential of this approach, and show the power and promise of this kind of treatment.

The added value of the model is that it accommodates the heterogeneity of a spatial landscape as well as introduces heterogeneity among economic agents (as discussed in detail in previous chapters). Moreover, the model gives us a tool to visualize some of the patterns that evolve. While some of the reactions are intuitively obvious (such as the shift of the trend away from the coast as the erosion line moves), it is hard to predict what spatial arrangements these transitions may have. Is there going to be more development on the periphery? Will the city change its overall size as the attraction of the shore becomes less pronounced? If the number of developed cells increases, do they appear in the zone beyond the safety line or not? All these details can be analyzed with a spatially explicit land market model. Naturally, several prongs for future work can be outlined. One of the most interesting aspects to study is the neighborhood effect. Specifically, individuals with low risk awareness who settle in the areas beyond the safety line may make these coastal areas even more attractive to others. .That is, if there are people living in the risk zone and nothing happens to them - they would probably drive even more people to live there. Their presence may work as a contamination effect. Introducing just several highly risk-tolerant individuals may change the pattern of the city, expanding it toward more risky areas. Presence of these risk-tolerant individuals can increasingly decrease the overall risk awareness of the population.

In summary, climate change which is likely to raise the sea level and to cause more wave and wind activity along the shores, may further increase the pressure from the seaside. Population growth and increase of urbanization in coastal area cause the human pressure on the coast to grow as well. These two processes lead to the increase of the coastal squeeze. This chapter demonstrated that one of the factors driving human pressure and, thus, contributing the coastal squeeze, is low perception of erosion probability by individuals. Knowing that, some policies, such as discussed in Chapter 2, can be developed to ease the human pressure and decrease the costs of coastal maintenance. 


\section{Using survey data to parameterize agents in a coastal land market model}

\subsection{Introduction}

Previous chapters explore the dynamics of spatial allocation in a coastal city based on theoretical foundations of urban economics and microeconomic theory of decisions under uncertainty applied within an agent-based computational economics framework. Although the presented agent-based model gives some useful insights into the processes in an urban land market in a coastal city, its validity can be increased if we are able: a) to compare the the model performance with some of the processes and facts that are observed in real coastal cities, and b) to feed the model with real-world data about agents' perceptions and preferences.

This chapter aims to pursue this task by means of answering two research questions: What are the real-world individual location preferences and perceptions of flood risk in the Netherlands? What are the outcomes of a spatially explicit land market where the distribution of economic agents' perception of risk of flooding is parameterized with real-world survey data? The chapter starts with the discussion of the results of the survey conducted in the Netherlands in 2008. The descriptive statistics and analysis of the survey results with respect to flood risk perception, factors affecting individual choice of location and individual willingness to pay for different spatial attributes of housing are presented. Next, the motivation for using survey data in spatial agent-based models and a brief review of existing research are outlined. Finally, we show the results of a coastal land market model parameterized with some of the survey data and provide discussion and conclusions.

\subsection{Survey about flood risk perception and housing choices in the Netherlands}

A household Internet and mail survey was conducted in February 2008 in the Dutch province of Zeeland. Its goal was to elucidate individual perception of flood risk, individual perspectives on the governmental responsibility and choice of location. The survey was carried out within a EU project "Floodsite", in which University of Twente participated. The questionnaire consisted of six sections: 1) socio-demographic data, 2) risk perception, 3) location preferences and willingness to pay, 4) flood protection measures, 5) evacuation, and 6) responsibility of the government. Detailed description of the questionnaire can be found in (Krywkow et al., 2008). The results were 
comprised of 436 records. The survey sample was randomly drawn from the population of Zeeland province in the area of Schelde delta, which was extensively flooded during the coastal storm in 1953 (the last coastal flood in the Netherlands). The summary statistics of the respondents is presented in Table 7.1

Table 7.1: Descriptive statistics of the respondents $(n=436)$.

\begin{tabular}{|l|c|c|c|c|}
\hline \multicolumn{1}{|c|}{ Variable } & Mean & St. dev & Min & Max \\
\hline Age & 56.2 & 15.1 & 19 & 90 \\
Years of education & 12.8 & 3.2 & 6 & 18 \\
Male, \% & $72 \%$ & & & \\
Estimated net income $^{50}$ & 39889.9 & 7668.8 & 16500 & 50000 \\
\hline
\end{tabular}

The average respondent was a 56 years old male with high education. The sample underrepresents women and young people. This is common for mail and Internet surveys where women and young people do participate less. However, the results of our survey are in agreement with other surveys (Berg et al., 2002; Kaiser et al., 2004; Bočkarjova et al., 2008; Terpstra and Gutteling, 2008), which present similar opinions on flood risk and make us convinced that we can use our survey to reflect opinions of Dutch people in general.

\subsubsection{Survey results: risk perception}

One of the aims of this survey was to capture individual perceptions of coastal flooding in the Netherlands. As widely discussed in literature on psychology, risk as perceived by lay people is different from how policy-makers treat it. The latter treat risk formally, as probability multiplied by effect. In contrast individuals normally understand risk not as "analysis" supported by rational reasoning and scientific deliberation but rather "as feelings" (Slovic et al., 2004). Psychometric theory considers feelings of dread as a major factor of individual perception and acceptance of hazard risk (Slovic, 1987). How worried an individual is about a specific hazard event, such as flooding, could be considered as a measure of risk perception, since it constitutes the latter (Krywkow et al., 2008). Together with preparedness and awareness the three variables build the level of dreadfulness, i.e. risk perception, of a hazard. Following Raaijmakers et al. (2008) we take worry as the central variable measuring individual risk perception.

The survey asked a question "How worried are you that flooding can affect you?". Figure 7.1. shows the frequency of opinions among respondents. There are two things to note here. First of all, the level of worry among individuals is dispersed (average level of worry is 2.31 with st.dev 1.05). Thus, residents of the Dutch province of Zeeland do not have homogeneous perceptions of risk.

\footnotetext{
${ }^{50}$ The question about income was not asked in the survey due to some administrative reasons. So, income was reconstructed using the regression from Dutch labor market analysis. Gross income is estimated according to the equation: $\ln (\mathrm{I})=9.1-$ $0.02 * \mathrm{Ed}+\left(0.29 * \mathrm{Ed}^{2}\right) / 100+0.079 * \mathrm{Age}-\left(0.078 * \mathrm{Age}^{2}\right) / 100$, where Ed is years of education (Bajdechi-Raita, 2005)

Further gross income is translated into the mean of a net income category.
} 


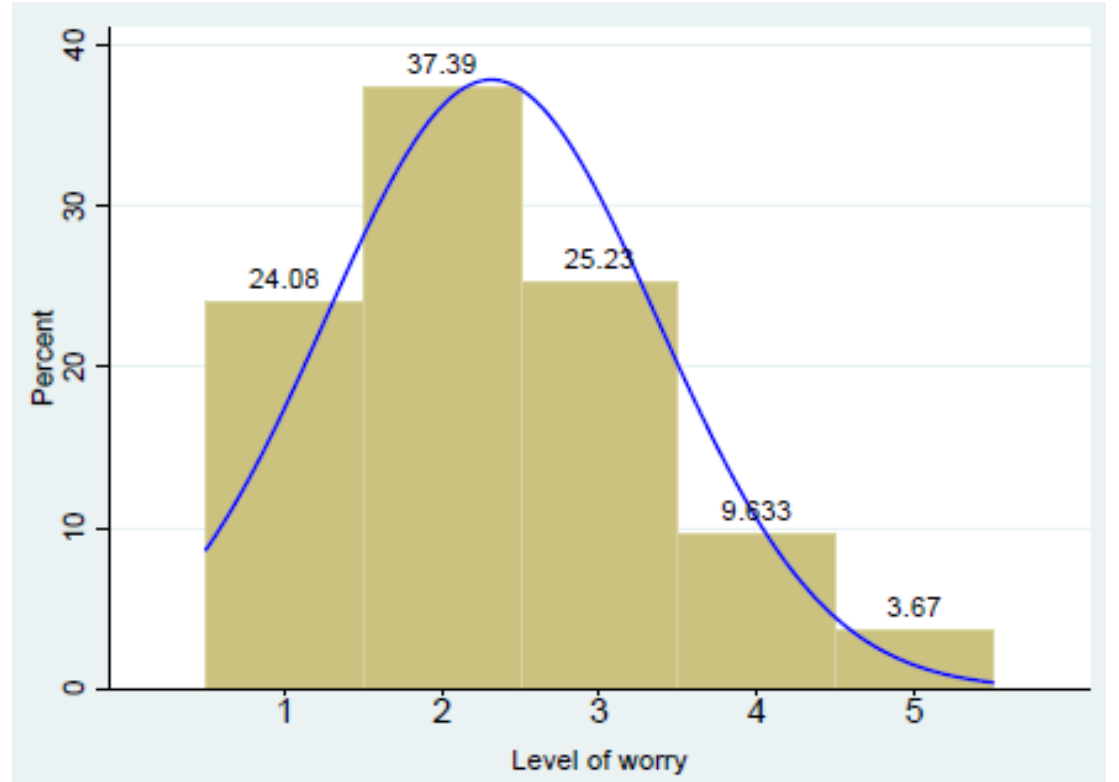

Figure 7.1: Distribution of individual level of worry that flooding could affect respondent personally (1- do not worry at all, 5 - worry very much).
Second, the peak of the distribution of worry is skewed to the left, meaning that the majority of people do not worry about flooding. This implies that in general individual risk awareness in low. Although, the fact that respondents are mostly male over 56 years of age may have influenced the outcomes, we tend to believe that our findings about flood risk perception being low and heterogeneous is applicable to the whole Dutch society, since this was also directly and indirectly shown in other surveys (Berg et al. 2002; Kaiser et al. 2004; Bočkarjova et al. 2008; Terpstra and Gutteling 2008).

In fact, the level of worry about potential flooding in the future is somewhat different between male and female respondents. On average women are more worried about this than men (see Figure 7.2.a), but their level is still quite low. Other socio-demographic data, such as education or income, do not appear to affect RP (i.e. level of worry) in a systematic way (the regression analysis showed that they are not explanatory variables for RP at the 95\% confidence level).

The individual level of worry about the risk of flooding correlates with the expectations of major flood occurrence in the future (Figure 7.2.b). As expected, people who think that large floods, such as the one happened in the Netherlands in 1953, will hardly happen again, are not worried about flood risk now (level of worry is below or equal to 2 ).

A quarter of the respondents have personal experience with flooding in the area where they live and another half of them have close friends or relatives who have experienced coastal flooding in the Netherlands in the past (see Table 7.2 below). Respondents were also asked whether flooding in 1953 in the Netherlands inflicted financial damage and brought causalities for their families. We expected that those who experienced real negative consequences would have higher risk perception. As Figures 7.2.c and 7.2.d show, in general the level of worry about flooding is higher in families with financial damage or causalities, but the standard error of this estimate is also high (especially in Figure 7.2.d). 
a)

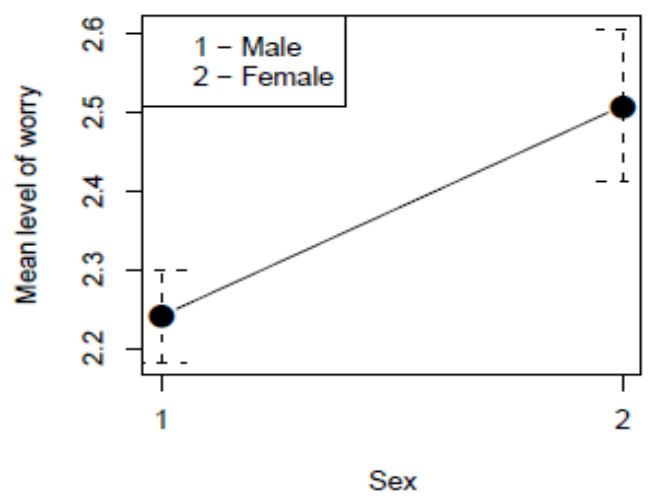

c)

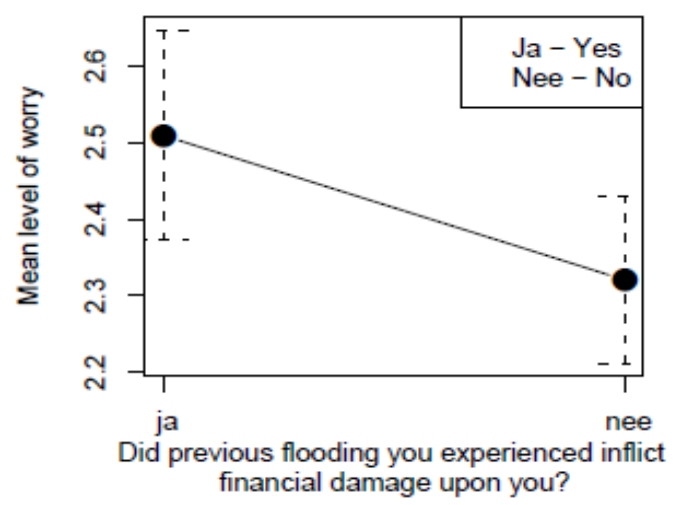

b)

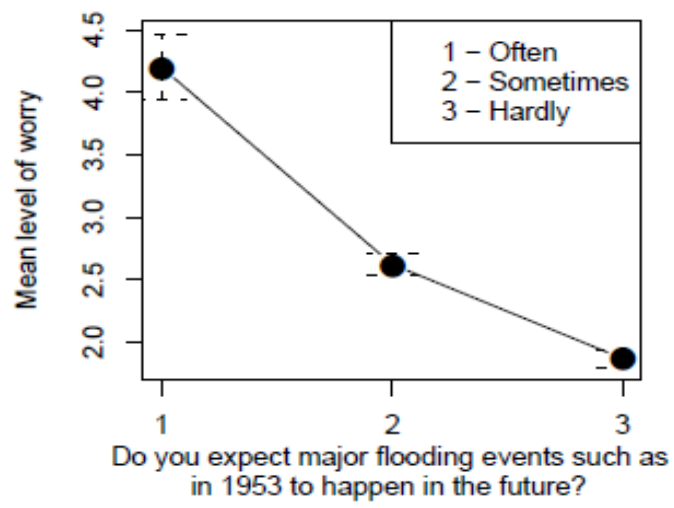

d)

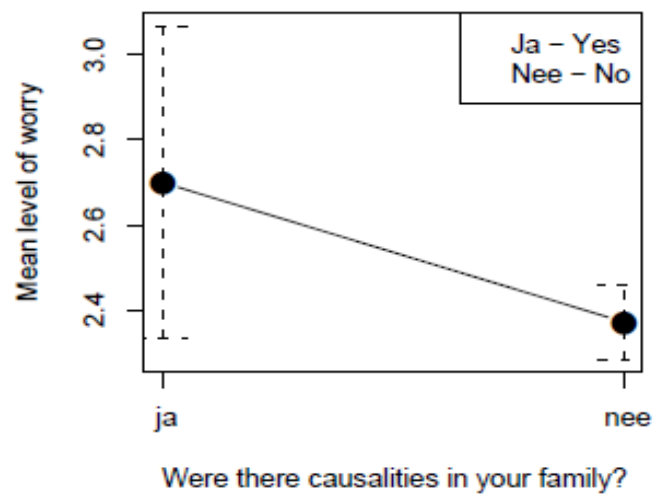

Figure 7.2: Plots of mean levels of worry grouped by relevant factor (based on answers to other questions in the survey). Black circles are mean values, dashed intervals are standard errors

Table 7.2 reports the experience that respondents or their relevant others (family and close friends) have with flooding. The question "Did you ever experience flooding?" differentiated between the flood event that happened in the Schelde area (where the last coast flood in the Netherlands caused much damage and loss of life), and elsewhere in the world. We expected that family or personal experience of coastal flooding in the Netherlands would make people more aware of this hazard.

Table 7.2: Flood experience of respondents $(n=436)$.

\begin{tabular}{|l|c|}
\hline \multicolumn{1}{|c|}{ Variable } & Percent \\
\hline Personal experience of flooding in Schelde & $25.5 \%$ \\
Personal experience of flooding elsewhere & $10.3 \%$ \\
Experience of flooding in Schelde of relevant others & $49.3 \%$ \\
Experience of flooding elsewhere of relevant others & $11.7 \%$ \\
\hline
\end{tabular}

However, in spite of the fact that the majority of respondents have experienced flooding, there is very low level of worry about it.

Figure 7.3 investigates the dependencies of the mean level of worry upon the flood experience in Schelde in the Dutch province of Zeeland, and in other places. Figures 7.3.a and 7.3.b report that 
respondents' personal experience of flooding in Schelde or experience of their relevant others does not correlate with increasing level of worry. Instead, these people on average are less worried about such an event happening in the future. The fact that standard errors are high (see the dashed intervals on both figures) does not allow us to say for sure that experience of flooding in Schelde has lowered individual risk perception. Still, clearly it did not make any difference in terms of increasing individual worry and risk perception of coastal flooding.

a)

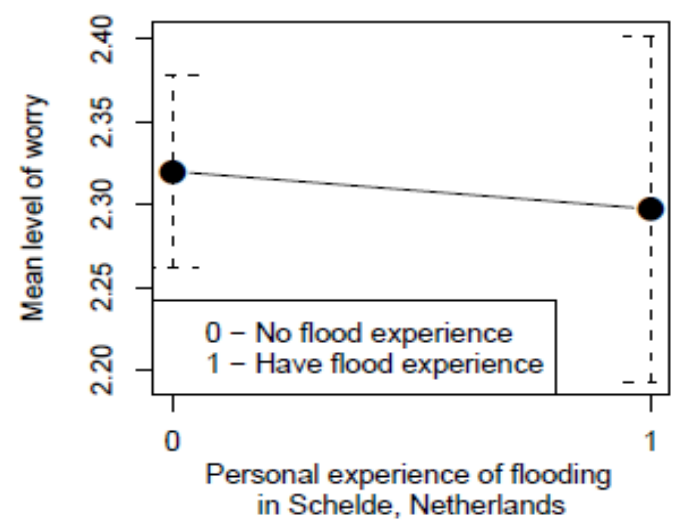

c)

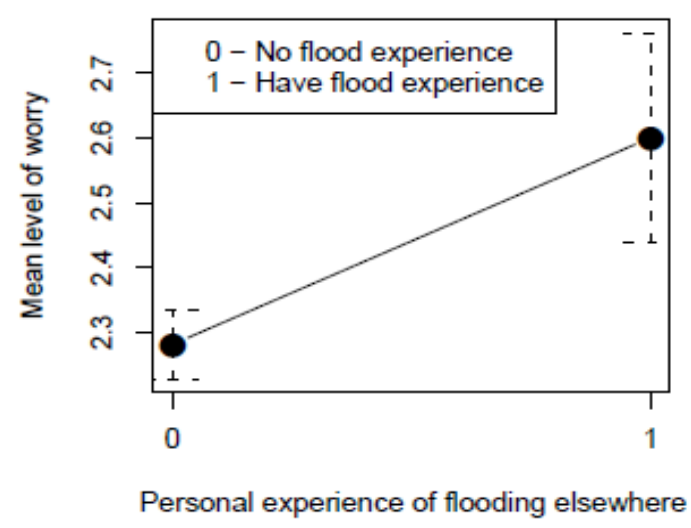

b)

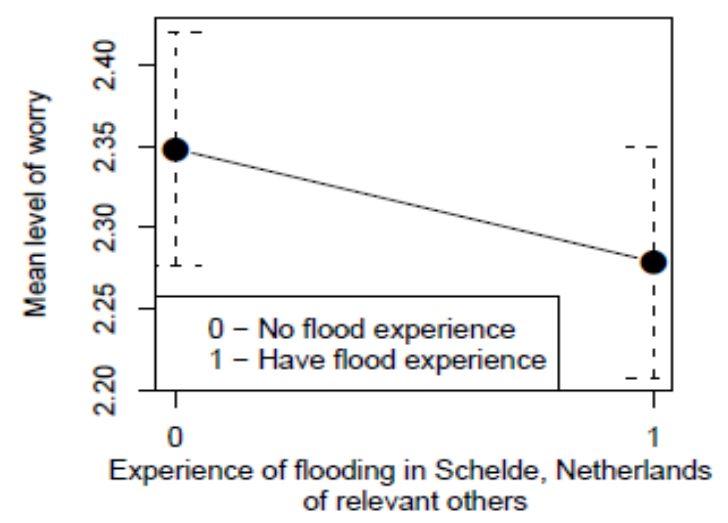

d)

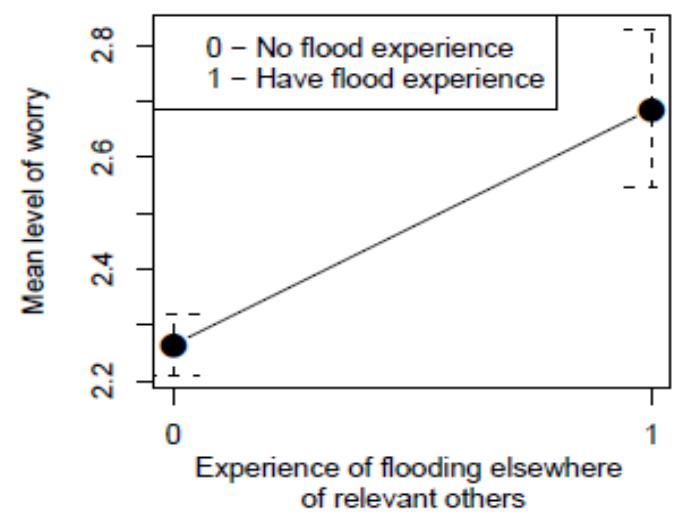

Figure 7.3: Plots of means of level of worry grouped by flood experience. Black circles are mean values, dashed intervals are standard errors.

In contrast to those who experienced the flooding in Schelde, respondents who have themselves or whose relevant others have experienced flooding elsewhere, have a higher risk perception. In both cases (see Figures 7.3.c and 7.3.d) their level of worry changed from "not worry" to "the average level of worry". A comparison of Figures 7.3.a-b with Figures 7.3.c-d shows that if Dutch citizens experienced flooding in another location, possibly another country, then their risk perception increased. However, if they experienced flooding in Schelde then this experience did not affect their risk perception at all and probably even lowered it. One possible explanation for this behaviour may be that after the devastating flooding of 1953 the Dutch government promised 
that "it would never happen again". With the implementation of the massive Delta plan - a system of dikes that protect Dutch Delta -the Netherlands obtained very high safety standards. Specifically in the area where the survey was administered the probability of flooding, according to the leaglly stipulated standards, is once in 4000 years. Dutch safety standards are much higher than elsewhere in the world in flood-prone areas. So, probably the experience of being flooded in Schelde was overwritten by the guarantees of the coastal flood defense policy in the Netherlands - something that was not the case when flood was witnessed in other places around the world.

\subsubsection{Survey results: location factors}

In addition to flood risk perception, the survey studied the importance of various factors when choosing where to buy a house. Different branches of economics suggest several reasons, which attract residential developments. Among them are the proximity to the employment centre (expressed in distance and time costs), environmental and urban amenities, public goods and social network connections. In this chapter we report only the survey results relevant to the general line of the thesis. Specifically, the importance of proximity to the employment centre, of green amenities and that of safety will be discussed. Figure 7.4 reports that time and distance to work are the two most important factors with the means of 3.34 and 3.27 and standard deviations of 1.44 and 1.41, respectively.

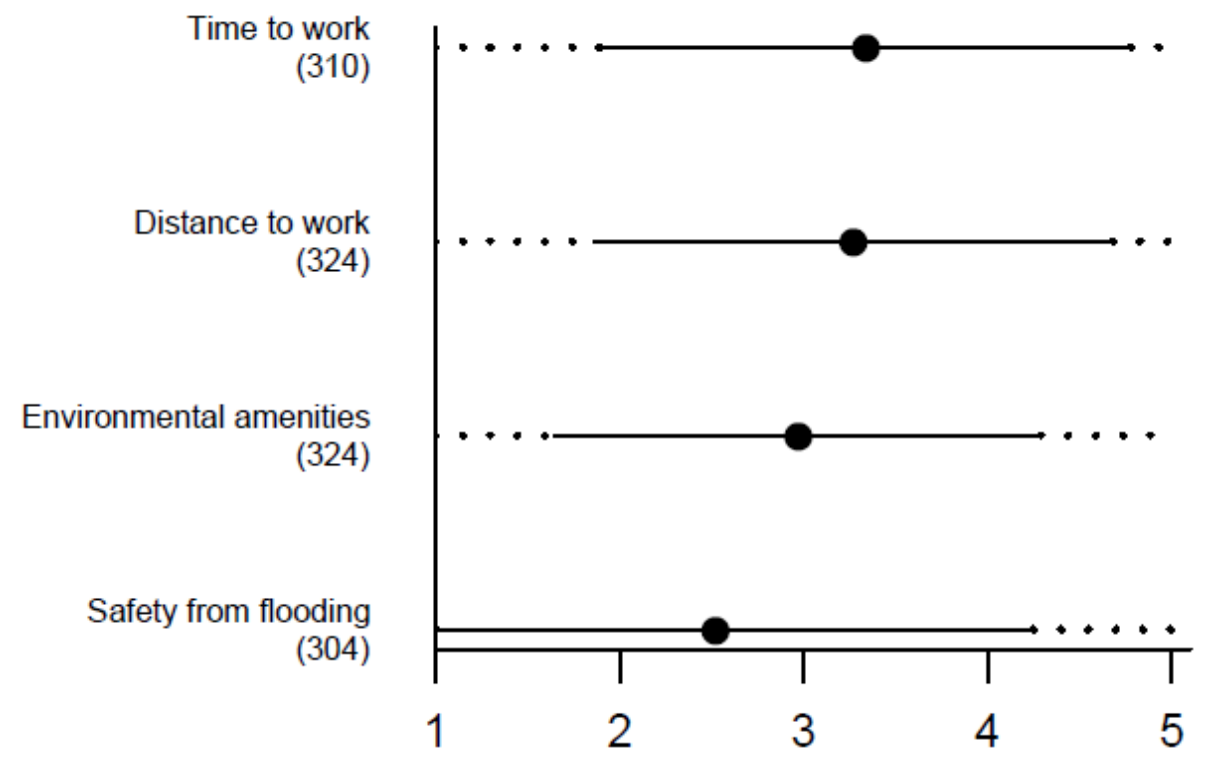

$\begin{array}{lr}\text { Many people considered } \\ \text { environmental amenities, } \\ \text { including } & \text { coastal } \\ \text { amenities, as } & \text { an } \\ \text { important factor } & \text { (mean } \\ 2.97, \quad \text { st.dev. } & 1.32 \text { ). }\end{array}$

However, amenities are less important to Dutch people compared to travel time costs to work. Safety from flooding is

Figure 7.4: Importance of different factors for people buying a house. $X$ axis: 1 - absolutely not important, 5 - extremely important. A number in brackets along $\mathrm{Y}$ axis is number of observations. A circle symbolizes the mean value, solid line shows st.dev., dotted line connects min and max values $^{51}$. the least important factor for Dutch people in their choice of a location to buy a house (mean 2.52

\footnotetext{
${ }^{51} \mathrm{R}$ code to create this graph is based on the example presented on http://tables2graphs.com/doku.php?id=03 descriptive_statistics
} 
and st.dev. 1.73). This means that an average respondent might settle in the flood-prone area along the coast if it provides coastal amenities, since importance of the latter is higher than safety for him. The four factors influencing the location choice follow different distributions. Importance of travel time to work and the distance to work are almost identical: the majority of respondents considered this factor as extremely important or very important (Figure 7.5.a and 7.5.b). Preferences for environmental amenities are less pronounced with a small peak in the middle (Figure 7.5.c). Preferences for choosing a house in a safe area appeared to be very polarized. The majority of respondents found it as not important at all (49\%). However, another $27 \%$ thought that safety from flooding was extremely important leaving just a small share of the sample in the neutral zone. Obviously, the first category of people are those who have low flood risk perception and the second one are individuals who are more aware of flooding.
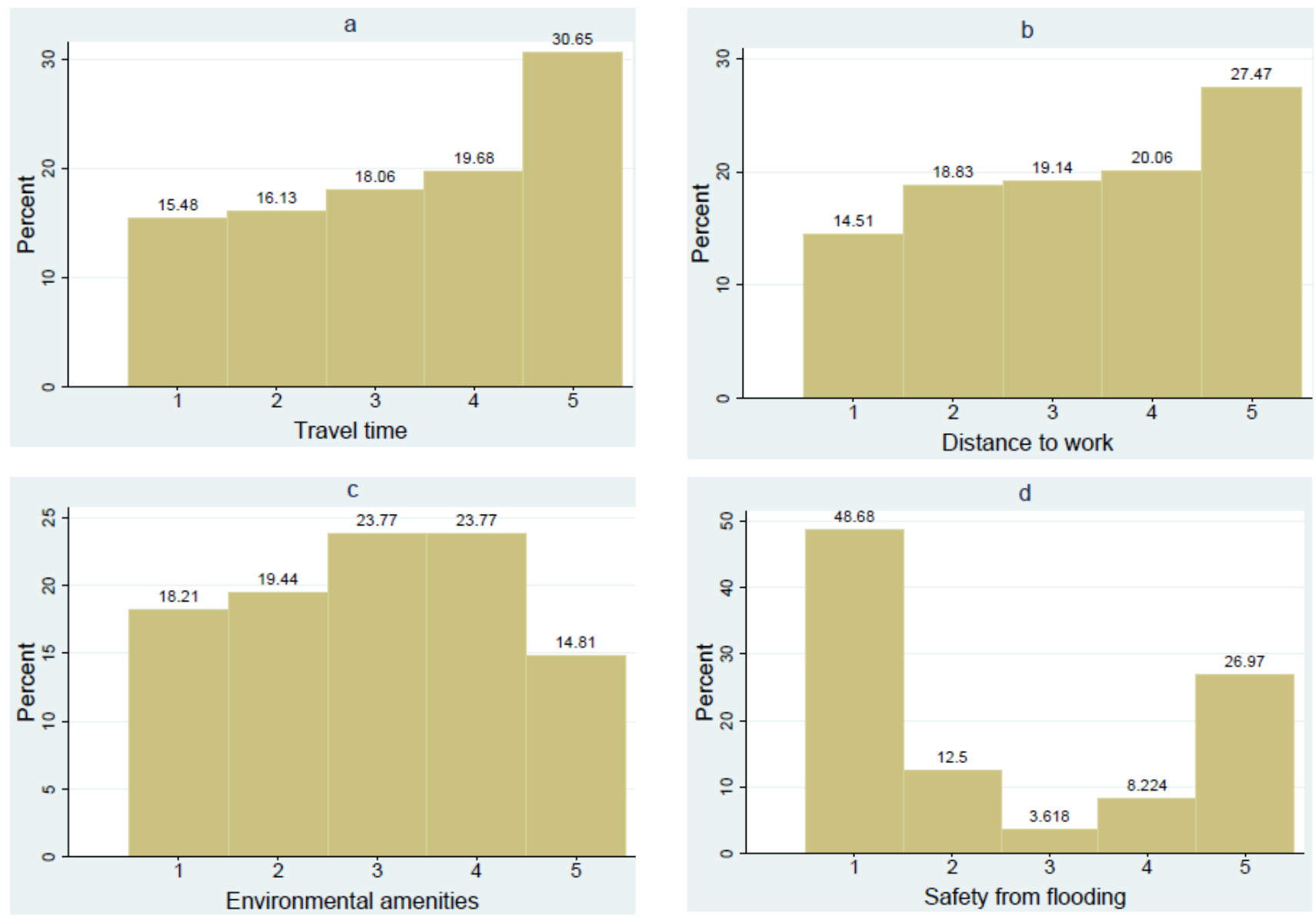

Figure 7.5: Distribution of responses about importance of each factor while choosing a house to buy (1absolutely not important, 5 - extremely important). 


\subsubsection{Survey results: willingness to pay questions}

Our survey used a contingent valuation (CV) approach to elucidate respondents' perceived monetary value of coastal amenities and safety from flooding attached to location. Willingness to pay (WTP) is a direct measure of a nonmarket resource being valued by asking respondents to state what they are willing to pay, not what they have actually paid. Therefore, compared to hedonic pricing it is not a value revealed from actual transactions but rather a value that respondents state at a hypothetical market. Stated and revealed preferences data (in other words hypothetical and actual demand functions) may sometimes be inconsistent (Shabman and Stephenson, 1996; Ready et al., 1997; Alberini et al., 2007). The CV method was used to value both environmental amenities (Alberini et al., 2005) and flood risk (Shabman and Stephenson, 1996). Although often it is the hedonic price technique which is used to extract the value of spatial attributes (such as amenities or flood risk) from the property value, there were reasons for us to use the CV method. One of the primary objectives was to capture whether Dutch people react to coastal flood risk in a property market. Since coastal flooding in the Netherlands is a rare event and risk perception is low, it is very unlikely that housing prices in the past have integrated flood risk. In the few recent years public attention was attracted to the issue of coastal disasters, particularly after hurricane Katrina. So, risk perception might have risen and people might start to be willing to pay for safety. Second, the Poelmann Commission has advised to allow developments in the unprotected areas of coastal towns (Rijkswaterstaat, 2002) in case individuals take these risks (Poelmann Commissie, 2005) (also see Chapter 6). However, the implementation of this advice is still under discussion. There is no official decision yet, as there are no actual transaction data, which can show whether people are willing to pay extra for flood safety or not. Thirdly, we wanted to grasp whether Dutch people do value more the houses that are built on artificial higher grounds compared to houses below sea level. There is a pilot project in the Netherlands to build developments on higher elevations, but there are no actual sales and transaction data for such housing. However, it is important to understand whether individuals in general would be willing to pay something for residing above sea level.

Four questions were asked, all designed in the same way: "Assume that you are considering buying a house. You have seen two identical houses, A and B, which suit your requirements (in terms of the type of house, number of bedrooms, floor area and land lot, etc.). The only difference between the houses is that the house A has a water view and house B does not have it. The house B costs $€ 200.000$ all inclusive. How much at most are you willing to pay for the house A?" The objective of this question is to determine the individual WTP for a coastal amenity. The average house price in the Zeeland province was taken as the base price for the similar house without sea view. 
The second question followed a similar scenario and asked about the WTP for a house in a safer area given that the base house price was $€ 200.000$. We did not ask for exact probability numbers here because this would be hard to communicate to people, and because there was no space in this survey for this ${ }^{52}$. Thus, we just used qualitative characteristics of "more safe". The third question asked about the WTP for a house located above sea level. The aim of this question is to elucidate the individual WTP for the house built on higher grounds. The idea of building new development uphill, i.e. on "terpens", is discussed in the Dutch water management, which served as a motivation for this question. The fourth question asked about maximum amount of tax a respondent was willing to pay monthly to double safety standards. It correlates with the idea of a local public good (being safety in this case) being financed by taxpayers (Tiebout, 1956).

The majority of respondents stated that they were willing to pay a positive amount for each location attribute (see Table 7.3). From 3\% to 5\% of the respondents expressed their willingness to be compensated instead (negative payment). About 17\%-34\% of the sample were indifferent (see “zero payment" in Table 7.3).

Table 7.3: Percentages of respondents answering the WTP questions $(n=436)$

\begin{tabular}{|l|c|c|c|c|}
\hline \multicolumn{1}{|c|}{$\begin{array}{c}\text { Variable } \\
(n=436)\end{array}$} & $\begin{array}{c}\text { Negative } \\
\text { payment }\end{array}$ & $\begin{array}{c}\text { Zero } \\
\text { payment }\end{array}$ & $\begin{array}{c}\text { Positive } \\
\text { payment }\end{array}$ & No answer \\
\hline WTP for coastal amenity & $5.05 \%$ & $17.2 \%$ & $63.99 \%$ & $13.76 \%$ \\
WTP for safety & $3.9 \%$ & $16.97 \%$ & $66.51 \%$ & $12.61 \%$ \\
WTP for being above sea level & $3.21 \%$ & $33.49 \%$ & $51.38 \%$ & $11.93 \%$ \\
WTP for safety tax & NA & $23.62 \%$ & $71.56 \%$ & $4.82 \%$ \\
\hline
\end{tabular}

For further analysis we consider only positive WTP statements, excluding the "protest" responses. The mean value of the four WTP measures are reported in Table 7.4 (standard deviation and sample size are presented in braces) for four groups: 1) all in sample, 2) respondents who had coastal flood experience (FE) in Schelde, 3) those who had flood experience elsewhere and, finally, 4) those who did not have any flood experience. In general respondents who had flood experience in Schelde or elsewhere are willing to pay more for safety compared to people with no flood experience: $23.64 \%, 27.22 \%$, and $23.64 \%$ above the base house price, correspondingly, compared to $22.08 \%$. The same happens with the WTP for being above sea level $(20.74 \%$ and $23.84 \%$ of the base house price compared to $17.69 \%$ for people with no flood experience). People with flood experience are willing to pay higher monthly tax for increasing safety standards compared to people with no flood experience. However, the same happens with the WTP for coastal view, which is either contrary to rational logic or implies that people do not assosiate the proximity to the coast (i.e. coastal view in this case) with any flood risk.

\footnotetext{
${ }^{52}$ These questions were part of a bigger survey carried out under the umbrella of another project with its own aims. Thus, the space for questions was limited.
} 
Table 7.4: The mean WTP ${ }^{53}$ (Notations: Mean (sd / n))

\begin{tabular}{|l|c|c|c|c|}
\hline \multicolumn{1}{|c|}{ Variable } & All & $\begin{array}{c}\text { With FE in } \\
\text { Schelde }\end{array}$ & $\begin{array}{c}\text { With FE } \\
\text { elsewhere }\end{array}$ & No FE \\
\hline WTP for coastal amenity & 44229 & 46713 & 47046 & 39709 \\
& $(30782 / 279)$ & $(31994 / 143)$ & $(28739 / 44)$ & $(28713 / 103)$ \\
WTP for safety & 47069 & 47273 & 54444 & 44151 \\
& $(30018 / 290)$ & $(30378 / 143)$ & $(29885 / 54)$ & $(29110 / 106)$ \\
WTP for being above sea level & 40380 & 41479 & 47674 & 35380 \\
& $(30672 / 224)$ & $(33541 / 115)$ & $(31308 / 43)$ & $(24920 / 79)$ \\
WTP for safety tax & 23.5 & 25.1 & 29.4 & 18.9 \\
& $(25.6 / 321)$ & $(26.9 / 159)$ & $(33.1 / 57)$ & $(20.3 / 110)$ \\
\hline
\end{tabular}

As it can be seen from the table, the average WTP value for each attribute of a location (coastal amenities, safety from flooding, being above sea level and safety tax) is almost the same as its standard deviation. This diversity in responses might have been caused by differences in individual preferences for coastal amenities and individual beliefs about the actual risks associated with flooding. Since the main focus of this thesis is coastal risk, we further focus mainly on the analysis of the WTP for safety and test the internal validity of the WTP responses. The results of the regression analysis of the four WTP measures explained by dummy variables are presented in Table 7.5 .

The specification of the regression function includes income level and the level of worry about flooding affecting the respondent personally. Such factors as sex and age appeared to be insignificant. Additionally, we tested whether the individual WTP for safety from flooding is dependent on how much a person trusts the government to take flood defence measures (TRUST), and on how much the respondents are preparing for flooding themselves (PREP). Two variables TRUST and PREP appeared to have no statistical significance for the value of WTP for safety. The $\mathrm{R}^{2}$ of the regression is low, 0.08 , which implies that the mean value of the WTP for safety is not a very good representation of the average value of the population. It shows again that people have a low flood risk perception (shown directly by this survey and also confirmed by the results of others (Kaiser et al., 2004; Terpstra and Gutteling, 2008)). Without being able to judge about actual flood risks, individuals answered irrationally. The data provides us with interesting insights into individual judgments on flood risk and decisions to buy a house.

Table 7.5: Regression analysis of the WTP for safety ${ }^{54}$.

\begin{tabular}{|l|c|c|c|c}
\hline & Estimate & St.error & $t$-value & $\operatorname{Pr}(>|t|)$ \\
\hline Intercept & -152283.2 & 93077.7 & -1.64 & 0.102 \\
Ln(wage) & 35283.8 & 8784.6 & 4.01 & 0.0 \\
Level of worry [1;5] & 6033.9 & 1647.7 & 3.66 & 0.0 \\
\hline
\end{tabular}

\footnotetext{
${ }^{53}$ Only respondents who stated positive WTP are considered

${ }^{54}$ Only respondents who stated positive WTP are considered
} 
According to economic logic it was expected that the value of the WTP should increase with income. In fact, the WTP for safety is positively and significantly associated with individual wages. The factor representing individual worry about effects of flooding is also positive and significant. This goes in line with our expectations since the more person is worried about flood risk the more he will be willing to pay for a house located in the safe zone.

\subsection{Agent-based modeling and survey data}

\subsubsection{Motivation and a review of the existing spatial ABMs using survey data}

Modeling land use change inevitably involves modeling of individual behavior of land users in addition to modeling of the spatial environment. The processes in the environment usually follow some physical laws. However, it is less straightforward for a modeler how to describe the process of human decision making (Berger and Schreinemachers, 2006; Brown and Robinson, 2006; Stites, 2006). While it is relatively easy to model the mechanistic part of an ABM such as the spatial environment, where dynamics is described by a set of straightforward deterministic rules (possibly with some uncertainty intervals), for human-beings it is not possible to say exactly how they (or, rather, we) make decisions. Theoretically, land use behavior is well formalized in economics (see Chapters 3 and 4 for discussion). However, decision making of an individual economic agent with respect to land is fully based on the assumption of rational maximization, equilibrium, and representative behavior. In reality people are boundedly rational, their behavior is often unrepresentative, they choose different strategies in the same situation, their decisions are biased by previous experiences and emotions, and people sometimes make irrational decisions. All these observed characteristics of human behavior make it difficult to use stylized theories of human decision making at the micro-level. Thus, how people make decisions (e.g. about land use) remains a black box for a modeler. The only way to open it a bit is to analyze real world micro-level data.

Empirical ABMs need micro-level information about agents' characteristics and/or agents' behavior due to their bottom-up nature. Normally, this micro-information is not available in national statistical reports since those largely provide aggregated data. Micro-level data could probably be obtained either by observing decision-making of a land-user in a controlled environment (for example in a role-playing game (Barreteau et al., 2001; Bousquet et al., 2005)), or from interviews with stakeholders and during participatory workshops with them, or by gathering data in the form of surveys (Fernandez et al. 2005; Brown and Robinson 2006). Extensive discussion of the empirical methods used to build ABMs is presented by Robinson et al (2007). 
Having access to the data from the above described survey in the Dutch province of Zeeland, we wanted to explore how it can be used in our ALMA-C ABM. Using surveys to feed ABMs with information about attributes and behaviors of agents is a natural step towards empirical modeling. Models in marketing (Bonabeau, 2002) and ABMs of financial markets (Hommes, 2006) pay more attention to using information obtained from survey data in ABMs compared to spatial ABMs, because they often have extended micro-information about individual market decisions. This is rarely the case for land market and other spatial models. Due to the costs of micro-level information acquisition and other challenges (Berger and Schreinemachers, 2006; Haase et al., 2008) not many spatial ABMs use survey data, but their number is growing. Beger (2001) defines three types of farm-level decision rules with respect to innovation diffusion in line with three groups of farmhouseholds identified in the survey in the agricultural sector. Bonabeau (2002) describes the TRANSIMS model, which simulates the population daily travel pattern in large metropolitan areas while information about agents' trips (origins, destinations, routes and timing) is taken from the surveys. An et al. (2005) explore the impacts of growing urban population on forests and panda habitat in China and instantiate agents with households' survey data about socio-economic situation, social network and attitudes towards fertility. Berger and Schreinemachers (2006) parameterize household agents with survey data from two farming villages in Uganda to explore the effects of unsustainable farming practices and increasing poverty as well as alternative policy interventions. Brown and Robinson (2006) explore several options to draw distribution of residential agents' preferences from survey data and analyze spatial urban patterns in each case. Haase (2007) uses survey data about individual preferences for location (accessibility, social infrastructure, noise etc.) for a model of residential mobility in a shrinking city. All this experience of using survey data in populating ABMs provides useful ground for further exploration of this topic since many methodological questions are still to be resolved.

\subsubsection{Data from the survey in the Dutch province Zeeland and ALMA-C}

The survey about location preferences and individual risk of flood perception presented in section 7.2 provides various micro-level data about factors influencing individual location choice. There are three sets of micro-data that are interesting to use in the ALMA-C model: importance of various spatial characteristics, individual WTP, and worry that flood event might affect a respondent personally. These three sets of survey data can in principle be associated with three corresponding data requirements of the ALMA-C model: preference in the utility function, willingness to change a bid on a house because of the presence of some spatial attributes, and perception of potential flood risk. Let us discuss each data-model parameters match separately. 
Importance of spatial characteristics such as environmental amenities or proximity to the employment center for the individual choice of location technically can enter agents' utility function (Equation 4.4. in Chapter 4 or Equation 5.2 in Chapter 5) as alpha and beta coefficients. The distribution of these coefficients can be drawn from the distribution of two factors: time to work (Figure 7.5.a) and environmental amenities (Figure 7.5.c). However, it is important to note that the survey was disseminated in the province of Zeeland, which covers not only coastal cities but also many other towns landwards. Due to technical and funding issues ${ }^{55}$ the survey could not be distributed in coastal towns only, which would be better for the purposes of this study. Thus, the survey data reflects the location preferences of Dutch citizens living in different cities, not only in coastal ones. As expected, time and distance to the employment center exhibit higher importance to the respondents living in the province (see Figure 7.4) compared to that of environmental amenities. In contrast, ALMA-C is a monocentric model and aims to simulate a small coastal town. Very often small coastal towns in the Netherlands become attractive only because they provide rich coastal amenities compared to similar small towns more landwards. The developments along the coast in such towns as Bergen aan Zee (Figure 6.2 in Chapter 6) are often holiday houses, which is likely to indicate that people who bought houses in these coastal towns have high preference for coastal amenities. Thus, it might not be accurate to parameterize agents operating in a monocentric coastal city with a distribution of preference of people from the whole province. Consequently, we leave preference parameterization for future work when ALMA will be extended to account for multiple or polycentric cities.

The WTP for different spatial attributes stated by the respondents might be used to parameterize the WTP functions of residential buyers (Equation 4.5 in Chapter 4 and Equation 5.4 in Chapter 5). Theoretically the estimated WTP for each spatial attribute, which follows some distribution with the mean and standard deviation, contributes to the overall bid that economic agents are willing to offer for a spatial good. Practically, the WTP values stated by the respondents are quite controversial. In particular, the means and standard deviations of the WTP measures are almost the same (see Table 7.4). Test for the internal validity of the WTP estimates showed that $\mathrm{R}^{2}$ is quite low. These two facts keep us from expanding these responses to Dutch population in general. However, the fact that about $50 \%$ to $70 \%$ of respondents (see Table 7.3 ) are willing to pay for coastal amenities, for a higher level of safety from flooding, for developments on higher elevation and for a flood safety tax, allows us to draw a general trend. For example, it is very likely that Dutch people will pay more for a house with coastal view compared to the similar house without it. Nevertheless, we cannot for sure say how much this WTP is and which of the factors

\footnotetext{
55 The questions, which are analyzed in section 6.2, were part of a bigger survey carried out under the umbrella of another project with its own aims. Thus, the space for questions and scope of respondents were given to us exogenously.
} 
(e.g. coastal view or safety from flooding) would outweigh the other ones in the overall WTP for a house. Thus, unfortunately, we will postpone the integration of the WTP responses in the ABM land market model until other data are available.

Worry that flood event might affect a respondent is an element characterizing individual risk perception according to the psychometric risk perception theory (Slovic, 1987; Krywkow et al., 2008). According to Slovic (2002) risk perception is a feeling rather than analysis of specific probabilities of a hazard. In Chapter 5 we run ALMA-C with agents having heterogeneous beliefs about probability of coastal flooding or erosion, i.e. having subjective probability of a hazard. Thus,

in Chapter 5 risk perception was treated more in line with the concept of "risk as analysis" (Slovic et al., 2004) and the traditional economic concept of expected utility. Here the survey question about "worry" goes more in line with the concept of "risk as feelings". Feelings are qualitative information - something sociological surveys normally deal with. Any model needs some kind of formalization of information. Naturally, there should be a decision made how to use qualitative survey information in the formal rules of the model (Haase et al., 2008). One way is to have worry about a flood event affecting someone personally be interpreted as individual perception of potential damage. The level of worry an individual has about potential negative effects might be formalized as a perceived damage individual thinks he might acquire by buying a house in a flood or erosion-prone area. In other words, individual worry about flood event affecting him personally might be used to parameterize the damage coefficient $C_{\text {dam }}$ (see Equation 5.2 in Chapter 5). Note, that the level of worry in Figure 7.1 varies from 1 to 5 and damage coefficient $C_{\text {dam }}$ varies from 0 to 1. Thus, to be able to use the distribution of worry to parameterize damage coefficients in the ALMA-C model we normalize them. The mean value is also translated to the appropriate number on the scale from 0 to 1 . Specifically, the average damage coefficient is 0.33 now.

\subsection{Experiments with the ALMA-C model}

As discussed in the previous section we will use the distribution of the individual level of worry about a flood event affecting respondents personally to parameterize individual damage coefficients in the ALMA-C model. We run three experiments with a population of agents having individual damage coefficients parameterized in three ways. In the first set of simulations agents have homogeneous damage coefficients equal to the average survey value $\left(\mathrm{C}_{\mathrm{dam}}=0.33\right)$. Second set of experiments is performed with agents that are heterogeneous with respect to damage coefficient. The proportion of agents' having a certain damage coefficient on the scale from 0 to 1 is chosen according to the proportion of respondents answers about their level of worry. Note, that distribution of damage coefficients in the second case is skewed as in the survey results. In the third 
experiment agents are instantiated with heterogeneous damage coefficients drawn from the uniform distribution. Each experiment run was performed 30 times to avoid random biases in the results.

The aggregated results of the ALMA-C simulations are spatially explicit rent gradients (i.e., realized land transaction prices at different distances from the city center), spatial patterns, and a set of economic and spatial metrics (bid, ask and transaction prices, average individual utility, total welfare of the urban population, urban size, and urban extent) the meaning of which was discussed in Chapters 4 and 5. In addition we estimate land rent gradient in the tradition of spatial econometrics.

All three experiments discussed in this chapter were performed on a $35 \times 63$ cell landscape, initialized with 1890 buyers and 1890 sellers. Residential buyers are homogeneous with respect to their preferences for green amenities, proximity to the CBD, and incomes. The only difference between the three experiments is the way individual damage coefficients of buyers are instantiated. Sellers are agricultural agents and their ask price is a price of agricultural land. The model parameters used in three experiments are listed in Table 7.6.

Table 7.6: Values of parameters in the simulation experiments

\begin{tabular}{|c|c|c|c|c|}
\hline Symbol & Meaning & $\operatorname{Exp} 7.1$ & $\operatorname{Exp} 7.2$ & $\operatorname{Exp} 7.3$ \\
\hline $\mathrm{Y}$ & Individual budget & 800 & 800 & 800 \\
\hline $\mathrm{P}_{\mathrm{ag}}$ & Price for agricultural land & 200 & 200 & 200 \\
\hline TCU & Transport costs per unit of distance & 1 & 1 & 1 \\
\hline $\mathrm{b}$ & Constant in WTP formula ${ }^{56}$ & 70 & 70 & 70 \\
\hline$\alpha$ & $\begin{array}{l}\text { Individual preference for green } \\
\text { amenities }\end{array}$ & 0.6 & 0.6 & 0.6 \\
\hline $\mathrm{C}_{\mathrm{PF} 1}$ & Coefficient in the Equation $4.1^{57}$ & 0.88 & 0.88 & 0.88 \\
\hline $\mathrm{C}_{\mathrm{PF} 2}$ & Coefficient in the Equation 4.1 & 4 & 4 & 4 \\
\hline $\mathrm{RP}_{\mathrm{dev}}$ & $\begin{array}{l}\text { Individual flood risk perception } \\
\text { deviation }\end{array}$ & 0 & 0 & 0 \\
\hline $\mathrm{PF}_{\text {obj }}$ at the coast & Probability of flooding & & & \\
\hline $\mathrm{C}_{\mathrm{dam}}$ & Flood damage coefficient & 0.33 & $\begin{array}{l}\text { Survey } \\
\text { distribution }\end{array}$ & $\begin{array}{l}\text { Uniform } \\
\text { distribution }\end{array}$ \\
\hline $\mathrm{avC}_{\mathrm{dam}}$ & Mean $C_{\text {dam }}$ in the buyers population & 0.33 & 0.33 & 0.5 \\
\hline
\end{tabular}

\subsubsection{Experiment 7.1: Agents with homogeneous coefficient of perceived damage equal to the mean value of the survey sample}

In this experiment we simulate a coastal city where a risk of flooding or erosion is present and agents estimates of potential risk (i.e. individual damage coefficients) are based on the empirical survey data. Agents' damage coefficient is homogeneous and equal to the mean of the survey sample. Exp 7.1 employs representative agent traditional for the conventional analytical model. Urban economics offers two analytical models each of which account for one spatial attribute: coastal amenities (Wu, 2001) and natural hazard risk (Tatano et al., 2004).

\footnotetext{
${ }^{56}$ See Chapter 4 for the details of WTP-WTA estimation

${ }^{57}$ See Chapter 4 for Equation 4.1
} 

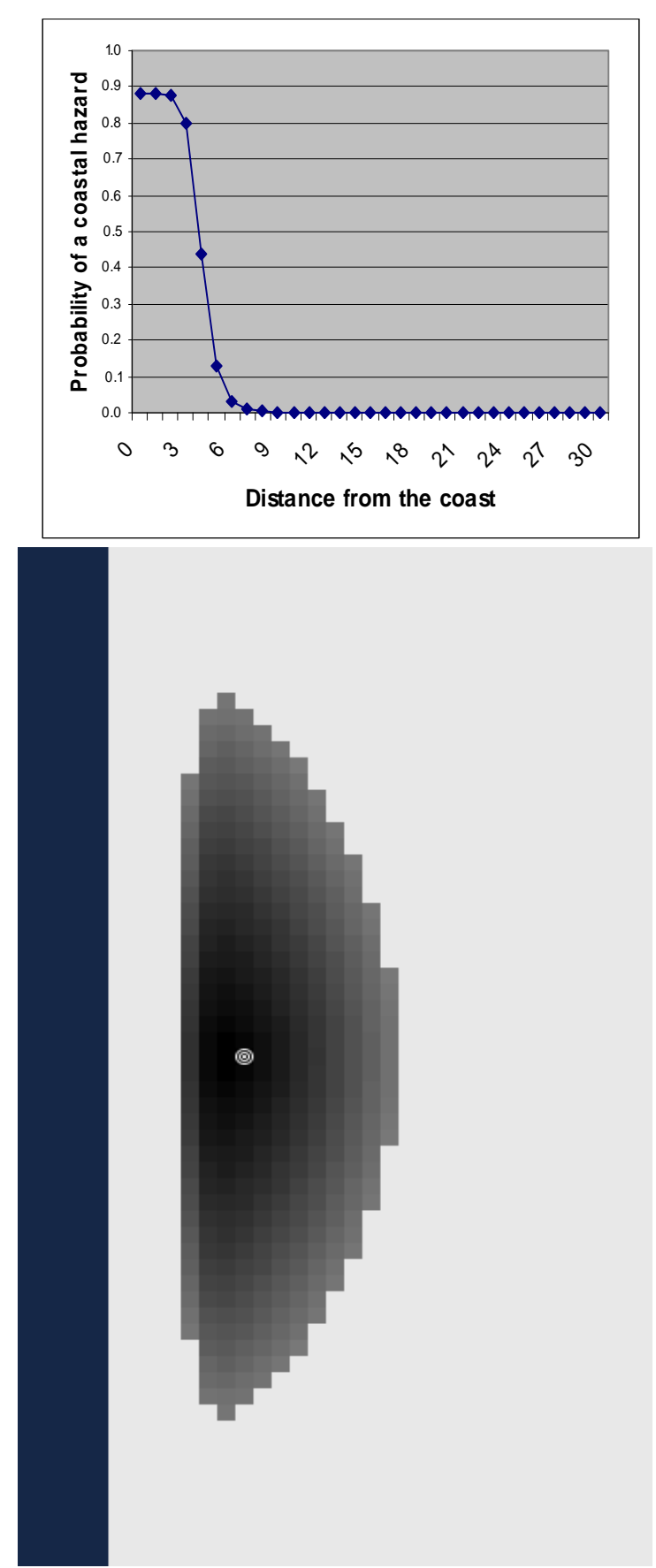

Figure 7.6: Top: function of the probability of a coastal hazard as a distance to the coast. Bottom: Rent gradients, Exp 7.1: homogeneous agents parameterized with the mean value from the survey
To our knowledge analytical model, which combines both factors, does not exist. But if would exist, it might be interesting to compare results of Exp 7.1 to the analytical model since the assumptions are the same. Moreover, if any predictions need to be made for policy and decision-support then most likely they would employ the conventional equilibrium model with averages of empirical data used. Since ALMA passed structural validation (i.e. proved to resemble the results of the analytical model if models assumptions are the same - see Chapters 4 and 5 for details), it is likely that Exp 7.1 would resemble the results of an analytical model with the damage coefficient of an average citizen as in survey data. The macro-outcomes of bilateral trading in this urban land market are presented in Table 7.7. Figure 7.7 shows the rent gradient of the realized transactions.

The top part of Figure 7.6 shows the graphical form of the probability of natural hazard function (see Equation 6.1 in Chapter 6 and parameters in Table 7.6), which is distant-dependent form the $\operatorname{coast}^{58}$. Its horizontal axis matches the map below. The bottom part of Figure 7.6 is the rent gradient of the realized transactions. As before the dark area on the left represents the ocean and the white circle in the middle is the CBD. The intensity of grey color symbolizes the value of land: the darker the color, the higher the land price. Light-grey area represents rural-urban fringe. Similarly to the experiment 5.2 in Chapter 5 land prices decrease with the distance from the CBD. There are no developments in the immediate proximity to the coastline: agents' expected utility there is too low making their bid price impossible for a successful transaction. Note, that this happens even if the average "worry", i.e. coefficient of perceived damage, is skewed to the left meaning that in average Dutch people are not

\footnotetext{
58 The fact that probability of erosion or flooding is distant-dependent from the coast is oversimplification. However, assuming that the spatial landscape has a homogeneous topography it can serve as an assumption. See Chapter 5 for more discussion.
} 
worried about the risk of coastal hazards. We will call the line at which the city's left seawards border stopped the "safety contour" to refer to it in the future.

Table 7.7: Economic and spatial metric outcomes of the ALMA-C experiments

\begin{tabular}{|l|c|c|c|}
\hline & Exp 7.1 & Exp 7.2 & Exp 7.3 \\
\hline Utility ${ }_{\text {indiv }}$, mean & 42.46 & 42.95 & 42.59 \\
\hline Utility $_{\text {indiv }}$ sd & 0.94 & 1.2 & 1.06 \\
\hline Aggregate utility, mean & 16982.79 & 26717.25 & 22843.56 \\
\hline Aggregate utility,sd & 0 & 5.5 & 273.73 \\
\hline Bid price, mean & 212.46 & 215.61 & 213.33 \\
\hline Bid price, sd & 7.87 & 9.74 & 8.66 \\
\hline Transaction price, mean & 206.23 & 207.81 & 206.67 \\
\hline Transaction price, sd & 3.94 & 4.87 & 4.33 \\
\hline Total land value in the city, mean & 82492.08 & 129256 & 110841.6 \\
\hline Total land value in the city, sd & 0 & 20.07 & 1322.52 \\
\hline City cize, mean & 400 & 622 & 536.33 \\
\hline City cize, sd & 0 & 0 & 6.39 \\
\hline City border, mean & 22.02 & 26.93 & 23.58 \\
\hline City border, sd & 0 & 0 & 0.68 \\
\hline Urban cells seaward from safety contour, mean & 0 & 204 & 121.9 \\
\hline Urban cells seaward from safety contour, sd & 0 & 0 & 6.38 \\
\hline Total value of land seaward from safety contour, mean & 0 & 42913.45 & 25267.48 \\
\hline Total value of land seaward from safety contour, sd & 0 & 0 & 1316.47 \\
\hline
\end{tabular}

If we consider model-generated transaction price as a function of two spatial characteristics (distance to the coast and to the CBD) graphically property values can be represented as a surface in a 3D space. Figure 7.7 shows a 3D scatterplot of the transaction data from Exp 7.1 at different angles. The highest dots along the vertical axis represent highest land prices. Note that this is not a 3D representation of the landscape, but a 3D visualization of a realized land rent gradient. The stripe closest to the coast is lower (i.e. land price is lower) than neighboring stripes more landwards.

The rent gradient of the model-generated data was estimated with the help of a regression model. Land rent is assumed to be a function of the distance to the CBD and distance to the coast. Cubic regression showed a good fit $\left(\mathrm{R}^{2}=0.98\right.$, Table 7.8$)$. 

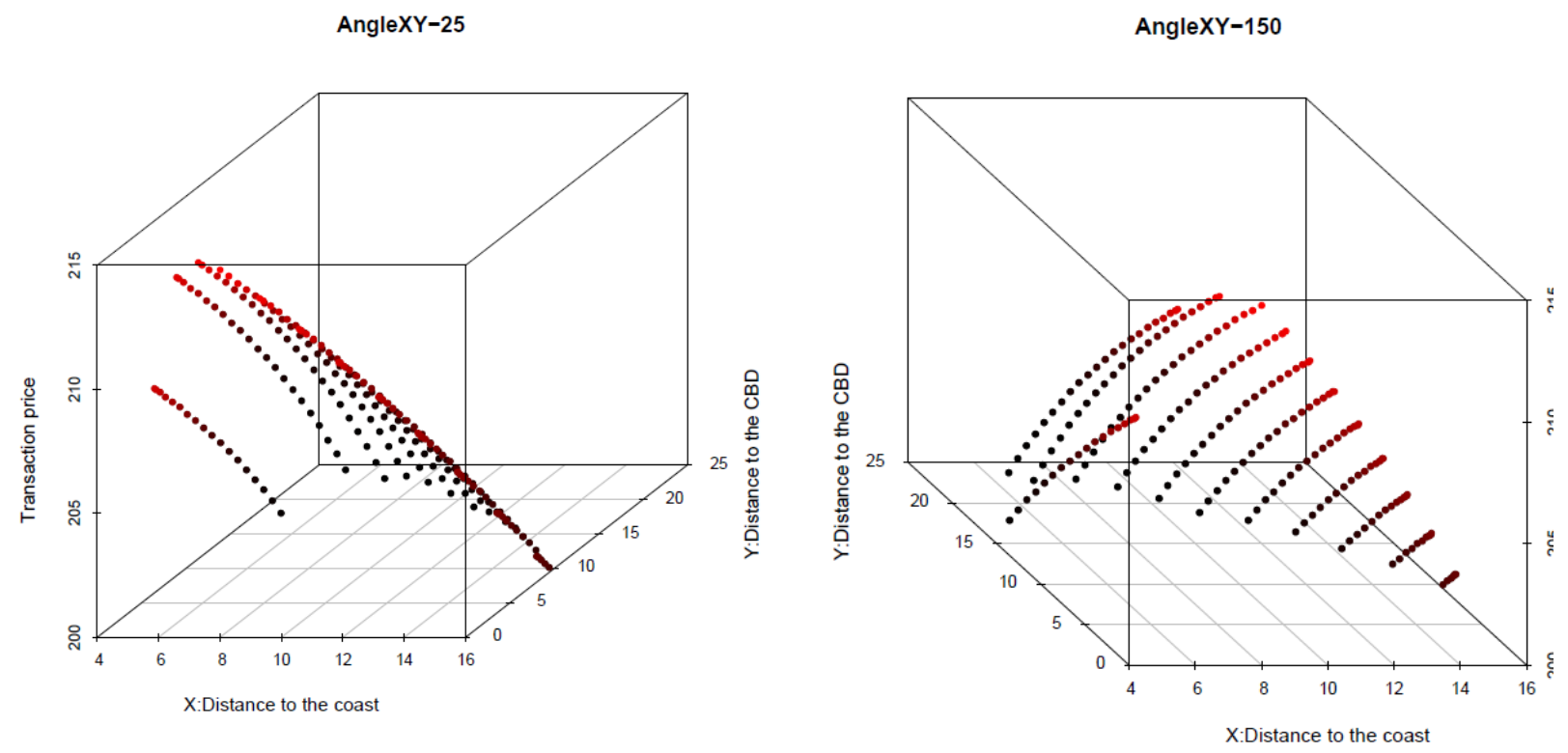

Figure 7.7: 3D scatterplot of transaction prices for Exp 7.1: coefficient of perceived damage is equal to the mean value of the survey sample

Table 7.8: Cubic regression of simulated land prices

(Notations: Estimate(st.error / t-value); $\mathrm{D}_{\mathrm{am}}$ - distance to the coast, $\mathrm{D}_{\mathrm{cbd}}$ - distance to the CBD)

\begin{tabular}{|c|c|c|c|}
\hline & $\operatorname{Exp} 7.1$ & $\operatorname{Exp} 7.2$ & $\operatorname{Exp} 7.3$ \\
\hline $\mathrm{R}^{2}$ & 0.9776 & 0.9729 & 0.7749 \\
\hline Intercept & $\begin{array}{c}181.26 \\
(0.28 / 644.93)\end{array}$ & $\begin{array}{c}223.13 \\
(0.18 / 1252.73)\end{array}$ & $\begin{array}{c}213.6 \\
(0.48 / 449.31)\end{array}$ \\
\hline $\mathrm{D}_{\mathrm{am}}$ & $\begin{array}{c}10.58 \\
(0.08 / 141.03)\end{array}$ & $\begin{array}{c}-1.41 \\
(0.04 /-34.69)\end{array}$ & $\begin{array}{c}0.89 \\
(0.11 / 8.31)\end{array}$ \\
\hline $\mathrm{D}_{\mathrm{am}}^{2}$ & $\begin{array}{c}-1.02 \\
(0.01 /-150.82)\end{array}$ & $\begin{array}{c}0.08 \\
(0 / 22.71) \\
\end{array}$ & $\begin{array}{c}-0.07 \\
(0.01 /-8.23) \\
\end{array}$ \\
\hline $\mathrm{D}_{\mathrm{am}}^{3}$ & $\begin{array}{c}0.03 \\
(0 / 136.76) \\
\end{array}$ & $\begin{array}{c}0 \\
(0 /-34.17) \\
\end{array}$ & $\begin{array}{c}0 \\
(0 /-5.66)\end{array}$ \\
\hline $\mathrm{D}_{\mathrm{cbd}}$ & $\begin{array}{c}-0.79 \\
(0.03 /-23.31) \\
\end{array}$ & $\begin{array}{c}-0.66 \\
(0.03 /-20.84) \\
\end{array}$ & $\begin{array}{c}-0.97 \\
(0.09 /-11.15) \\
\end{array}$ \\
\hline $\mathrm{D}_{\mathrm{cbd}}^{2}$ & $\begin{array}{c}0.0184 \\
(0.002 / 9.95) \\
\end{array}$ & $\begin{array}{c}0.004 \\
(0.002 / 2.16)\end{array}$ & $\begin{array}{c}0.0297 \\
(0.005 / 5.48) \\
\end{array}$ \\
\hline $\mathrm{D}_{\mathrm{cbd}}^{3}$ & $\begin{array}{l}-1.00 \mathrm{E}-04 \\
(0 /-2.35)\end{array}$ & $\begin{array}{c}-3.00 \mathrm{E}-04 \\
(0 / 2.16)\end{array}$ & $\begin{array}{c}-4.00 \mathrm{E}-04 \\
(0 / 5.48)\end{array}$ \\
\hline $\mathrm{D}_{\mathrm{am}}^{2} * \mathrm{D}_{\mathrm{cbd}}$ & $\begin{array}{c}0.0021 \\
(0 / 10.51)\end{array}$ & $\begin{array}{l}-2.00 \mathrm{E}-04 \\
(0 /-1.50)\end{array}$ & $\begin{array}{c}0.0025 \\
(0 / 6.63)\end{array}$ \\
\hline $\mathrm{D}_{\mathrm{am}} * \mathrm{D}_{\mathrm{cbd}}^{2}$ & $\begin{array}{c}-0.003 \\
(0 /-24.63) \\
\end{array}$ & $\begin{array}{l}2.00 \mathrm{E}-04 \\
(0 / 1.97)\end{array}$ & $\begin{array}{c}-0.0026 \\
(0 /-9.07)\end{array}$ \\
\hline$D_{a m} * D_{c b d}$ & $\begin{array}{c}0.0172 \\
(0.005 / 3.58)\end{array}$ & $\begin{array}{c}0.0022 \\
(0.004 / 0.56)\end{array}$ & $\begin{array}{c}0.0111 \\
(0.011 / 1.05)\end{array}$ \\
\hline
\end{tabular}

Graphical representation of the estimated rent gradient is shown in Figure 7.8 by a green curve. Motivation and detailed explanation of the graph is presented in Section 5.2 of Chapter 5. In summary, Figure 7.8 presents a 2D cross-section of the city land values done along the perpendicular connecting CBD to the coast. Axis $\mathrm{Y}$ represents the value of a spatial good, and axis $\mathrm{X}$ represents distance to the coast. Since the cross-section is done along the perpendicular 
connecting $\mathrm{CBD}$ to the ocean, the distance to the $\mathrm{CBD}$ (situated 8 spatial units away from the coast) can be directly translated into distance to the coast (using $\mathrm{D}_{\mathrm{CBD}}=\left|\mathrm{D}_{\text {coast }}-8\right|$ ).

Rent gradient from Exp 7.1 (green line) peaks at the CBD and decreases seawards because agents perceive risk (their coefficient of perceived damage is equal to the mean value of the survey sample). Developments do not expand beyond the safety contour.

\section{Cubic regression fit}

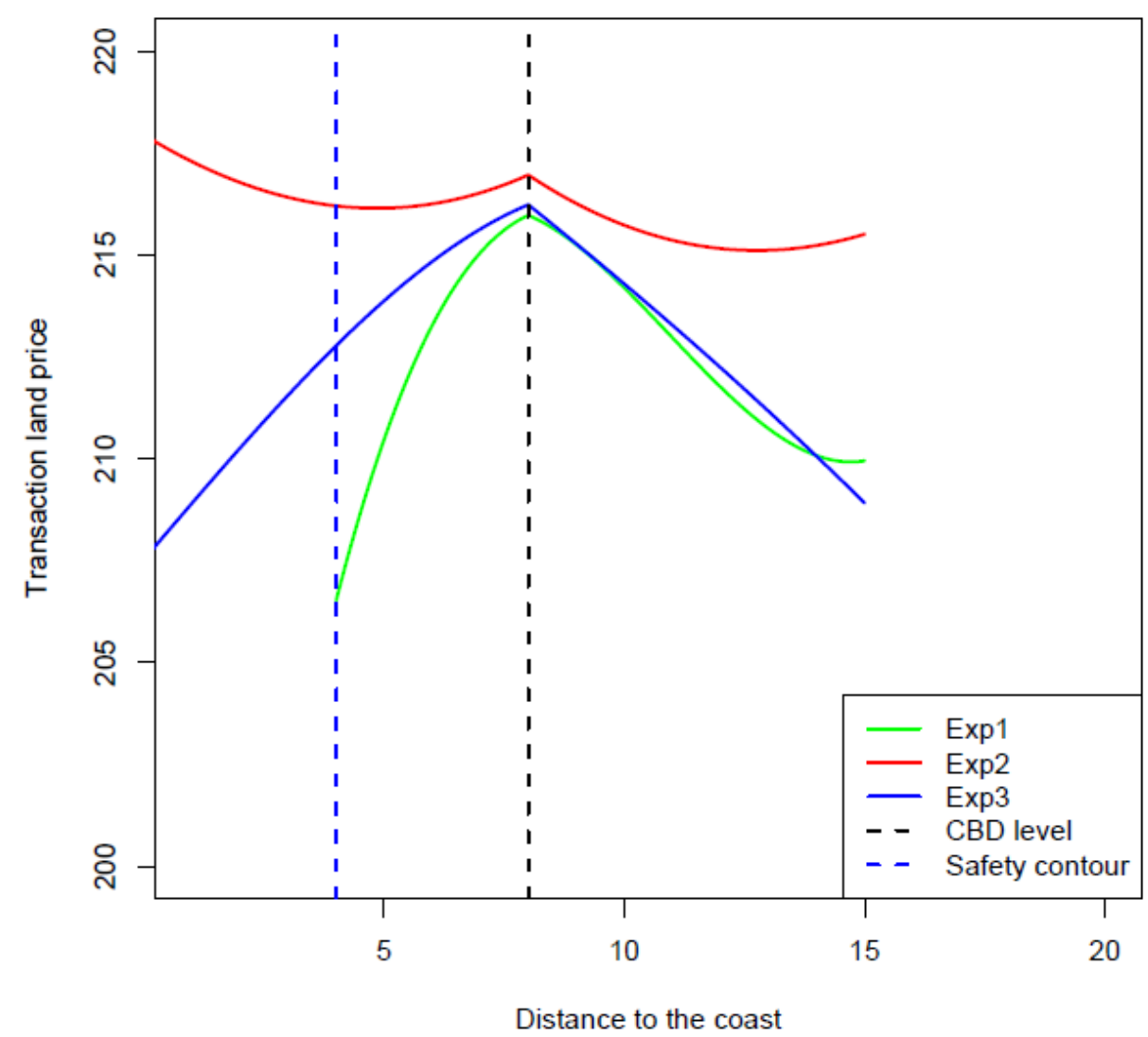

Figure 7.7: 2D cross section of rent gradient

\subsubsection{Experiment 7.2: Agents with heterogeneous coefficients of perceived damage parameterized using the survey data}

In Exp 7.2 we model a coastal city where a risk of a coastal hazard is present and agents' coefficients of perceived damage are heterogeneous and are based on the distribution of 'worry' observed in the survey data. Thus, the difference with Exp 7.1 is that a representative agent with the damage coefficient equal to the mean value of the survey sample is replaced by a heterogeneous population of agents imitated with the empirical distribution of "worry". Statistical bias between Exp 7.1 and Exp 7.2 is absent since average perceived damage coefficient of heterogeneous agents is equal to the mean value of survey data, i.e. damage coefficient in Exp 7.1. 
Average bid price and consequently transaction price in Exp 7.2 is a bit higher than in Exp 7.1 (see Table 7.7). Since there are agents in the population that have low perceived damage coefficients, they will underestimate risks even more than the representative agent in Exp 7.1, whose damage coefficient is already skewed to the left. Thus, these economic agents value land in a flood-prone zone quite high (because the proximity of coastal amenities is present and flood or erosion risk is not perceived). As a result spatial patterns in Exp 7.2 differ significantly from Exp 7.1 in spite of the fact that micro-attributes of agents in two experiments are on average the same. In contrast to Figure 7.6 almost all the area along the coastline in Figure 7.8.a is converted into developed use. On average about 204 cells were converted into urban use in the zone seaward from safety contour making up to $33 \%$ of the total property value in this coastal city economically inefficient and under risk (Table 7.7).

Figure 7.8.b shows the distribution of agents' perceived damage coefficients. Notably, the most seaward area where the probability of flooding or erosion is significant (see upper part of Figure 7.6) is occupied by agents with the lowest perceived damage coefficient, $\mathrm{C}_{\mathrm{dam}}=0$. At the same time agents with higher $\mathrm{C}_{\mathrm{dam}}$ (darker color in Figure 7.8.b) settle more landward. This sorting is an emergent model outcome, since it is a result of a land market allocation. Specifically, agents with $C_{d a m}=0$ have much higher expected utility along the coast compared to agents with $C_{\text {dam }}>0$. Thus, the former outcompete those with higher worry about potential risk of a coastal hazard.

One can also observe that, in spite of the fact that agents are heterogeneous, the land prices over almost the whole landscape are dispersed as if there were homogeneous agents operating in the land market (compare Figure 7.8.a to Figure 5.3 in Chapter 5). There is dispersion in land prices only in the area bordering the safety contour. This can also be seen from the 3D scatterplot of transaction data from Exp 7.2 (Figure 7.9). This is not something we had expected but there is an explanation for this. Agents are heterogeneous only with respect to their coefficients of perceived damage so they differ from each other in their bids on the spatial goods characterized by different probability of a coastal hazard. The market allocates agents with zero damage coefficients seawards from the safety contour (Figure 7.8.b). It implies that these economic agents are homogeneous since they do not feel any risk and bid in the land market as if there was no flood or erosion risk disamenity associated with this land (i.e. results for the land transactions seawards form the safety contour are comparable to those in Exp 5.1 in Chapter 5). Landwards from the safety contour there are agents heterogeneous with respect to their perceived damage coefficients (Figure 7.8.b) but the actual chance of a coastal hazard is already approaching zero (upper part of Figure 7.6). It makes spatial landscape homogeneous with respect to flood/erosion risk, so heterogeneous damage coefficients do not affect transaction prices. This situation resembles Exp 5.2 in Chapter 5. There is 
only a narrow stripe of land in the immediate proximity to the safety contour where the actual probability of flooding/erosion is still essential and agents with non-zero coefficients of perceived damage find it economically efficient to locate.

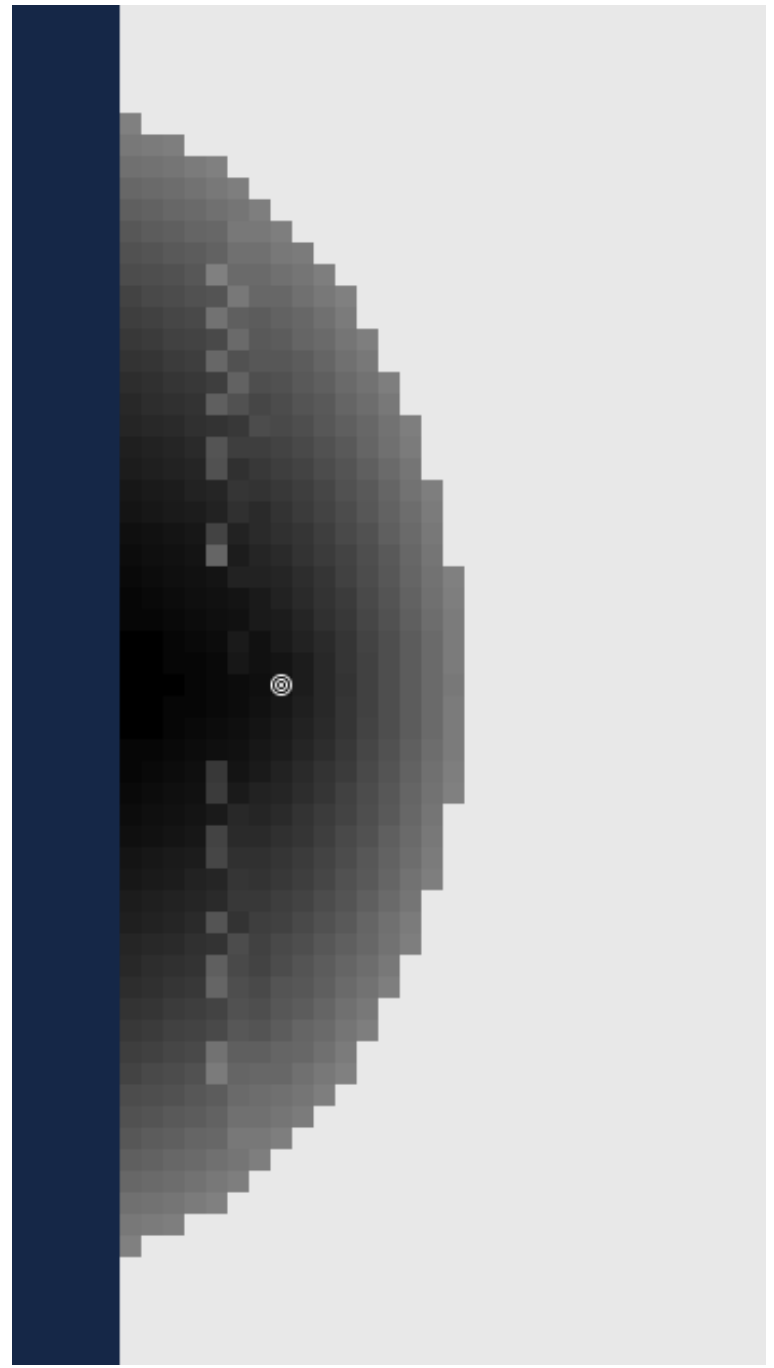

a) Rent gradients

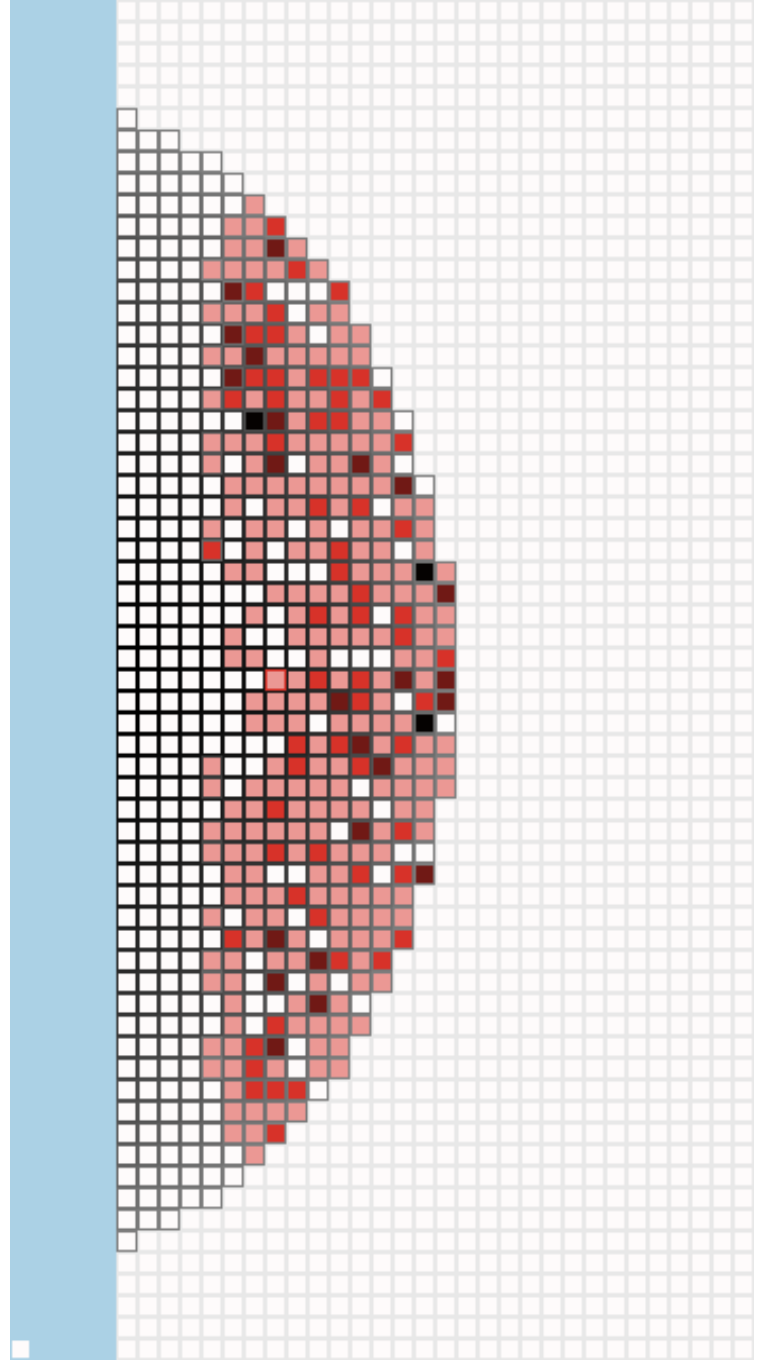

b) Map of perceived damage coefficients of agents settled in the city. White color means $\mathrm{C}_{\mathrm{dam}}=0$, darkest red means $\mathrm{C}_{\mathrm{dam}}=1$

Figure 7.8: Results of Exp 7.2: heterogeneous agents parameterized with empirical survey data

The $2 \mathrm{D}$ crossection of the land rent gradient represented as a red cubic regression curve in Figure 7.7 behaves very different from the green curve showing estimated land rent gradient of data from Exp 7.1. The estimated land gradient from Exp 7.2 not only goes beyond the safety contour. The red curve also grows with proximity to the coast meaning higher land prices in the area beyond the safety contour and consequently, higher direct potential damage in the case of a hazard - all caused only by the empirically-parameterized heterogeneity among agents. 

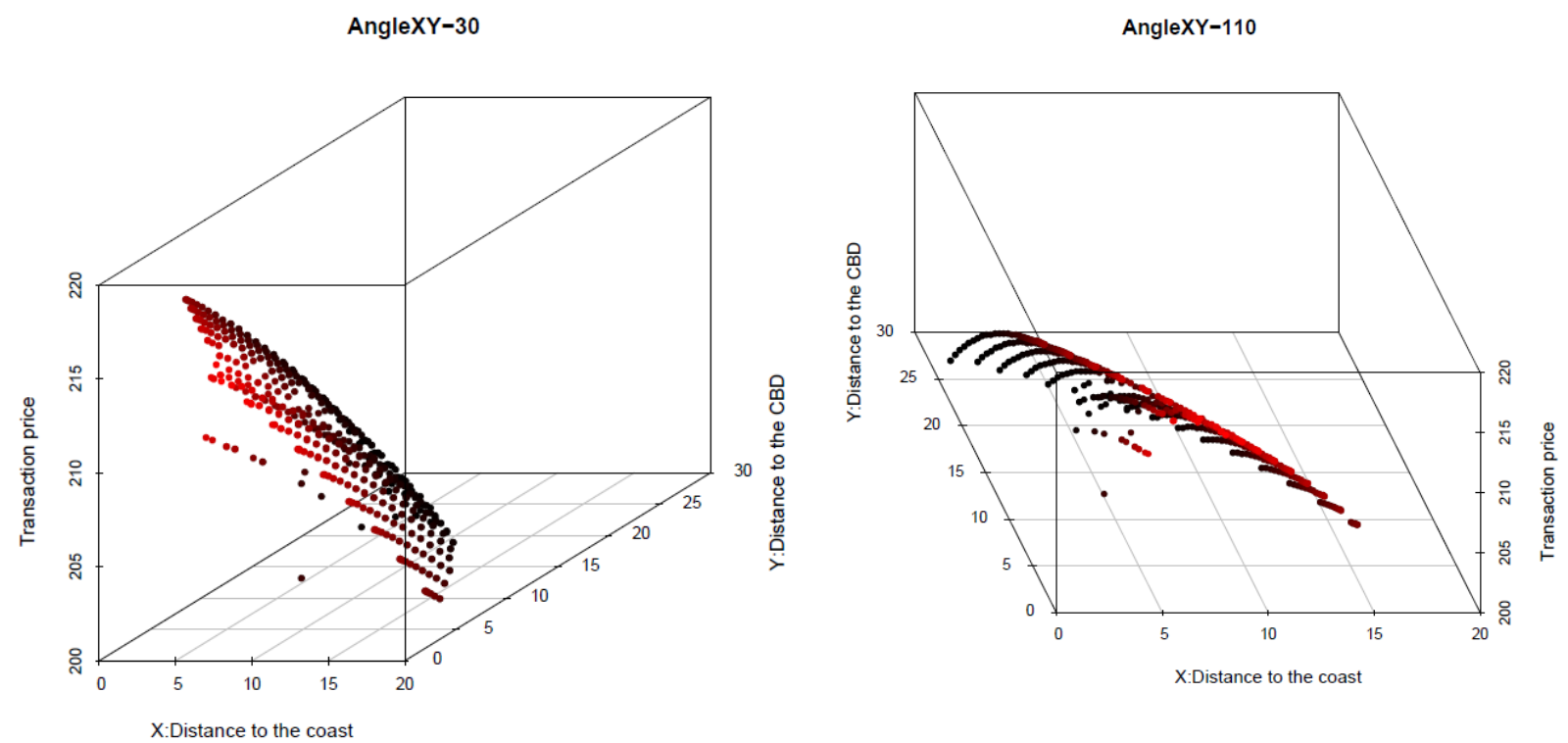

Figure 7.9: 3D scatterplot of transaction prices for Exp 7.2: agents with heterogeneous coefficients of perceived damage parameterized using the survey data

\subsubsection{Experiment 7.3: Agents with heterogeneous coefficients of perceived damage parameterized using uniform random distribution}

In the first two experiments we used survey data to parameterize agents' perceived damage coefficient. The survey carried out in the Dutch province of Zeeland elucidated individual opinions concerning worry about risk coastal hazard. This implies that respondents gave a thought to the current coastal flood situation and stated their feelings towards risk. Apparently, the risk awareness is low (i.e. distribution of worry is skewed). We are interested to compare the results of the previous two experiments with the outcome of the simulation where agents are assumed to have completely random coefficients of perceived damage. This case can be compared to the situation where people do not have any information at all about potential flood risk and just make a wild guess about the effect it might exhibit. In Exp 7.3 we parameterize agents' damage coefficients with uniform distribution. This experiment shows what the aggregated land market outcomes will be if nothing is known about agents' real-world distribution of worry about flood risk and if they are assumed to be completely random.

The first difference from Exp 7.2 manifests itself in the spatial morphology of the city as can be seen from comparison of Figures 7.10.a and 7.8.a. The city border has shrunk by $12 \%$ and urban population has decreased by $14 \%$ as can be seen in Table 7.7. The amount of urban cells seawards from the safety contour has decreased almost twice compared to Exp 7.2. The proportion of total property value liable to the economically inefficient risk is $23 \%$ of the total value in the city compared to $33 \%$ in $\operatorname{Exp} 7.2$. 


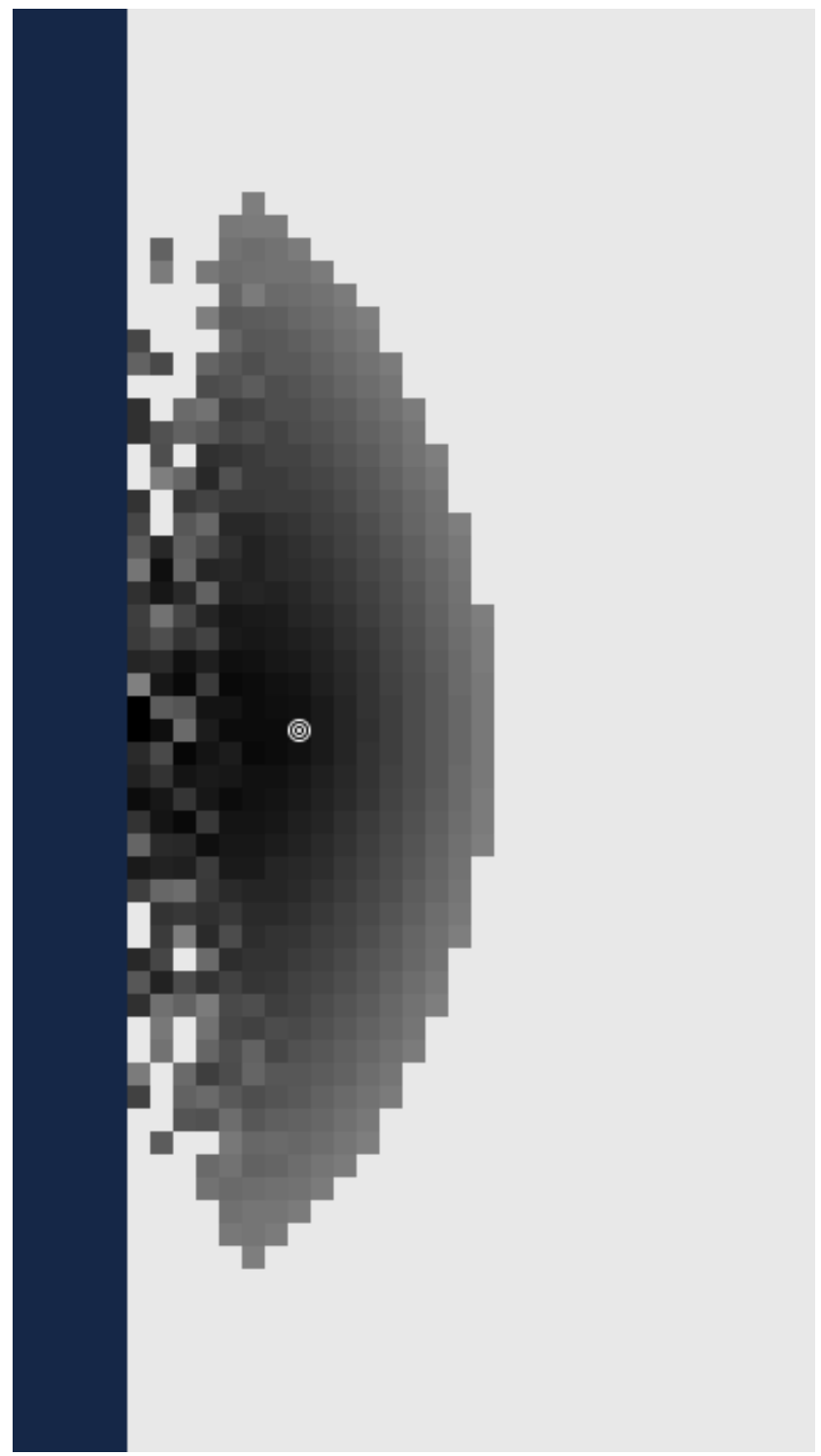

a) Rent gradients

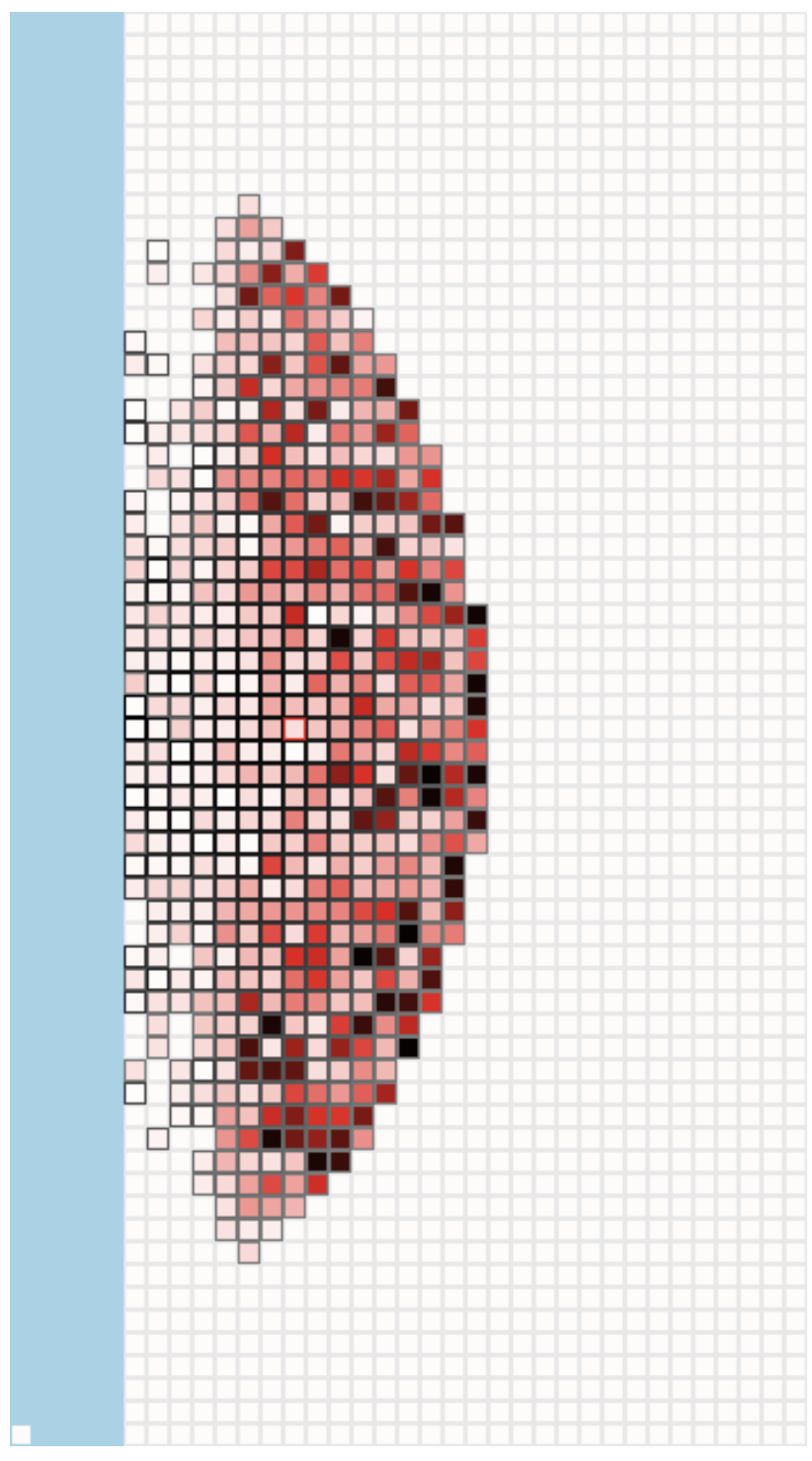

b) Map of perceived damage coefficients of agents settled in the city. White color means $\mathrm{C}_{\mathrm{dam}}=0$, darkest red means $\mathrm{C}_{\mathrm{dam}}=1$

Figure 7.10: Results of Exp 7.3: heterogeneous agents parameterized with uniform distribution

In comparison to Exp 7.1 completely random agents in Exp 7.3 caused the city to expand but not at all at the extent the agents with real-world perception of flood risk did in Exp 7.2. Two facts need to be mentioned here. First, agents in Exp 7.2 are parameterized with skewed empirical distribution and agents in Exp 7.3 are parameterized with uniform distribution $\left(a C_{d a m}=0.33\right.$ vs. $\operatorname{avC}_{\mathrm{dam}}=0.5$, Table 7.6). So, it might not be so surprising that balanced uniform distribution causes fewer developments in the risky zone compared to the skewed to the left distribution of worry. Nevertheless, other studies report that a uniform distribution provides the upper bound of variation of aggregated outcomes compared to the parameterization with survey data (Brown and Robinson, 2006). Second, a land market, with heterogeneous agents parameterized with a uniform distribution, allocates more developed land in the zone liable to flooding than a land market with a representative 
agent with skewed damage coefficient does. Note, that a representative agent is parameterized with the mean value of worry from the skewed distribution. However, it is the heterogeneity of agents parameterized with a uniform distribution that causes developments in the risky zone. Surprisingly, completely random agents making a "wild guess" about potential risks would not invest as much in the flood-prone zone as would agents parameterized with the empirical survey distribution do. It appears that current governmental policies might lure homeowners to deliberately locate in more risky areas.

The land gradient in Figure 7.10.a is very much dispersed in price range to the left of the safety contour and is almost homogeneously declining with distance to the CBD to the right of the contour. Similarly to the landscape in Exp 7.2 the landscape landwards from the safety contour has a probability of a coastal hazard approaching zero (upper part of Figure 7.6). So, heterogeneous agents do not differentiate between cells with almost zero probability of flooding and, thus, behave as homogeneous (agents' preferences for the proximity to the CBD and coastal amenity - two other dimensions of spatial heterogeneity - are homogeneous). However, seawards from the safety contour - where probability of a coastal hazard matters - heterogeneous agents with uniformly distributed damage coefficients bid differently on different spatial goods. Figure 7.10.b shows that there is a sorting of agents emerged during the land market allocation, as in Exp 7.2. However, agents who settled seawards the safety contour are not all with zero damage coefficients: they have very low but still heterogeneous damage coefficients (compare light pink color of cells along the coast in Figure 7.10.b to the white color in Figure 7.8.b). As a result the land prices are heterogeneous along the coast in Exp 7.3 and are homogeneous landwards (see 3D scatterplot of land rent gradient in Figure 7.11).
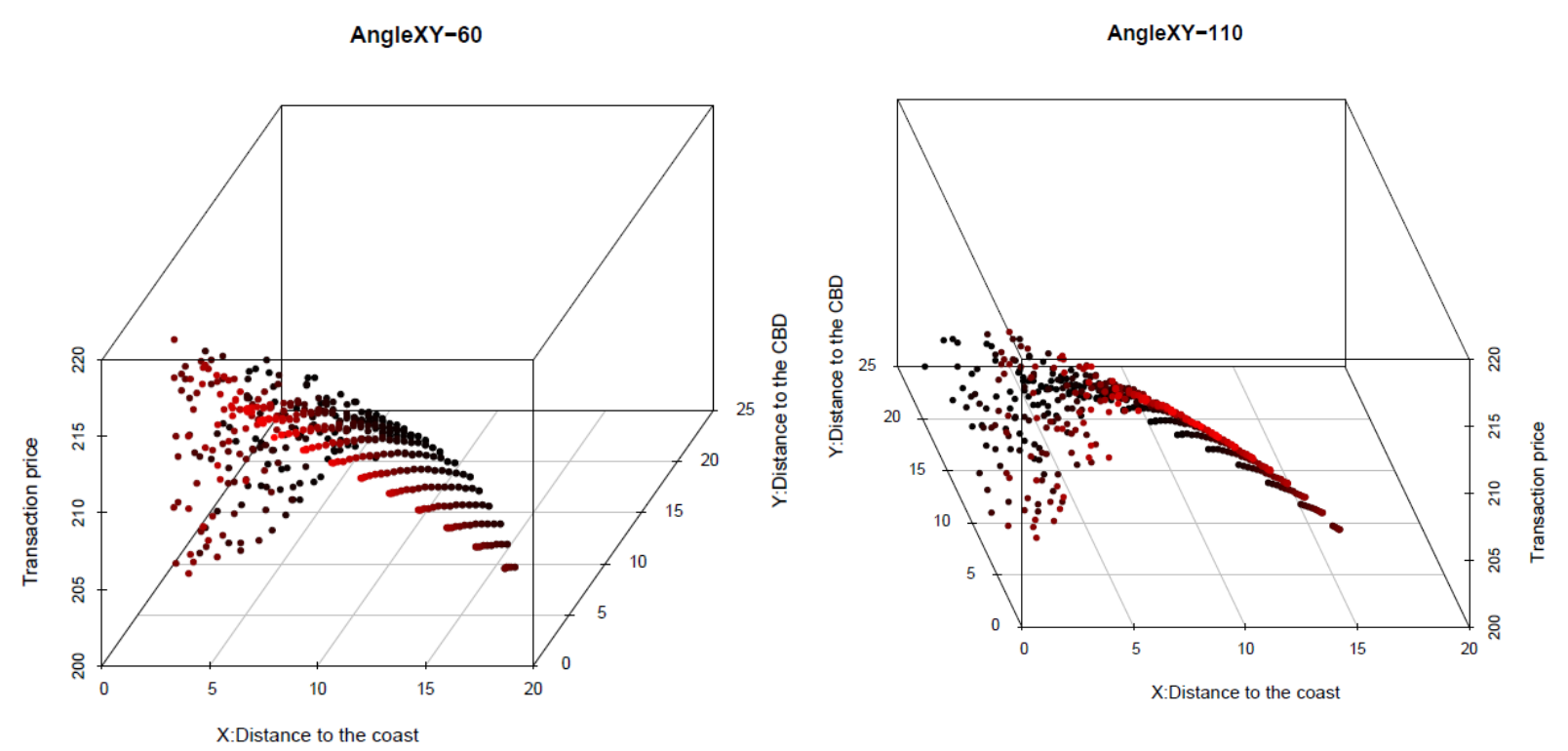

Figure 7.11: 3D scatterplot of transaction prices for Exp 7.3: agents with heterogeneous coefficients of perceived damage parameterized using uniform distribution 
The 2D land rent gradient of the transaction prices from Exp 7.3, which is a cubic regression $\left(\mathrm{R}^{2}=0.7749\right)$ estimation of land price as a function of distance to the coast and to the $\mathrm{CBD}$, is shown in Figure 7.7. The blue curve represents a 2D crosssection of a 3D land gradient surface along the perpendicular axis between the CBD and the coastline. Compared to the red estimated rent gradient of Exp 7.2 the blue curve goes down seawards from the CBD. Even if it still goes beyond the safety contour the total value of the property under risk is much lower.

\subsection{Discussions and conclusions}

Combining agent-based modeling with micro-level data from surveys is becoming more popular. Naturally, the biggest obstacle in doing so is the costs of acquisition of survey data. In this Chapter we analyzed the results of the survey carried out in the Dutch province of Zeeland and designed, among other things, to elucidate individual risk perception and factors affecting location choice (Krywkow et al., 2008). The survey showed that Dutch people have low or very low worry about coastal flooding affecting them personally. The conclusion about low flood risk awareness in the Netherlands was also confirmed by other independent surveys (Berg et al., 2002; Kaiser et al., 2004; Bočkarjova et al., 2008; Terpstra and Gutteling, 2008). Apparently, the level of worry about coastal flooding is not correlated with the experience of flooding that respondents had in the Netherlands, but does correlate with flood experienced by respondents elsewhere in the world. This is probably caused by the fact that the Dutch government promised that coastal flooding should never happen again in the Netherlands and current flood risk communication policy is not making people aware of and prepared for a potential hazard. The survey also showed that time and distance to work are two most important factors that affect individual choice of location. Coastal amenity compared to the importance of safety from flooding has a priority for the respondents. For the reasons outlined in section 7.3.2 we used only the survey data about distribution of worry to parameterize agents in the ALMA-C model.

We performed three experiments with our ABM of a coastal land market. First, homogeneous agents were parameterized with the mean value of worry about flood risk, which meant to show the results of a model with a representative agent. Second, heterogeneous agents were parameterized with the survey distribution of worry about flood risk, which meant to show the difference between using homogeneous and heterogeneous empirical data at micro-level. Third, heterogeneous agents were parameterized with a uniform distribution of the coefficient of perceived damage, which was to show the difference between micro-level parameterization with skewed data (Exp 7.2) vs. uniform data (Exp 7.3). In addition, it meant to compare aggregated land market outcomes with 
agents that had an empirical distribution of the perceived damage to outcomes from markets driven by agents with purely random "wild guess" perception of damage.

From previous chapters we have already seen that the replacement of a representative agent in a land market model by a set of heterogeneous ones create bias in aggregated market outcomes and lead sometimes to qualitatively different results. The detailed discussion concerning these qualitative differences in relation to economic and econometric models using a representative agent is presented in Chapter 5 and we will not repeat it here. What is special about Exp 7.1 and Exp 7.2 is the sue of an empirical distribution to parameterize agents' micro-attribute, specifically the coefficient of perceived damage. Noteworthy, the distribution of this parameter in the survey data is skewed (Figure 7.1). It is not be surprising that the population of agents with very low worry about potential coastal flood risk would settle in the flood-prone area absolutely ignoring risks.

The results of the ALMA-C run where agents are parameterized with survey data showed that there is sorting occurring through bilateral land market trading. The land market allocates people with a lower coefficient of perceived damage closer to the coast. People with high "worry" will always bid lower for the land along the coast and higher for the areas farther from the coast, i.e. in safer areas. Thus, as the survey showed people with higher level of "worry" have higher WTP for safety. In contrast, the people who have low "worry" bid high for the land along the coast. This might well correlate with the survey conclusion that the majority of respondents (who have very low level of worry about coastal risk) considered coastal view to be more important than safety.

The results of the land market simulations with heterogeneous agents parameterized with the survey data were compared to the results of the market where agents have absolutely random uniform distribution of perceived damage. Brown and Robinson (2006) also used a uniform distribution of preferences in comparison to the survey distribution to explore their residential location model SOME. Their finding is that uniform case represents the upper limit of variation. In this chapter we have found that uniform case, i.e. Exp 7.3, produces less variation than the land market model with heterogeneous agents parameterized with survey data. This implies that even if decisions where made based on absolutely random wild guess about flood risk in the coastal zone area, they would still result in fewer developments in the risky, and therefore economically inefficient zone, and less potential damage than what is happening when agents in the land market have the skewed risk perception specific for the Dutch population. 


\section{Conclusions and discussions}

Understanding the relationships between micro and macro-scales in economic systems is essential. From a broad range of topics related to this question, this thesis focused particularly on exploring how aggregated phenomena in a land market emerge from interactions of economic agents at the micro-level. The interest in interdisciplinary research, particularly in application to coastal cities in the Netherlands, encouraged the development of a spatially explicit land market model. The goal of the thesis was to identify traceable connections between micro and macroeconomic scales in application to a hypothetic city, which replicates the structure and complexity of a typical Dutch coastal city. Six research questions, which we review below, were answered. Furthermore in these conclusions we outline the achievements, as well as limitations of the current and directions of future research. Finally, the considerations for practical applicability of the thesis results to coastal risk management are presented.

\subsection{Answers to research questions}

Q1: How do micro-level preferences and perceptions (e.g. flood risk awareness) of economic agents affect macro-economic spatial outcomes and how can policy-makers use these micro-macro links for coastal risk management?

In Dutch water management risk is defined as a product of probability of disaster and potential damage from it. Thus, decreasing either of the two multipliers can reduce coastal flood risk. In Chapter 2 it is shown that macroeconomic features, such as land prices and land patterns, and, consequently, potential direct damage in flood or erosion-prone areas, are the outcomes of microeconomic decisions in the land market. Moreover, a review of theoretical and empirical economic literature demonstrates that if individual risk awareness is high, then property prices in flood-prone areas go down, leading to a decrease in direct damage from coastal flooding. Conversely, low risk awareness biases microeconomic decisions in a land market, and leads to inefficient economic land use outcomes. However, recent surveys on coastal flood risk perception carried out in the Netherlands provide evidence that coastal flood risk awareness is low. Policy makers may consider affecting microeconomic behavior in a coastal land market, specifically individual risk awareness, for the purpose of decreasing total risk in coastal areas.

The literature review identified four factors that influence risk awareness and have measurable effects on individual land market behavior: personal experience, risk communication, financial instruments (specifically, flood insurance), and engineering (in particular, building on higher elevations). Obviously, only the last three factors can be used by policy makers as proactive risk 
management instruments. Risk communication is a useful and important tool, however its effects might become evident only in the long-term. Flood insurance as a risk communication device so far was omitted from the general discussion about its applicability in the Netherlands. However, it is very efficient in making individuals integrate coastal risk when they are making location choices. Building on higher elevations, in contrast to traditional technical measures, not only decreases probability of damage but is also likely to increase individual flood risk awareness. The latter two instruments create a ground for shared responsibility between government and individuals for flood risk reduction by giving individuals an opportunity to act.

Q2: How can a land market be modeled in a spatially explicit way and what are the challenges arising from transforming an economic equilibrium framework into a dynamic spatial context?

The problem of aggregation in economics in a spatial context along with the needs for interdisciplinary applications requires that the land market be modeled in a spatially explicit way. Spatial economics concentrates on modeling aspatial land markets, while cellular land use models do incorporate heterogeneity and a spatially explicit setup but without explicitly modeling markets. Chapter 3 describes a conceptual scheme that accommodates both factors - direct modeling of a land market and spatial explicitness, - and then discusses how an agent-based market can be formalized. Agent-based modeling was chosen as the appropriate methodology to accommodate heterogeneity of agents, their interactions, the spatially explicit heterogeneous landscape, and the out-of-equilibrium dynamics. The Agent based Land MArket (ALMA) model was developed. As in cellular land use models, the spatial environment is presented by a cellular grid, and as in economics, the behavioral part is modeled with agents trading spatial goods (land or housing) on a market.

The ALMA model explicitly includes both demand and supply. As in other agent-based markets, the centralized price determination mechanism is replaced by a set of bilateral trades, making the transition from an equilibrium framework to a dynamic market with local interactions. In addition, land is recognized as a specific good: each spatial good has unique characteristics (differentiable), land is immobile and durable, different land uses create externalities, and land is not frequently purchased, so that learning about optimal pricing behaviour (frequently used in other agent-based markets) is limited. These distinctions of agent-based land markets from conventional equilibrium land markets and from other agent-based markets with homogeneous goods call for specific methodological solutions (e.g. who are the agents in a land market, how land price is determined, etc.). These are discussed in Chapter 3 in detail. 
Q3: How comparable are the results of a land market with homogeneous agents where the centralized equilibrium price determination mechanism is replaced by the spatially distributed bilateral trading to the results of the conventional monocentric urban model?

From a conceptual model we then moved to the actual computer implementation of the ALMA model. The program was written using Netlogo software (Wilensky, 1999), which allows spatial modeling and is frequently used in social simulations. A monocentric urban model by Alonso (1964), the basic model in which many models in urban economics are grounded, serves as an analytical base for comparisons. To be able to perform structural validation (Manson, 2002), i.e. to see how well the simulation model matches the analytical model, assumptions identical to the analytical monocentric model are employed. In particular, all buyers as well as sellers are assumed to be homogeneous, and the landscape is a featureless plain except for the exogenously given city centre (central business district - CBD). The buyer's willingness to pay resembles the properties of the microeconomic demand function: it increases with income and with utility gained from the housing good, while it decreases with transportation costs and with relative prices of other goods as comparative statics ${ }^{59}$ shows (see Chapter 4).

The experiments with ALMA demonstrate that macro-scale model behavior conforms with the qualitative behaviors of the standard model. Specifically, land is traded to the highest bidder, transaction prices (land rents) are identical at locations equidistant from the CBD, and land rents decline monotonically as distance from the CBD increases. The land rent gradient is downward sloping as estimated through regression analysis, using model generated transaction prices as the dependent variable, and distance as the independent variable.

The value added by the agent-based technique is in accommodating features that go beyond conventional models. In particular, the ALMA model separates the underlying valuation of buyers and sellers (their willingness to pay and willingness to accept) from their bid and ask prices, facilitating modeling of alternative pricing behavior, and analysis of the division of gains from trade under different market circumstances. The experiments with "buyers" (i.e. when there are more sellers willing to sell and buyers are in advantageous situation) and "sellers" (vice versa) markets show that the speed of information update affects pricing behavior and creates unjustifiably higher bid or low ask prices. It increases the proportion of gains from trade that accrue to the agents with relative market power.

The computer model is developed in such a way that the user can choose from several pricing behaviors of both buyers and sellers (whether buyers should bid their actual willingness to pay, or whether sellers should account for the market situation, etc.). Agents' preferences and incomes can

\footnotetext{
${ }^{59}$ Comparative statics is the analysis of the changes of the endogenous variables of a model caused by a change in its exogenous variables (i.e. determination of the sign of each partial derivative).
} 
also be tuned. In Chapter 4 the model was run for a monocentric city; however, the ALMA model provides the possibility to initiate a landscape with green amenities, or a coast/river view. Technically, it is possible to upload GIS maps with various spatial characteristics of interest. The model produces output files (in comma separated format), which describe each land market transaction along with the buyer and seller, their preferences, private pricing information and public bid and ask prices as well as spatial attributes of the traded land. Also, all the unsuccessful attempts to trade, in which a buyer and a seller did not find it possible to trade, are also recorded for potential further analysis. In fact, the ALMA model may serve as a computational laboratory in which a researcher has a full understanding of the agent-level and spatial factors that influence bid prices, ask prices, and realized transactions. Such a laboratory allows exploring the statistical predictions that emerge from land market models, creating an opportunity for greater understanding of the potential processes that have generated the transaction data that we observe in the real world.

Q4: What are the results (e.g. land rent gradient, size of the city, welfare metrics) of a spatially explicit land market if spatial heterogeneity (amenities and disamenities) and agent heterogeneity are introduced?

Motivated by the problems of Dutch coastal towns, this thesis provides insights into the land markets interactions in a coastal town. Chapter 5 expands the previous one by introducing amenities (coastal view) and disamenities (probability of flooding or erosion) in the landscape. The results of socio-psychological research (Kahneman and Tversky, 1979; Simon, 1997) show that economic agents are not really behaving as rational as economic theory assumes, and that people have difficulties understanding probabilistic risks (Slovic, 1987). Therefore, Chapter 5 presents another experiment with agents having heterogeneous beliefs about the probability of a coastal disaster.

The coastal land market model (ALMA-C) in a landscape where only amenities are present and all agents are homogeneous is an implementation of the analytical urban model of a coastal city (Wu, 2001). This structural validation shows that if agents are homogeneous and only coastal amenities are present, then the ALMA-C model with a bilateral decentralized market performs qualitatively the same as the equilibrium based analytical model. Currently, the analytical urban model could incorporate only one spatial attribute in addition to the distance to the CBD: that was either the environmental amenity (Wu, 2001) or environmental risk (Tatano et al., 2004). The agentbased methodology, however, makes it possible to analyze the effects of multiple spatial factors, producing a land market model that includes more real-world heterogeneity than conventional economic models. It is important to incorporate both spatial amenities and disamenities in the land market modeling, especially if they are spatially correlated (Bin et al., 2008). If the probability of 
coastal erosion is present and individuals perceive it objectively, then this spatial factor serves as a distracter for people choosing a location. In this case, at the aggregated level, land prices decrease approaching the coast, the seawards city border shifts landwards, and the aggregated utility of agents settled in the city decreases.

The third experiment with the ALMA-C model in Chapter 5 aims at relaxing the agent homogeneity assumption: economic agents operating in a coastal land market are assumed to have heterogeneous beliefs about the probability of flooding in the city (with a zero, on average, deviation from objective probability - i.e. agents expectations are unbiased in comparison to the homogeneous case). It is demonstrated that the introduction of heterogeneity at the micro-level produces qualitatively different behavior at the macro-level in contrast to a representative agent approach. In particular, the land price distribution is different, and urban development expands into the zone that a representative agent would consider economically inefficient. Note that, economic models used to support policy decisions usually assume a representative agent that, as the experiments showed, underestimates developments in the flood-prone area.

A regression analysis (i.e. estimation of the land rent gradient) is performed on modelgenerated data in two stages: first using only spatial attributes of the environment (the data usually available for econometric analysis) and, second, including data on the individual characteristics of buyers, specifically their subjectively perceived flood probability (usually unobservable directly in the real-world). Comparison of the two regressions shows that estimates based only on spatial data may give policy-makers a biased picture of land market dynamics. While data about real-world perceptions of the probability of flooding is hard to obtain, an agent-based land market model such as ALMA-C presented in Chapter 5 can be used as a computational laboratory to understand the potential implications of missing data.

Another important conclusion that resulted from this analysis is the connection between aggregated market outcomes (land prices and patterns of urban location) and individual beliefs about probability of flooding. The ALMA-C model shows that people who underestimate the probability of disaster can drive land market dynamics, causing the city to expand into a high-risk zone. 
Q5: How do land markets respond (in terms of changed land prices, city size, and amount of urban developments under risk) to an increasing probability of flooding or erosion? How variations in individual perceptions of erosion probability affect aggregated patterns of development?

For many coastal towns in the Netherlands, an essential attribute of land is the probability of erosion. Erosion points can be estimated based on different scenarios of sea level rise and frequency of coastal storms. Consequently, the erosion line may move to a different position depending on whether climate change and other factors are taken into account or not. In fact, the flood defence line (which is based on the position of the erosion line) divides a city into a legally protected zone and a legally unprotected one. The Commission of Poelmann (2005) that aimed to give advice with respect to further developments of those areas outside the dikes, recommended to allow developments in the legally unprotected zone but at the risk of individuals. The question is how the urban developments may go on in these cities, especially if erosion line shifts landwards due to climate change impacts.

Chapter 6 uses ALMA-C as a schematized model aimed to qualitatively replicate the case of these Dutch cities under risk. If the probability of erosion increases (erosion line shifts landwards) and individuals perceive probability of erosion objectively, then, ceteris paribus, individual expected utility from a location in this coastal city decreases and urban developments move away from the coast. This is what a conventional economic analysis, assuming a representative rational economic agent in a land market, could predict as well.

In reality, people have subjective perceptions of natural hazard (e.g. erosion) probability, which often depends on individual socio-economic and demographic characteristics and previous experience of hazardous events (Kaiser et al., 2004). As a result, in real-world land markets there may be individuals who overestimate or underestimate the probability and consequences of a hazardous event. The ALMA-C model with heterogeneous agents shows that even with the landward shift of the erosion line and increase of the probability of erosion close to the coast, there still will be some urban developments beyond the erosion line. Consequently, for the coastal zone policy context and for the coastal cities to which Poelmann commission advice applies, it means that if there are some people who underestimate erosion probability (which is the case in the Netherlands - see surveys results in $\mathrm{Ch} 2$ and $\mathrm{Ch} 7$ ) they are likely to locate in the risky area and will increase the amount of capital at risk.

In addition, Chapter 6 discusses the effect known as a 'coastal squeeze', i.e. increasing pressure on the coastal margin from human system and the global dynamics of nature. The results of the ALMA-C experiments show that low individual perception of the probability of a coastal 
hazard drives urban developments seawards. Thus, as one of the reasons behind the human pressure it contributes to the increase of coastal squeeze.

Q6: What are the real-world individual location preferences and perceptions of flood risk in the Netherlands? What are the outcomes of a spatially explicit land market where the distribution of economic agents' perception of risk of flooding is parameterized with real-world survey data?

The real value of agent-based models is when they are combined with real-world data, for example with micro-level data from surveys. In March 2008 a survey aimed to elucidate individual risk perception and factors affecting location choice, along with other aims, was carried out in the Dutch province of Zeeland (Krywkow et al., 2008). The survey showes that most Dutch people do not worry about coastal flooding affecting them personally (i.e. perceived flood risk is low). Apparently, levels of worry about coastal flooding hardly correlate with the experience of coastal flooding that some respondents had in the Netherlands in 1953. The survey data also demonstrates that time and distance to work are two most important factors that affect individual choice of location. Coastal amenity compared to the importance of safety from flooding has a priority to the respondents. Moreover, the survey elucidated the willingness to pay for coastal view, for flood safety and for developments above sea level (i.e. elevated grounds) (see Chapter 7).

Three experiments with the ALMA-C model are performed to incorporate the survey results i.e. empirical data at micro-level. First, homogeneous agents are parameterized with the mean value of perceived flood risk derived from the survey data. Second, heterogeneous agents are parameterized with the survey distribution of perceived flood risk. Third, heterogeneous agents are parameterized with a uniform distribution of perceived risk, which is to show the difference between output produced by micro-level parameterization with skewed survey data and the one that comes out of a uniform distribution. Additionally, the last two experiments compare aggregated land market outcomes where agents are parameterized with empirical distribution of the perceived risk to the results produced by agents that had a purely random "wild guess" about risk.

As before, models parameterized with the average vs. heterogeneous data from the survey produce qualitatively different results (city with the representative agent stays away from the coast while heterogeneous agents settle everywhere in a coastal town). The results of the ALMA-C run where agents are parameterized with heterogeneous survey data show that there is sorting occurring through bilateral land market trading. The land market allocates people with lower coefficient of perceived damage closer to the coast. In compliance with the survey data, people with higher level of flood risk awareness have higher WTP for safety. In contrast, people, who do not worry about 
coastal flooding, prefer to settle close to the coast and have high bid for the land there - this is also shown by ALMA-C. This result correlates well with the survey conclusion that in average the respondents have very low level of worry about coastal risk and consider coastal view more important than safety.

Furthermore, model runs where individuals are parameterized with uniform levels of risk perception produce less variation than the land market model with heterogeneous agents parameterized with survey data. This implies that even if decisions where made based on absolutely random wild guess about flood risk in the coastal zone area, they would still result in fewer developments in the economically inefficient zone and less potential damage than what is happening when agents in the land market have the skewed risk perception specific for the Dutch population.

\subsection{Achievements, limitations and future work}

\subsubsection{Achievements}

The ALMA model presented in the current thesis has the following achievements compared to previous research:

1. A new spatially explicit land market model structure facilitates the coupling of economic models with the process-based ecological ones. The model is closely related to analytical urban economics, cellular automata and spatial econometrics:

a. Compared to urban economics: a land market in a monocentric city is modeled in a spatially explicit way and with a possibility of including heterogeneous spatial environment, heterogeneous agents, and direct modeling of interactions;

b. Compared to cellular automata land use models: use of agents exhibiting microeconomic behavior and biased or unbiased perceptions of flood risk adds a behavioral component to the cellular grid;

c. Compared to statistical spatial models: the agent-based land market model does not just report the dependencies between aggregated variables (e.g. land price as a function of distance). Rather it allows understanding the processes behind these aggregates.

2. The model produces land prices in addition to land patterns - the traditional results of the land use models. The modeling of prices is important for several reasons:

a. Land use models often associate a certain land use type without consideration of whether the land in that location is affordable for an agent's income; 
b. Urban development patterns are usually irreversible but land prices for the same urban area can change dramatically over time affecting preferences and choices of agents searching for location;

c. Governmental policies aiming at more sustainable land use, environmental protection or flood protection normally use market mechanisms such as subsidies, taxes or insurances to affect land use decisions (Martínez et al., 2007). These market mechanisms largely affect land prices and only indirectly land patterns;

d. Furthermore and most important for the purpose of this research is that in the flood or erosion-prone areas the direct economic damage depends on the property price along with the land use type.

3. Links between individual preferences and perceptions at micro-level and aggregated land market outcomes are defined and explicitly modeled using the agent-based approach. The model allows understanding the effects of changed microeconomic motives or conditions of the spatial environment on land prices, land patterns and welfare measures. The recording of all the agent-level information (i.e. incomes, preferences, perceptions, private willingness to pay in addition to agent's bid price) along with transaction data and spatial attributes of the traded land brings insights into the aggregated behavior of some land market indices such as estimated rent gradients (note the test of adding agent-level data in the regression analysis in Chapter 5). Thus, the model can serve as a computational laboratory (Parker et al., 2002; Tesfatsion, 2006) to test hypothesis about real-world estimated land rent gradients and stylized facts about the agents' behavior.

4. Effects of changed micro-behavior on macro-indices can be quantified and visualized. Aggregated numbers tell little about the spatial pattern of urban developments, e.g. size of the city may stay the same but the developed areas may be located in or outside a floodprone area. Similarly, aggregated numbers alone neither uncover the qualitative aspects of land rent gradient behavior (note the importance of the 3D land rent gradient representation in Chapters 5 and 7), nor the nature of microeconomic behavior that causes those changes in the aggregated land rent gradient (see 2D land gradients for a low, average and high flood probability perception group in Chapter 5).

\subsubsection{Limitations}

At the current moment the model has the following limitations:

- At this point little empirical data is utilized. The model presented in this thesis mainly tries to answer theoretical, methodological questions about scales and aggregation in economics 
in the spatial context. The first step toward an empirical model was presented in Chapter 7 where some of real-world microeconomic data from a survey were used to parameterize agents. The model can be considered as a building block toward combining theoretical economic models with real world complexity of land use change. Specifically, the ALMA model is spatially explicit, dynamic and is able to accommodate heterogeneity of spatial environment and agents. Future work will move further towards empirical land market modeling as outlined in Chapter 3.

- The use of more empirical data will require the import of real-world maps and consideration of real time. Technically, it is possible to upload GIS data ${ }^{60}$ in the ASCII format. With respect to real time accounting for the dynamic model run: one of the options might be to translate the number of transactions into years (or months depending on which time scale is more appropriate for the problem in hand).

- Although ALMA produces land prices - something that many land use models lack - so far these prices cannot be directly compared to the real world land prices. Nevertheless, they still convey very important comparative information about the demand for and the scarcity of land (Buurman, 2003). The most important fact is that the spatial distribution of land prices in the ALMA model resembles the general stylized facts from empirical spatial and environmental economics research. In particular, prices grow with the proximity to the employment center (i.e. CBD), prices are higher close to environmental amenities and land prices decrease if individuals understand environmental risk associated with location.

Some of the limitations of the model affect its predictive power. However, the main purpose of this research is to explore what are the links between individual economic decisions at micro-level and aggregated land market outcomes in a spatial context. The main methodological question on one hand, was to combine fully modeled land market and spatial explicit potential of cellular models on one hand. On the other hand, the methodological issue was to bring agent-based computational economic models into a spatial context at least at some extent. From the point of applied importance it was essential to explore, rather than exactly predict (Brugnach et al., 2008), the consequences of different types of individual agent behavior in a land market on the macro-indices that are of interest to policy makers (e.g. land patterns and prices, potential flood damage, etc.). Explorative analysis implies the identification of main cause-effect links and trends of system development and this is what was done in this thesis.

\footnotetext{
${ }^{60}$ See (Castle and Crooks, 2006; Crooks, 2007) for the comprehensive discussion of the value added and challenges associated with integration of $\mathrm{ABM}$ and GIS
} 


\subsubsection{Future work}

Direction for future research:

- Real-world has more actors involved in a land market. A governmental agent was already added to ALMA (Filatova, 2007b) but additional testing should be carried out. Adding a developer agent and different types or aspects of economic behavior of buyers and sellers can serve as a promising direction of future work. Since the economic and sociopsychological literature offers numerous theories describing human behavior in different situations, the choice of additional behavior patterns to be added to the land market model depends highly on the particular problems and research questions in hand.

- The implementation of learning algorithms in a land market, in which a spatial good (i.e. land) is highly heterogeneous and infrequently traded by one agent, is limited ${ }^{61}$. As a future improvement, the learning algorithms can be employed to make agents "learn" the optimal price strategy as in other agent-based computational economics markets. Potentially, a real estate agent who is involved in numerous land transactions might be suitable for this role.

- Scenarios of alternative coastal risk management strategies (e.g. taxes and flood insurances, different flood defense measures, spatial planning policy) could be further investigated with the model.

- Modeling of urbanized area with polycentric cities, not just a single open city model could add more realism to the study. It will be particularly interesting to get insights in the relocation behavior in this context.

- The presence of spatially explicit setup allows for accounting of neighborhood effects. Neighborhood externalities in space largely affect land use change. A simple model to account for the neighborhood effects was implemented (Filatova, 2007a) but more research in this direction will be useful.

\subsection{Considerations for practical applicability of the results for coastal risk management}

Reduction of the potential damage from flooding and erosion is of major concern for coastal risk management. The potential damage is strongly related to such macroeconomic indices as land prices and land patterns. For effective policy-making in general, and for coastal risk management in particular it is crucial to understand how the micro and macro-levels are connected, and how they affect each other. In particular, aggregated land prices and land patterns, and consequently potential

\footnotetext{
${ }^{61} \mathrm{ACE}$ markets normally endue agents with a learning algorithm to adapt and to learn an optimal pricing strategy. Learning is able to occur because there are numerous trades, in which each agent is involved. Moreover, the good itself is homogeneous.
} 
flood damage, can be changed by affecting individual preferences and perceptions of flooding risk. This research can have policy implications in a variety of aspects.

A recent survey of coastal flood risk perception and location choices in the Netherlands showed that Dutch citizens have low coastal flood risk awareness (more than $60 \%$ of respondents do not worry about the fact that coastal flood risk might affect them in the future). Moreover, one of the spatial attributes to which the respondents gave high importance was the proximity to environmental amenities, although safety from flooding was not considered as important (Chapter 7). At the same time simulation results of a land market model with heterogeneous agents show that people with low flood risk awareness can drive land market dynamics, causing a city to expand into a high-risk zone. In fact, urban developments in a city where individuals are with low flood risk awareness go beyond the zone, which a representative agent ${ }^{62}$ considers economically efficient (Chapter 5). Furthermore, it was shown that increase in risk awareness can decrease land prices and change land patterns to decrease of total flood risk, which is a product of probability and effect (Chapter 2). Therefore, measures to increase flood risk awareness at the individual level (such as risk communication, financial and technical instruments) can be employed by policy makers to reduce total flood risk along with traditional flood defence measures.

The survey data and the model results have important implications for the Dutch coastal cities considered by the Poelmann Commission (Chapter 6). As our model shows, even if the land market in the coastal zone area was driven by absolutely random flood risk perceptions, we should expect fewer developments in the risky zone and less potential damage than what we have with individuals with perceptions skewed toward lower risk, as in the Netherlands today (Chapter 7). The conventional economic model, which is based on representative agent and does not grasp the heterogeneity among agents, would predict no developments in the high risk zone. Therefore, the ALMA model can serve as a useful tool for policy-makers.

A spatially explicit land market model, such as ALMA, can link microeconomic behavior with macro-phenomena and show how changes at micro-level affect the aggregated outcomes. Getting insights of how micro and macroeconomic levels are connected may help policy makers to identify the elements in the economic system that they can impact to get a desired policy outcome. Furthermore, the knowledge about these links can be used to influence microeconomic behavior. For instance, the ALMA model is applied to a hypothetical city to test whether such a policy instrument for coastal ecosystem preservation as $\operatorname{taxes}^{63}$ can indeed stop the expansion of urban

\footnotetext{
${ }^{62}$ Conventional economic models, which are used for decision support in policy-making, (i.e. general equilibrium or statistical models) use a "representative" agent model. Representative agent is a typical firm or household, the behavioral model of which can be extended to represent the behavior of the whole group of economic agents.

${ }^{63}$ It is considered that market mechanisms such as subsidies, taxes and insurances can help to preserve coastal ecosystem function from destruction by the expansion of urban areas along the coasts (Martínez et al., 2007)
} 
developments into the primary coastal zone that is especially valuable from the ecological point of view (Filatova, van der Veen and Voinov, 2008). The result of model runs with the assumption that all economic agents have the same income (i.e. representative agent) showed that market mechanisms indeed work and urban developments shift away from the coast if tax policy is introduced. Thus, the result, at which policy aimed, seems to be achieved. However, if the assumption of the identical incomes is relaxed (i.e. heterogeneous agent) then the aggregated outcomes of the tax policy qualitatively change. Specifically, people with high incomes are still able to buy land along the coast causing further urban expansion (although at a lower speed). However, this creates a situation of social injustice since most valuable land along the coast was affordable to high-income people only. We can see that the effects of government intervention may be contrary to the anticipated ones.

We therefore conclude with the following considerations for practical application of this study results for coastal risk management:

a. Measures to increase flood risk awareness at the individual level (such as risk communication, financial and technical instruments) can be employed by policy makers to reduce total flood risk along with traditional flood defence measures;

b. In addition to conventional general equilibrium or statistical models based on a representative agents, policy makers should embrace models that accommodate links between micro and macro-levels, include heterogeneity among individuals and account for a spatially explicit heterogeneous environment (such as ALMA);

c. Spatial distribution of land prices is as important as patterns of development and have to be considered in decision-making. There may be unexpected outcomes of market based policies that spatially explicit land market models like ALMA can help to foresee and understand. 



\section{References}

Alberini, A., P. Rosato, A. Longo and V. Zanatta (2005). "Information and Willingness to Pay in a Contingent Valuation Study: The Value of S. Erasmo in the Lagoon of Venice." Journal of Environmental Policy and Management 48(2): 155-176.

Alberini, A., V. Zanatta and P. Rosato (2007). "Combining actual and contingent behavior to estimate the value of sports fishing in the Lagoon of Venice." Ecological Economics 61(2-3): $530-541$.

Alonso, W. (1964). Location and Land Use. Cambridge, MA: Harvard University Press.

An, L., M. Linderman, J. Qi, A. Shortridge and J. Liu (2005). "Exploring complexity in a humanenvironment system: An agent-based spatial model for multidisciplinary and multiscale integration." Annals of the Association of American Geographers 95(1): 54-79.

Anas, A., R. Arnott and K. A. Small (1998). "Urban Spatial Structure." Journal of Economic Literature 36(3): 1426-1464.

Arnott, R. (1987). Economic Theory of Housing. Handbook of Regional and Urban Economics. E. S. Mills. Volume II: 959-988.

Arnott, R., R. Braid, R. Davidson and D. Pines (1999). "A general equilibrium spatial model of housing quality and quantity." Regional Science and Urban Economics 29: 283-316.

Arsenault, A., J. Nolan and R. Schoney (2007). Using a Multi-agent Simulation to Model Bidder Learning and Heterogeneous Landscapes in a Repeated Farmland Auction Markets. Joint AAEA/WAEA/CAE Annual Meetings (Eds), Portland, OR, AgEcon Search.

Arthur, W. B. (2006). Out-Of-Equilibrium Economics and Agent-Based Modeling. Handbook of Computational Economics Volume 2: Agent-Based Computational Economics L. Tesfatsion and K. L. Judd (Eds). Amsterdam, Elsevier B.V.: 1551-1564.

Arthur, W. B., S. N. Durlauf and D. Lane (1997). The economy as an evolving complex system II. Santa Fe Institute Studies in the Science of Complexity, Vol. XXVII, Addison-Wesley.

Arthur, W. B., J. Holland, B. LeBaron, R. Palmer and P. Tayler (1997). Asset pricing under endogenous expectations in an artifcial stock market. The economy as an Evolving Complex System II, SFI Studies in the Science of Complexity, Vol. XXVII. W. B. Arthur, S. N. Durlauf and D. A. Lane, Westview Press: 15-44.

Axelrod, R. (1997). The complexity of cooperation: agent-based models of competition and collaboration. Princeton, New Jersey, Princeton University Press.

Axtell, R. (2005). "The Complexity of Exchange." The Economic Journal 115(June): F193-F210.

Bajdechi-Raita, S. M. (2005). The risk of investment in human capital, PhD Thesis, Universiteit van Amsterdam and Tinbergen Institute Research Series.

Baker, F. (1990). "Risk Communication about Environmental Hazards." Journal of Public Health Policy 11(3): 341-359.

Balmann, A. and K. Happe (2000). Applying Parallel Genetic Algorithms to Economic Problems: The Case of Agricultural Land Markets. "Microbehavior and Macroresults", IIFET 2000 Proceedings (Eds), Corvallis, Oregon USA.

Barreteau, O., F. Bousquet and J.-M. Attonaty (2001). "Role playing game for opening the black box of multi-agent systems: method and lessons of its application to Senegal River Valley irrigated systems." Journal of Artificial Societies and Social Simulation 4(2): 12.

Batty, M., Y. Xie and Z. Sun (1999). "Modeling urban dynamics through GIS-based cellular automata." Computers, Environment and Urban Systems 23(3): 205-233.

Bell, K. P. and E. G. Irwin (2002). "Spatially explicit micro-level modelling of land use change at the rural-urban interface." Agricultural Economics 27(3): 217-232.

Benenson, I. (1998). "Multi-Agent Simulations of Residential Dynamics in the City." Computers, Environment and Urban Systems 22(1): 25-42. 
Benenson, I. and P. Torrens (2004). "Geosimulation: object-based modeling of urban phenomena." Computers, Environment and Urban Systems 28(1-2): 1-8.

Berg, A. v. d., M. Jacobs and L. F. (2002). Beleving kustveiligheid. Alterra-Rapport 583. Wageningen, Alterra, Research Instituut voor de Groene Ruimte: 1-98.

Berger, T. (2001). "Agent-based spatial models applied to agriculture: A simulation tool for technology diffusion, resource use changes, and policy analysis." Agricultural Economics 25(23): 245-260.

Berger, T. and P. Schreinemachers (2006). "Creating Agents and Landscapes for Multiagent Systems from Random Samples." Ecology and Society 11(2): art.19.

Bier, V. M. (2001). "On the state of the art: risk communication to the public." Reliability Engineering and System Safety 71: 139-150.

Bin, O. and J. B. Kruse (2006). "Real Estate Market Response to Coastal Flood Hazards." Natural Hazards Review 7(4): 137-144.

Bin, O., J. B. Kruse and C. E. Landry (2008). "Flood hazards, insurance rates, and amenities: Evidence from the coastal housing market." The Journal of Risk and Insurance 75(1): 63-82.

Bin, O. and S. Polasky (2004). "Effects of flood hazards on property values: evidence before and after hurricane Floyd." Land Economics 80(4): 490-500.

Bočkarjova, M., A. van der Veen and P. A. T. M. Geurts (2008). How to Motivate People to Assume Responsibility and Act upon Their own Protection from Flood Risk in the Netherlands if They Think They are Perfectly Safe? Society for Risk Analysis - Europe (Eds), Valencia, 2225 September 2008.

Bockstael, N. E., R. Costanza, I. Strand, W. Boynton, K. Bell and L. Wainger (1995). "Ecological economic modelling and valuation of ecosystems." Ecological Economics(14): 143-159.

Bonabeau, E. (2002). "Agent-based modeling: Methods and techniques for simulating human systems." Proceedings of the National Academy of Sciences 99(6): 7280-7287.

Botzen, W. J. W. and J. C. J. M. van den Bergh (2008). "Insurance against climate change and flooding in the Netherlands: Present, future, and comparison with other countries." $\underline{\text { Risk }}$ Analysis 28(2): 413-426.

Bousquet, F. and C. Le Page (2004). "Multi-agent simulations and ecosystem management: a review." Ecological Modelling 76(3-4): 313-332.

Bousquet, F., G. Trebuil and B. Hardy (2005). Companion Modelling and Multi-Agent Systems for Integrated Natural Resource Management in Asia. Los Banos, Philippines, International Rice Research Institute.

Bouwer, L. M. and P. Vellinga (2002). Changing climate and increasing costs - Implications for liability and insurance Climatic Change: Implications for the Hydrological Cycle and for Water Management. M. Beniston (Eds). The Netherlands, Kluwer Academic Publishers: 429-444.

Brock, W. A. and S. N. Durlauf (2001). "Discrete choice with social interactions." Review of Economic Studies 68(2): 235-260.

Brown, D. G. and D. T. Robinson (2006). "Effects of heterogeneity in residential preferences on an agent-based model of urban sprawl." Ecology and Society 11(1): art.46.

Brown, D. G., D. T. Robinson, L. An, J. I. Nassauer, M. Zellner, W. Rand, R. Riolo, S. E. Page, B. Low and Z. Wang (2008). "Exurbia from the bottom-up: Modeling multiple actors and their landscape interactions." Geoforum 39(2): 805-818.

Brueckner, J. K. (1987). The Structure of Urban Equilibria: a Unified Treatment of the Muth-Mills Model. Handbook of Regional and Urban Economics. E. S. Mills (Eds). Amsterdam, Elsevier Science Publishers B.V. 2: 821-845.

Brugnach, M., C. Pahl-Wostl, K. E. Lindenschmidt, J. A. E. B. Janssen, T. Filatova, A. Mouton, G. Holtz, P. van der Keur and N. Gaber (2008). Complexity and Uncertainty: Rethinking the Modelling Activity. Developments in Integrated Environmental Assessment. A. J. Jakeman, A. A. Voinov, A. E. Rizzoli and S. H. Chen. Volume 3: 49-68. 
Bucx, T., E. Calle, N. Eernink, M. v. Koningsveld, J. Mulder, L. v. Rijn, H. Schelfhout and A. v. d. Spek (2008). Staat en Toekomst van de Delta. Achtergronddocument Thema Veiligheid. Delft, the Netherlands, Deltares.

Buurman, J. (2003). Rural Land Markets: a Spatial Explanatory Model, PhD Thesis, Vrije Universiteit Amsterdam.

Buurman, J., P. Rietveld and H. Scholten (2001). The Land Market: A Spatial Economic Perspective. Land Use Simulation for Europe. J. Stillwell and H. Scholten, Kluwer Academic Publishers: 65-83.

Camerer, C. F. and H. Kunreuther (1989). "Decision Processes for Low Probability Events: Policy Implications." Journal of Policy Analysis and Management 8(4): 565-592.

Caruso, G., D. Peeters, J. Cavailhes and M. Rounsevell (2007). "Spatial configurations in a periurban city. A cellular automata-based microeconomic model." Regional Science and Urban Economics 37(5): 542-567.

Castle, C. J. E. and A. T. Crooks (2006). Principles and Concepts of Agent-Based Modelling for Developing Geospatial Simulations. London, Centre for Advanced Spatial Analysis University College London.

Chave, J. and S. Levin (2003). "Scale and Scaling in Ecological and Economic Systems." Environmental and Resource Economics 26: 527-557.

Chess, C. (2001). "Organizational Theory and Stages of Risk Communication." Risk Analysis 21(1): 179-188.

Chivers, J. and N. E. Flores (2002). "Market Failure in Information: The National Flood Insurance Program." Land Economics 78(4): 515-521.

Cigler, B. A. (2007). "The "Big Questions" of Katrina and the 2005 Great Flood of New Orleans." Public Administration Review 67: 64-76.

Clark, W. A. V., Y. Huang and S. Withers (2003). "Does commuting distance matter? Commuting tolerance and residential change." Regional Science and Urban Economics 33: 199-221.

Clark, W. A. V. and F. J. Van Lierop (1987). Residential mobility and household location modeling. Handbook of Regional and Urban Economics. P. Nijkamp (Eds). Amsterdam, Elsevier Science Publishers. Volume I.

Costanza, R., F. Andrade, P. Antunes, M. van den Belt, D. Boesch, D. Boersma, F. Catarino, S. Hanna, K. Limburg, B. Low, M. Molitor, J. G. Pereira, S. Rayner, R. Santos, J. Wilson and M. Young (1999). "Ecological Economics and Sustainable Governance of the Oceans." Ecological Economics 31: 171-187.

Costanza, R., R. d'Arge, R. de Groot, S. Farberk, M. Grasso, B. Hannon, K. Limburg, S. Naeem, R. V. O’Neill, J. Paruelo, R. G. Raskin, P. Suttonkk and M. van den Belt (1997). "The Value of the World's Ecosystem Services and Natural Capital." Nature 387: 253-260.

Couzin, I. D. (2009). "Collective cognition in animal groups." Trends in Cognitive Sciences 13(1): 36-43.

Crooks, A. T. (2007). The Repast Simulation/Modelling System for Geospatial Simulation. London, Centre for Advanced Spatial Analysis University College London.

Daniel, V. E., R. J. G. M. Florax and P. Rietveld (2007). Long term divergence between ex-ante and ex-post hedonic prices of the Meuse River flooding in The Netherlands. 47th Congress of the European Regional Science Association "Local Governance and Sustainable Development" (Eds), Paris, 1-20.

Dasqupta, P. (2002). Modern economics and its critics. Fact and Fiction in Economics: Models, Realism and Social Construction U. Mäki, Cambridge University Press: 57-90.

Deltacommissie (1960). Rapport Deltacommissie. 's-Gravenhage, Staatsdrukkerij- en Uitgeverijbedrijf.

Deltacommissie (2008). Samen werken met water: Een land dat leeft, bouwt aan zijn toekomst. Bevindingen van de Deltacommissie 2008, Hollandia Printing. 
Diappi, L. and P. Bolchi (2008). "Smith's rent gap theory and local real estate dynamics: A multiagent model." Computers, Environment and Urban Systems 32(1): 6-18.

DiPasquale, D. and W. C. Wheaton (1995). Urban Economics and Real Estate Markets, Prentice Hall.

Dixit, A. and Stiglitz (1977). "Monopolistic Competition and Optimum Product Diversity." The American Economic Review 67(3): 297-308.

Epstein, J. M. and R. Axtell (1996). Growing Artificial Societies Social Science From the Bottom $\underline{\text { Up}}$, Brookings Institution Press and MIT Press.

Ettema, D., K. de Jong, H. Timmermans and A. Bakema (2007). PUMA: multi-agent modelling of urban systems. Modelling Lnad-Use Chnage: progress and applications. E. Koomen, J. Stillwell, A. Bakema and H. Scholten (Eds). Dordrecht, Springer: 237-258.

Filatova, T. (2007a). Neighborhood externalities in a residential land market: a spatially explicit agent-based land market model (ALMA). Term paper for the course CSS-645. Fairfax, VA, USA, George Mason University: 1-30.

Filatova, T. (2007b). Public Services and Tiebout Hypothesis: Households' Location Sorting via the Spatially Explicit Agent-Based Land Market Model (ALMA). Term paper for the course CSS610. Fairfax, VA, USA, George Mason University: 1-26.

Filatova, T., D. Parker and A. van der Veen (2009). "Agent-Based Urban Land Markets: Agent's Pricing Behavior, Land Prices and Urban Land Use Change." Journal of Artificial Societies and Social Simulation 12(1): 3 .

Filatova, T., D. C. Parker and A. van der Veen (2007). Agent-Based Land Markets: Heterogeneous Agents, Land Prices and Urban Land Use Change. Proceedings of the 4th Conference of the European Social Simulation Association (ESSA'07), September 10-14, 2007, Toulouse, France. F. Amblard (Eds). Toulouse, France, ESSA: 263-275.

Filatova, T. and A. van der Veen (2007). Scales in coastal land use: policy and individual decisionmaking (an economic perspective). Issues in Global Water System Research. Global Assessments: Bridging Scales and Linking to Policy. C. v. Bers, D. Petry and C. Pahl-Wostl (Eds). Bonn, The Global Water System Project. \#2: 61-68.

Filatova, T., A. van der Veen and D. Parker (2008). Introducing Preference Heterogeneity into a Monocentric Urban Model: an Agent-Based Land Market Model. Second World Congress on Social Simulation (Eds), Fairfax, VA.

Filatova, T., A. van der Veen and D. Parker (Under review). "Land market interactions between heterogeneous agents in a heterogeneous landscape-tracing the macro-scale effects of individual trade-offs between environmental amenities and disamenities." Canadian Journal of Agricultural Economics.

Filatova, T., A. van der Veen and D. C. Parker (2007). Modeling of a residential land market with a spatially explicit agent-based land market model (ALMA). Second Workshop of a Special Interest Group on Market Dynamics "Agent-based models of market dynamics and consumer behaviour", W. Jager (Eds), Groningen, The Netherlands.

Filatova, T., A. van der Veen and A. Voinov (2008). An Agent-Based Model for Exploring Land Market Mechanisms for Coastal Zone Management. Proceedings of the iEMSs Fourth Biennial Meeting: International Congress on Environmental Modelling and Software (iEMSs 2008). J. B. M. Sànchez-Marrè, J. Comas, A. Rizzoli and G. Guariso (Eds). Barcelona. II: 792-800.

Forni, M. and M. Lippi (1997). Aggregation and the Microfoundations of Dynamic Macroeconomics, Oxford University Press.

Fujita, M., P. Krugman and A. Venables (2001). The Spatial Economy: Cities, Regions, and International Trade, The MIT Press.

Fujita, M. and J.-F. Thisse (2002). Economics of agglomeration. Cities, industrial location and regional growth, Cambridge University Press. 
Gayer, T., J. T. Hamilton and W. K. Viscusi (2000). "Private values of risk tradeoffs at superfund sites: Housing market evidence on learning about risk." Review of Economics and Statistics 82(3): 439-451.

Gibson, C. C., E. Ostrom and T. K. Ahn (2000). "The concept of scale and the human dimensions of global change: a survey." Ecological Economics(32): 217-239.

Gilbert, N. and K. G. Troitzsch (2005). Simulation for the social scientist. Second edition. Glasgow, Open University Press.

Gode, D. and S. Sunder (1993). "Allocative Efficiency of Markets with Zero-Intellegence Traders: Market as a Partial Substitute for Individual Rationality." The Journal of Polictical Economy 101(1): 119-137.

Grevers, W. (2007). Land Markets and Public Policy. Enschede, Netherlands, University of Twente. PhD thesis.

Grevers, W. A. J. and A. van der Veen (2008). Serious games for economists. Complexity and Artificial markets. K. Schredelseker and F. Hauser (Eds). Heidelberg, Springer. 614: 159-164.

Grimm, V. and S. F. Railsback (2005). Individual-based Modeling and Ecology, Princeton University Press.

Groenendijk, H. A. (1997). Terpen: a Shared Responsibility for a Shared Interest. Archaeological Heritage Management in the Netherlands. W. J. H. Willems, H. Kars and D. P. Hallewas, Uitgeverij Van Gorcum: 239-255.

Gupta, K. L. (1969). Aggregation in Economics: A Theoretical and Empirical Study, Rotterdam University Press.

Haase, D. (2007). "A new housing demography under conditions of shrinkage? A household-based model approach to conceptualise residential mobility and residential vacancy." Landschaftsentwicklung und Umweltforschung 20: 479-482.

Haase, D., S. Kabisch, A. Haase, T. Filatova, A. van der Veen, T. Tötzer, W. Loibl, S. Scatasta, S. Schetke, A. Zuin and F. von Walter (2008). Actors and factors - bridging social science findings and urban land use change modeling. Fourth Biennial Meeting: International Congress on Environmental Modelling and Software (iEMSs 2008), M. Sànchez-Marrè, J. Béjar, J. Comas, A. Rizzoli and G. Guariso (Eds), Barcelona, Catalonia, 2059-2073.

Hallstrom, D. G. and V. K. Smith (2005). "Market Responses to Hurricanes." Journal of Environmental Economics and Management 50: 541-561.

Happe, K. (2004). "Agricultural policies and farm structures - Agent-based modelling and application to EU-policy reform." IAMO Studies on the Agricultural and Food Sector in Central and Eastern Europe 30.

Happe, K., K. Kellermann and A. Balmann (2006). "Agent-based Analysis of Agricultural Policies: an Illustration of the Agricultural Policy Simulator AgriPoliS, its Adaptation and Behavior." Ecology and Society 11(1): 49.

Heckbert, S. and A. Smajgl (2005). Analysing Urban Systems using Agent-Based Modelling. MODSIM 2005 International Congress on Modelling and Simulation "Advances and Applications for Management and Decision Making ", A. Zerger and R. M. Argent, Modelling and Simulation Society of Australia and New Zealand, 0-9758400-2-9. .

Henderson, J. V. and J.-F. Thisse (1999). "On the Pricing Strategy of a Land Developer." Journal of Urban Economics 45: 1-16.

Hommes, C. H. (2006). Heterogeneous Agent Models in Economics and Finance. Handbook of Computational Economics Volume 2: Agent-Based Computational Economics L. Tesfatsion and K. L. Judd, Elsevier B.V.: 1110-1186.

Hubacek, K. and J. C. J. M. van den Bergh (2006). "Changing concepts of 'land' in economic theory: From single to multi-disciplinary approaches." Ecological Economics(56): 5-27.

Huizinga, H. J. (2003). Economisch GIS: Methodiekbeschrijving, Rijkswaterstaat.

Irwin, E. G. and N. E. Bockstael (2002). "Interacting Agents, Spatial Externalities and the Evolution of Residential Land Use Patterns." Journal of Economic Geography 2: 31-54. 
Irwin, E. G. and N. E. Bockstael (2004). "Land use externalities, open space preservation, and urban sprawl." Regional Science and Urban Economics(34): 705- 725.

Irwin, E. G., C. Jayaprakash and Y. Chen (2007). A Dynamic Model of Household Location, Regional Growth, and Endogenous Natural Amenities with Cross-Scale Interactions. The Frontiers of Environmental Economics (Eds), Resources for the Future, Wachington D.C.

Isard, W. (1972). Location and Space-Economy: A General Theory Relating to Industrial Location, Market Areas, Land Use, and Urban Structure, The MIT Press.

IWR (1998). Empirical Studies of the Effect of Flood Risk on Housing Prices. IWR REPORT 98PS-2. Alexandria, USA, Institute for Water Resources, U.S. Army Corps of Engineers: 1-72.

Janson, S., M. Middendorf and M. Beekman (2005). "Honeybee swarms: how do scouts guide a swarm of uninformed bees?" Animal Behaviour 70(2): 349-358.

Janssen, M. A. (2002). Complexity and Ecosystem Management: The Theory and Practice of MultiAgent Systems, Edward Elgar Publishing Ltd.

Jantz, C. A., S. J. Goetz and M. K. Shelley (2003). "Using the SLEUTH Urban Growth Model to Simulate the Impacts of Future Policy Scenarios on Urban Land Use in the BaltimoreWashington Metropolitan Area." Environment and Planning B 30: 251 - 271.

Johnson, B. B. and C. Chess (2006). "From the Inside Out: Environmental Agency Views about Communications with the Public." Risk Analysis 26(5): 1395-1407.

Kahneman, D. and A. Tversky (1979). "Prospect Theory:An Analysis of Decisions under Risk." Econometrica 47(2): 263-292.

Kaiser, G., S. Reese, H. Sterr and H.-J. Markau (2004). COMRISK Subproject 3: Public Perception of Coastal Flood Defence and Participation in Coastal Flood Defence Planning. Final Report. Kiel, Germany: 1-212.

Kan, K. (2002). "Residential mobility with job location uncertainty." Journal of Urban Economics 52: 501-523.

Kirman, A. P. (1992). "Whom or what does the representative individual represent?" Journal of Economic Perspectives 6(2): 117-136.

Kirman, A. P. (2006). "Heterogeneity in economics." Journal of Economic Interaction and Coordination(1): 89-117.

Kirman, A. P. and N. J. Vriend (2001). "Evolving Market Structure: An ACE Model of Price Dispersion and Loyalty." Journal of Economic Dynamics and Control 25: 459-502.

Kok, M. (2005). Een waterverzekering in Nederland: mogelijk en wenselijk? O. A. Water, HKV: LIJN IN WATER: 1-33.

Kok, M., J. K. Vrijling, P. H. A. J. M. van Gelder and P. Vogelsang (2002). Risk of flooding and insurance in The Netherlands. Flood Defence. B. Wu, Z.-Y. Wang, G. Wanget al (Eds). New York, Science Press. Volume 1: 146 - 154.

Kolkman, M. J., A. van der Veen and P. A. T. M. Geurts (2007). "Controversies in water management: Frames and mental models." Environmental Impact Assessment Review 27(7): 685-706.

Kraus, M. (2006). Monocentric Cities. A Companion to Urban Economics. R. Arnott and D. McMillen (Eds). Malden, USA, Blackwell Publishing Ltd: 96-109.

Krugman, P. (1991). "Increasing Returns and Economic-Geography." Journal of Political Economy 99(3): 483-499.

Krutilla, J. V. (1966). "An Economic Approach to Coping with Flood Damage." Water Resources Research 2(2): 183-190.

Krywkow, J., T. Filatova and A. van der Veen (2008). Flood risk perceptions in the Dutch province of Zeeland: does the public still support current policies? FLOODrisk 2008, The European Conference on Flood Risk Management (Eds), Oxford, UK.

Lambin, E. and H. Geist, Eds. (2006). Land-use and Land-cover Change: Local Processes, Global Impacts. New York, Springer Berlin Heidelberg. 
Lave, T. R. and L. B. Lave (1991). "Public Perception of the Risks of Floods: Implications for Communication." Risk Analysis 11(2): 255-267.

LeBaron, B. (2001). "Empirical regularities from interacting long- and short-memory investors in an agent-based stock market." IEEE Transactions on Evolutionary Computation 5(5): 442-455.

LeBaron, B. (2006). Agent-Based Computational Finance. Handbook of Computational Economics Volume 2: Agent-Based Computational Economics L. Tesfatsion and K. L. Judd, Elsevier B.V.: 1187-1233.

Levin, S. (1992). "The Problem of Pattern and Scale in Ecology." Ecology 73(6): 1943-1967.

Levin, S. (2003). "Complex Adaptive Systems: Exploring the Known, the Unknown and the Unknowable." Bulletin of the American Mathematical Society 40(1): 3-19.

Levin, S. (2005). "Self-organization and the Emergence of Complexity in Ecological Systems." BioScience 55(12): 1075-1079.

Levine, J. (2006). Zoned Out: Regulations, Markets, and Choices in Transportation and Metropolitan Land-Use. Washington DC, USA, RFF Press.

Lux, T. (1998). "The socio-economic dynamics of speculative markets: interacting agents, chaos, and the fat tails of return distributions." Journal of Economic Behavior \& Organization 33: 143165.

Lynch, L. and S. J. Lovell (2003). "Combining spatial and survey data to explain participation in agricultural land preservation programs." Land Economics 79(2): 259-276.

MacDonald, D. N., J. C. Murdoch and H. L. White (1987). "Uncertain Hazards, Insurance, and Consumer Choice: Evidence from Housing Markets." Land Economics 63(4): 361-371.

Mackie-Mason, J. K. and M. P. Wellman (2006). Automated Markets and Trading Agents. Handbook of Computational Economics Volume 2: Agent-Based Computational Economics L. Tesfatsion and K. L. Judd (Eds). Amsterdam, Elsevier B.V.: 1381-1431.

Manski, C. F. (2000). "Economic analysis of social interactions." Journal of Economic Perspectives 14(3): 115-136.

Manson, S. M. (2002). Validation and Verification of Multi-Agent Systems. Complexity and Ecosystem Management: The Theory and Practice of Multi-Agent Systems. M. A. Janssen, Edward Elgar Publishing Ltd: 63-75.

Manson, S. M. (2008). "Does scale exist? An epistemological scale continuum for complex humanenvironment systems." Geoforum 39: 776-788.

Marchand, M., A. Crosato and F. Klijn (2006). Flood Risk Analysis for the River Scheldt Estuary FLOODsite Report T25-06-01. Delft, The Netherlands, Delft Hydraulics: 1-25.

Marks, R. (2006). Market Design Using Agent-Based Models. Handbook of Computational Economics Volume 2: Agent-Based Computational Economics L. Tesfatsion and K. L. Judd (Eds). Amsterdam, Elsevier B.V.: 1339-1380.

Martínez, M. L., A. Intralawan, G. Vázquez, O. Pérez-Maqueo, P. Sutton and R. Landgrave (2007). "The Coasts of Our World: Ecological, Economic and Social Importance." Ecological Economics 63: 254-272.

Matthews, R. B., N. G. Gilbert, A. Roach, J. G. Polhill and N. M. Gotts (2007). "Agent-based landuse models: a review of applications." Landscape Ecology 22: 1447-1459.

McCluskey, J. J. and G. C. Rausser (2001). "Estimation of perceived risk and its effect on property values." Land Economics 77(1): 42-55.

McNamara, D. E. and B. T. Werner (2008). "Coupled barrier island-resort model: 1. Emergent instabilities induced by strong human-landscape interactions." Journal of Geophysical ResearchEarth Surface 113(F01016).

Meulen, M. J. v. d., A. J. F. van der Spek, G. de Lange, S. H. L. L. Gruijters, S. F. van Gessel, B.-L. Ngyuyen, D. Maljers, J. Schokker, J. P. M. Mulder and R. A. A. van der Krogt (2007). "Regional Sediment Deficits in the Dutch Lowlands: Implications for Long-Term Land-Use Options." Journal of Soils and Sediments, 7(1): 9-16. 
Miller, E., J. D. Hunt, J. E. Abraham and P. A. Salvini (2004). "Microsimulating urban systems." Computers, Environment, and Urban Systems 28: 9-44.

Miyake, M. (2003). "Precise Computation of a Competitive Equilibrium of the Discrete Land Market Model." Regional Science and Urban Economics 33: 721-743.

Narayanan, C. (2003). "On the discrepancy in long wave scaling." Coastal Engineering 48(1): 6774.

Nicholls, R. J., P. P. Wong, V. R. Burkett, J. O. Codignotto, J. E. Hay, R. F. McLean, R. S. and C. D. Woodroffe (2007). Coastal systems and low-lying areas. Climate Change 2007: Impacts, Adaptation and Vulnerability. Contribution of Working Group II to the Fourth Assessment Report of the Intergovernmental Panel on Climate Change. M. L. Parry, O. F. Canziani, J. P. Palutikof, v. d. L. P.J. and H. C.E., Cambridge University Press, Cambridge, UK: 315-356.

Nicolaisen, J., V. Petrov and L. Tesfatsion (2001). "Market power and efficiency in a computational electricity market with discriminatory double-auction pricing." IEEE Transactions on Evolutionary Computation 5(5): 504-523.

O'Callaghan, J. R. (1996). Land use: the interaction of economics, ecology and hydrology. London, Chapman\&Hall.

O’Neill, R. V., A. R. Johnson and A. W. King (1989). "A hierarchical framework for the analysis of scale." Landscape Ecology 3(3): 193-205.

Otter, H. S., A. van der Veen and H. J. de Vriend (2001). "ABLOoM: Location behaviour, spatial patterns, and agent-based modeling." Journal of Artificial Societies and Social Simulation 4(4): $<$ http://www.soc.surrey.ac.uk/JASSS/4/4/2.html $>$.

Parker, D., D. Brown, J. G. Polhill, S. M. Manson and P. Deadman (2008). Illustrating a new 'conceptual design pattern' for agent-based models and land use via five case studies: the MR POTATOHEAD framework. Agent-based Modelleling in Natural Resource Management. A. L. Paredes and C. H. Iglesias (Eds). Valladolid, Spain, Universidad de Valladolid: 29-62.

Parker, D. C. (2007). "Revealing "Space" in Spatial Externalities: Edge-Effect Externalities and Spatial Incentives." Journal of Environmental Economics and Management 54(1): 84-99.

Parker, D. C., T. Berger and S. M. Manson, Eds. (2002). Agent-Based Models of Land-Use and Land-Cover Change: Report and Review of an International Workshop, October 4-7, 2001. LUCC Report Series Bloomington, LUCC Focus 1 office.

Parker, D. C. and T. Filatova (2008). "A conceptual design for a bilateral agent-based land market with heterogeneous economic agents." Computers, Environment and Urban Systems 32: 454463.

Parker, D. C., A. Hessl and S. C. Davis (2008). "Complexity, land-use modeling, and the human dimension: Fundamental challenges for mapping unknown outcome spaces." Geoforum 39: 789-804.

Parker, D. C., S. M. Manson, M. A. Janssen, M. Hoffmann and P. Deadman (2003). "Multi-agent systems for the simulation of land-use and land-cover change: A review." Annals of the Association of American Geographers 93(2): 314-337.

Parker, D. C. and V. Meretsky (2004). "Measuring pattern outcomes in an agent-based model of edge-effect externalities using spatial metrics." Agriculture, Ecosystems and Environment 101: 233-250.

Plough, A. and S. Krimsky (1987). "The Emergence of Risk Communication Studies: Social and Political Context." Science, Technology, and Human Values 12(3/4): 4-10.

Poelmann Commissie (2005). Advies van de Commissie Bescherming en Ontwikkeling van Buitendijks gebied in Kustplaatsen, Haarlem.

Polasky, S., E. Nelson, E. Lonsdorf, P. Fackler and A. Starfield (2005). "Conserving species in a working landscape: land use with biological and economic objectives." Ecological Applications 15(4): 1387-1401.

Polhill, J. G., D. Parker and N. M. Gotts (2008). Effects of land markets on competition between innovators and imitators in land use: results from FEARLUS-ELMM. Social Simulation 
Technologies: Advances and New Discoveries. C. Hernandez, K. Troitzsch and B. Edmonds (Eds). Hershey, PA, Information Science Reference: 81-97.

Polhill, J. G., D. C. Parker and N. M. Gotts (2005). Introducing Land Markets to an Agent Based Model of Land Use Change: A Design. Representing Social Reality: Pre-Proceedings of the Third Conference of the European Social Simulation Association, K. Troitzsch (Eds), Koblenz, Germany, September 5-9, 2005, Verlag Dietmar Völbach, 150-157.

Raaijmakers, R., J. Krywkow and A. van der Veen (2008). "Flood risk perceptions and spatial multi-criteria analysis: an exploratory research for hazard mitigation." Natural Hazards(DOI 10.1007/s11069-007-9189-z).

Randall, A. and E. N. Castle (1985). Land Resources and Land Markets. Handbook of Natural Resources and Energy Economics. Volume II. A. V. Kneese and J. L. S. Sweeney, Elsevier Science Publishers B.V.: 571-619.

Ready, R. C., M. C. Berger and G. C. Blomquist (1997). "Measuring amenity benefits from farmland: Hedonic pricing vs. contingent valuation." Growth and Change 28(4): 438-458.

Ricardo, D. (1821/2001). On the Principles of Political Economy and Taxation. Ontario, Canada, Batoche Books.

Rijkswaterstaat (1990). Kustverdediging na 1990 (1e Kustnota); Beleidskeuze voor de Kustlijnzorg. Den Haag, Ministerie van Verkeer en Waterstaat,.

Rijkswaterstaat (2002). Towards an Integrated Coastal Zone Policy - Policy agenda for the coast,. The Hague, Ministerie van Verkeer en Waterstaat Rijkswaterstaat, Direct Dutch Publications BV.

Rijkswaterstaat (2005a). Flood Risks and Safety in the Netherlands (Floris). Floris study - interim report. Delft, Ministry of Transport, Public Works and Water Management, Rijkswaterstaat.

Rijkswaterstaat (2005b). Hoofdrichtingen voor risicobeheersing in kustplaatsen. Den Haag, Ministerie van Verkeer en Waterstaat

Rijkswaterstaat (2005c). Risicobeheersing in kustplaatsen: Beheersing van kansen en gevolgen van kustafslag en overstroming tijdens zware storm in buitendijks gebied. Den Haag, Ministerie van Verkeer en Waterstaat

Rijkswaterstaat (2005d). Standard Method 2004. Damage and Casualties Caused by Flooding. Ministerie van Verkeer en Waterstaat Rijkswaterstaat.

Robinson, D. T., D. Brown, D. C. Parker, P. Schreinemachers, M. A. Janssen, M. Huigen, H. Wittmer, N. Gotts, P. Promburom, E. Irwin, T. Berger, F. Gatzweiler and C. Barnaud (2007). "Comparison of empirical methods for building agent-based models in land use science." Journal of Land Use Science 2(1): 31-55.

Rodiek, J. (2007). "Landscape planning in hazardous zones, lessons from Hurricane Katrina, August 2005." Landscape and Urban Planning 79(1): 1-4.

Rosen, S. (1974). "Hedonic prices and implicit markets: product differentiation in pure competition." Journal of Political Economy 82(1): 34-55.

Rotmans, J. and D. S. Rothman (2003). Scaling in integrated assesment. Lisse, Swets\&Zeitlinger.

Sasaki, Y. and P. Box (2003). "Agent-Based Verification of von Thünen's Location Theory " Journal of Artificial Societies and Social Simulation 6(2): $<$ http://jasss.soc.surrey.ac.uk/6/2/9.html $>$

Schelling, T. (1978). Micromotives and Macrobehavior. New York, W.W. Norton\&Company, Inc.

Schleupner, C. (2008). "Evaluation of coastal squeeze and its consequences for the Caribbean island Martinique." Ocean \& Coastal Management 51(5): 383-390.

Shabman, L. and K. Stephenson (1996). "Searching for the correct benefit estimate: Empirical evidence for an alternative perspective." Land Economics 72(4): 433-449.

Shultz, S. D. and P. M. Fridgen (2001). "Floodplains and Housing Values: Implications for Flood Mitigation Projects." Journal of the American Water Resources Association 37(3): 595-603.

Simon, H. (1997). Models of Bounded Rationality. Vol 3: Emperically Grounded Economic Reason, MIT Press. 
Singh, N. and V. Xavier (1984). "Price and Quantity Competition in a Differentiated Duopoly." The RAND Journal of Economics 15(4): 546-554.

Sjoeberg, L. (2000). "Factors in Risk Perception." Risk Analysis 20(1): 1-11.

Slovic, P. (1987). "Perception of Risk." Science 236: 280-285.

Slovic, P., M. L. Finucane, E. Peters and D. G. MacGregor (2004). "Risk as analysis and risk as feelings: Some thoughts about affect, reason, risk, and rationality." Risk Analysis 24(2): 311322.

Slovic, P. and E. U. Weber (2002). Perception of Risk Posed by Extreme Events. Risk Management strategies in an Uncertain World (Eds), Palisades, New York.

Smith, K. (2001). Environmental Hazards: Assessing Risk and Reducing Disaster. London.

Smith, L. B., K. T. Rosen and G. Fallis (1988). "Recent Developments in Economic Models of Housing Markets." Journal of Economic Literature 26(1): 29-64.

Smits, A. J. M., P. H. Nienhuis and H. L. F. Saeijs (2006). "Changing Estuaries, Changing Views." Hydrobiologia 565(1): 339-355.

Speyrer, J. F. and W. R. Ragas (1991). "Housing prices and flood risk: An examination using spline regression" The Journal of Real Estate Finance and Economics 4(4): 395-407.

Sterr, H. (2008). "Assessment of vulnerability and adaptation to sea-level rise for the coastal zone of Germany." Journal of Coastal Research 24(2): 380-393.

Stites, J. (2006). "Agent-based modeling. The future of financial markets." Santa Fe Bulletin Winter 2006: 31-35.

Strazsheim, M. (1987). The Theory of Urban Residential Location. Handbook of Regional and Urban Economics. E. S. Mills (Eds). Amsterdam, Elsevier Science Publishers B.V. Volume II: 717-757.

Tatano, H., K. Yamaguchi and N. Okada (2004). Risk perception, location choice and land-use patterns under disaster risk: long-term consequences of information provision in a spatial economy. Modelling spatial and economic impacts of disasters. Y. Okuyama and S. Chang, Springer: 163-181.

Terán, O., J. Alvarez, M. Ablan and M. Jaimes (2007). "Characterising Emergence of Landowners in a Forest Reserve " Journal of Artificial Societies and Social Simulation 10(36): $<$ http://jasss.soc.surrey.ac.uk/10/3/6.html $>$.

Terpstra, T. and J. M. Gutteling (2008). "Households' Perceived Responsibilities in Flood Risk Management in TheNetherlands." Water Resources Development 24(4): 551-561.

Tesfatsion, L. (2001). "Introduction to the special issue on agent-based computational economics." Journal of Economic Dynamics \& Control(25): 281-293.

Tesfatsion, L. (2006). Agent-Based Computational Economics: A Constructive Approach To Economic Theory. Handbook of Computational Economics Volume 2: Agent-Based Computational Economics L. Tesfatsion and K. L. Judd (Eds). Amsterdam, Elsevier B.V.: 831880.

Tesfatsion, L. and K. L. Judd (2006). Handbook of Computational Economics Volume II: AgentBased Computational Economics Elsevier B.V.

Tiebout, C. M. (1956). "A Pure Theory of Local Expenditures." Journal of Political Economy 64(5): 416-424.

Torrens, P. M. (2007). "A geographic automata model of residential mobility." Environment and Planning B: Planning and Design 34: 200-222.

van Daal, J. and A. H. Merkies (1984). Aggregation in Economic Research: From Individual to Macro Relations. Dordrecht, D.Reidel Publishing Company.

van Delden, H., P. Luja and G. Engelen (2007). "Integration of multi-scale dynamic spatial models of socio-economic and physical processes for river basin management." Environmental Modelling \& Software 22: 223-238.

van der Burgh, L. M., K. M. Wijnberg, S. J. M. H. Hulscher, J. P. M. Mulder and M. van Koningsveld (2007). Linking coastal evolution and super storm dune erosion forecasts. Coastal 
Sediments '07, Proceedings of the Sixth International Symposium on Coastal Engineering and Science of Coastal Sediment Processes, N. C. Kraus and J. Dean Rosati (Eds), New Orleans, Louisiana, Reston Virginia, USA, 1813-1826.

van der Veen, A. and C. Logtmeijer (2005). "Economic Hotspots: Visualizing Vulnerability to Flooding." Natural Hazards (36): 65-80.

van der Veen, A. and H. Otter (2003). Scales in economic theory. Scaling in integrated assesment. J. Rotmans and D. S. Rothman (Eds). Lisse, Swets\&Zeitlinger: 125-138.

van der Vlist, A. J., C. Gorter, P. Nijkamp and P. Rietveld (2002). "Residential Mobility and Local Housing-Market Differences." Environment and Planning A 34: 1147 - 1164.

Varian, H. R. (1992). Microeconomic Analysis, W. W. Norton.

Veraart, J. A., S. Brinkman, J. E. M. Klostermann and K. P., Eds. (2007). Climate Changes Spatial Planning. Introduction to the Dutch National Research Programme. CcSP-Brochure. Wageningen, the Netherlands.

Verburg, P. H., G. H. J. de Koning, K. Kok, A. Veldkamp and J. Bouma (1999). "A spatial explicit allocation procedure for modelling the pattern of land use change based upon actual land use." Ecological Modelling 116: 45-61.

Vigmostad, K. (2003). Michigan Real Estate Developer Perspectives on Development, Sustainability, and Nature: An Autoethnography. Resource Development. East Lansing, Michigan State University. PhD.

VLIZ (2005). Europese duurzaamheidsindicatoren voor kustgebieden in Nederland:een eerste inventarisatie. . Ostende, Belgium, Vlaams Instituut voor de Zee

Voinov, A. (2008). Systems Science and Modeling for Ecological Economics, Academic Press.

von Thünen, J. H. (1826/1966). Isolated State: An English Edition of Der Isolierte Staat Oxford, Pergamon Press.

Wagner, K. (2007). "Mental Models of Flash Floods and Landslides." Risk Analysis 27(3): 671682.

Waugh, W. L. and R. B. Smith (2006). "Economic development and reconstruction on the Gulf after Katrina." Economic Development Quarterly 20(3): 211-218.

Weber, A. (1965). Theory of the Location of Industries University Of Chicago Press

Wesselink, A. J. (2007). "Flood safety in the Netherlands: The Dutch response to Hurricane Katrina." Technology in Society 29: 239-247.

Wet op de Waterkering (1995). Den Haag, Ministerie van Verkeer en Waterstaat, Ministerie van Justitie.

White, R. and G. Engelen (1993). "Cellular automata and fractal urban form: A cellular modeling approach to the evolution of urban land-use patterns." Environment and Planning A 25(8): 1175-1199.

Wilensky, U. (1999). NetLogo. http://ccl.northwestern.edu/netlogo/. Center for Connected Learning and Computer-Based Modeling, Northwestern University. Evanston, IL.

Williams, B. L., S. Brown, M. Greenberg and M. A. Kahn (1999). "Risk Perception in Context: The Savannah River Site Stakeholder Study." Risk Analysis 19(6): 1019-1035.

Wooldridge, M. J. (2002). An Introduction to Multiagent Systems. Chichester, England, New York John Wiley \& Sons, Ltd.

Wu, J. (2001). "Environmental Amenities and the Spatial Pattern of Urban Sprawl." American Journal of Agricultural Economics 83(3): 691-697.

Wu, J., R. M. Adams and A. J. Plantinga (2004). "Amenities in an Urban Equilibrium Model: Residential Development in Portland, Oregon." Land Economics 80(1): 19-32.

$\mathrm{Wu}, \mathrm{J}$. and A. J. Plantinga (2003). "The influence of public open space on urban spatial structure." Journal of Environmental Economics and Management 46(2): 288-309.

$\mathrm{Wu}$, J. J. and E. G. Irwin (2008). "Optimal Land Development with Endogenous Environmental Amenities." American Journal of Agricultural Economics 90(1): 232-248. 



\section{List of publications}

1. Filatova, T., J. P. M. Mulder and A. van der Veen (2009). "Coastal risk management: how to motivate individual economic decisions to lower flood risk?" Submitted to Ocean and Coastal Management.

2. Filatova, T., D. Parker and A. van der Veen (2009). "Agent-Based Urban Land Markets: Agent's Pricing Behavior, Land Prices and Urban Land Use Change." Journal of Artificial Societies and Social Simulation 12(1): 3

3. Filatova, T., A. van der Veen and D. Parker (2009). "Land market interactions between heterogeneous agents in a heterogeneous landscape - tracing the macro-scale effects of individual trade-offs between environmental amenities and disamenities." Canadian Journal of Agricultural Economics. Under revisions.

4. Parker, D. C. and T. Filatova (2008). "A conceptual design for a bilateral agent-based land market with heterogeneous economic agents." Computers, Environment and Urban Systems 32: 454-463.

5. Krywkow, J., T. Filatova and A. van der Veen (2008). Flood risk perceptions in the Dutch province of Zeeland: does the public still support current policies? Flood Risk Management: Research and Practice. P. Samuels, S. Huntington, W. Allsop and J. Harrop (Eds). London, Taylor \& Francis Group: 1513-1521.

6. Brugnach, M., C. Pahl-Wostl, K. E. Lindenschmidt, J. A. E. B. Janssen, T. Filatova, A. Mouton, G. Holtz, P. van der Keur and N. Gaber (2008). Complexity and Uncertainty: Rethinking the Modelling Activity. Developments in Integrated Environmental Assessment. A. J. Jakeman, A. A. Voinov, A. E. Rizzoli and S. H. Chen (Eds). Volume 3: 49-68.

7. Filatova, T., A. van der Veen and A. Voinov (2008). An Agent-Based Model for Exploring Land Market Mechanisms for Coastal Zone Management. Proceedings of the iEMSs Fourth Biennial Meeting: International Congress on Environmental Modelling and Software (iEMSs 2008), J. B. M. Sànchez-Marrè, J. Comas, A. Rizzoli and G. Guariso (Eds). Barcelona. II: 792-800. ISBN 978-84-7653-074-0.

8. Haase, D., S. Kabisch, A. Haase, T. Filatova, A. van der Veen, T. Tötzer, W. Loibl, S. Scatasta, S. Schetke, A. Zuin and F. von Walter (2008). Actors and factors - bridging social science findings and urban land use change modeling. Proceedings of the iEMSs Fourth Biennial Meeting: International Congress on Environmental Modelling and Software (iEMSs 2008), M. Sànchez-Marrè, J. Béjar, J. Comas, A. Rizzoli and G. Guariso (Eds), Barcelona. III: 2059-2073. ISBN 978-84-7653-074-0, Available online from: http://www.iemss.org/iemss2008/index.php?n=Main.Proceedings.

9. Filatova, T., A. van der Veen and D. Parker (2008). Introducing Preference Heterogeneity into a Monocentric Urban Model: an Agent-Based Land Market Model. Second World Congress on Social Simulation, K. Takadama, G. Deffuant and C. Cioffi Revilla (Eds), Fairfax, VA.

10. van der Veen, A. and T. Filatova (2007). Microeconomic dynamics of urban land use in coastal zone area. Framing Land Use Dynamics II, E. Addink, A. Barendregt, D. Ettema, D. Karssenberg and T. de Nijs (Eds), Utrecht, The Netherlands, 196-197.

11. Filatova, T., D. C. Parker and A. van der Veen (2007). Agent-Based Land Markets: Heterogeneous Agents, Land Prices and Urban Land Use Change. Proceedings of the 4th Conference of the European Social Simulation Association (ESSA'07), F. Amblard (Eds), Toulouse, France, 978-2-9520326-7-4, 263-277.

12. Filatova, T., A. van der Veen and D. C. Parker (2007). Modeling of a residential land market with a spatially explicit agent-based land market model (ALMA). Second Workshop of a Special Interest Group on Market Dynamics "Agent-based models of market dynamics and consumer behaviour", W. Jager (Eds), Groningen, The Netherlands, Available online: http://www.essa.eu.org/simulationwiki/SecondWorkshopOnMarketDynamics2007/FilatovaVeenParker.pdf.

13. Filatova, T. and A. van der Veen (2007). Scales in coastal land use: policy and individual decision-making (an economic perspective). Issues in Global Water System Research. Global Assessments: Bridging Scales and Linking to Policy. C. v. Bers, D. Petry and C. Pahl-Wostl. Bonn, The Global Water System Project. 2: 61-68.

14. Filatova, T. (2007a). Neighborhood externalities in a residential land market: a spatially explicit agent-based land market model (ALMA). Term paper for the course CSS-645 by D.C. Parker. Fairfax, VA, USA, George Mason University: 1-30.

15. Filatova, T. (2007b). Public Services and Tiebout Hypothesis: Households' Location Sorting via the Spatially Explicit Agent-Based Land Market Model (ALMA). Term paper for the course CSS-610 by R. Axtell. Fairfax, VA, USA, George Mason University: 1-26. 
16. Filatova, T. and A. v. d. Veen (2006a). Microeconomic Drivers of Land Use Change in Coastal Zone Area. Proceedings of the 3rd Biennial Summit on Environmental Modelling and Software of the International Environmental Modelling and Software Society, A. Voinov, A. Jakeman and A. Rizolli (Eds), University of Vermont, USA, IEMSs, ISBN 1-4243-0852-6, Available online from: http://www.iemss.org/iemss2006/.

17. Filatova, T. and A. van der Veen (2006b). Questions and Methods to Model Emergence of Land Use Patterns in Coastal Zone Area. Proceedings of the 3rd Biennial Summit on Environmental Modelling and Software of the International Environmental Modelling and Software Society, A. Voinov, A. Jakeman and A. Rizolli (Eds), University of Vermont, USA, IEMSs, ISBN 1-4243-0852-6, Available online from: http://www.iemss.org/iemss2006/.

18. Filatova, T. (2006). Agent-based modelling for coastal zone management policy: land-use aspects. Proceedings of the International Conference 'Public Administration in the XXI century: traditions and innovations' (Eds), Moscow, Russia, Lomonosov Moscow State University, 250-254.

19. Glazyrina, I. P. and T. Filatova (2005). "Ecological footprint as a quality of growth indicator." Environmental Economics 2: 60-76 (in Russian).

20. Filatova, T. (2005). Quality of growth indicators for regional economies. I. P. Glazyrina and I. M. Potravnyi (Eds). Moscow, NIA-PRIRODA: 30-148.

21. Stauvermann, P. and T. Filatova (2005). Eco-efficiency of the region's absorption capacity. International Conference of the Russian Society for Ecological Economics "Globalisation, New Economy and the Environment: Business and Society Challenges for Sustainable Development” (Eds), St.Petersburg, Russia, RSEE, 74-76.

22. Filatova, T. (2004a). Eco-efficiency indicator as a regional indicator of sustainable development. 5th Regional Science conference of the Russian branch of the Regional Economics Society (Eds), Moscow, Russia, International Academy of the Regional Development and Cooperation, 228-239.

23. Filatova, T. (2004b). Quality of growth indicators based on Ecological Footprint concept. 8th Biannual Conference of the International Society of Ecological Economics ISEE'04 'Challenging Boundaries: economics, ecology and governance' (Eds), Montreal, Canada, CD, 4p.

24. Glazyrina, I. P., P. Stauvermann and T. V. Filatova (2004). Ecological adjusted indicators of economic growth. IV scientific conference 'Kulagin's recitation' (Eds), Chita, Russia, Administration of Chita region and Chita State University, 106-111.

25. Steenge, A. E. and T. V. Filatova (2004). The NAMEA approach to environmental accounting: perspectives of its implementation in Russia. Baikal Economic Forum, Conference 'The natural resources potential of Asian Russia and contiguous countries: geoeconomical, geoecological and geopolitical dividing into rayons' (Eds), Irkutsk, Russia, 210-213.

26. Filatova, T. (2003a). Accounting for the indicators of sustainable development for Chita region with the Ecological Footprint concept. International Conference of the Russian Chapter of the International Society for Ecological Economics 'Economic Development and the Environment: information, modelling and management' (Eds), Baikal, Russia, RSEE/ISEE, 68-73.

27. Filatova, T. (2003b). How to evaluate sustainability of the region with the ecological footprint concept. Youth Academic Forum 'Youth and Science in Siberia' (Eds), Chita, Russia, ZabGPU, 174-178.

28. Filatova, T. (2003c). Is the development of Chita region sustainable? Assessments with Ecological footprint concept. Scientific Conference of Young Scientists held by the Siberian Branch of Russian Academy of Sciences (Eds), Chita, Russia, 81-87.

29. Brezgin, V. and T. Filatova (2002). Information system for the evaluation of the ecological functions of forest ecosystems. Baikal Economic Forum, Conference 'Natural resources of the Asiatic Russia and neighbouring countries: the ways of enhancement of nature use' (Eds), Irkutsk, Russia, 118-119.

30. Brezgin, V. and T. V. Filatova (2001). Carbon credit accounting with the NPV formula. International Conference of the Russian Chapter of the International Society for Ecological Economics 'Ecological Economic Management and Planning in Regional and Urban Systems' (Eds), Moscow, Russia, RSEE/ISEE, 20-21. 


\section{About the author}

Tatiana Filatova was born in Chita, Russia, on June $15^{\text {th }}$ 1981. After graduating with honors from the Technical Lyceum in 1998, she started her studies in 'information systems in economics' at Chita State Technical University (CSTU). In 2001 Tatiana became interested in environmental problems related to economic growth when she started as a volunteer researcher at the NGO “Transbaikal Research Centre for Ecological Economics". In 2003 she obtained her MSc degree with CumLaude from CSTU. After this she joined the postgraduate school at the Institute of Natural Resources, Siberian Branch of Russian Academy of Sciences in Chita. At the same time she was teaching at Chita State University and continued as a part-time researcher at the same NGO. In 2003-05 Tatiana participated in several projects in ecological economics, including Dutch-Russian project "Quality of Growth in Transition Countries", which brought her to the Netherlands for two months in 2004. Also, she attended several international and regional conferences and was on organising committee for the conference of the Russian Chapter of International Society for Ecological Economics in 2003.

In March 2005 Tatiana started her $\mathrm{PhD}$ at the Water Engineering and Management Department, University of Twente in the Netherlands. She joined the project on "Congruent Scales in Economics, Coastal Engineering and Morphology" as an economist, developing a spatially explicit land market model. During her PhD period Tatiana was a research visitor at National Institute of Coastal and Marine Sciences, $\mathrm{RIKZ}^{64}$, (where she explored current coastal management policy practices in the Netherlands), and at the Gund Institute for Ecological Economics, University of Vermont, USA (studying spatial modeling and environmental impacts of land use change). She also started a lasting collaboration with the Department of Computational Social Science at George Mason University, USA where she eventually did a significant part of her PhD.

While working on her dissertation, Tatiana published several papers in international journals and co-authored two book chapters. She also participated in several international conferences. Twice, her presentations at conferences were recognized with the best paper award. In addition, Tatiana was a guest lecturer in a number of universities in Europe and USA to give talks about her research on agent-based land market modelling in application to water management. She serves as a reviewer for several international journals in the field of land use research and modelling, agentbased modelling and environmental economics. Currently Tatiana is at University of Twente, continuing her research in spatial agent based economic simulation in application to coastal risks.

\footnotetext{
${ }^{64} \mathrm{RIKZ}$ is now part of Deltares
} 